AN BMBROIDERY

HATTERN BOOK
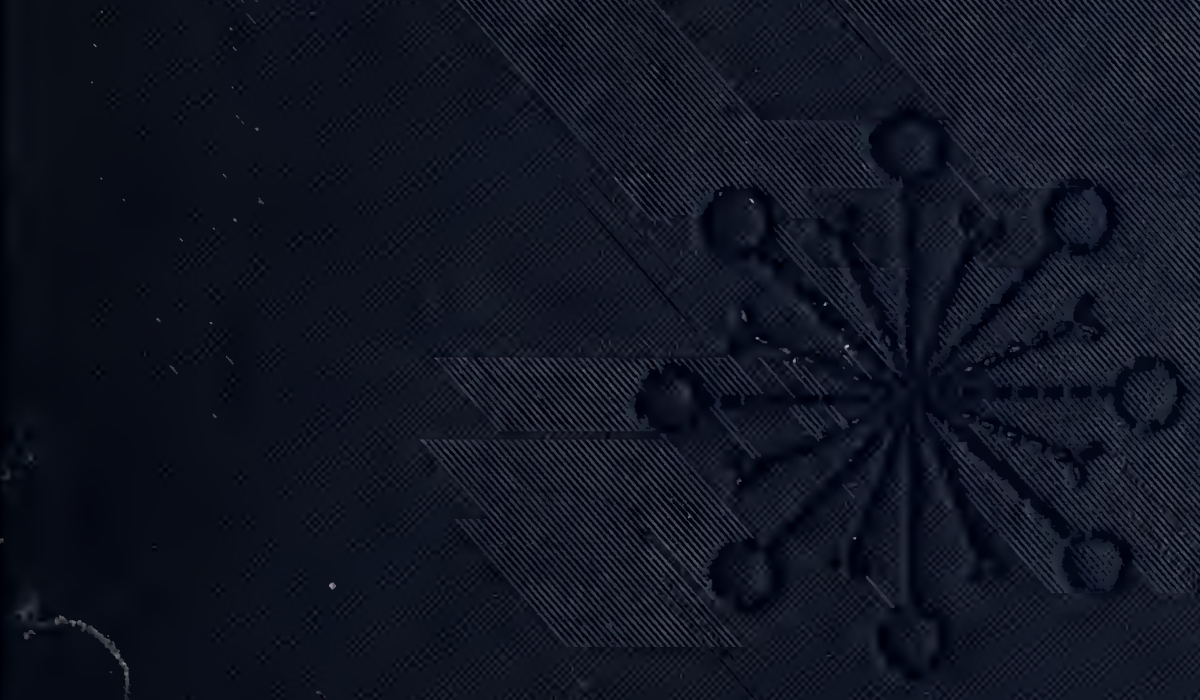

MARY IS WARING 


\section{LIBRARY OF THE}

COOPER-HEWITT MUSEUM OF DESIGN

- SMITHSONIAN INSTITUTION •

Bequest from

Estate of Marian Hague

* 


AN EMBROIDERY
PATTERN BOOK 


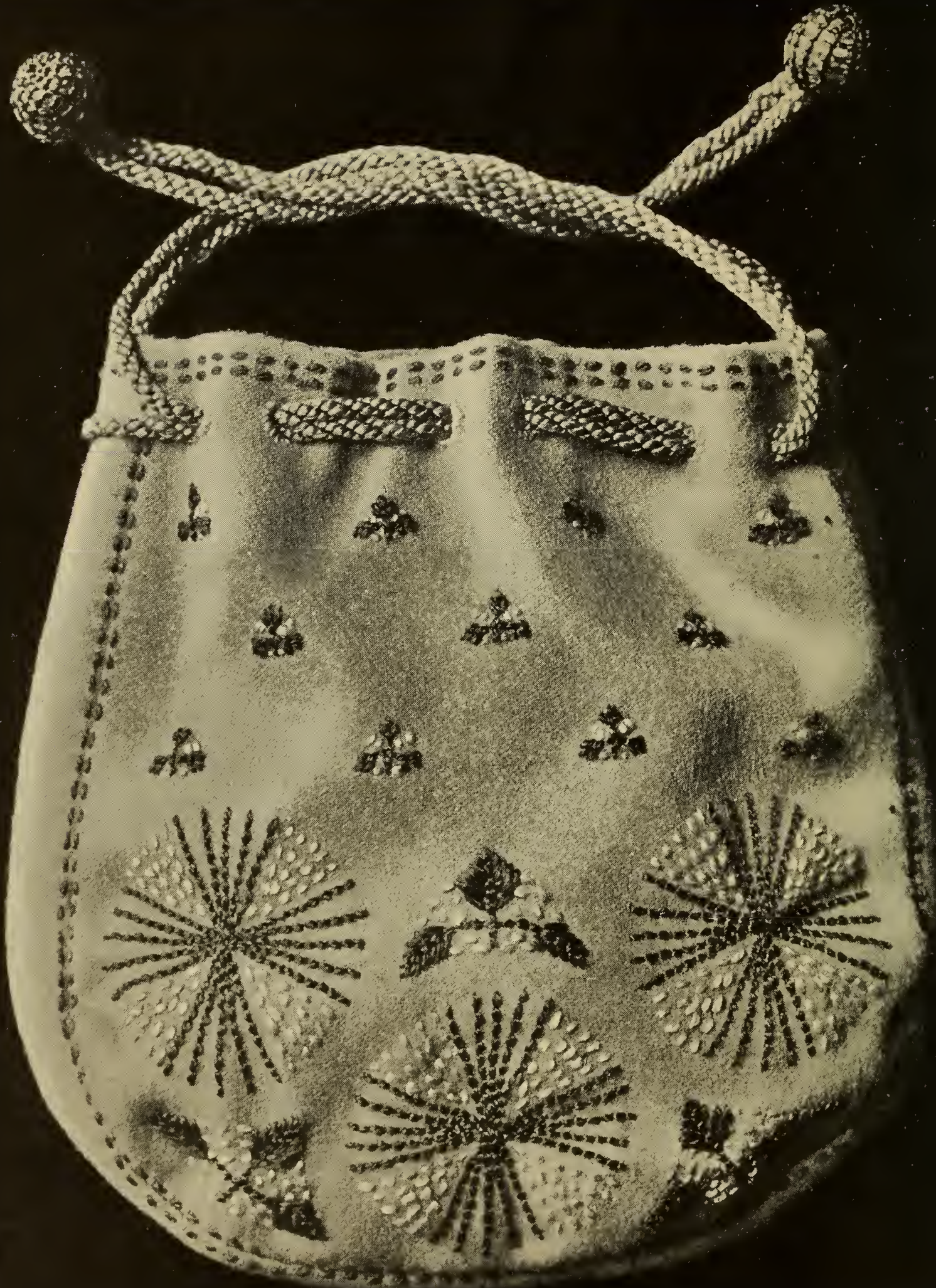


AN EMBROIDERY

PATTERN BOOK

BY

MARY E. WARING

WITH A FOREWORD BY

W. R. LETHABY

PROFESSOR OF DESIGN, THE ROYAL COLLEGE OF ART, SOUTH KENSINGTON

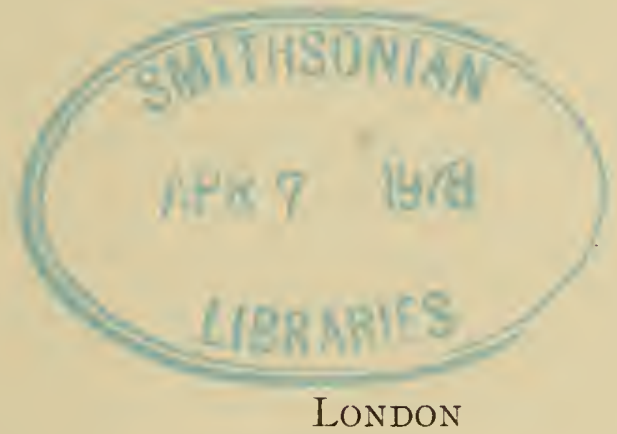

Sir Isaac Pitman \& Sons, Ltd., 1 Amen Corner, E.C.

Bath, New York and Melbourne 


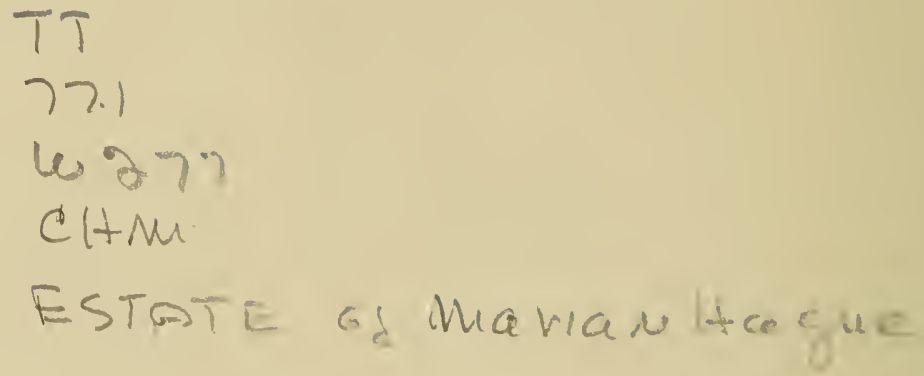

Printed by Sir Isaac Pitman \& Sons, Ltd., London, Bath, New York and Melbourne 


\section{FOREWORD.}

THE delightful art of embroidery has long been carried on by most people in going over with the needle " patterns " obtained all ready-made at a shop, and design has been thought of as a somewhat dreadful mystery.

Now there are many levels of " design." The alteration of a dress or re-trimming of a hat requires design; and a great part of the design for needlework was done in much the same way, by adapting and rearranging units which were in common use. Many of the charming things shown in our Museums were, in fact, thus designed. We modern people, however, have first identified design with drawing, and having confused ourselves still further with opinions about genius, and art, and originality, and style, the whole thing has become too complicated. Some of our art teaching has consisted in frightening people out of their wits, whereas it should boldly lead them to produce.

It is obvious that embroidery based on patterns personally selected and adapted is on a higher plane of interest than the mere filling in of a purchased pattern; it is "playing the game" as it were. Think how dreary any other game would be if it were limited to the going over of a fixed plan! As a matter of fact, there are fixed elements in all games-the moves-and the interest arises in solving new combinations: games are played as it were from a pattern book.

Designing of this sort is no mystery that requires " genius " (besides, if it did, we have enough for the purpose) ; it is of the same kind as the art of planting a garden border, or laying the breakfast table 
vi

FOREWORD.

properly. It produces, however, a much higher type of interest and intelligence than the "working" of a pattern got from a shop or a paper. It is certain, moreover, that most embroideresses who will begin by adapting the elements given in this pattern book, and gain interest and confidence in so doing, will go forward insensibly to varying the elements themselves and to taking flowers and animals direct from nature.

This particular Pattern Book is the work of a highly competent designer of embroidery, and I heartily recommend it. Further, I recommend all girls to practise the fascinating game of playing with the needle and the pattern book.

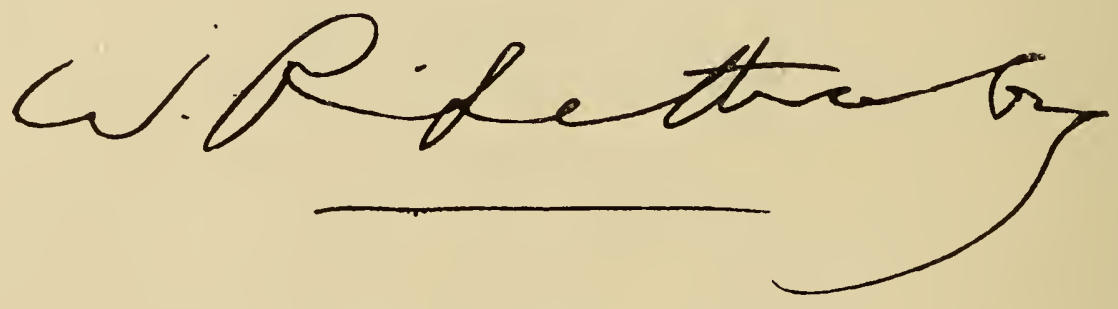




\section{CONTENTS.}

FOREWORD

INTRODUCTION

PLATES

I-IV. BORDERS DESIGNED ON THE THREADS OF THE MATERIAL 6

V. EMBROIDERED BORDERS . . . . . . 14

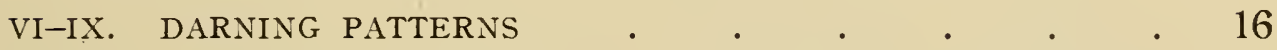

X-XII. CROSS-STITCH PATTERNS . . . . . . . 24

XIII-XIX. BORDERS DESIGNED ON STRAIGHT LINES . • . 30

$\mathrm{XX}, \mathrm{XXI}$. DECORATIVE SQUARES . . . . . . . 44

XXII, XXIII. DECORATIVE CIRCLES . . . . . . 48

XXIV-XXVI. DECORATIVE CIRCLES AND SQUARES EMBROIDERED . 52

XXVII-XXX. DECORATIVE TREES . . . . . . . 58

XXXI-XXXIV. BORDERS BASED ON CURVED LINES . . . . . 66

XXXV. POWDERED FILLINGS . . . . . . 74

XXXVi. GEOMETRICAL FILlingS • . • . . . . 76

XXXVII. LEAF-FILLINGS . . . . . . . . 78

XXXVIII-XLI. DECORATIVE LEAVES AND STEMS . . . . 80

XLII. FLOWERS DEVELOPED FROM BUTTONHOLE WHEELS • 88

XLIII-XLV. DECORATIVE FLOWERS AND SPRIGS . . . . 90

XLVI-XLIX. DECORATIVE PLANTS . . . . . . . 96

L. INSECTS, ETC. . . . . . . . . 104

LI-LVi. APPLIQUÉ PATtERNS . . . . . . . 106

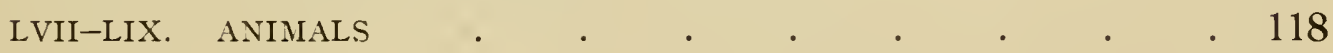

LX-LXII. BIRDS . . . . . . . . . 124

LXIII, LXIV. INTERLACING KNOTS • . . . . . 130

LXV. INTERLACING BORDERS . . . . . . . 134 
viii

CONTENTS.

PLATES

LXVI, LXVII. REPEATING INTERLACING PATTERNS

LXVIII, A ROMAN ALPHABET

LXIX. A TENTH CENTURY VERSAL ALPHABET . . . 142

LXX. EMBROIDERED INITIALS AND MONOGRAMS . . . 144

LXXI-LXXIII. “BRODERIE ANGLAISE” AND WHITE EMBROIDERY 146

LXXIV. EMBROIDERED EDGINGS • • • • • . . 152

LXXV. EMBROIDERED COLLARS . . . . . . . 154

LXXVI. FAGGOT-STITCHING . . . . . . . 156

LXXVII, LXXVIII. TWO CUSHION COVERS . . . . . . . . 158

LXXIX. A CIRCULAR BOX . . . . . . . . . 162

I.XXX. A BIB . . . . . . . . . . 164

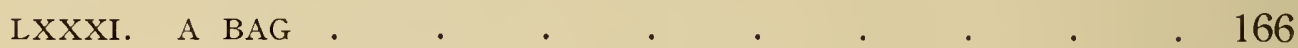

LXXXII. A HANDKERCHIEF CASE . . . . . . 168

Frontispiece. AN EMBROIDERED BAG . • • . . . . . . 170

LIST OF BOOKS FOR REFERENCE _ . . . . 171 


\section{AN EMBROIDERY PATTERN BOOK.}

\section{INTRODUCTION.}

EVERY student of the history and tradition of embroidery is well acquainted with the lace and embroidery pattern books which were used all over Europe in the sixteenth and seventeenth centuries by lace-makers and embroideresses.

Mrs. Palliser, in her History of Lace, says that the earliest dated example was published at Cologne in 1527. Other works on the subject followed in rapid succession, and their number gives us some idea of the extraordinary amount of interest and pleasure taken in embroidery and lace-making in those days. In the few remaining to us, those patterns which are intended for embroidery are drawn in strong, black outline, clear enough to make tracing an easy matter. The choice of subjects for embroidery is very curious and delightful. Much of their charm lies in the fact that they suggest rather than dictate fresh arrangements of pattern.

Until we come to the second half of the sixteenth century, it is not at all easy to acquire much information about English secular embroidery, with which this book is exclusively concerned. Only a few isolated examples are accessible to us, such as the Bayeux Tapestry, the surcoat of the Black Prince, embroidered with fine gold thread and still preserved in Canterbury Cathedral, and a few rare specimens of heraldic appliqué. We have some written evidence of the existence of important specimens of embroidery not devoted to church use in the records of household expenditure, and in the wills of famous personages; and on some of the effigies of the fifteenth century, such as those of Richard II and his Queen in Westminster Abbey, traces can be found of patterns which were undoubtedly copies of existing embroideries. Such records as these, however, convey little meaning to the embroideress of to-day, who is constantly searching for new stitches and methods of using the needle and thread; and, above all, for patterns which can be quickly adapted and applied to some piece of work in contemplation.

But, when we come to the sixteenth century, we are able to consult not only pattern books, but actual examples of some of the finest secular embroidery that England has ever produced. With the coming of the Reformation, 
the activities of the Church embroideress were brought temporarily to a close - permanently so far as their high standard of taste and execution was concerned-and the skill which formerly had been employed in making splendid the setting of the Catholic Church was transferred, in the reign of Elizabeth, to the clothing of human beings more sumptuously than they ever had been before or have been since in the history of our country. During her reign, and on into that of James I, the output of embroidery must have been enormous; at no later period did it attain to such a pitch of excellence. There was a positive outburst of the creative faculty; no time, labour, or expense was spared in perfecting the object of the worker's skill and ingenuity. Of this rich harvest, some beautiful examples remain in public and private collections; another source of information is available in portraits of the period, in which embroidered garments are often easily distinguishable.

There is invariably a beauty and charm about this work which are lacking in even the best examples of the late seventeenth and the eighteenth centuries; then the source of inspiration was the East, and strange flowers and birds not known to women living in England were an important feature in all kinds of embroidery executed at this time. But the sixteenth century relied to a great extent on English traditions. No doubt the tremendous outburst of activity in all the fine arts owed its origin to the far-reaching effects of the Italian Renaissance, yet pattern designing in England was more distinctly English in character than any that has been produced since. It is for this reason I feel that students of embroidery who wish not to waste their time and skill on patterns lacking in vitality and designs which are merely the outcome of a fashion, will obtain the finest results if they examine searchingly the work available to us of the late sixteenth and early seventeenth centuries. Not with any thought of reproducing such patterns, for, in many instances, the technique of the embroidery is far too complicated and tedious for the modern worker; but with the object of trying to understand the spirit of the craftsmen which made such work possible. They possessed patience, one of the qualities essential to good workmanship; they were content to find beauty in the things immediately surrounding them-the flowers they used in their embroidery were of no rare variety, but just everyday blossoms, like the cowslip, the foxglove, or the sweet-pea, and these were drawn with no trace of affectation.

There is a strong feeling in their work of the steadying influence of geometry, in which lies the greatest strength of the sixteenth century designers. Patterns, which tend to ignore the supporting structure of geometry have always proved to be on the down grade, and rapidly become decadent in character. Even when the Elizabethans use the "all-over" scrolling pattern, the scrolls are well-ordered, approaching almost to circlesvery different from the graceful but uncertain curves of the "all-over" patterns of the early eighteenth century. 
Finally, the Elizabethans were sure enough of themselves and of the results of their work to give free rein to their innate sense of humour. The embroideress could find a use in her embroidery for caterpillars and snails; to her mind there was nothing incongruous in representing on the same stomacher stags and bees and little bunches of flowers. (See the miniature of Mrs. Holland in the Salting Collection, Victoria and Albert Museum.) English people, when producing work of a very high standard, never try to exclude the humorous element. The cathedrals of England, the sacred vestments and stained-glass windows, the illuminated manuscripts, all give us evidence of the mirthful spirit of the master craftsman taking pleasure in his work. Now that in the matter of the handcrafts we have fallen far below the standards of the Middle Ages and the Renaissance, our sense of fitness is disturbed at the introduction of humour, and we prefer to treat our work with excessive solemnity and respect.

The art of embroidery has passed through many stages since the Elizabethans helped to make it so splendid a craft. In the nineteenth century, nothing worth being really proud of was executed but a little silk embroidery during the period of the First Empire, and the exquisite white work of the first part of the century; then there was an epidemic of badly chosen woolwork, and, after that, for several years, a quiescent period, when nothing worth mentioning in the way of embroidery was produced at all. But, for the last fifteen or twenty years, good hand embroidery has been struggling to be re-instated; an extraordinary interest is being taken in all forms of embroidered decoration, and the old ever-recurrent desire to produce something beautiful with needle and thread has begun to re-assert itself in real. earnest.

But, for the worker not skilled in drawing and designing, no pattern books exist, and the only source open to her lies in the transfer patterns so. liberally supplied by any shop with a needlework department. Unfortunately, the public as a whole is entirely satisfied with these anaemic offspring of the late seventeenth and the eighteenth centuries: it takes delight in black satin cushions and tea-cosies decorated with the inevitable basket of flowers, without structure and therefore without beauty; in the vacuous bows of ribbon all executed in artificial silk. It is a pity that often quite good workmanship should be wasted on such miserable efforts. But, as Mr. Clutton. Brock has remarked, "It is not enough to preach peace by talking of the: horrors of war, for men are so made that they prefer horrors to dullness:"

I have therefore planned this book with the object of trying to show the embroideress who makes use of transfer patterns that it is really not a very difficult matter to arrange her own designs, and that surprisingly good results can be obtained by the intelligent use of a compass and ruler. The design of Plate XIX, for instance, can be reproduced by any one on sectional paper with the aid of a ruler; the circular and square designs, illustrated in 
Plates XX-XXIII, when repeated, make quite interesting " all-over " patterns; the trees can all be measured off; the flowers of Plate XIII need no other preparation than a circle drawn on the material. Collected together in one book are patterns and motives for practically all forms of simple hand embroidery. The first part has been arranged especially for the needs of students attending the courses in Simple Embroidery and Design held in the various Day and Evening Classes.

The plates have been arranged in progressive order so that the student may pass by gradual stages to the execution of varied designs. As we have no recent tradition in embroidery from which to build up a strong school of pattern designing, I have felt obliged, especially in the first part of the book, to take up a primitive point of view and try to show what satisfactory results can be obtained by relying, to begin with, almost entirely on geometrical construction.

Our ideas about pattern-making, as about everything else, have become far too complicated; it is necessary that we should realise again the beauty of simple decoration well executed and well applied, and, above all, that our embroidery should be destined for things we are not afraid to use every daythings that can be washed and worn and still keep their freshness. Those beloved black satin cushions would be ruined in a week if any sacrilegious person dared to put them to the uses of an ordinary cushion. The machineembroidered muslin collars, so fashionable just now, present a very shabby appearance when they return from the second or third wash. Indeed, from a practical, economical, and moral point of view, it is well worth while to take into our own hands the making and decoration of our personal belongings. Practical, because, when the choice of material and colour lies entirely with the worker, her work is far more likely to suit the purpose for which it is intended, if she is a person of some intelligence, than when she is limited to a ready-made selection; economical, because a home-made article, carried out in good material, will outlast a dozen shop-made rivals; and moral, because a piece of handwork well done will often bring a sense of satisfaction to an otherwise restless mind, and the consciousness of having produced work of good quality invariably increases self-respect and permanently improves good taste and power of discrimination.

There are no stitch diagrams included in this book to explain the working of the stitches referred to. This hardly lies in the province of a pattern book. A list of references has been arranged of works on embroidery which will give all the information on this point that an elementary or advanced student can possibly require. 
EMBROIDERY PATTERNS. 


\section{BORDERS DESIGNED ON THE THREADS OF THE MATERIAL.}

\section{$\therefore$ Group 1. Plate I.}

THE groups of borders illustrated in the five following Plates, which come under the heading " Borders Designed on the Threads of the Material," represent the very first step in the growth of embroidered decoration.. In character they strongly resemble weaving, and indeed, those illustrated on Plate I could be equally well carried out with a needle and thread, or woven upon a hand-loom.

In the next three Plates, however, the borders, though still exceedingly simple, give a little more scope for the use of a needle, and belong more definitely to the field of embroidery. The modern mind may be inclined to disdain patterns which are so simple and so obvious in their structure, but for certain purposes, to be described later, nothing will give the embroideress quite so much satisfaction as this particular method of applying decoration. They are especially suited to the needs of theibeginner, although she is unfortunately often fired with far more ambitious schemes; but, with this method of work, success is assured if she has patience enough to be accurate in counting the threads of the ground material. As for the technique, any one capable of darning a stocking will find there is nothing fresh to learn in darning these borders-the processes are identical.

In Plate $\mathrm{V}$ are shown some examples carried out in D.M.C. thread on a coarse linen ground. 


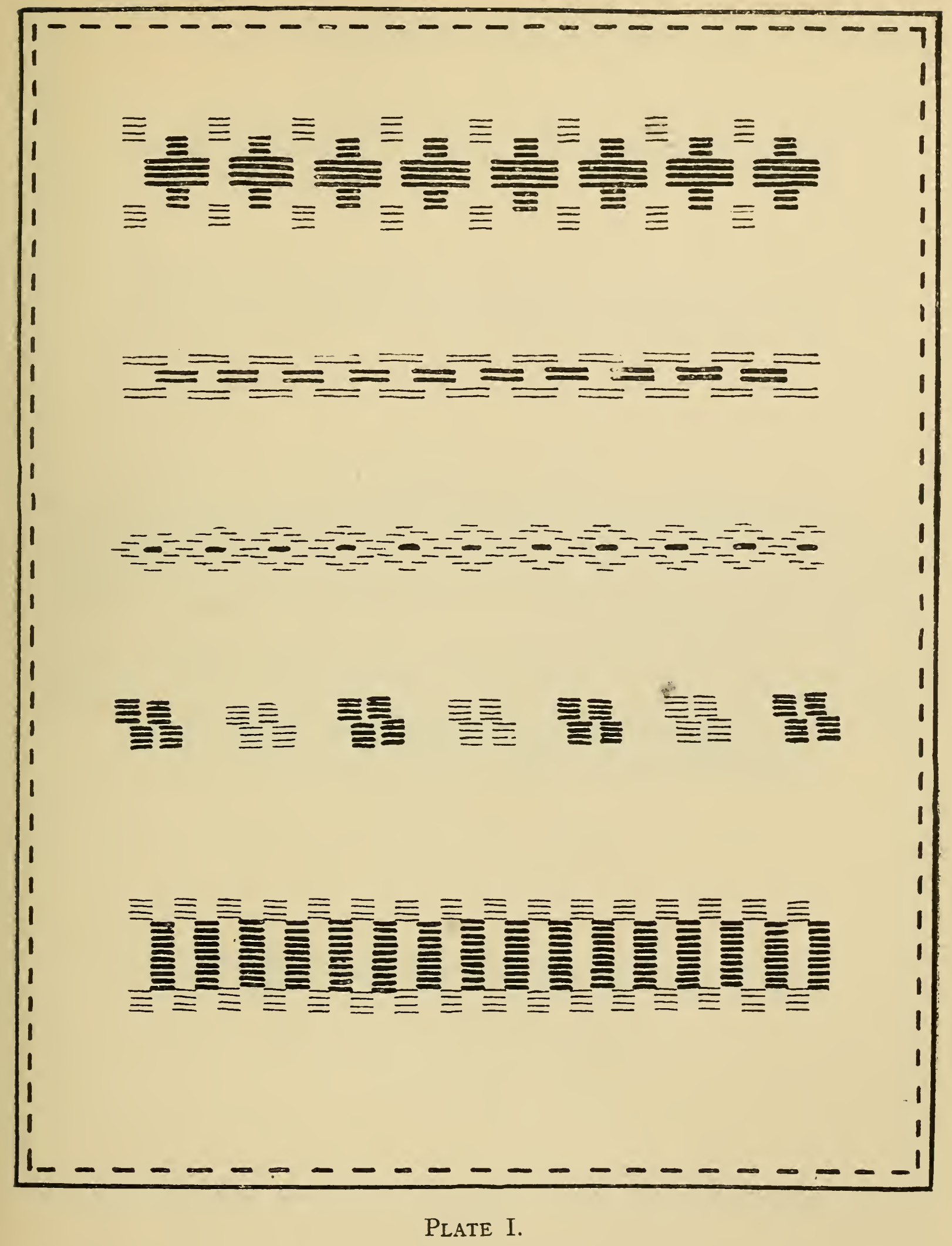




\section{Group 2. Plate II.}

The borders illustrated in Plate II differ essentially from those in Plate I in that the pattern is worked on both warp and weft threads of the ground material. The upright lines will have to be embroidered in satin stitch, the horizontal ones can be carried out as those in Plate I by darning the thread in and out of the material.

It is very important that this thread should be large enough to cover the ground spaces between the stitches, as one which is too small will give an impoverished appearance to the work, and quite destroy the very definite effect these patterns should have when completed. 


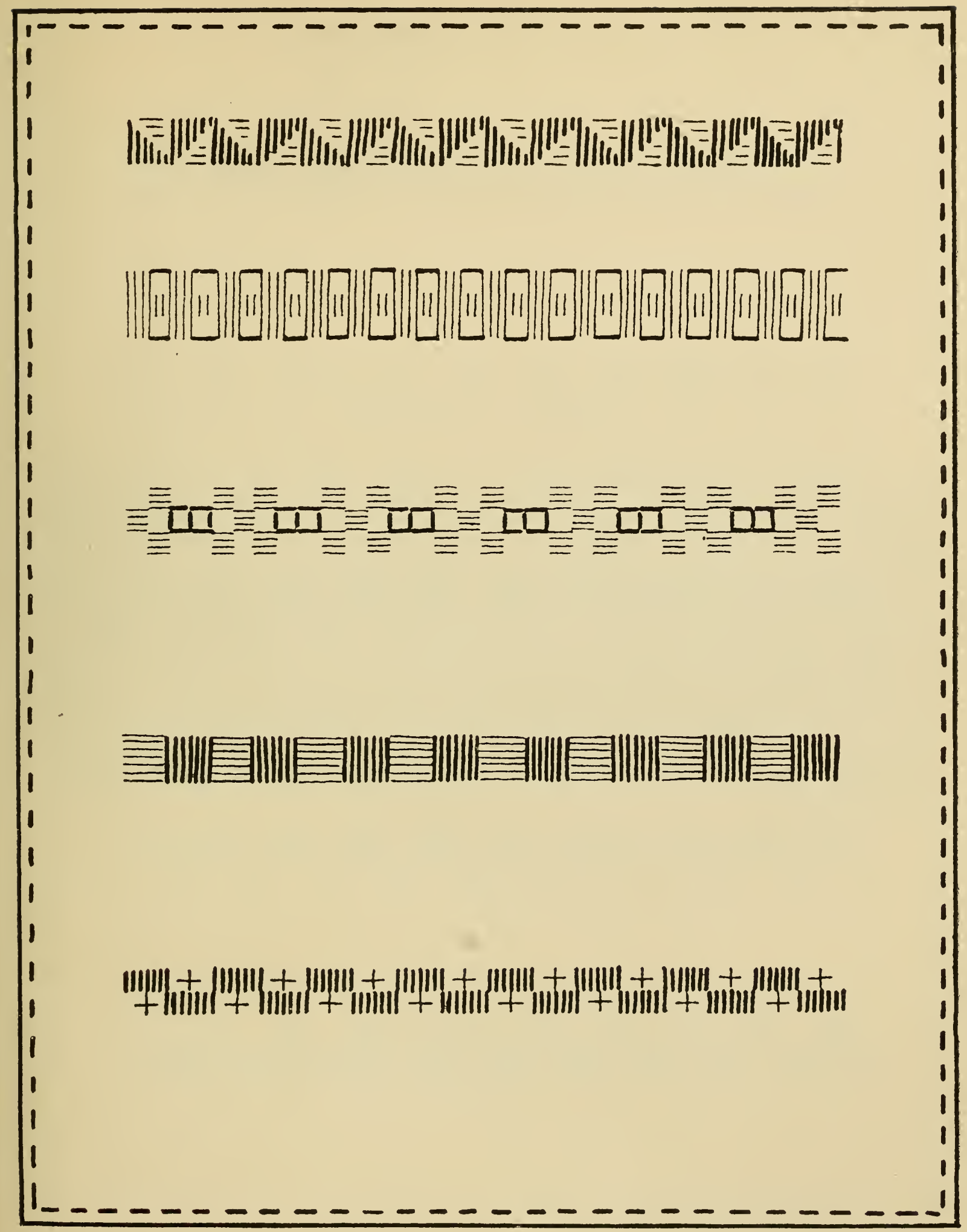

Plate II. 
Group 3. Plate ili.

In the two former plates we have dealt solely with the use of satin stitch and darning as a means of applying decoration. Plate III takes us a step further, and introduces the use of back stitch combined with the two former stitches. The last two borders on the opposite page are carried out in back stitch only. Perhaps it would be as well to explain here that the phrase "back stitch" in embroidery is only a glorified term for the way the needle is used in ordinary stitching. In these patterns the stitches are worked at various angles, but the methods are identical. The embroideress should be careful, when using a loosely woven material, not to pull her thread too tight in working back stitch, or gaps will appear between the threads of the ground and the embroidery. The stitches in the first three borders should always cover the same number of threads (i.e., about four), so the longer lines in the pattern will have to be divided in half and worked with two separate back stitches. 


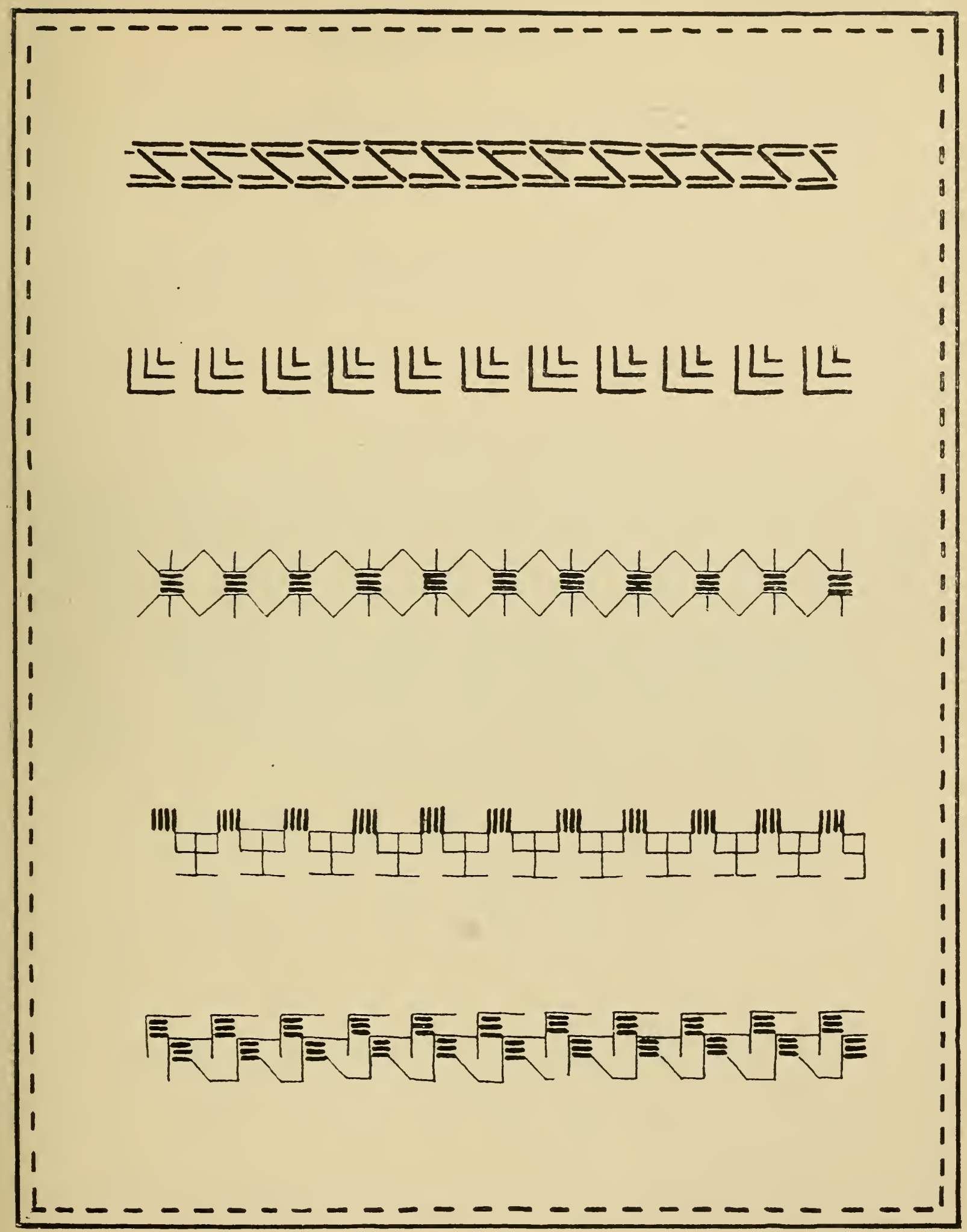

Plate III. 


\section{Group 4. Plate IV.}

The last set of borders illustrated in Plate IV are simply outline patterns carried out in back stitch. They are quite easy to design on sectional paper, and they give an entirely different effect from the borders in which blocks of satin stitch and darning are used. On the whole they look best embroidered in one colour, but possibly, if a second colour were used for the small squares in the first and sixth borders, it would give them a more interesting effect.

Almost any kind of good linen would make a suitable ground for these borders, but the worker, if she values her eyesight, will choose one in which the threads are coarse enough to be easily counted; there is also a primitive character about these patterns which would make them seem out of place on a very finely woven material. On some of the Holbein portraits, borders such as these can be seen used as a dress decoration. 


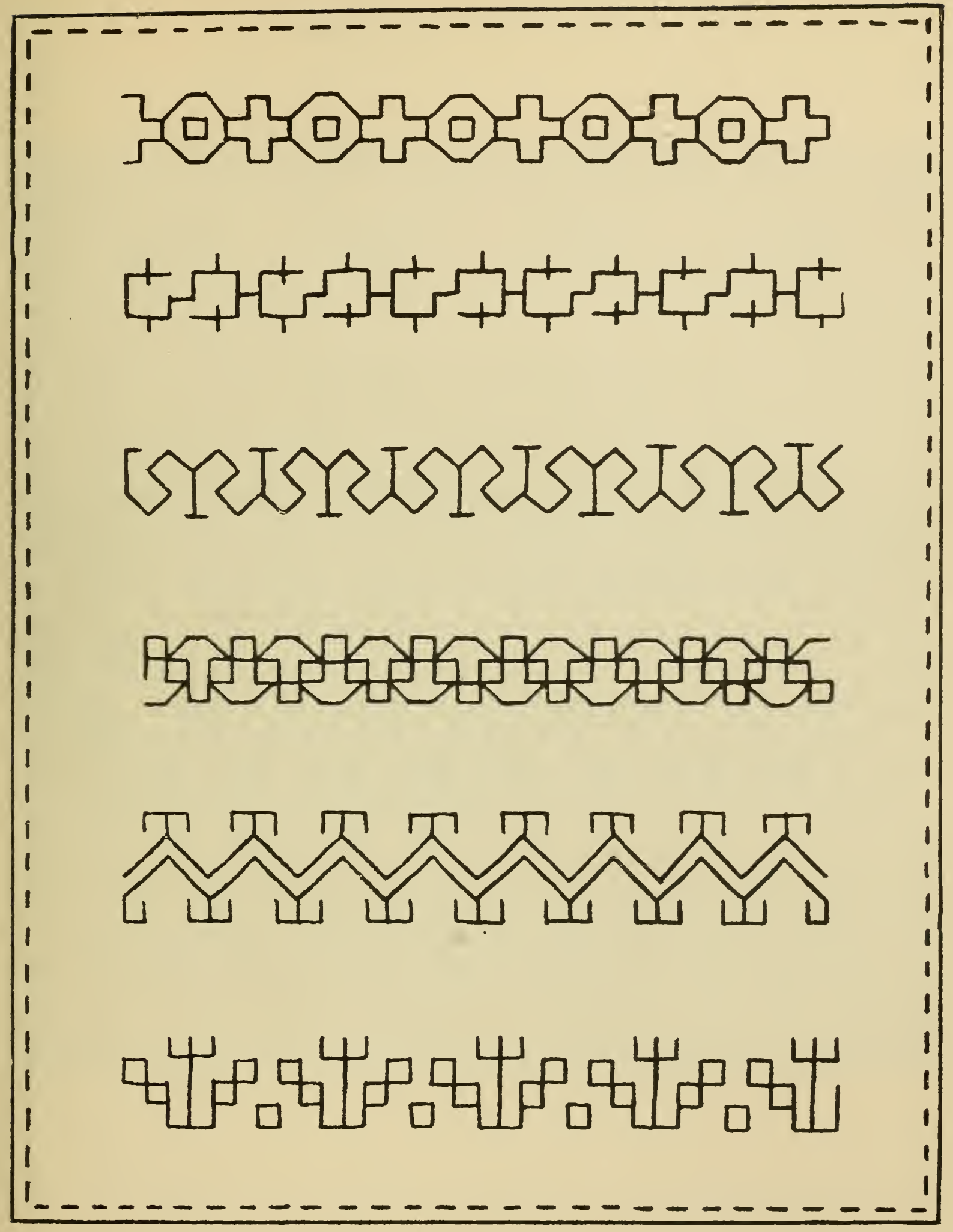

Plate IV. 


\section{EMBROIDERED BORDERS.}

\section{Plate V.}

THE borders in Plate $\mathrm{V}$ are all worked in D.M.C. ingrain thread, size No. 12. Pearsall's Mallard floss or Hermes silk would be equally suitable, but the Hermes silk particularly would add to the expense of the work and might be reserved for more important undertakings.

Two colours should be used for these borders, which, in the original, are worked in blue and white thread on a string-coloured ground. Four of them are carried out in darning, but the middle one shows the combined use of darning and back stitch. Any of these patterns could be applied to children's garments, and could be worked round the top of a hem or the edge of a belt or cuff. On a larger scale they could be used in conjunction with other patterns for washing cushion covers, sideboard cloths or toilet covers, or in fact on any simple article for which the material can be cut to a straight edge. The: technique is perfectly simple, and has been described on pages 6 and 10 . 




Plate V. 


\section{DARNING PATTERNS.}

\section{Group 1. Plate VI.}

DARNING patterns in embroidery are a very fine way of applying decoration. They may be a little tedious to execute if used on an extensive scale, but they well repay the care that has to be taken in counting the threads of the ground correctly by the rich and intricate quality that the use of them gives to a. finished piece of work. There are many different ways of using darning patterns; for instance, the leaves and flowers in a large design can be completely filled with some of these geometrical designs, or they can play the part of background to a very sharply defined design, and so prevent too sudden a contrast between the embroidered pattern and the ground material. On the other hand, beautiful designs can be constructed with darning patterns alone, in which case they are perhaps best suited to upholstery purposes for which a coarse material and a coarse thread can be used, thus considerably reducing the labour involved. It is very important to get the right effect of tone in embroidering a darning pattern, and very beautiful results can be obtained by using sharply contrasted colours which are yet practically of the same tone. If a pronounced dark and light effect is required, the background should represent the middle tone upon which both the dark and light threads will retain their true values. 


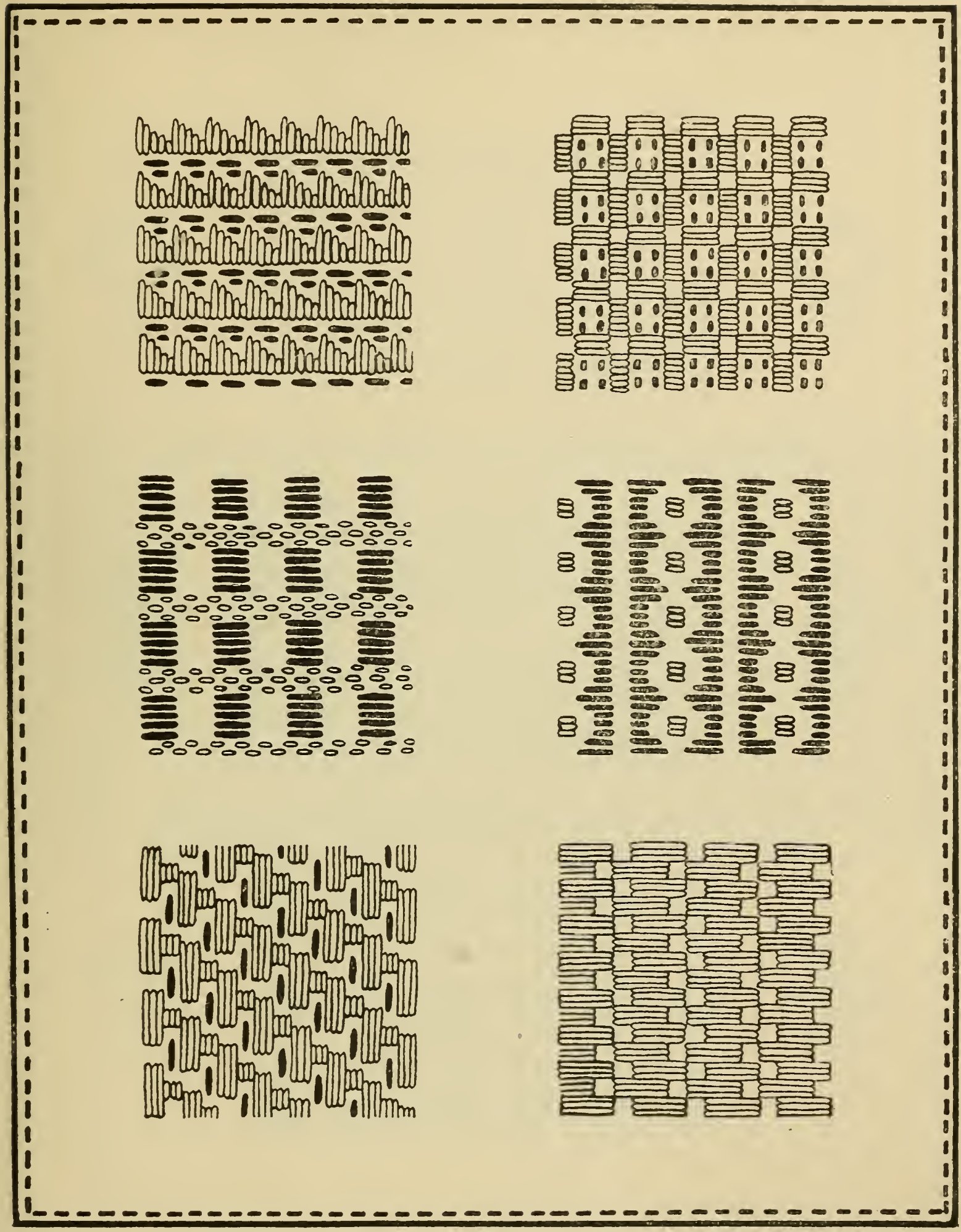

Plate VI. 


\section{Group 2. Plate VII.}

The question of tone and colour in darning patterns depends almost entirely on the purpose and scope of the embroidered decoration. If darning is used as a background, it must always appear lighter in effect than the pattern to which it is only playing a subsidiary part. For this purpose one, or at the most two, colours should be used, provided they are of practically the same tone. The simple patterns are always the most suitable for background effects, and, of those illustrated in Plates VI, VII, VIII, the first and second ones in Plate VII, and the bottom one in Plate VIII would work out very satisfactorily for this purpose.

For decorating leaves and flowers, the darning patterns can be a little more assertive than when they are used as a background only. Several different designs could be used on one piece of work without in the least confusing the general effect, provided that a strong outline is worked afterwards all round the patterned leaves and flowers. It would be as well not to have more than two or three colours for a design of this kind, for too great a variety would tend to introduce a feeling of restlessness into the embroidery far more than any number of different arrangements of the working threads. 


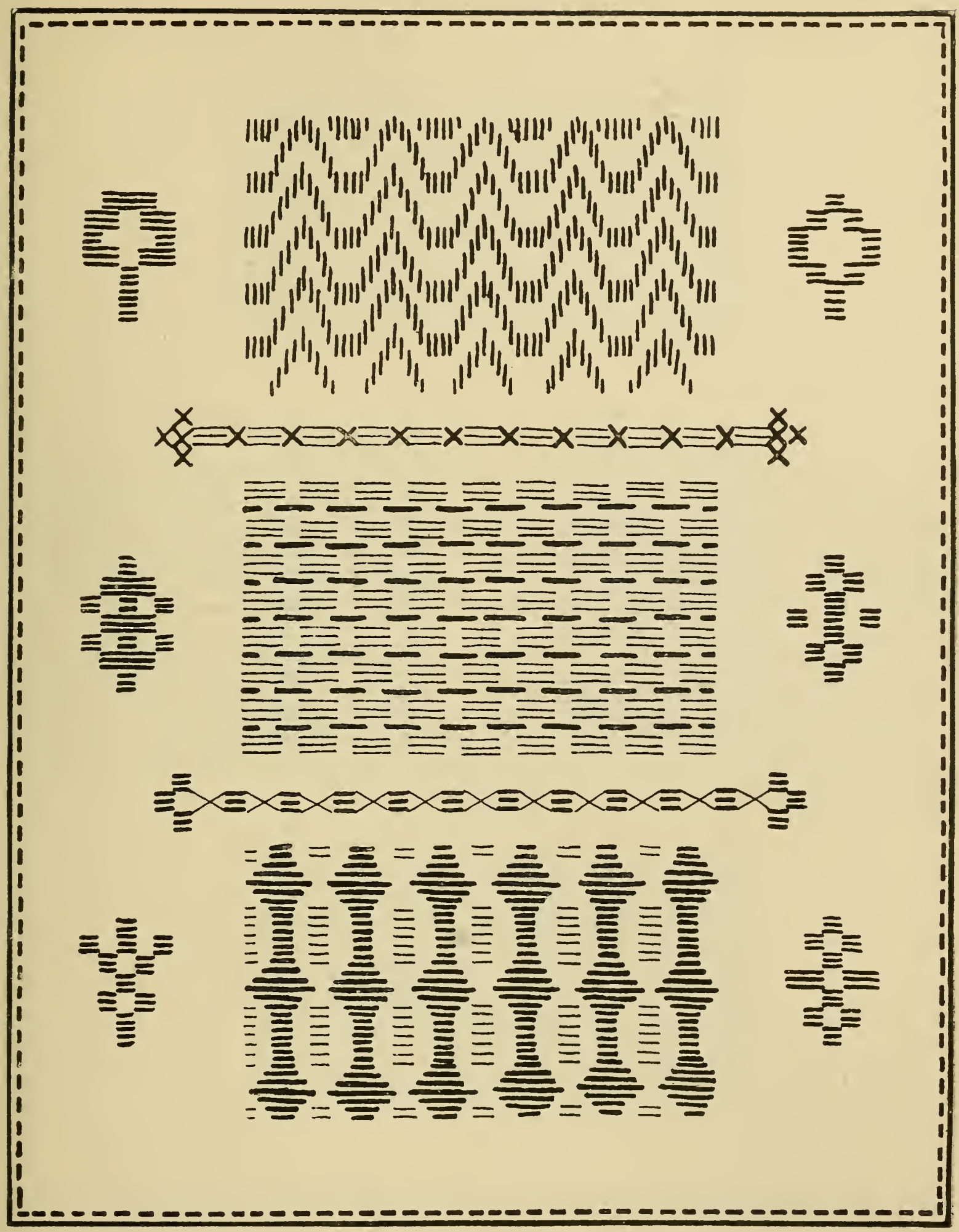

Plate VII. 


\section{Group 3. Plate VIII.}

The darning patterns illustrated in Plate VIII are particularly suited to designs which are to be carried out entirely in this method. With this object in view, the darning should be quite definite both in arrangement and colour; pale colours are entirely out of place, for they would become quite indistinguishable at a distance, whereas a rich scheme of pure, fresh colour would always be pleasant to look upon either from the other side of a room or close at hand.

In Plate LXXVII, at the end of the book, a design for a cushion is illustrated which will explain how to carry out a pattern entirely in darning and what principles must be observed in arranging a design of this kind. One of the most important of these is contrast in effect both of shape and colour, and another thing which must be carefully considered is the size of the embroidery thread in relation to the ground. 


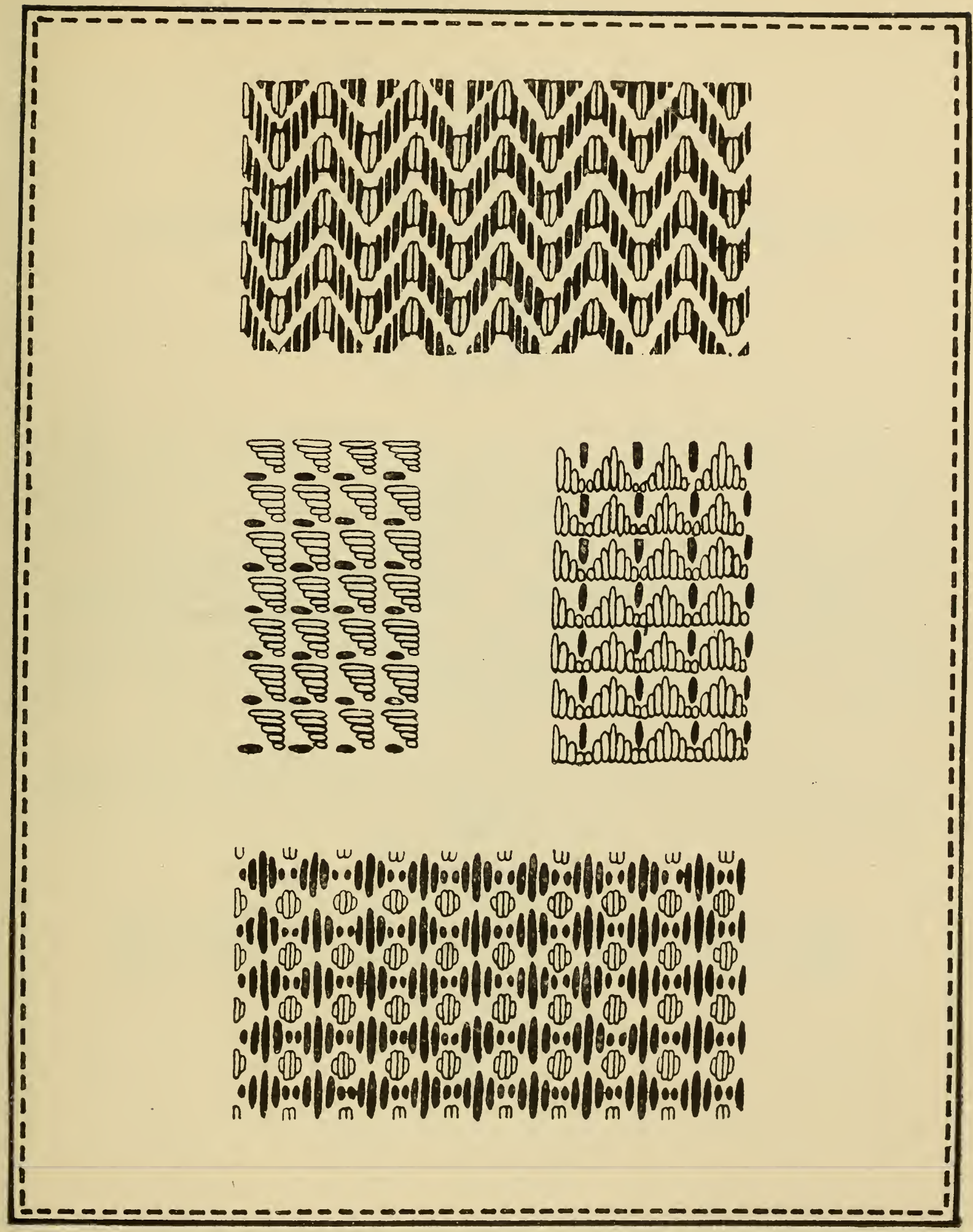

Plate VIII. 


\section{Group 4. Plate IX.}

Plate X illustrates three different arrangements of patterns in which a decorative square carried out in darning stitches is combined with a simple border embroidered in the same way. They have already been referred to once on page 16. These designs are, of course, too big to be used as dress decorations; their proper field is on objects of household use such as toilet covers, mantel borders, or sideboard cloths, as suggested on page 14 .

The decorative squares, if repeated with $2 \frac{11}{2}$ of border connecting them, would provide a pattern exceedingly easy to manipulate, but yet of sufficient importance to make no other addition to the design necessary. Any of the darning borders illustrated in Plates $\mathrm{I}-\mathrm{V}$ could be substituted for those shown in Plate IX, provided that they did not seem too heavy for the centre square.

A cushion cover, embroidered with one of these designs arranged as a border round the four edges of the material, could be improved by dotting over the plain centre at regular intervals some of the small isolated sprigs illustrated in Plate VII. 


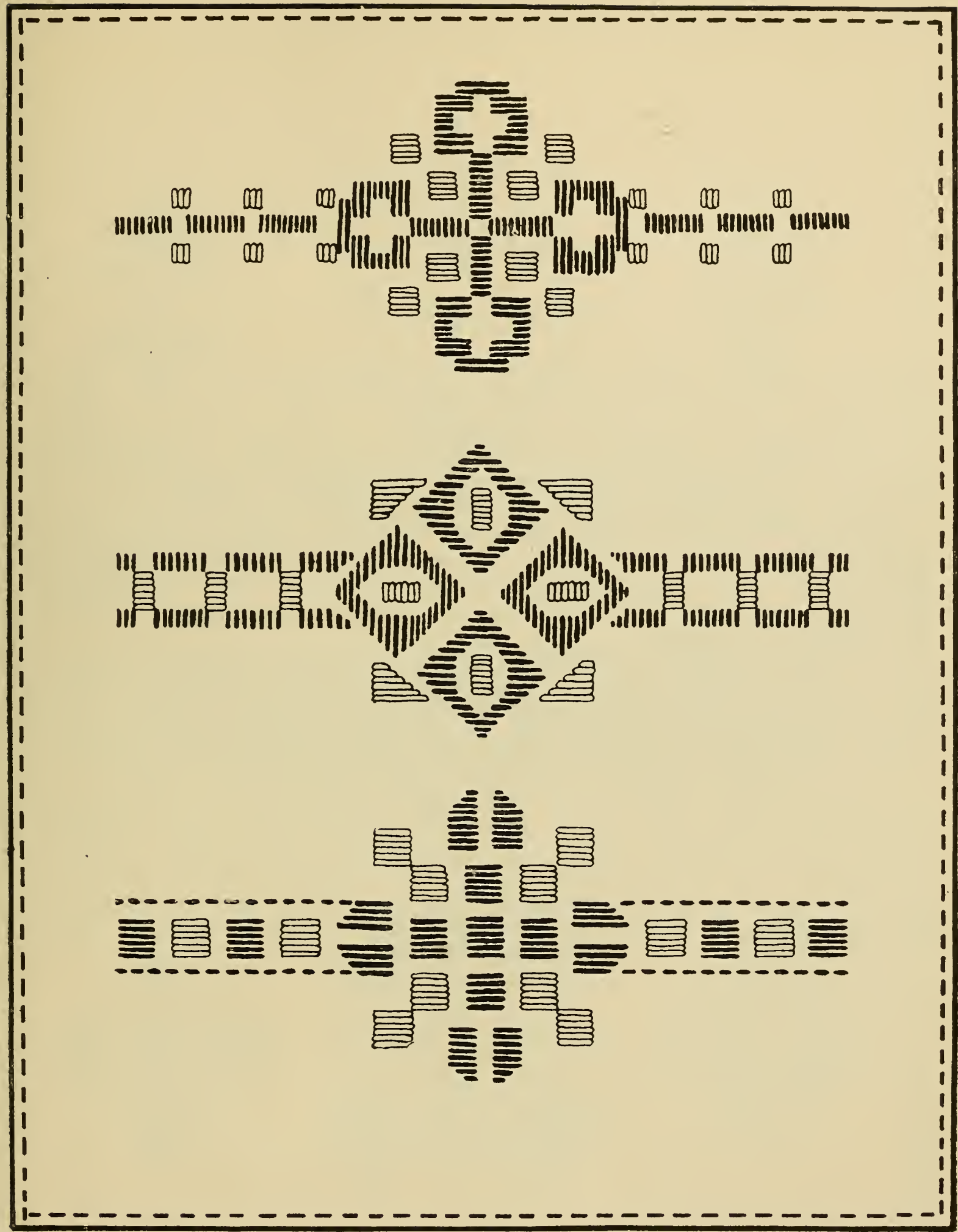

Plate IX. 


\section{CROSS-STITCH PATTERNS.}

Group 1. Plate X.

Plates X, XI, XII give a collection of cross-stitch patterns which, with a little arrangement or alteration, would provide an endless variety of designs. This form of embroidery is particularly suited to beginners, for the technique is so simple and the result so extraordinarily decorative; the very limitations of cross stitch are a blessing in disguise, for they effectively prevent weak or undecided curves in the drawing, or naturalistic treatment of any sort.

Household linen of all kinds can be very suitably decorated with crossstitch patterns, and so can children's dresses and sometimes those of grown-up people (the corner of a cross-stitch collar is shown in Plate LXXV), but the ground material should always be rather coarse on account of the difficulty of counting the threads.

At the top of Plate $\mathrm{X}$ is shown a tree which is connected with a border, and on either side of it is a small sprig. The tree could be made much larger, if necessary, by simply extending the branches; or, on the other hand, it could easily be cut down to a smaller size. The sprigs, if repeated at intervals, would make a fine decoration round the hem of a child's dress.

In the middle of Plate $\mathrm{X}$ is a wide border based on the counterchange principle (see Plate LVI), and in the centre at the bottom of the plate is a square with interlacing corners. By comparing the three plates it will be found that practically all types of design can be reproduced in, or adapted to, this method. It is well to arrange the colours in definite masses or the result may be somewhat confused, and the colour itself applied to such a simple type of embroidery should be fresh and bright. 


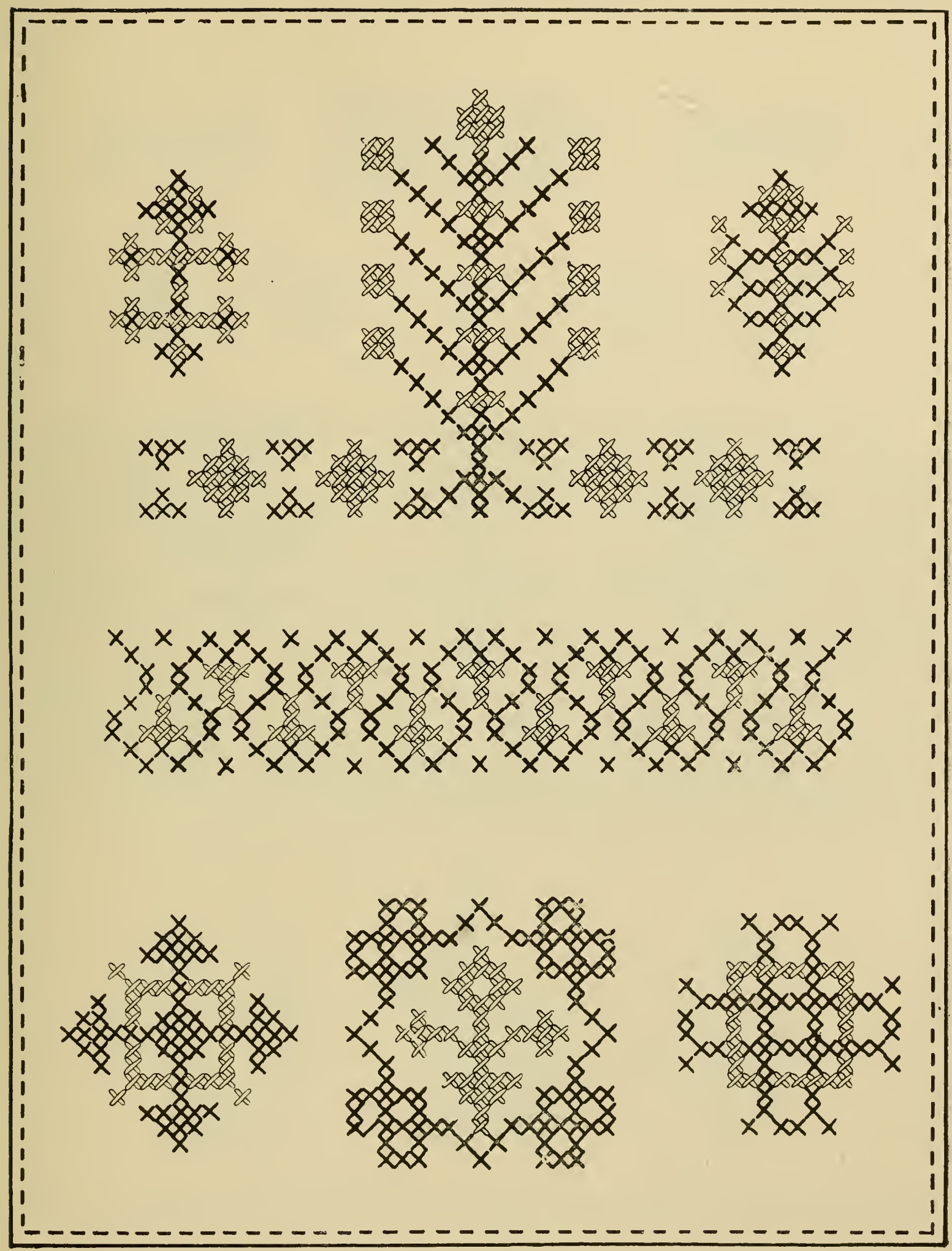

Plate X. 


\section{Group 2. Plate XI.}

Some of the patterns illustrated in Plate XI are very suitable for decorating articles which belong to children; for instance, the row of black pigs at the top lof the Plate could be embroidered on a bib, or, with the addition of some other animals, might form a border that could be applied to a nursery table cover or curtain.

At the bottom of the plate a rabbit is shown sitting between two plants. These three objects might be used just as they are for decorating some small article, or they could be repeated to form a border design, and in that case other animals might be introduced as well as the rabbit.

The two borders and the flower sprigs, also illustrated in Plate XI, might be embroidered on any article for which cross stitch is a suitable decoration. The sprigs could be adapted to a collar design, repeated to form a border, or used as an all-over spot pattern. Any plant with a definite outline can be translated into cross stitch, and if it were small enough, could be substituted in a design for those illustrated in Plate XI. 


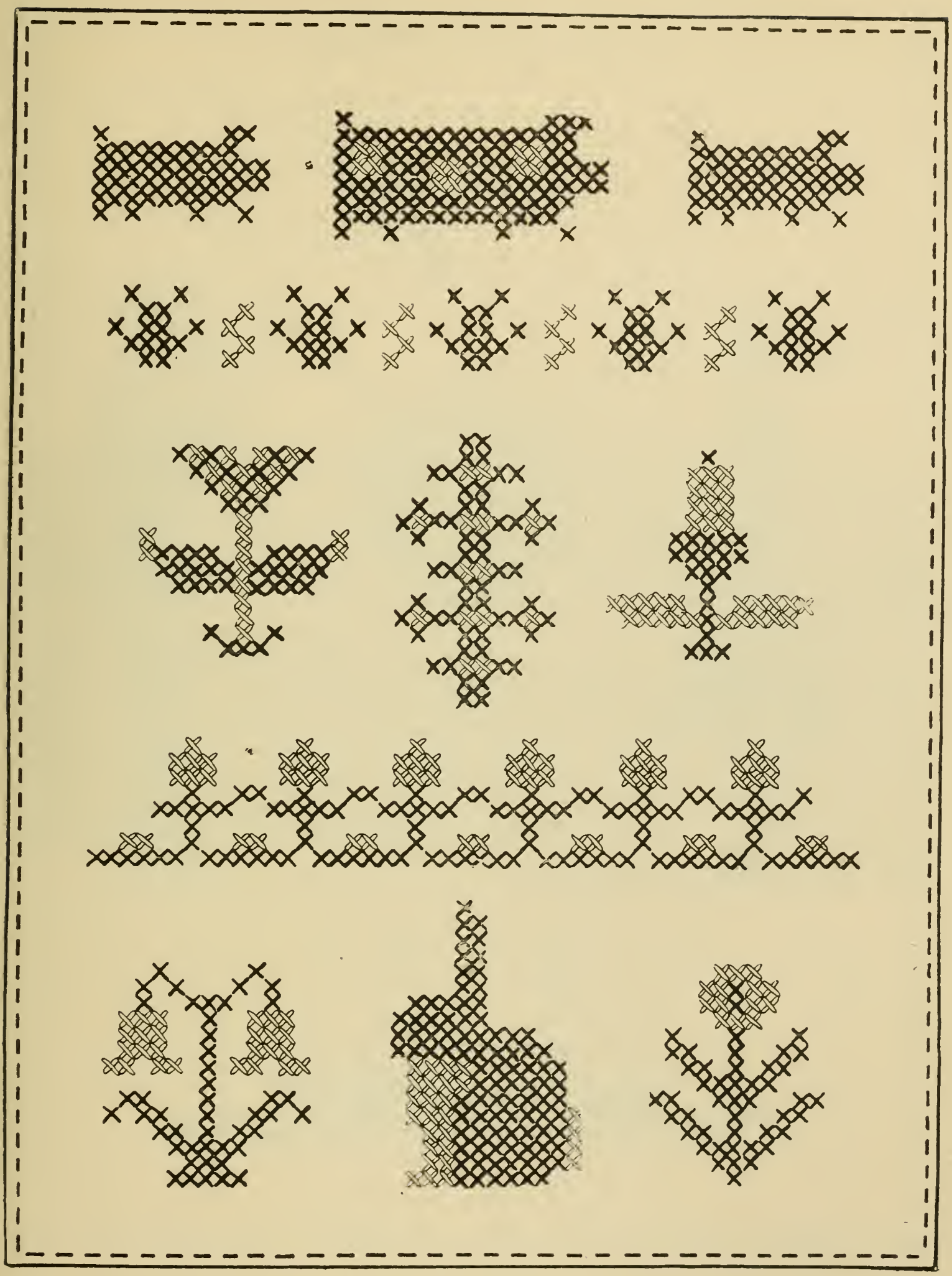

Plate XI. 


\section{Group 3. Plate XII.}

Plate XII is devoted to objects of topical interest which are intended for decorating articles that belong to children. With a little assistance a child could embroider the patterns herself, and might be encouraged to adapt other objects, with which she is familiar, to cross-stitch embroidery. This process would have a good deal of educational value, for the technique of cross stitch accentuates the structure of any natural form, and leaves no room for anything but absolute essentials.

The aeroplane illustrated at the top of Plate XII should not be embroidered in more than two colours, and these should not be very bright, for shape rather than colour is the chief characteristic of an aeroplane, and the same can be said of the balloon, while the battleship must, of course, be carried out in tones of grey. The Scottish soldier could have a brightly-coloured kilt and stockings, though his tunic must be of khaki colour. The sailor's uniform, though it must be confined entirely to dark blue and white, could have the tunic and trousers embroidered in two shades of blue, provided that they were of exactly the same tone. 


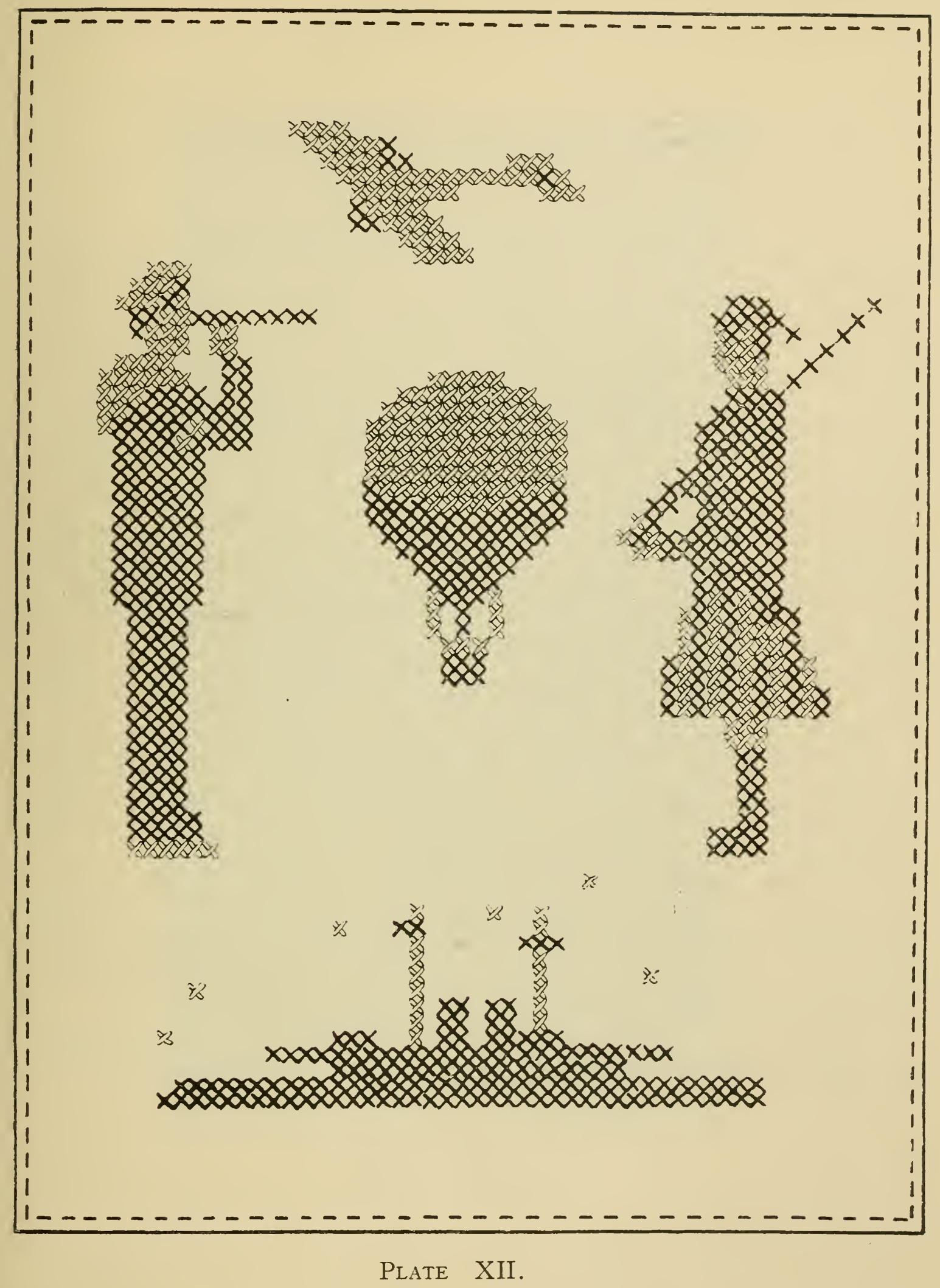




\section{BORDERS DESIGNED ON STRAIGHT LINES.}

\section{Group 1. Plate XIII.}

In this pattern book, borders suitable for simple hand embroidery have been arranged under three different headings, viz., darning borders, which have been already described, borders designed on straight lines, and those which are developed from curved or meandering lines. A good deal of space has been devoted to this subject, as practically every piece of embroidery involves. the use of a border or outline of some kind. Those illustrated in the five following plates are all worked in D.M.C. ingrain thread, size No. 12, and D.M.C. mercerized thread, size No. 8, which is sold in balls, and is the lighter colour. Straight lines, the width apart of the border, should be ruled on the material before commencing the embroidery, and for most of the patterns. a centre line also is necessary.

Buttonhole stitch, which is quite one of the most indispensable embroidery stitches, forms the basis of the five borders illustrated in Plate XIII.

Beginning from the top, the first border is carried out in buttonhole. stitch and Roumanian stitch, one buttonhole stitch fitting between a pair of Roumanian stitches.

The second border is worked in twisted buttonhole stitch, with the addition of two interlacing threads of another colour which are run in and out of the heading.

The third border shows another variety of buttonhole stitch, which in this case is the only one employed. The outline is worked in ordinary buttonhole stitch, broken at regular intervals by a crossed one. Along the centre of the border buttonhole loops are embroidered, which are arranged on one thread and are not worked into the material.

The fourth border is carried out mainly in buttonhole stitch, three stitches being worked into one hole to form the small white triangles; the heading is afterwards whipped with a contrasting colour, and the space between the triangles filled by a crossed fly stitch. This stitch is made on the same principle as the ordinary fly stitch, except that the thread is crossed over the needle first and then under it, as in tailor's buttonhole.

The fifth border is composed of two rows of crossed buttonhole stitches, the space between them being filled with double back or close herring-bone. The buttonhole stitch should be worked last. 


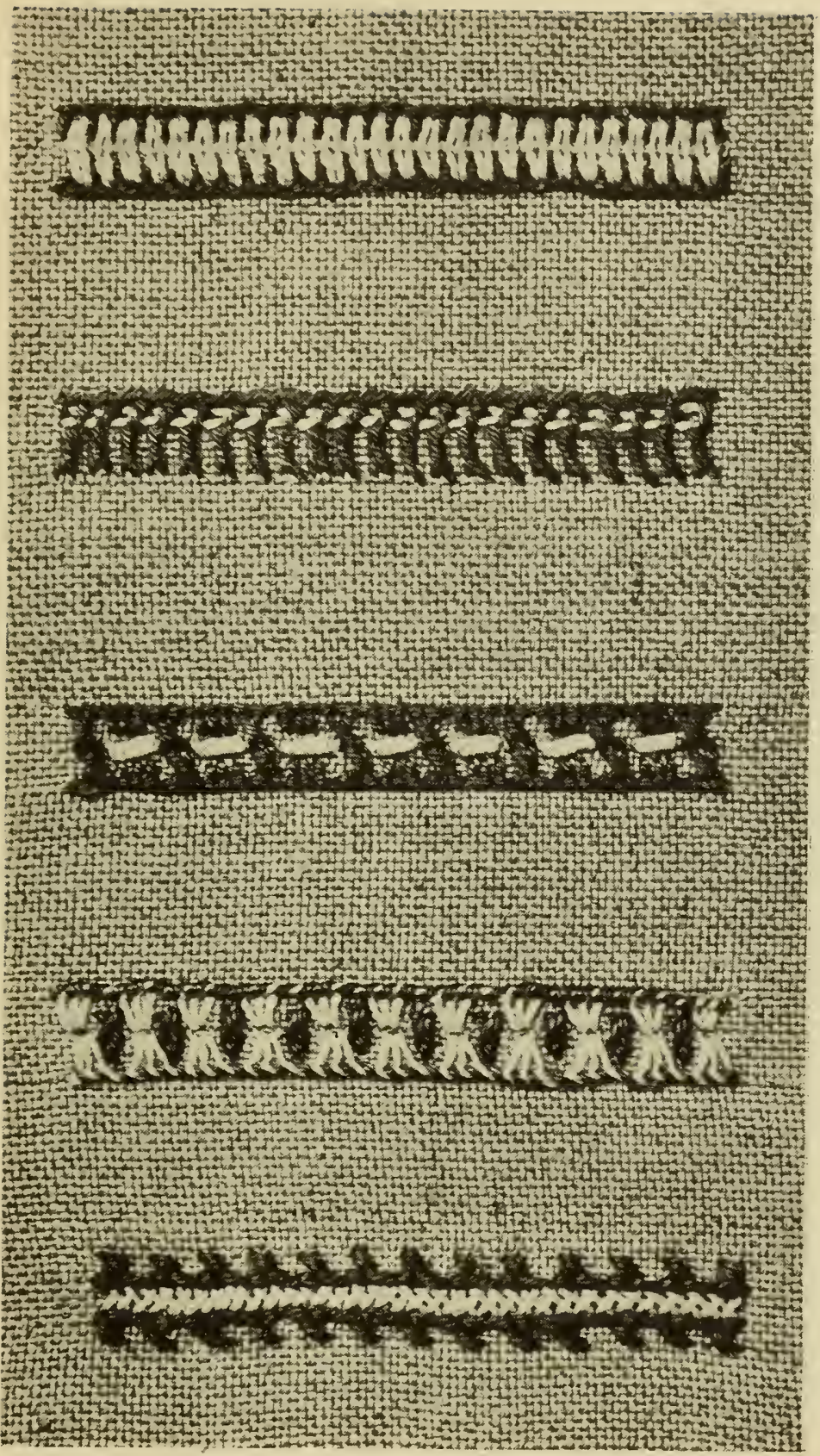

Plate XIII. 


\section{Group 2. Plate XIV.}

The five embroidered borders illustrated in Plate XIV show a greater variety of stitch and treatment than those already described on page 30 .

For the first border, beginning from the top, the solid blocks are worked in fish-bone stitch, the spaces between them are filled with two French knots, and an outline is suggested by the addition of three back stitches, but these could very well be dispensed with if necessary.

The second border is carried out in Roumanian stitch, through which are interlaced four threads in a contrasting colour; there should be two on either side of the centre ridge.

The third border is embroidered in solid blocks of Cretan stitch alternating with smaller ones of ladder stitch. The contrast between the two would be too sudden without the threads which are interlaced in and out of the ladder stitch.

The fourth border is much the same in proportion and spacing as the third one, but in this case it is composed of solid blocks of satin stitch between which are threads laid at right angles to each other and caught down where they intersect by a single small stitch.

The fifth border is worked in ladder stitch, the cross bars of which are caught together in pairs by a back stitch in a lighter coloured thread. 


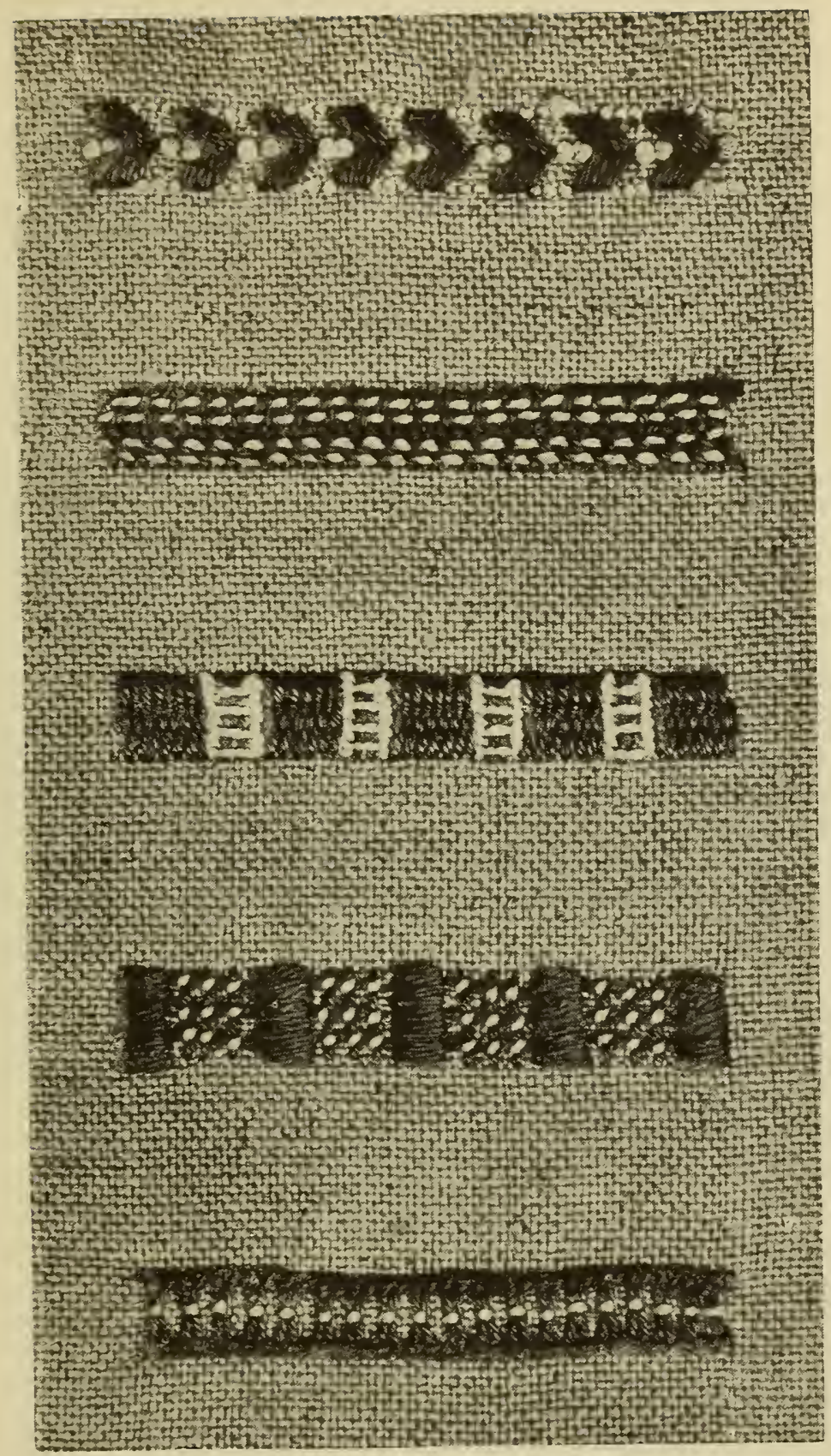

\section{Plate XIV.}




\section{Group 3. Plate XV.}

The first border in Plate XV is worked in fish-bone stitch arranged in solid blocks, and between these are two small crosses, placed diagonally.

The second border is a little more difficult to explain but quite simple to embroider. It is worked in detached Roumanian stitches, two colours being used. One set of stitches is worked first leaving an even space between each pair which will be afterwards filled by the second set, "carried out in a contrasting colour.

The third border is composed of wheatsheaf bundles and small sprigs of fern stitch. The former are worked in the same way as the wheatsheaf faggot stitching, which is described in the D.M.C. Encyclopaedia of Needlework. The latter can be found in Embroidery (Part V, J. Pearsall \& Co.).

The fourth border illustrates another variety of buttonhole stitch, but as the needle is put into the material first on the right and then on the lefthand side of the border, it might be more correctly described as feather stitch. A daisy stitch is added to the border to give a little variety, but bullion stitch, or French knots, would be quite as suitable.

The fifth border is embroidered in fern stitch worked on a straight line, and a thread of a darker colour is looped into each branch of the fern stitch on either side of the centre line. 


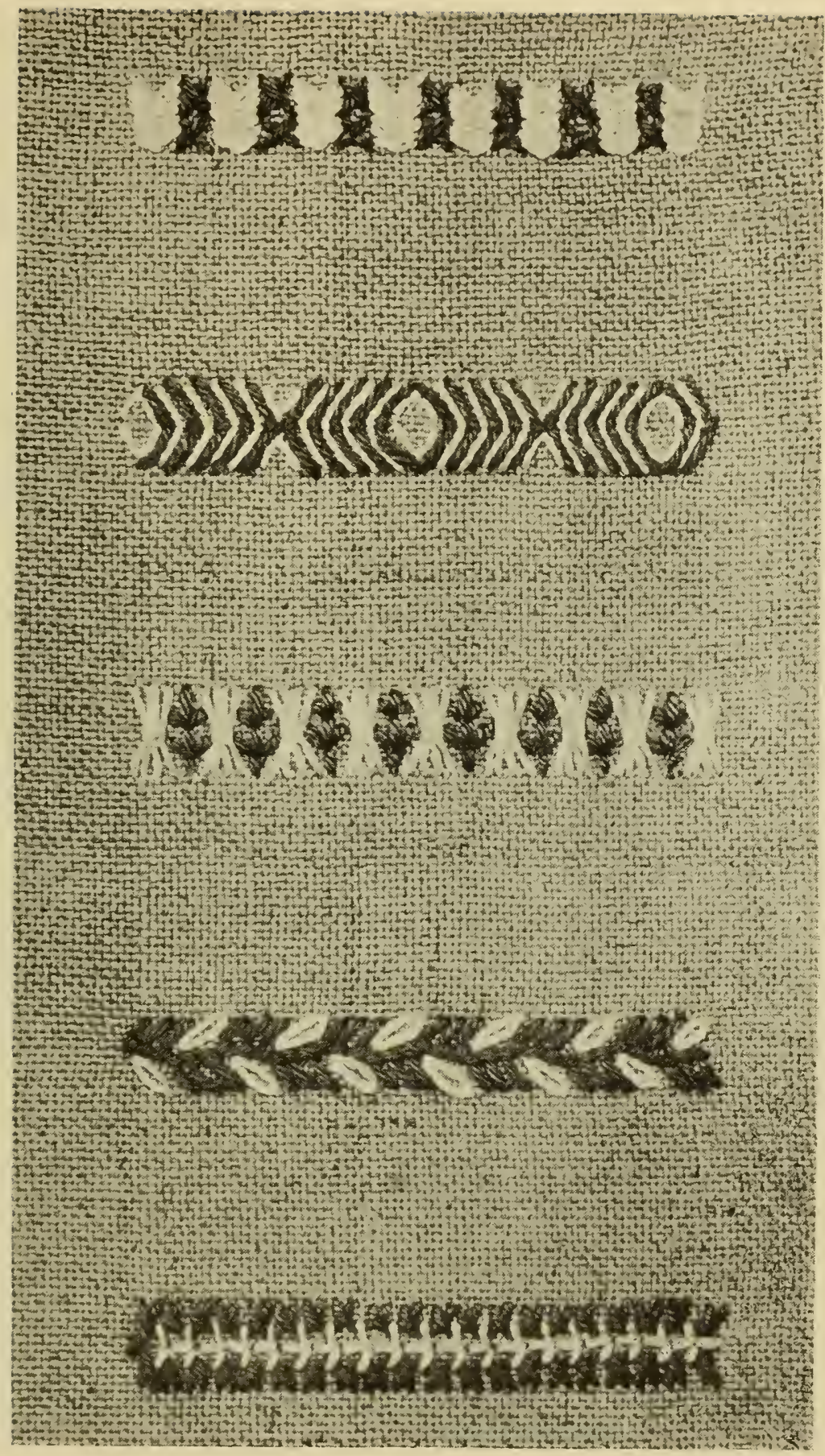

Plate XV. 


\section{Group 4. Plate XVI.}

The top border in Plate XVI is less complicated than it appears to be; a band of double chain is worked first, and in and out of this are interlaced two threads of a darker colour.

The second border somewhat resembles the fifth border in Plate XV, but it is embroidered in quite a different way, viz., by working two rows of ordinary herring-bone, and where they touch in the centre, white crosses are arranged in a straight line.

The third border shows what an interesting effect can be obtained by working simple feather stitch and then adding, in a contrasting colour, single stitches, which should lie at the same angle as the feather stitches.

The fourth border is worked in zigzag chain, a row on either outline; the points of the zigzag must come opposite to each other or the two upright connecting stitches will not be of the same length, which would quite spoil the effect of the embroidery.

The fifth border is such a simple one that it hardly needs any explanation. It is composed of two rows of ordinary buttonholing, the headings of which meet on the centre line of the border, and between every pair of buttonhole stitches a daisy stitch is embroidered in a contrasting colour. 


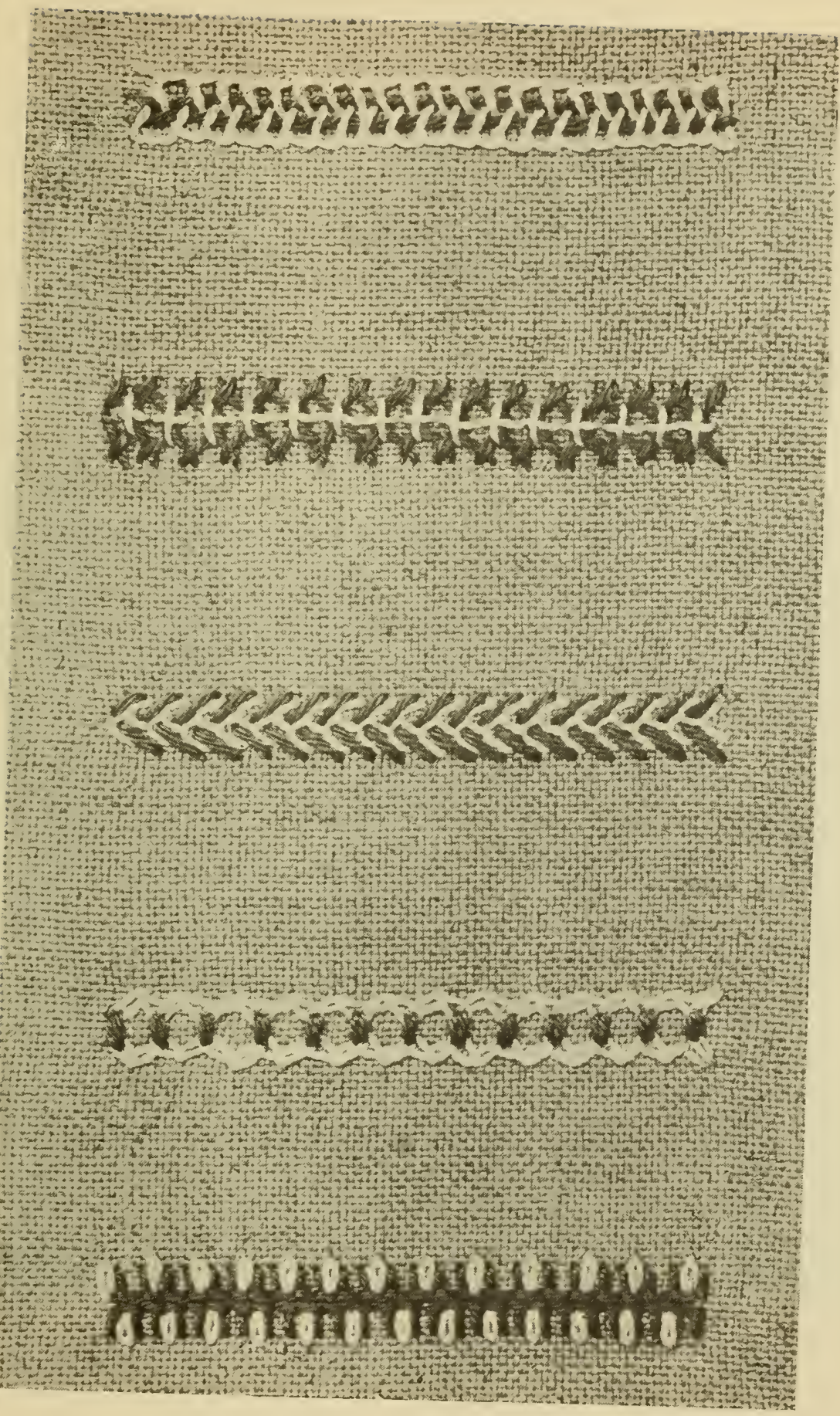

Plate XVI. 


\section{Group 5. Plate XVII.}

The borders illustrated in Plate XVII are intended for decorating children's garments, but they might also be used for other purposes.

The first one is made with a row of crossed fly stitches (see page 30), and between each pair a French knot is embroidered.

The second border is exceedingly simple to work, being composed of pairs of daisy stitches placed at regular intervals along the line, and the space between them is filled by a small single fly stitch.

The third border is outlined with run and thread; this stitch is worked by whipping an even row of running stitches with the same thread or one of a contrasting colour. The border is completed by French knots placed at even intervals between the outlines.

The fourth border is composed of small sprigs of fern stitch facing each other in pairs, and separated by single French knots.

The fifth border belongs to an upright variety; it is made up of a series of fly stitches, in contrasting colours, one of them much smaller than the other, and the border is completed with French knots, which should be worked in the same colour as the smaller fly stitch. 


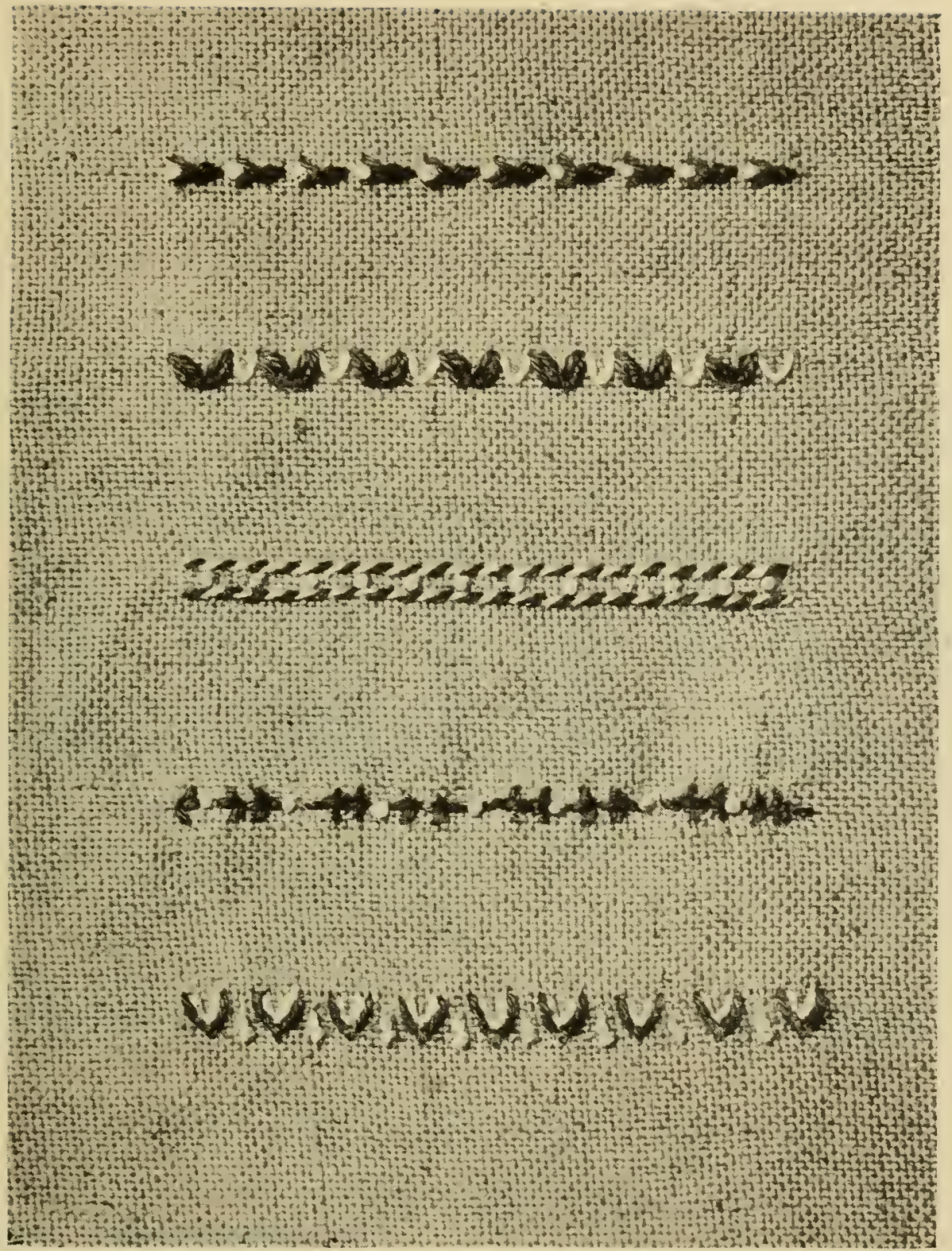

Plate XVII. 


\section{Group 6. Plates XVIII and XIX.}

The borders illustrated in the two coloured Plates XVIII and XIX are a further development of the set of borders based on straight lines which have already been described and illustrated. The setting out is again purely geometrical, and the patterns themselves are entirely dependent on a few well-known embroidery stitches arranged in a decorative manner.

The first two borders in Plate XVIII show yet another adaptation of the indispensable buttonhole stitch.

In the top border that part of the pattern worked in scarlet thread should be embroidered with a row of buttonhole stitches arranged in groups of five into one hole. The green stems could be worked in either chain, stem, or back stitch; the small leaves are, of course, single daisy stitches.

In the middle border all the green lines are worked in buttonhole stitch, the red flowers are made of groups of fly stitches all meeting in one centre, and further enriched by the addition of four single stitches in the same colour.

The bottom border is entirely dependent on chain and daisy stitches which are really the same, except that the latter are worked separately. The green outline is in zigzag chain, the small flowers are composed of four daisy stitches meeting in one centre, which is covered by a French knot; the scarlet leaves are also in daisy stitches of a larger size, and are connected with the outline by a single stitch in green. This border divided in half, lengthways, would still make a pretty design. 


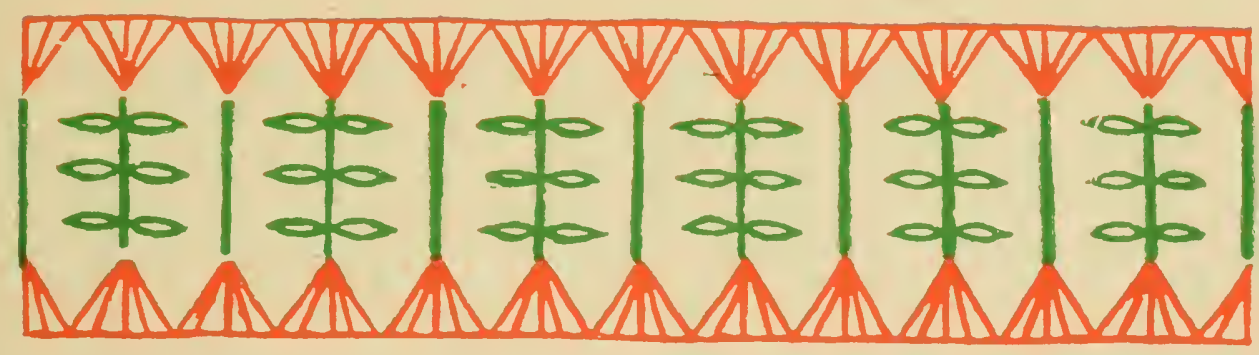

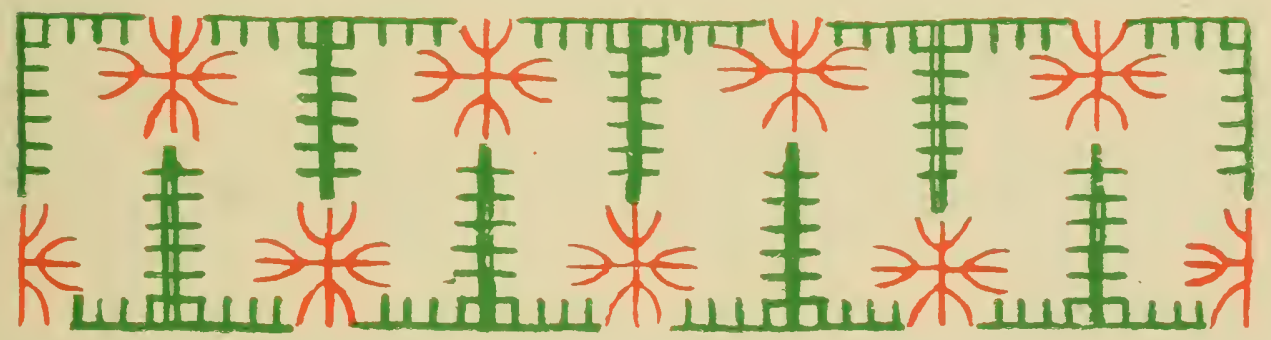

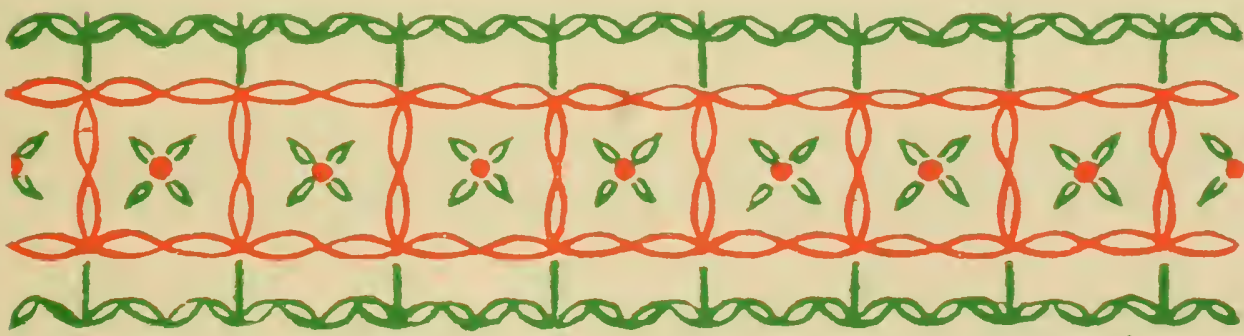

Plate XVIII 
The borders illustrated in the coloured Plate XIX are just a little more elaborate in effect, but in execution quite as simple as those already described.

In the first one the outline is of stem or back stitch, and the upright crossed lines which spring from it should be in the same stitch, as are also the same green lines occurring in the centre of the design. The remainder of the pattern is quite obviously composed of buttonhole wheels, arranged both in groups of four and singly along the edge of the border.

The second border in Plate XIX is composed of upright bands of Roumanian stitch worked in blocks of four stitches; as a background to these are three zigzag lines of running stitches, the apex of each angle being accentuated by a small fly stitch.

The third and last border will readily explain itself to any one with a knowledge of simple stitches. The small red squares are made by a large back stitch for each side of the square and a French knot in the centre. Any firm outline stitch will do for the stems, and the double crosses need no explanation. 


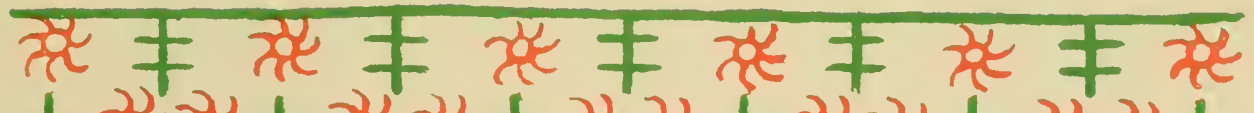

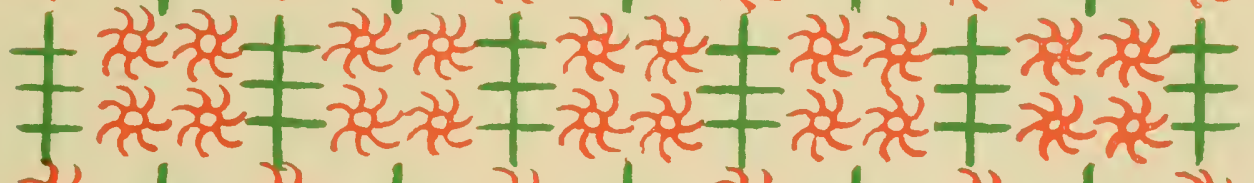

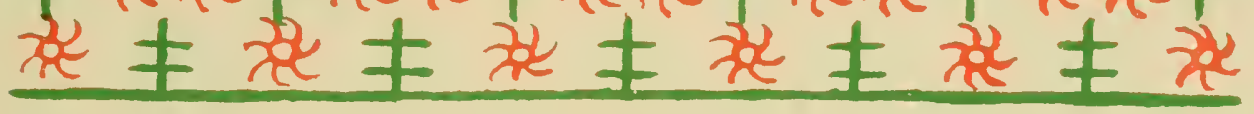
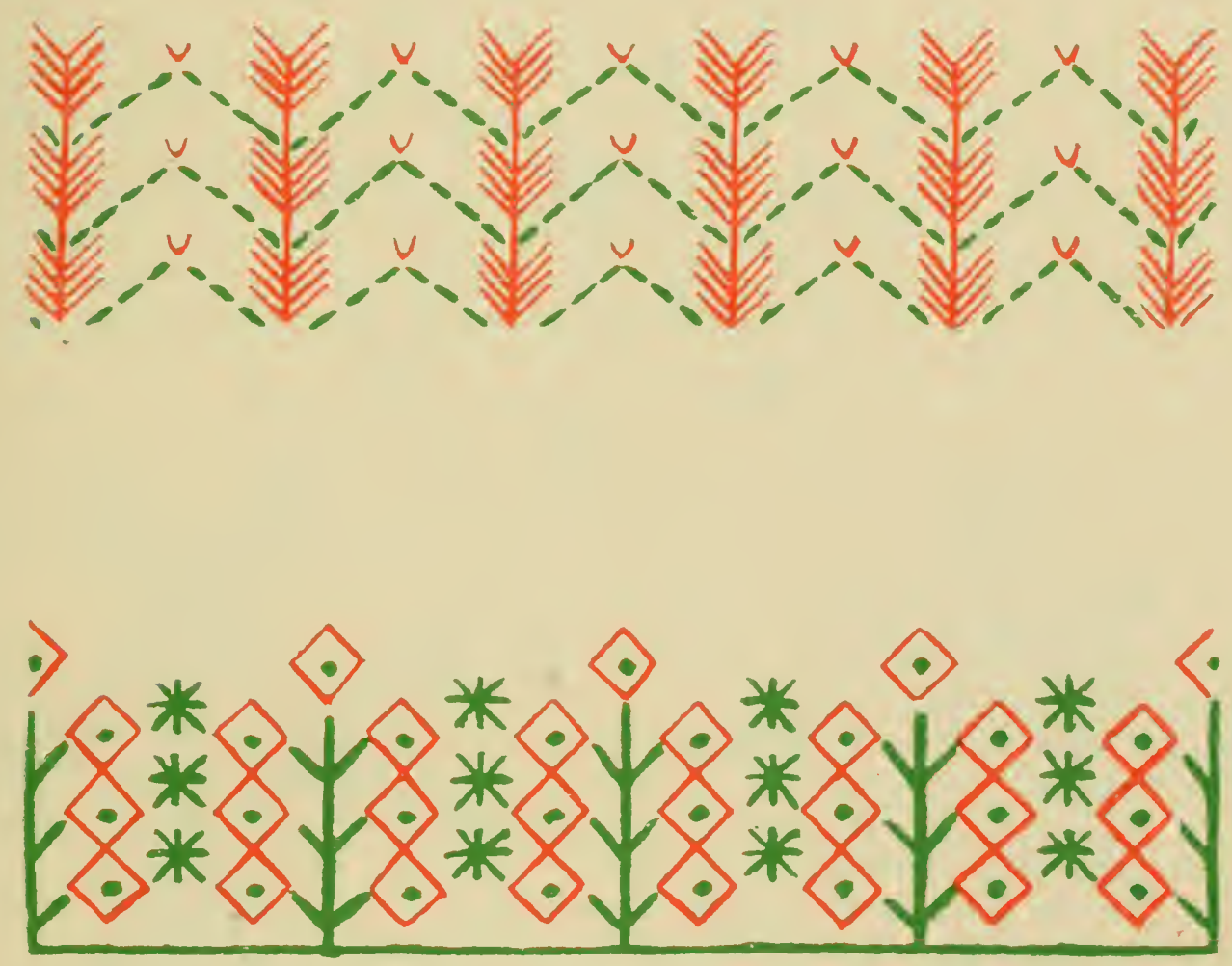

Plate XiX. 


\section{DECORATIVE SQUARES.}

\section{Group 1. Plate XX.}

THE decorative circles and squares, illustrated in Plates XX-XXIII, suggest so many different possibilities of grouping and arrangement to the designer that it is difficult to know which one to indicate in particular. Repeated, they would make fine " all-over" patterns. This could be done with one variety or with two; in the latter case, they should be of different sizes, or one of them should be embroidered with a much heavier treatment than the other. In each plate there is at least one pattern light enough in effect to form a good background to a superimposed design. (See page 48.)

The more conventional squares would make most effective centres for a large circular or square design, and could be combined with some of the symmetrical sprigs or flowers shown in Plates XLI, XLIV, XLVIII, and so develop quite an elaborate pattern. Repeated in a row, splendid borders could be constructed from this material. Arranged diagonally in a group of four, with a contrasting decorative square or circle in the centre, they would immediately provide a most suitable design for a bag, etc. They can be combined with small straight or curved borders, with isolated sprigs or powdered fillings.

One example of the use of a decorative circle will be found in the embroidered bag illustrated in the Frontispiece, and the cushion-cover design in Plate LXXVIII, showing the adaptation of two decorative squares to a repeating pattern. By using this form of decoration, an inexperienced student will be able to attempt quite elaborate pieces of embroidery, and at the same time learn to understand one of the most important principles of design, i.e., the value of repetition.

The set of squares illustrated on Plate XX are purely geometrical in character without the introduction of any floral element.

The top left-hand one was taken from a piece of Italian work of the sixteenth century now in the Victoria and Albert Museum. The centre square is from a pattern stitched on a Coptic shoe of the second to seventh centuries, also in the museum; the other three are original.

The top left-hand square is carried out in satin stitch and back stitch.

The top right-hand one is in stem stitch for the outlines, running or back stitch for the scrolls, and Roumanian stitch for the filling; the small square in the centre of the design is, of course, in satin stitch.

The bottom left-hand square is embroidered in satin stitch and daisy stitches, with chain or stem stitch for the lines of the middle square.

The bottom right-hand square is practically all in satin stitch, and the tiny fly stitches, etc., should be worked in a different colour.

The centre Coptic design is one that would make a good background pattern. For this purpose it must be worked in running or back stitches. In the original the latter stitch was used. 


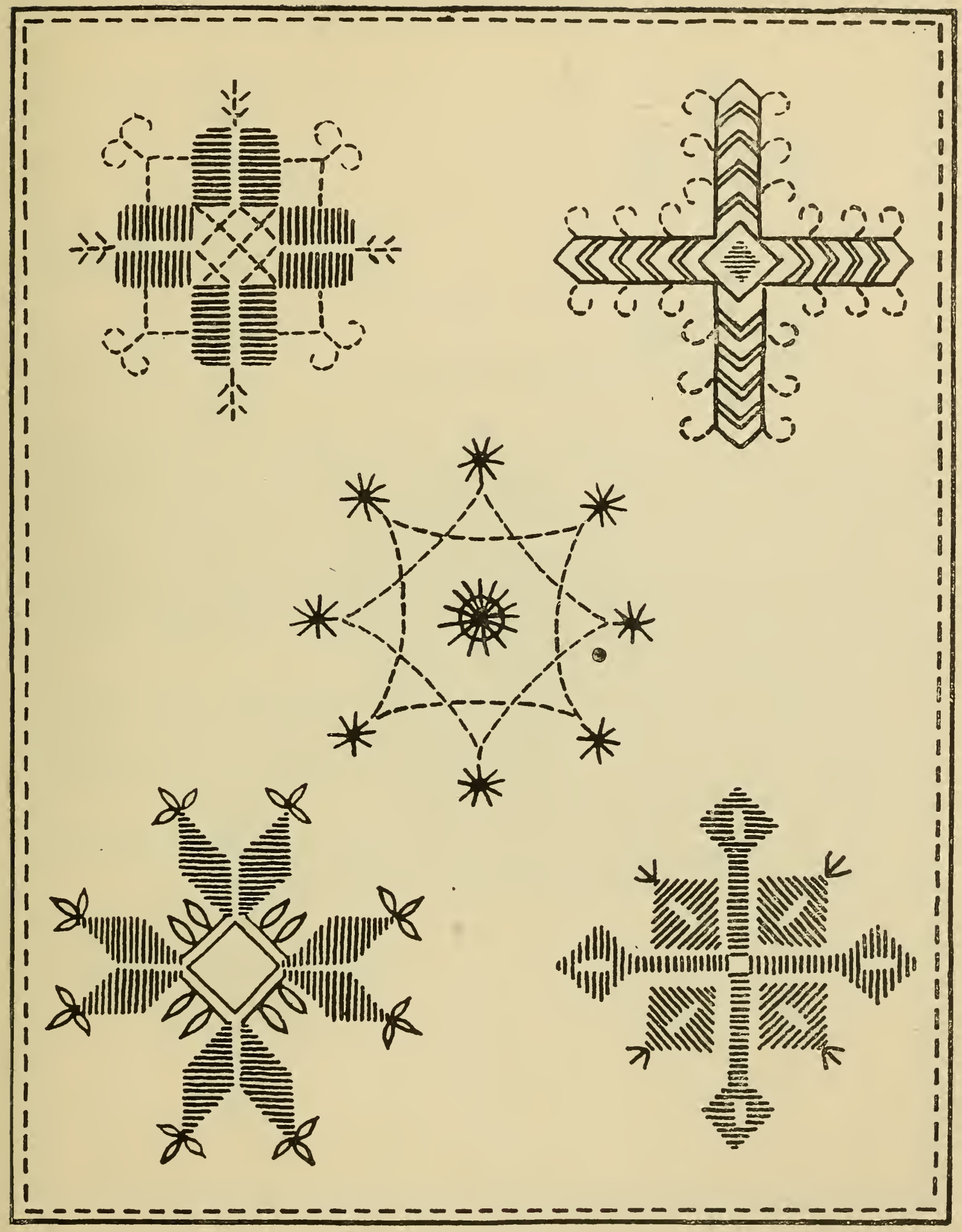

Plate XX. 


\section{Group 2. Plate XXI.}

The squates illustrated in Plate $\mathbb{X} \mathbf{T}$, with the exception of the centre onc, are just a litte mote floral in chatacter than these described on pise th.

The top left-hand one could be carried ont in varions stitches: the flowers, for instance, might be worked in satin or buttonhole stitch, or a quicker method rould be to construct each petal with a single dais stitch: the stems conld be worked with two lines of fine stitching or with a single one of chain or coral stitch. The centre circle must have some solid stitching in it.

The epp right-himd squate also gives a good deal of scope for different treatuents: ele black flowers conld be worked with two lines of chain stitch set cluse together, or agatin with satin or buttonhole stitch worked solidly: the k.wes woukl look well in Romminian or satin stitch worked in two colours: the stems should be in some thin ontline stitch.

The square in the centre of the opposite pase would make a very effective backstound pattern. For this purpose it should be worked entirely in rumnins or scparated back stitches: if used in other ways the desism would look more interesting corriced ont in two stitches-lines of rummins stitch for one: and cither stem, cham, or back stiteh for the other.

The two botfom squares introluce the use of intertacing lines for the construction of the design: any good ontline stitch will do for working this pat of the paterm. The detaits practically explain themselves. 


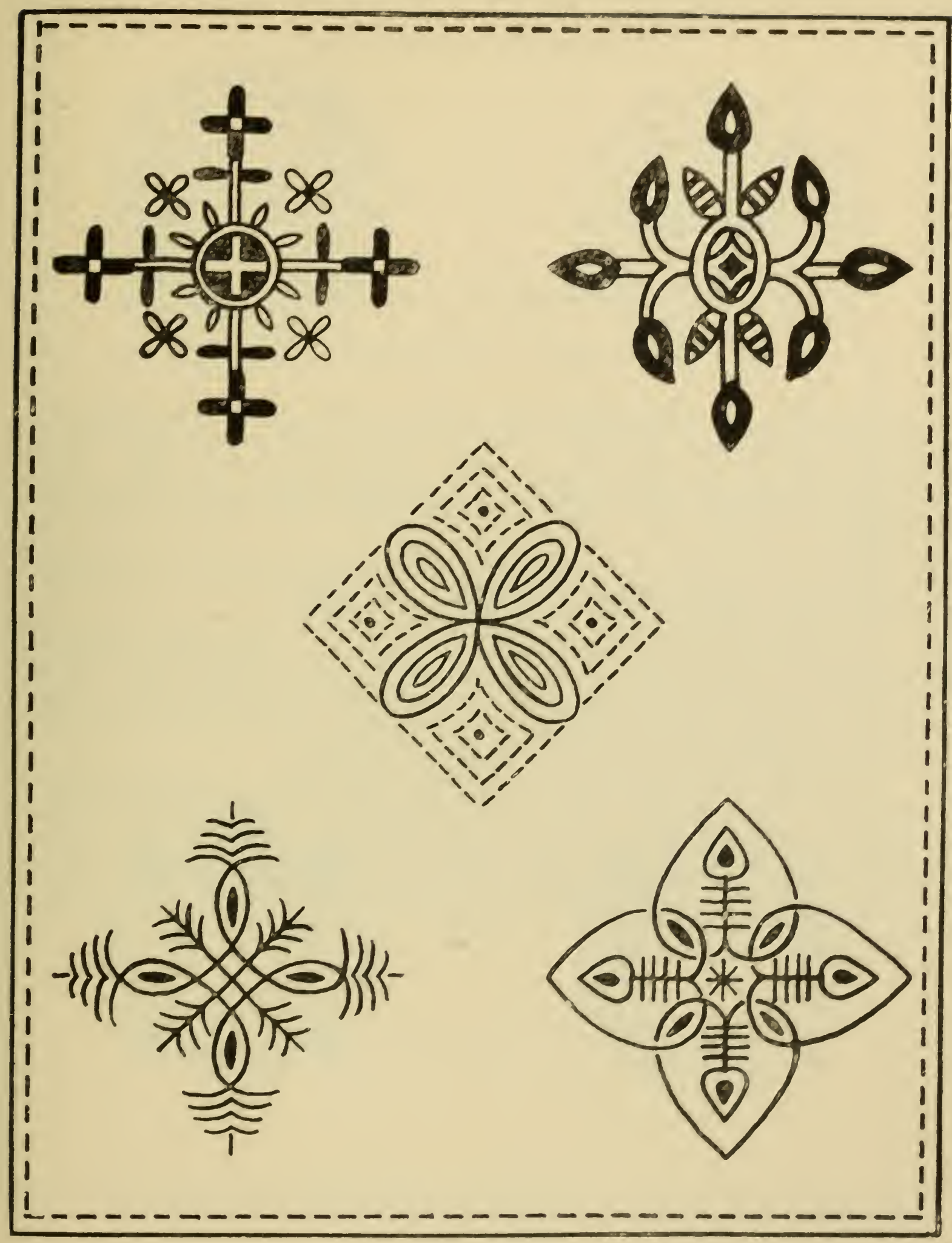

Plate XXI. 


\section{DECORATIVE CIRCLES.}

\section{Group 1. Plate XXII.}

THE decorative circle designs illustrated in Plate XXII are, with one exception, purely geometrical in character. The circle in the centre of the plate shows another adaptation from a Coptic shoe decoration ( $c f$. Plate XX). This circle, being light in effect and quick to work, would make a good all-over or background pattern, which would look well carried out in either one or two colours.

The top left-hand circle could be worked in herring-bone for the outside ring, and any simple outline stitch for the centre filling.

The top right-hand circle is described on page 170 in connection with the embroidered bag illustrated in the Frontispiece. The bottom left-hand circle has an outer ring of buttonhole wheels which alternate with small crosses; the two plain circles could be worked in stem or chain stitch, the inner one being decorated with blocks of satin stitches: and in the very centre of the decorative circle a double cross should be placed.

The bottom right-hand circle is set around with small conventional leaves. These and the circle from which they spring could be embroidered in chain stitch, and the leaves then enriched by the addition of a daisy stitch in a contrasting colour; the running stitches which are placed between the two plain circles could be of the same colour. The centre is filled by a double cross, which should be worked in stem or back stitch with the addition of a French knot at the end of each line. 


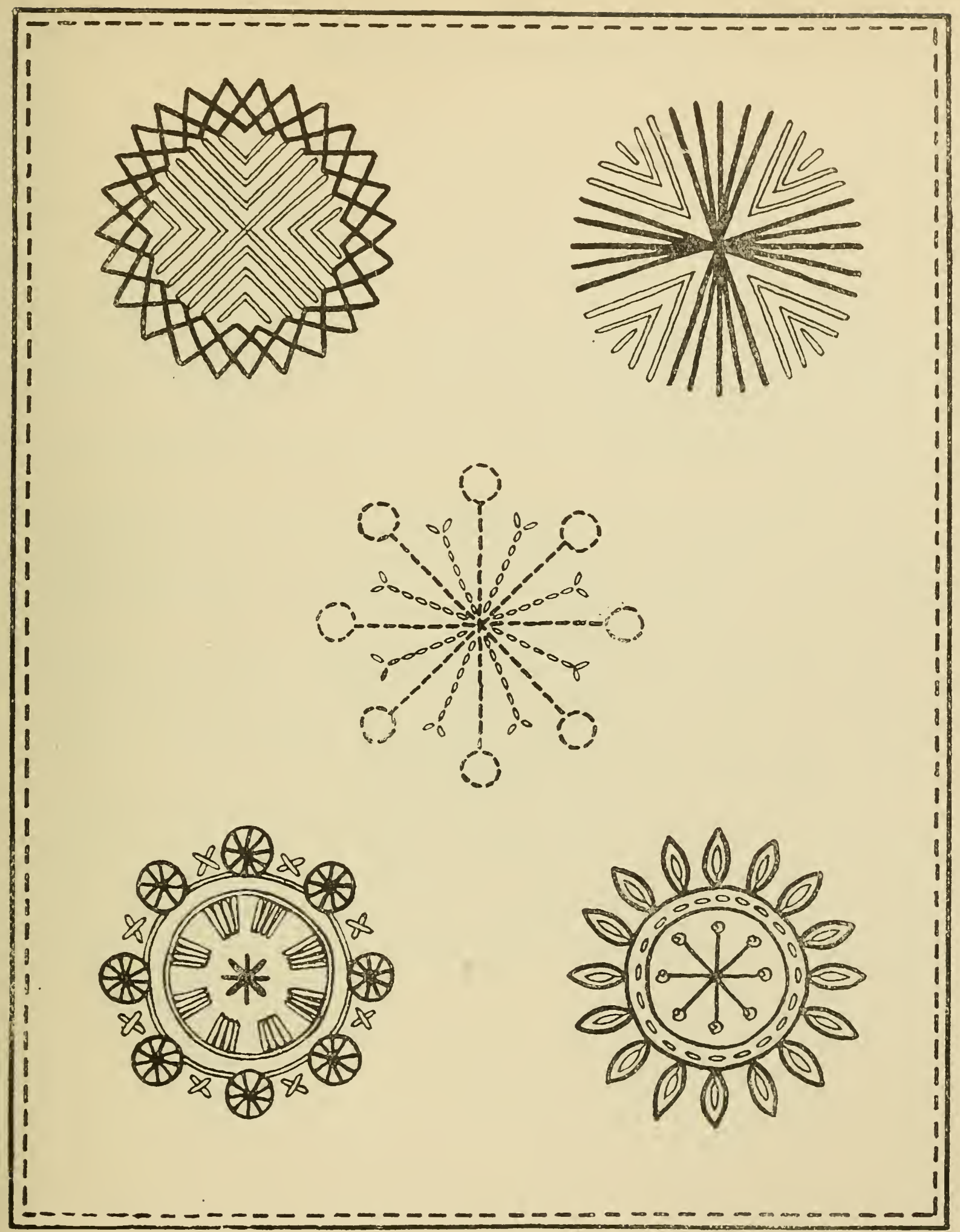




\section{Group 2. Plate XXIII.}

The top left-hand decorative circle in Plate XXIII must be worked in ladder stitch, for no other stitch but this will suggest the severe, steady character of the design. The thread in which the circle is embroidered should be rather coarse, and two colours must be used.

The top right-hand circle is of the same type as the one mentioned on page 48 as being suitable for a background pattern, and the treatment could be the same.

The bottom left-hand circle was suggested by an embroidered flower on a piece of Indian work in the Victoria and Albert Museum. In the original, the petals were carried out in silk thread of two colours; the thread was about the thickness of Pearsall's filo-floss, and each petal was. composed of two rows of chain stitch meeting in a point. The solid portions of the centre could be worked in satin or buttonhole stitch.

The bottom right-hand circle has rather a flowery appearance although no flowers are used in the design. A strong outline should be worked first in chain or coral stitch round each division of the circle; the fillings are then added, being composed alternately of clusters of French knots and groups of five single stitches all worked into the same hole.

The floral circle in the middle of the plate can be very quickly embroidered if the small leaves growing from the outer circle are made with daisy stitches, which will look a little more interesting if a single stitch of a different colour is worked in the centre of each leaf. The circular stem could be embroidered in chain stitch, and the flowers might be worked solidly in satin stitch or made with single daisy stitches; but probably the former treatment would be more satisfactory, as it would afford a sharp contrast to the working of the outer circle. 


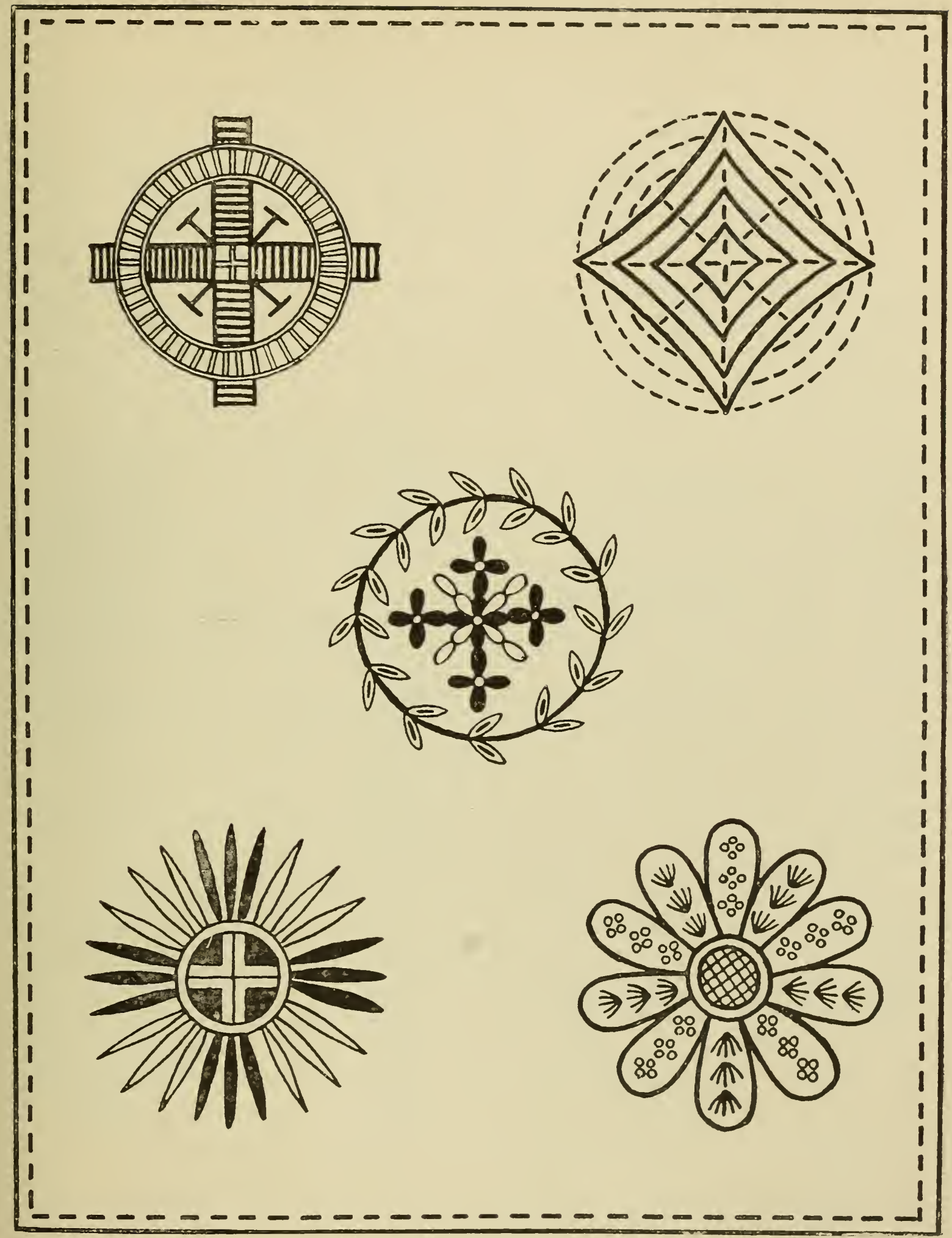

Plate XXIII. 


\section{DECORATIVE CIRCLES AND SQUARES EMBROIDERED.}

\section{Group 1. Plate XXIV.}

PLAtes XXIV-XXVI show embroidered examples of decorative circles and squares which, as already stated on page 44 , can be of such immense value in simple pattern-designing. Combined with them are four straight-lined borders that could be used in conjunction with any of the circles and squares on the same piece of work.

The border on Plate XXIV, which can be worked either horizontally or vertically, is composed of two rows of Spanish coral stitch (see Miss Pesel's Portfolio of Stitches) set about $\frac{1}{4}$ " apart. They are connected by a thread of a different colour, which is interlaced in and out the heading of the coral stitch.

The top square is composed of four blocks of Roumanian stitch worked on both diagonals of the square; the cross in the middle and the running stitches should be of a contrasting colour.

The second square, which is really made of a cross with the points curled round, is worked in coral stitch, with the addition of fly stitches in a contrasting colour.

The third square is outlined with buttonhole stitch, a smaller square of the same stitch is worked in the middle, and daisy stitches of a different colour help to accentuate each corner of the square; the small cross in the centre should be of the same colour as the daisy stitches.

On the other side of the border, the top circle is carried out entirely in buttonhole stitch, with the exception of the outer ring, which has a few stem stitches added to fill the spaces between the buttonhole points.

The second circle is an example of the use of couching and chain stitch.

The third circle is worked in two concentric bands of close buttonhole stitch. To break the edge of the outer one, a row of ordinary herring-bone stitch is added in a different colour, the space between the two circles and in the centre being filled with interlacing threads of the same colour as the herring-bone stitch. 


\section{Group 2. Plate XXV.}

The left-hand border in Plate XXV is constructed of two lines of buttonhole, three stitches into one point, and a band of double back stitch, which fills the space between.

The other border, which looks equally effective on a small scale, is made up of Cretan stitch, the bars of which are tied together in pairs by the addition of single back stitches in a contrasting colour.

The top square between the borders represents a small fruit tree of uncertain variety. The centre stem is worked in back stitching, the side branches in fern stitch, and the fruit in large French knots of the same colour as the centre stem.

The centre square is composed of several different stitches, e.g., fish-bone, outlined with stem stitch for the small solid squares, chain stitch for the large cross and outlines of the outer square, run and thread for the interlacing knot, while the centre is filled with small single crosses.

The third square could more rightly claim to be called a decorative rendering of a small fir-tree. The centre line in chain stitch should be worked first, and then all the main branches in the same stitch and colour. The spaces between the branches are filled with feather stitching, which should most certainly be of a contrasting colour to the branches. 


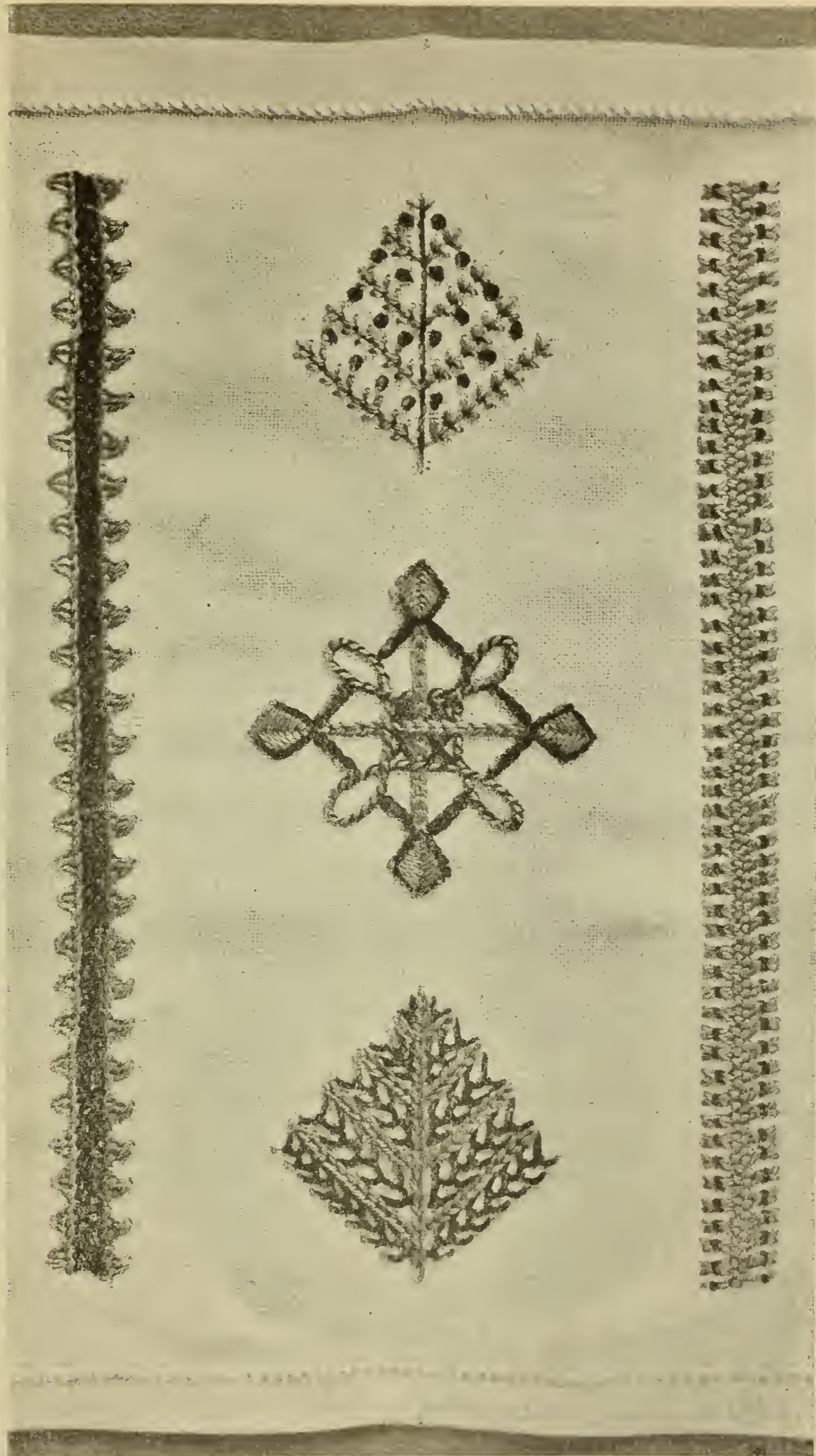

Plate XXV. 


\section{Group 3. Plate XXVI.}

The third group of decorative circles and squares (Plate XXVI) has a border in the middle composed of blocks of Roumanian stitch and daisy stitches in pairs placed opposite each other. Two colours should be used for this border.

The top circle is really a spiral, made up of buttonhole stitch with the heading whipped in a different colour; this could easily be arranged to form a continuous scrolling pattern.

The second circle has what appears to be a rather intricate interlacing centre, but the working of it is really very simple; the diagonal lines of the same colour are laid first without interlacing, the vertical ones in a contrasting colour are then interlaced in and out the diagonal threads. Around this centre is worked a circle of stem-stitch, the small outside petals are embroidered in fish-bone stitch, and between them are clumps of four buttonhole stitches.

The third circle illustrates the use of ladder stitch, and its suitability for producing strong even bands of colour. The small crosses are worked in a different shade.

The embroidered squares illustrated on the same plate show the use of stitches on a slightly smaller scale.

In the top square the flowers are made up of groups of fly stitches, in the centre of each of which a single stitch is added. The serrated stems are made of two rows of buttonhole stitch set back to back, the small stars of the same stitch worlsed spirally. The cross in the centre is worked in the same coloured thread as the flowers.

In the second square the leaves are in double back, the stems in stem stitch, and the small squares in large back stitches, the centre being filled with a small cross.

The last square is made up of small circles in buttonhole stitch, to which are added French knots. The leaves and centre stems are in back stitch, and four daisy stitches form the small cross in the centre. 


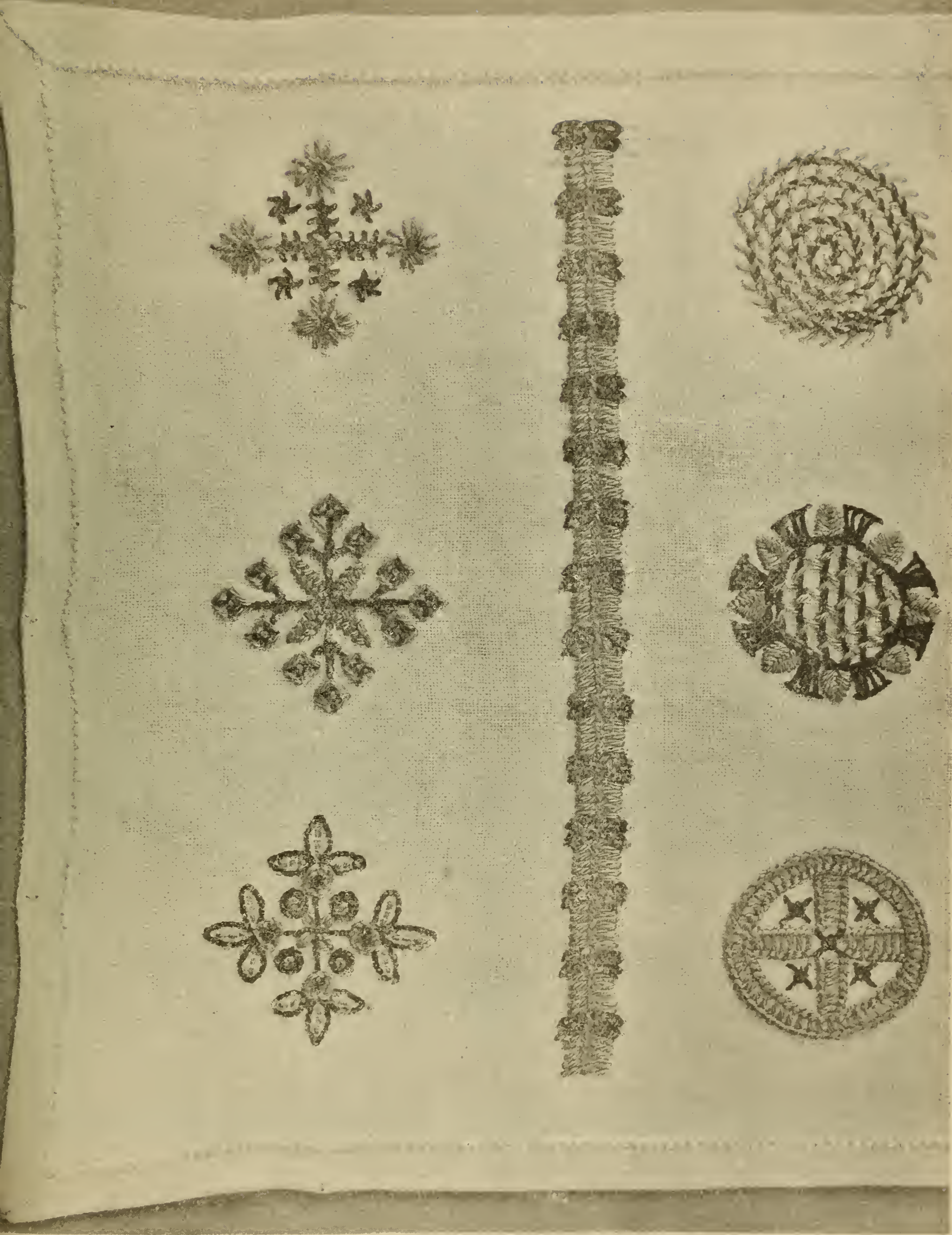




\section{DECORATIVE TREES.}

\section{Group 1. Plate XXVII.}

ALL the trees illustrated in the four following Plates, with the exception of four examples to be described later, can easily be copied by an embroidery student possessing little or no knowledge of drawing. To do this successfully, it is only necessary to make a few accurate measurements and rule the main constructional lines, the leaves and natural growth of the tree being suggested entirely by embroidery stitches.

To begin with the lower tree in Plate XXVII, the centre stem should first be measured and drawn, then the main side branches, each pair being exactly on the same level or the tree will not look properly balanced. These branches are decorated with small curved twigs arranged in pairs at regular intervals, which should be measured first. The solid portions can be embroidered without any preliminary drawing or measuring; for these, Roumanian stitch is particularly suitable, and for the branches and twigs some knotted stitch. If the tree is a small one, coral stitch, but if on a larger scale than the drawing, German knot stitch or Portuguese knotted stem stitch (see Miss Pesel's Portfolio of Stitches) would give a very rich effect.

For the upper tree the V-shaped lines must be ruled first and then the parallel side branches, which are of varying lengths but can easily be measured. A decorative rendering of the fine twigs which grow on the tops of main branches is obtained by the double crosses worked at the end of each line. Whipped stem and chain, or ordinary chain or coral stitch, would be quite suitable for working the branches of this tree. 


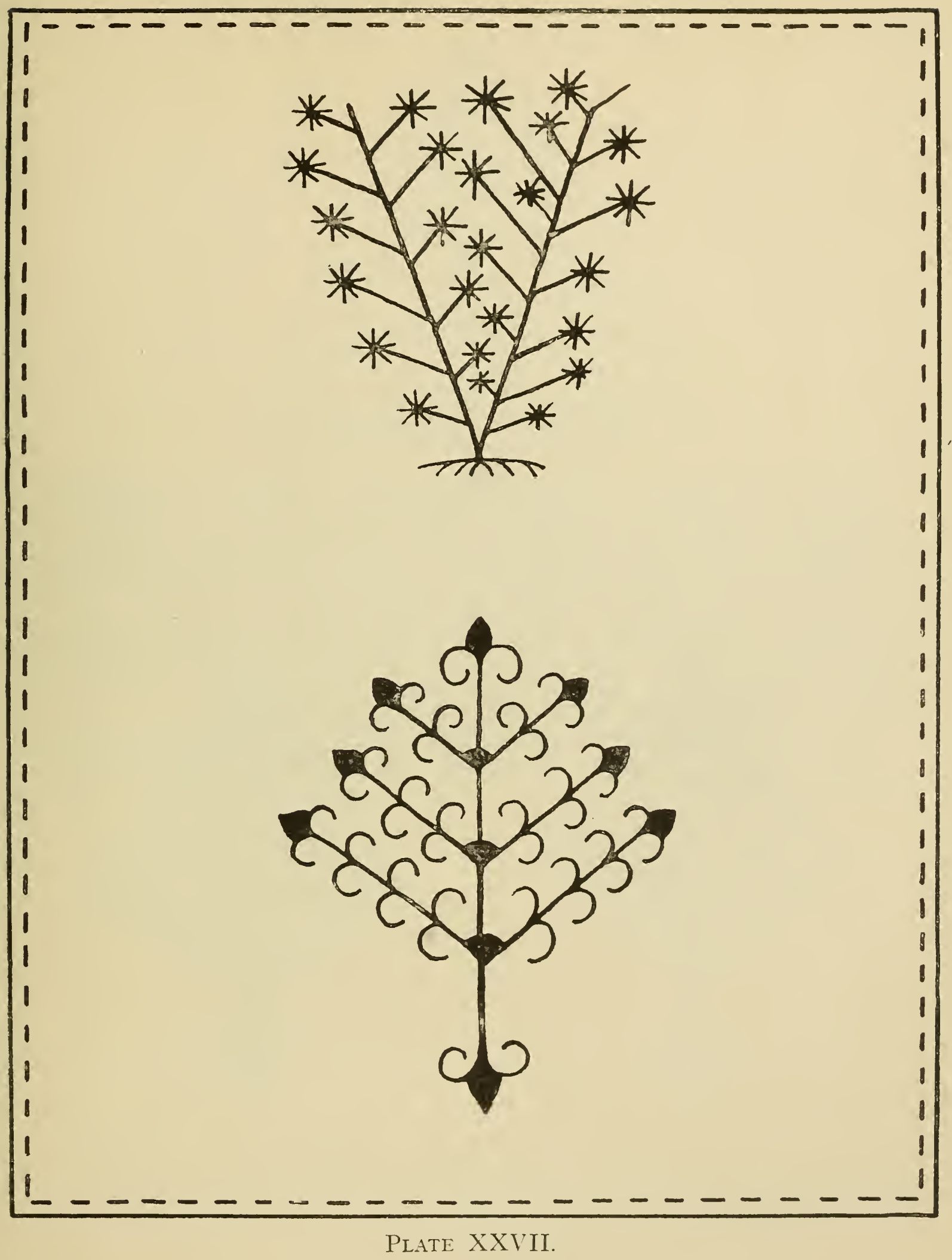




\section{Group 2. Plate XXVIII.}

The fir-tree at the top of Plate XXVIII is one of the four examples mentioned on page 58 that cannot be reproduced entirely by geometrical construction. The waving branches require a little free-hand drawing, but by ruling the centre stem and marking off the spaces between the main branches and the distance of each from the ground, not very much will remain to be done by the hand unaided. The broken lines between the branches should be worked in detached back stitches, for these will be more pronounced than simple running stitches. The stem and main branches could be worked in stem, chain or run and thread; that is, unless the tree is drawn much larger than the original, when a thicker stitch should be used.

The two small trees at the bottom of the plate have both been described in detail on page 54, where a photograph is shown of them actually carried out in embroidery. 


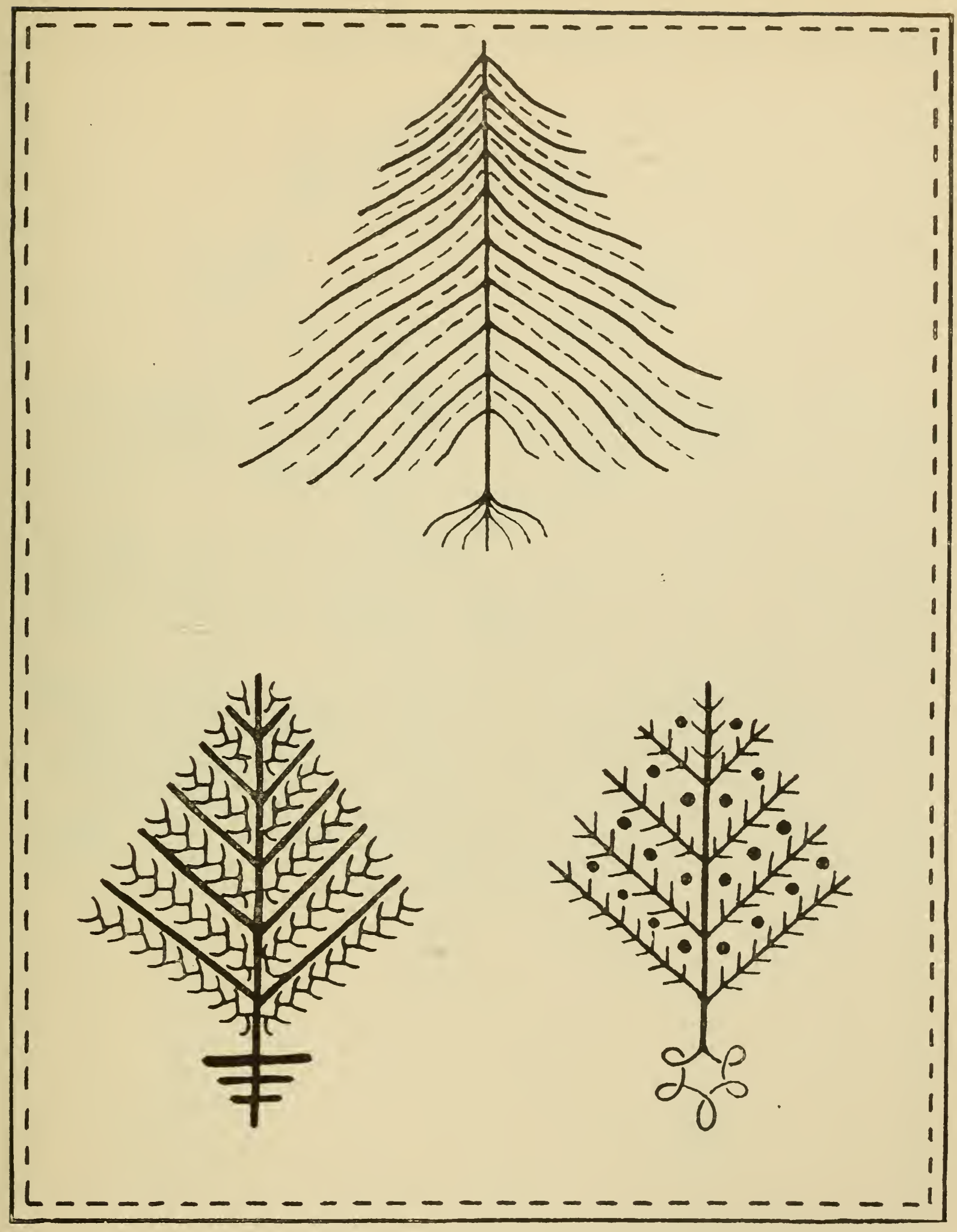

Plate XXVIII. 


\section{Group 3. Plate XXIX.}

There is only one tree in Plate XXIX that can be copied by the simple method of measuring and ruling the main lines, and that is obviously the bottom right-hand one, which somehow suggests a young apple-tree, but its nature does not really matter very much so long as the finished result is unaffected and pleasant to look upon.

When the main stem and branches have been measured and ruled correctly, the embroidery can be commenced, for the small upright twigs are merely part of a line of buttonhole stitching of which the heading forms the main branches. The young leaves are represented by daisy stitches arranged carefully on the point of each buttonhole stitch. The centre stem and roots should be worked in stem stitch.

The small date palm on the left is worked in fish-bone stitch for the branches and chequered chain for the dates; the stem is decorated with little blocks of satin stitch. A subtle contrast of colour in the branches, and a very definite one for the dates, would make the tree much more interesting in appearance.

In the centre of the page is shown an immature chestnut tree, the main branches of which are the only parts that cannot be drawn mechanically. The chestnuts themselves are buttonhole wheels decorated with a French knot, the leaves in outline can be made with daisy stitches, but close buttonhole or satin stitch would make quite a satisfactory solid treatment. 


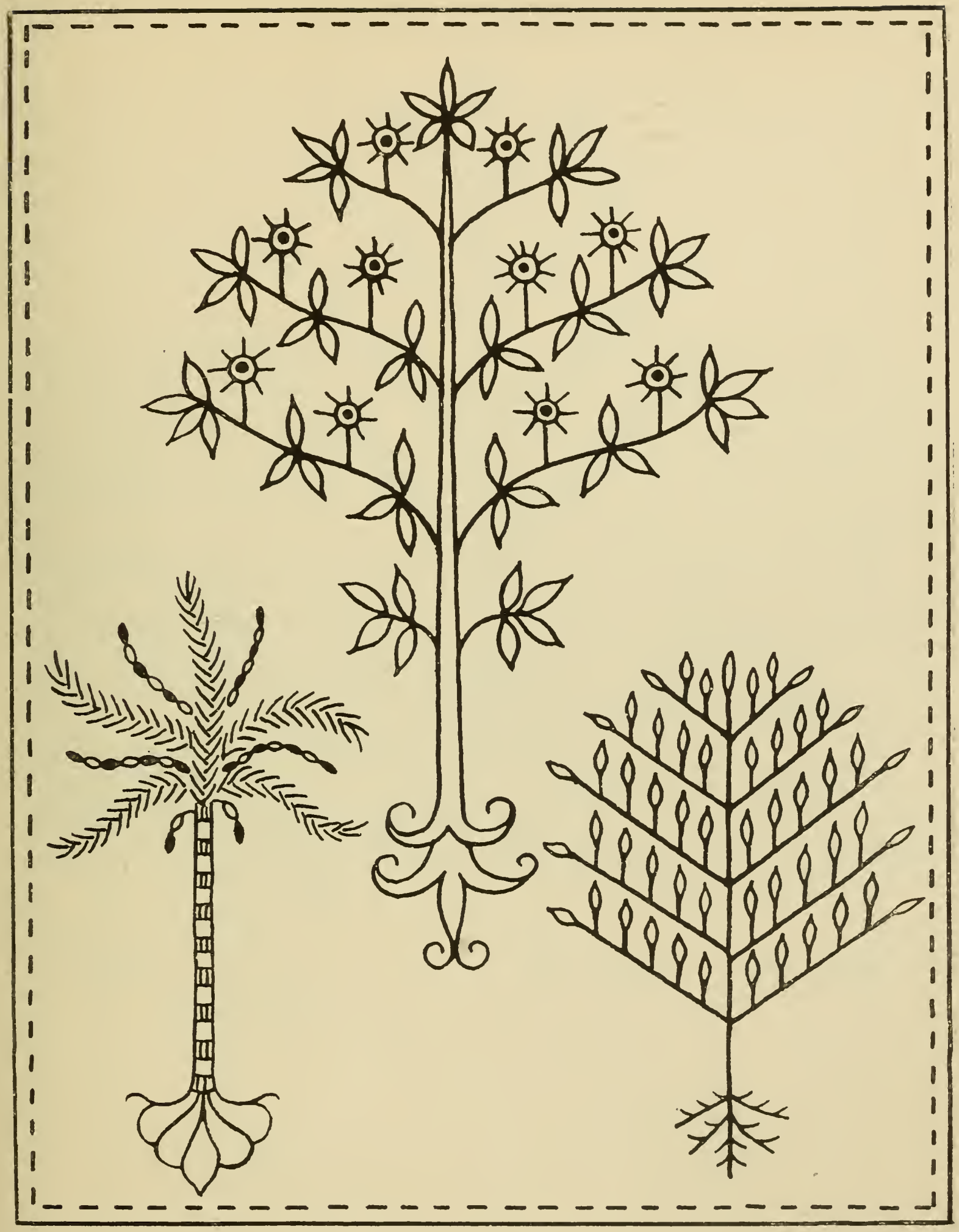

Plate XXIX. 


\section{Group 4. Plate XXX.}

At the top of Plate XXX is shown yet another representation of a firtree ( $c f$. pages 54 and 60 ). It is only necessary to rule the centre stem and large side branches before commencing the embroidery. The side branches are worked in Roumanian stitch, with the addition of one or two stem stitches to lengthen the space between the blocks of Roumanian stitch. The centre stem is entirely worked in stem stitch except for the little clump of Roumanian stitches at the very top of the tree. The pint cones are made with thick bullion knots of a contrasting colour.

The bottom left-hand tree is quite frankly one that ignores geometrical construction, but it can be copied by advanced students and traced by those who have less knowledge of drawing. This tree should be worked in some kind of knotted stitch, as the ordinary outline stitches, such as chain or stem, would seem a little monotonous. Whatever the colour scheme decided on, the berries should be embroidered in some pure bright colour that will show clearly against the stems and branches.

The last tree to be described needs very little explanation. It has rather a wintry appearance, for there are no leaves on it. The small twigs are formed by fly stitches growing closely to the main stem. For these, and for the main branches, rather a thick thread should be used, or the tree will have a thin, impoverished appearance, and nothing that is not sound and flourishing should ever be represented in embroidery. 


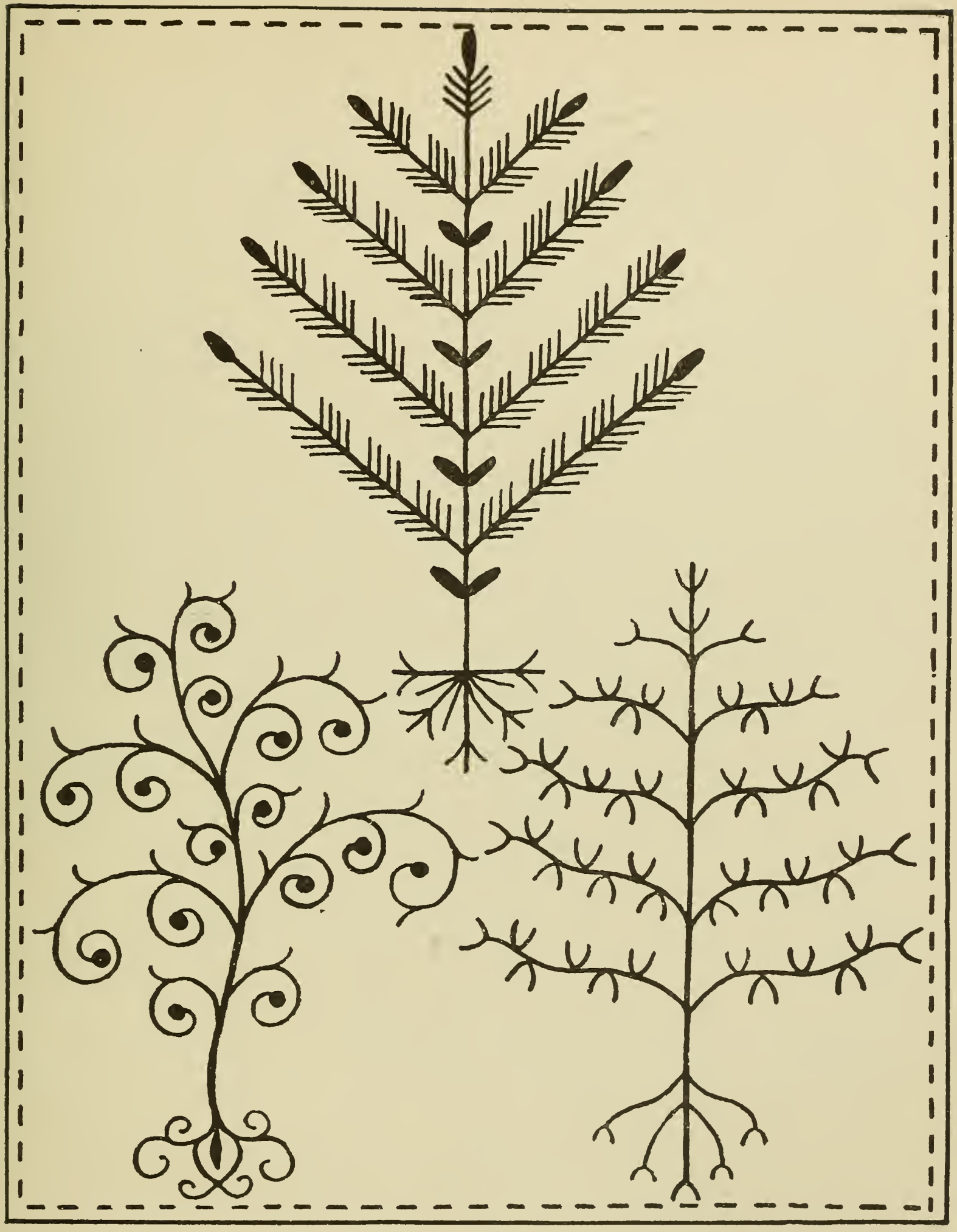

Plate XXX. 


\section{BORDERS BASED ON CURVED LINES.}

\section{Group 1. Plate XXXI.}

THE curved borders illustrated in the four following plates cannot be constructed entirely by mechanical means, as is the case with those developed from straight lines, but the amount of freehand drawing entailed is really very slight if a guiding line is ruled to touch the top and bottom of the curves, and the spaces between the flowers or small motives are carefully measured. Nearly all these borders are based on a meandering line, but a few of them are constructed on segments of circles, for which a compass can be used if necessary.

The top border in Plate XXXI is one of the very simplest examples of the use of a meandering line. It is worked with a line of run and thread, on each side of which is a row of running stitches.

In the second border the curves are sharper and almost suggest a zigzag effect, being made by couching two threads with a single thread of another colour; small upright stitches are then placed in each curve of the main line; and finally a running thread is arranged on each side of the border to fit neatly on the top of each upright stitch.

The third border is composed of two meandering lines in ordinary running stitch which cross at regular intervals, and groups of fly stitches placed at the intersection of the meandering lines.

The fourth border is constructed on a meandering line, and from the middle of each curve grows an off-shoot; the lines are embroidered in back stitch and the solid filling in satin stitch.

The fifth border shows the meandering line broken at regular intervals to form separate sprigs, which are worked in stem stitch for the stems, and daisy stitch for the small leaves, a French knot being placed at the top of each stem. 


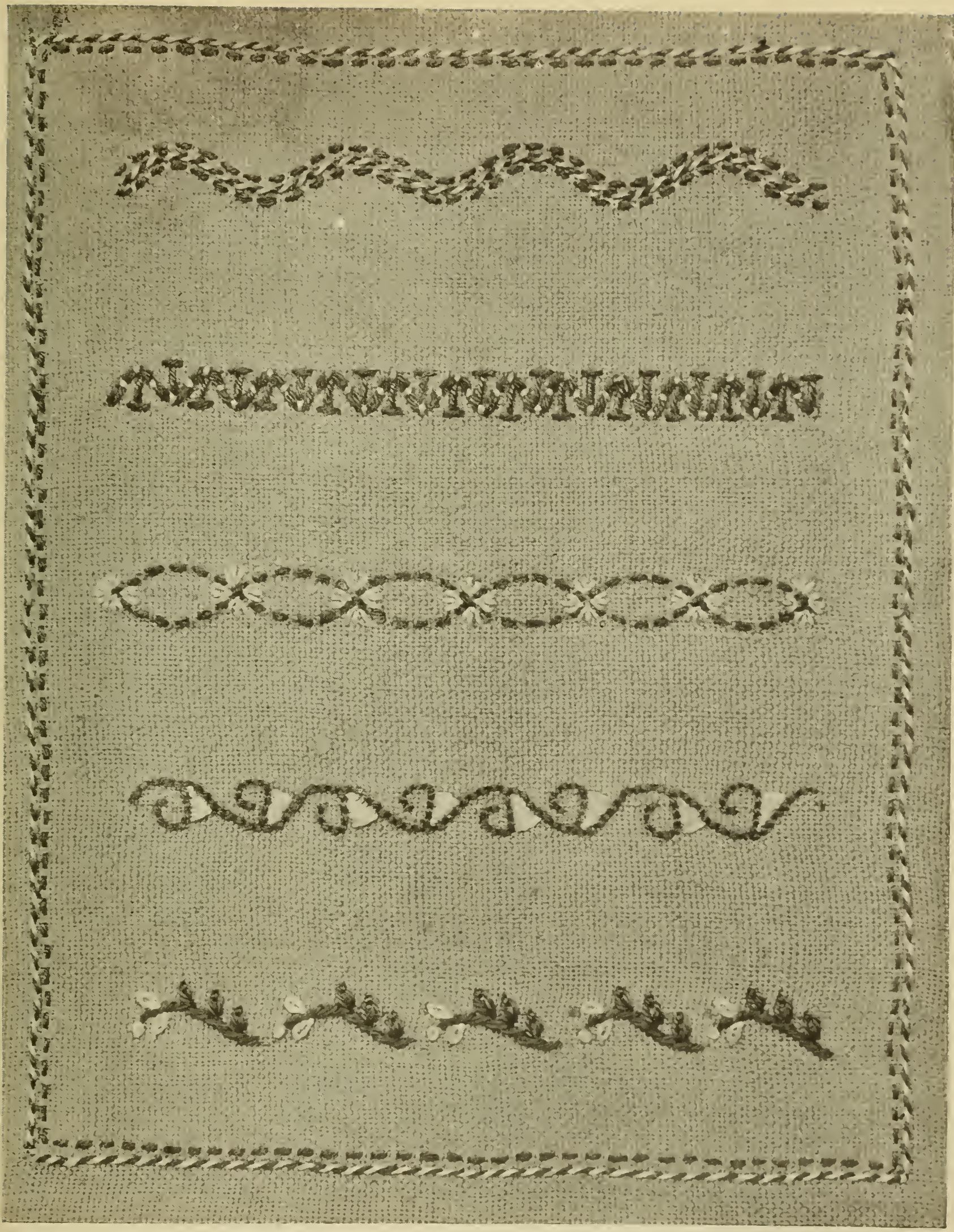

Plate XXXI. 


\section{Group 2. Plate XXXII.}

The top border in Plate XXXII is composed of two parallel curved lines, with small circles in groups of three at regular intervals. These are worked in radiating buttonhole stitch with a French knot in the centre; the curved lines are in run and thread.

The second border is worked in buttonhole stitch for the curved lines, and satin stitch for the solid triangle, which is outlined with a fly stitch; and lastly, a French knot is placed at regular intervals along the bottom line.

The third border is worked almost entirely in buttonhole stitch. Although the straight line between the curves has to be embroidered in stem stitch, it is quite easy to change from one stitch to the other if, in working the stem stitch, the thread is always to the right of the needle.

The fourth border, which is a very simple one, would be suitable for decorating the dress of a small child. It is the only border in this plate based on a meandering line, and is worked in stem stitch with small upright stitches added. The flowers are made with four daisy stitches and four single stitches, all meeting in one centre. The French knots should be of the same colour as the stem-stitch line.

In the fifth border the straight lines are worked in back stitch, the curves are in buttonhole stitch, and the small upright sprigs in fern stitch. 


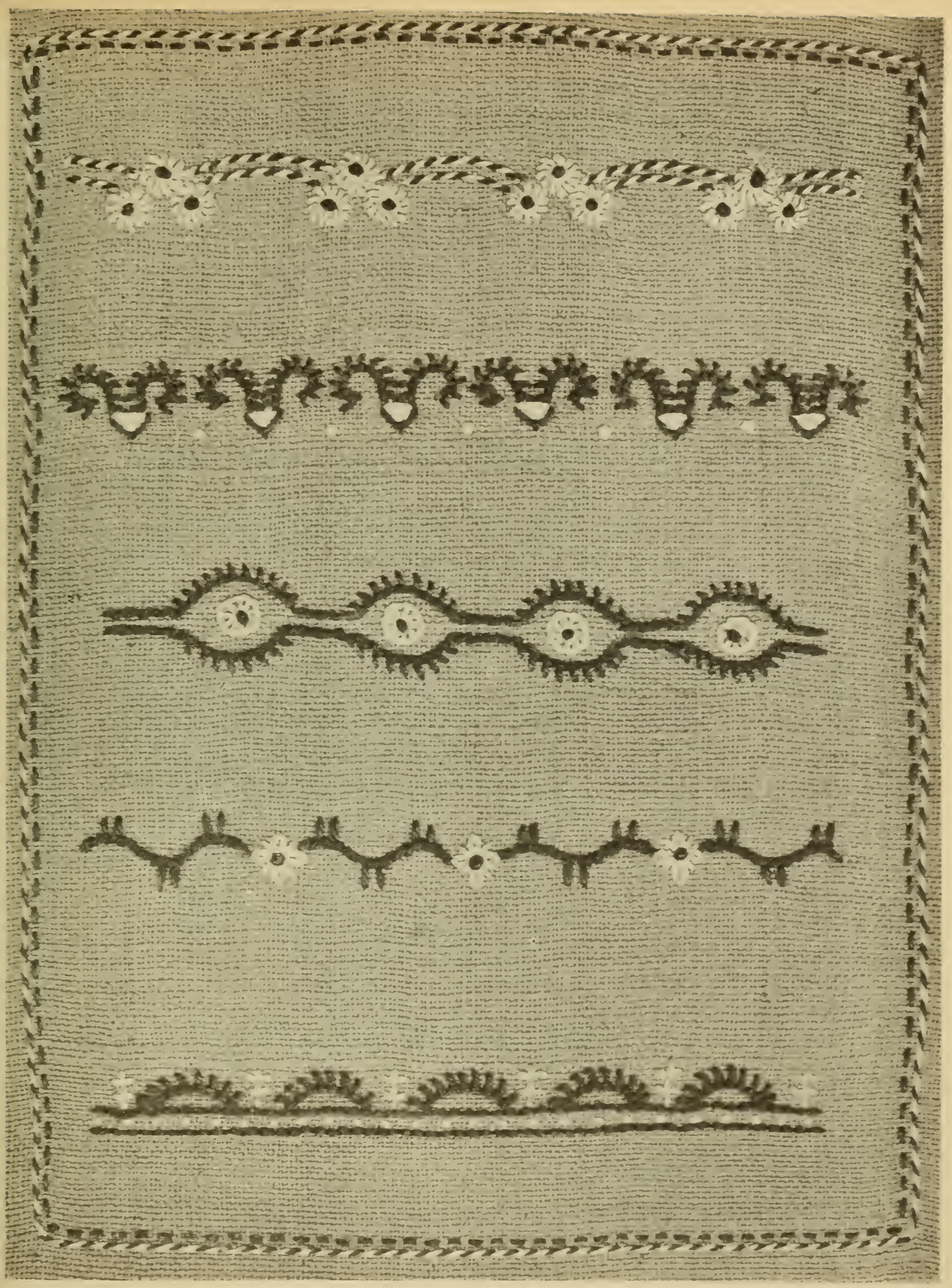




\section{Group 3. Plate XXXIII.}

The top border in Plate XXXIII is worked entirely in back stitch. The meandering line should be embroidered first of all; then the small circles, for which two colours must be used, and then the curved lines which connect the circles.

The second border is much bolder in effect than the first, and could be enlarged if necessary without spoiling the character of the design. The main line is worked in chequered chain, the leaves in fish-bone stitch, and the stem which connects them with the meandering line is made with a single stitch.

For the third border, coral stitch is used for the meandering line, and the little sprigs are composed of three daisy stitches and two French knots.

For the fourth border the curved lines are worked in stem stitch, and at the end of each curve four single stitches, all meeting in one centre, are arranged. Between these groups are small flowers which are composed of four daisy stitches.

The fifth border is a very simple one. The curved line is worked first in run and thread, and on top of this are placed small sprigs which are made with-two Roumanian stitches. 


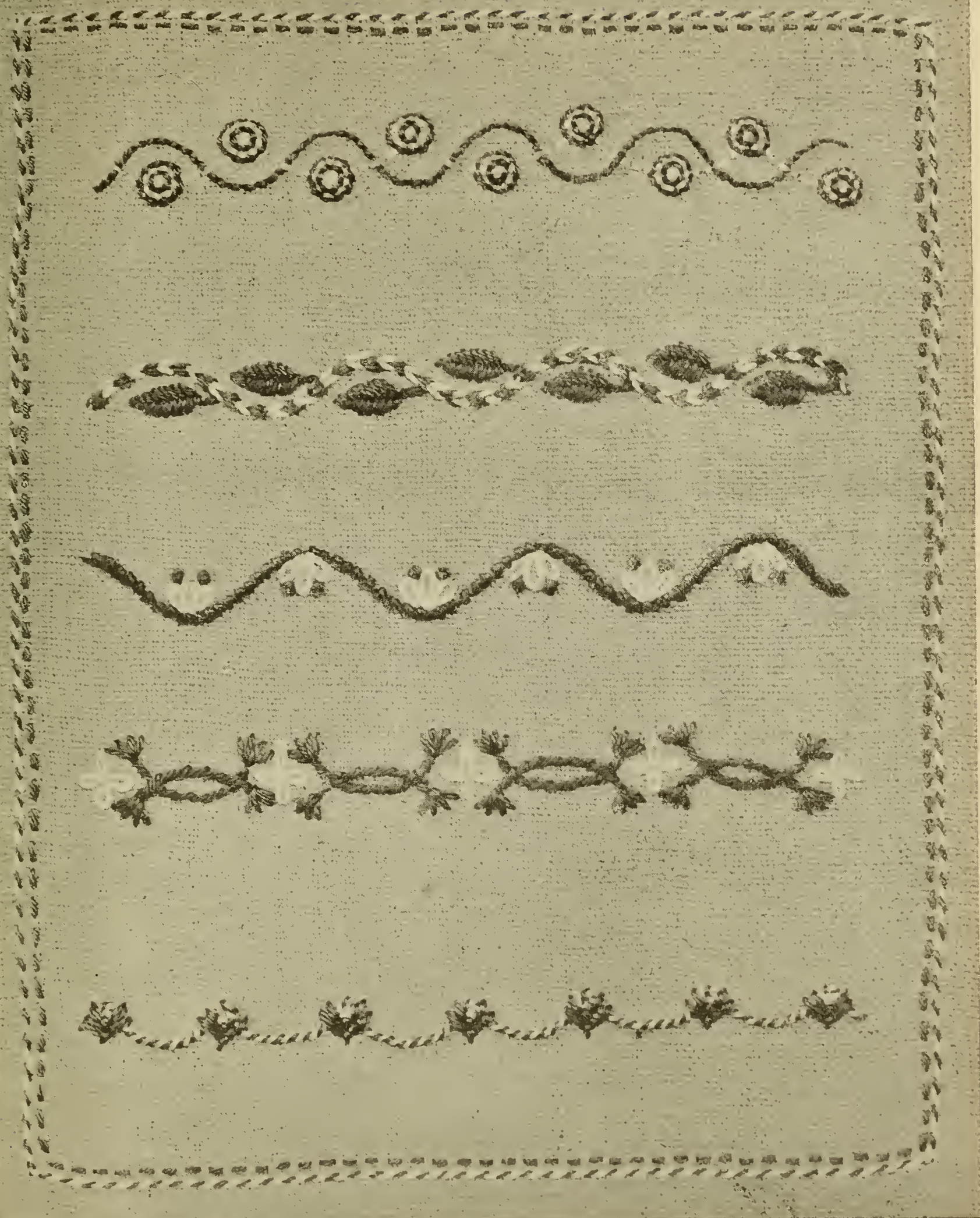




\section{Group 4. Plate XXXIV.}

With the exception of the last border, those illustrated in Plate XXXIV are a little more elaborate than those already described.

The first one is embroidered in back stitch for the curved sprigs and radiating lines, the centre line being couched.

In the second border, the centre line is worked in run and thread, and, arranged in pairs on each side of this line, are alternating groups of French knots and small crosses.

The third border, which can be very quickly embroidered, is mainly composed of two rows of buttonhole stitch set back to back; the stitches are worked rather far apart, but, as the two headings are whipped together, the effect is not ungainly. At the top of every other buttonhole stitch, three small stitches are worked to give a little variety to the outline.

In the fourth border the main lines are also embroidered in buttonhole stitch, the two rows being set back to back as in the third border. These lines are broken at intervals by small squares, which are composed of four Roumanian stitches and one single stitch. A running line is arranged on each side of the border so that it just touches each of the buttonhole stitches.

The fifth border is composed of a meandering line worked in stem stitch. The lines radiating from it are made with single stitches, which are held in position by a curved row of back stitches. 


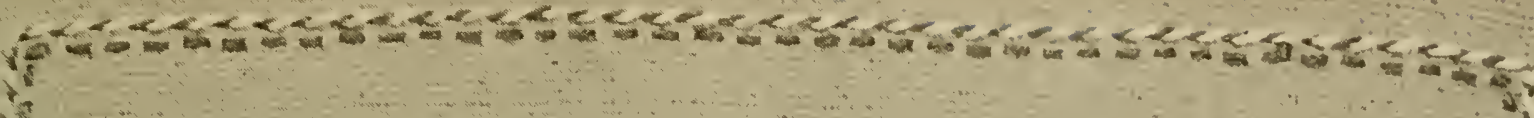
is

is

है

$\sqrt{5}$

is

is

और

is

พy

7

솨

$\checkmark$

17

15

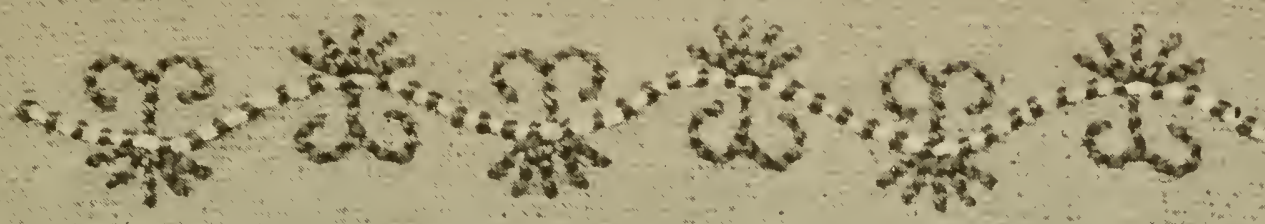

it

8

is

is

$+1$

13

is

है?

is

18

is

1

i.

है

11

18

is

e

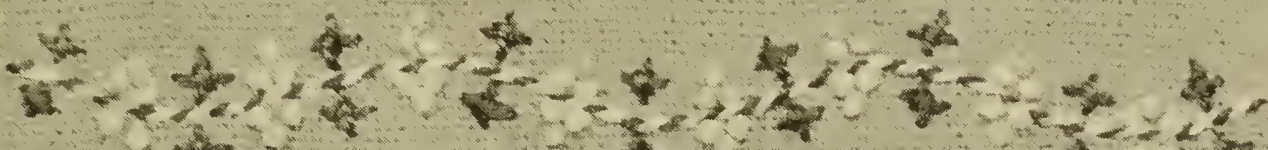

i)

3

is
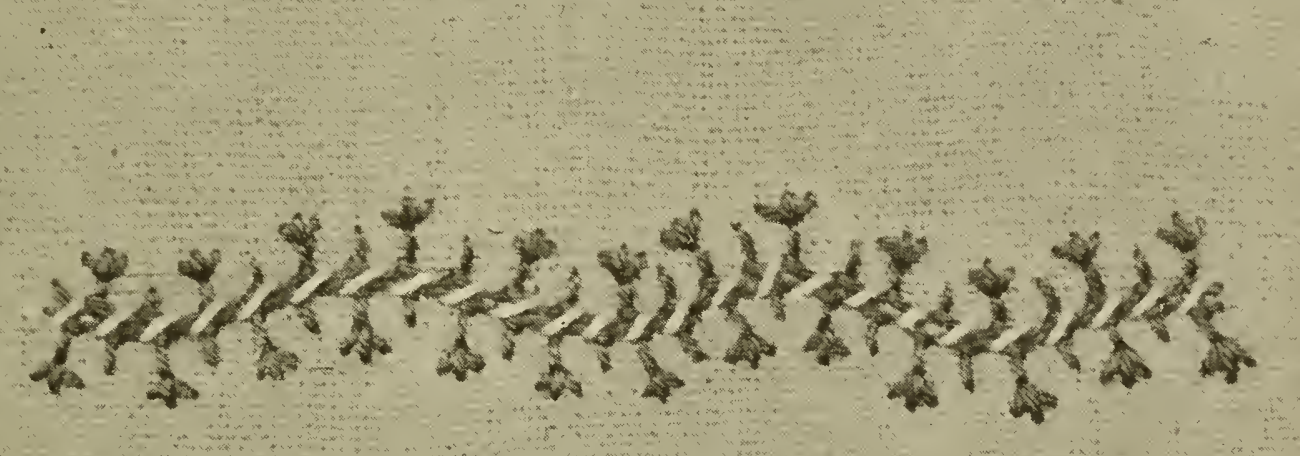

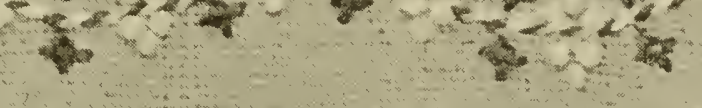

$y^{3}$

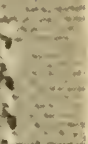

$$
\text { … }
$$




\section{POWDERED FILLINGS.}

\section{Plate XXXV.}

POWDERED fillings can be made to serve many purposes in the planning and carrying out of embroidered decoration. For example, in a design which radiates from the centre of a square or circle, there is often a space in the middle that needs some form of pattern spotted over it to prevent it from looking too empty and uninteresting. Leaves and flowers can, of course, be filled with one of these patterns somewhat in the manner of those illustrated on Plate XXXVII. Or, again, the upper portion of a bag may require some lighter form of decoration in addition to the more solid embroidery. The small bag illustrated in the Frontispiece will easily explain this use of a powdered decoration.

Those illustrated on the opposite page are extremely simple to work, but they should not be commenced in a haphazard way without a proper geometrical setting. If the ground material is not coarse enough to arrange the stitches on the threads, straight lines must be painted on the material and the fillings embroidered on these.

Beginning at the top left-hand corner of Plate XXXV, the first filling consists of small buttonhole wheels and running stitches.

The second one consists of zigzag and upright lines of fern stitch and French knots, the small diamond being simply made of four single stitches.

The third filling is merely a series of small circles, each made of a French knot with running stitches around it.

The fourth filling is composed of fly stitches and French knots; and the fifth of daisy stitches separated by lines of running stitches.

The sixth filling is made by single stitches over which are placed small crosses of a contrasting colour.

The seventh filling is made up of a networl: of large running or back stitches, the spaces between being filled with alternating crosses and French knots.

The eighth and last filling is composed of groups of four crosses set close together, and single French knots. 


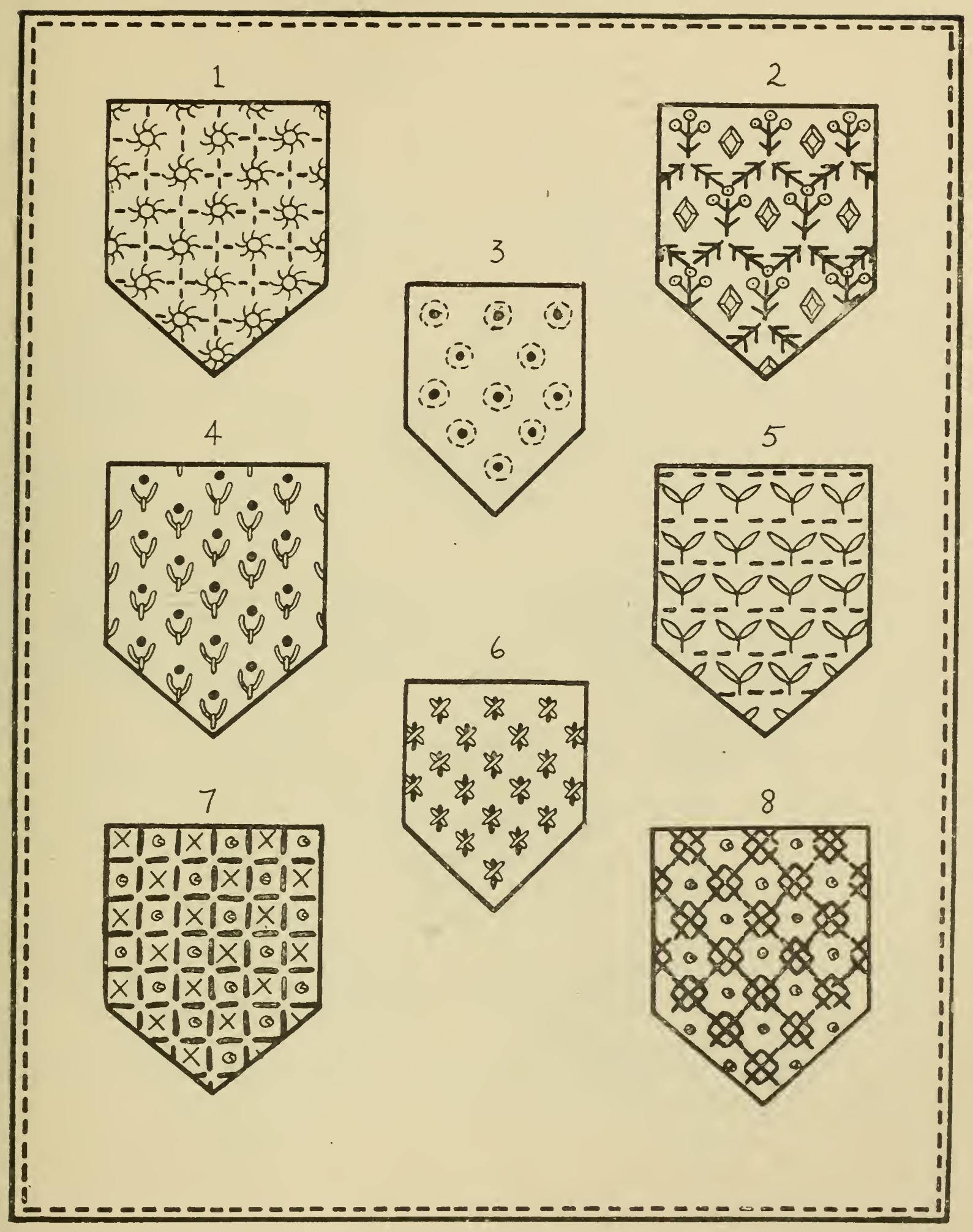

Plate XXXV. 


\section{GEOMETRICAL FILLINGS.}

\section{Plate XXXVI.}

ANy large leaf, or flower, or geometrical shape which forms part of an embroidery design, could be decorated with one or other of the geometrical patterns shown on Plate XXXVI. These, being purely conventional treatments, should never be combined with more realistic floral patterns, nor should they be used on a very small scale, but reserved for larger pieces of embroidery of the kind more especially suited to upholstery purposes. Three of these fillings, viz., Nos. 1, 2, and 5, were adapted from a Portuguese embroidered hanging of scarlet cloth executed in the seventeenth century, and now in the Victoria and Albert Museum; this piece of work is well worth studying, as the design is beautiful and the treatment full of interest to an embroideress.

To return to the fillings on the opposite page, No. 1 is composed of large crosses and bands of stitches tied down with threads of the same colour; the small circles are formed by a line of running stitches slipped under the ends of the couched threads.

In working the second filling, the crosses, which are each composed of four threads, are embroidered first; the interlacing lines are simply run in and out afterwards, and are not worked into the ground material at all.

No. 3 is made by laying two or three threads from side to side of the square at regular intervals and then couching them with a thread of contrasting colour.

No. 4 is just another variety of No. 2 ; the crosses are smaller and the threads are interlaced in a slightly different manner.

No. 5 needs a little more explanation. In working the pattern, the long lines should be embroidered first in stem stitch, and then the small crosses added where these lines intersect; the double crosses, surrounded by small running stitches, should then be worked in the centre of each square, and lastly the triangles, which should be composed of four satin stitches.

Nos. 6 and 7 are both worked on the same principle, so that only one description is necessary. In neither of these patterns does the needle pass through the ground material except at the edges of the design; the straight lines are laid first diagonally across the square, and, when these have been placed quite evenly, the other threads, which may be of the same or of a contrasting colour, are interlaced.

No. 8 shows a filling composed of a series of straight lines, held where they intersect by small crossed stitches and single ones. 


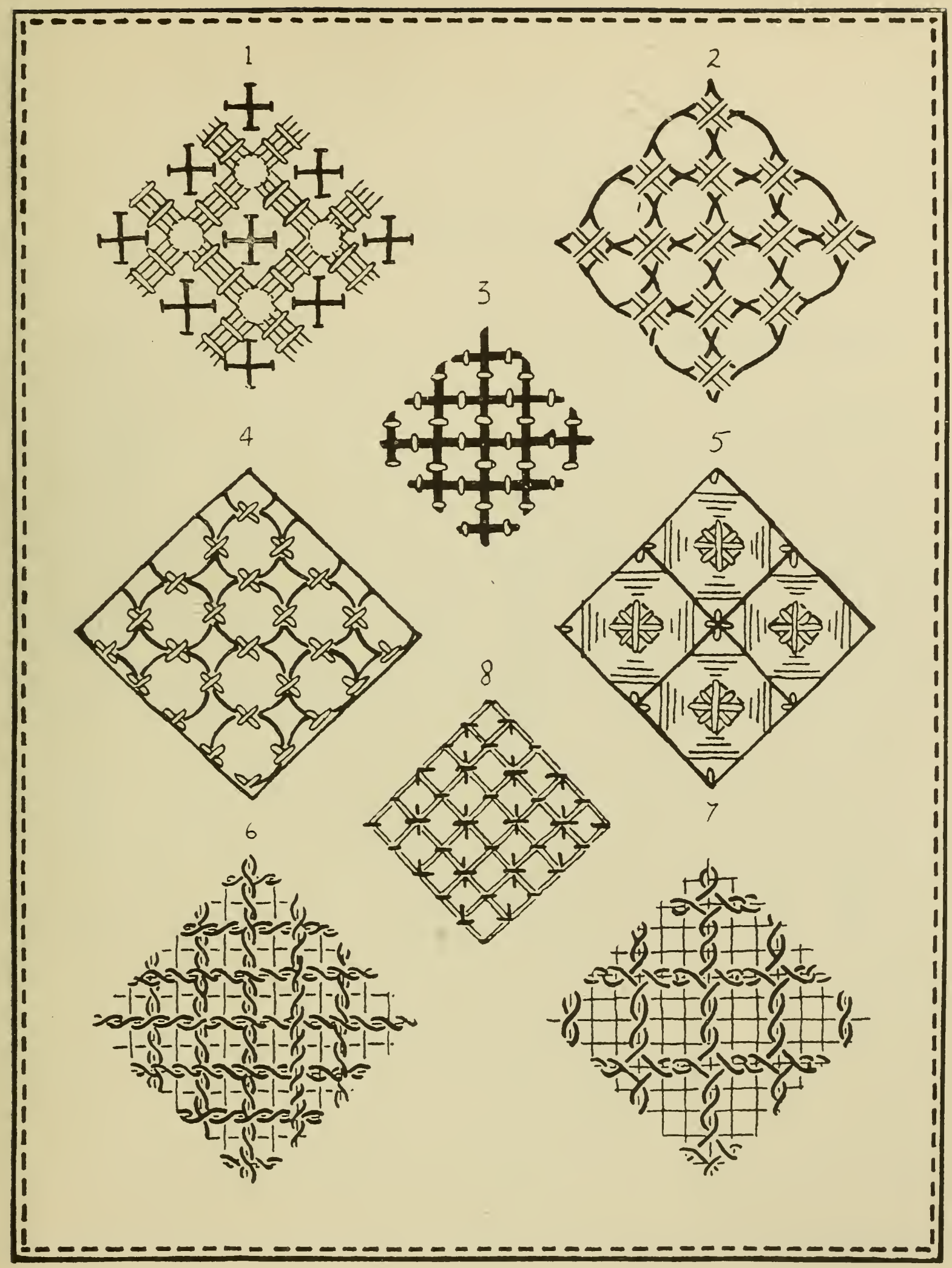




\section{LEAF-FILLINGS.}

\section{Plate XXXVII.}

THE leaf-fillings illustrated in Plate XXXVII are all adapted from a very beautiful piece of Swiss work of the sixteenth century which is now in the Victoria and Albert Museum. This kind of treatment for leaves or flowers should be used only for a bold design, and when the ground is coarse enough for the threads to be counted easily. The fillings must have a distinctly geometrical character, which can only be obtained when the stitches are worked exactly to the proper number of threads of the material.

For all five leaves the outline is the same, i.e., run and thread.

The top left-hand leaf is patterned with alternating bands of satin stitch and Roumanian stitch worked rather openly.

The top right-hand leaf is embroidered with rows of buttonhole stitch, worked in groups of three stitches and separated by a band of double back stitch, for which a different colour should be used.

The centre leaf is carried out entirely in buttonhole stitch, partly worked into the ground and partly on a single thread, to form the small buttonhole loops.

The bottom left-hand leaf hardly needs any explaining; it is embroidered very simply with bands of satin stitch and small crossed threads.

The bottom right-hand leaf is slower to work, but has a very rich appearance when finished. The light stripe is made up of five rows of run and thread set close together, for which only one colour should be used; the space between is filled with double back stitch.

D.M.C. ingrain thread, No. 16, was used for the dark colour; the light was Cartier-Bresson floche thread, size No. 10. 


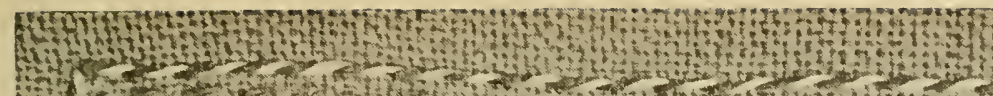

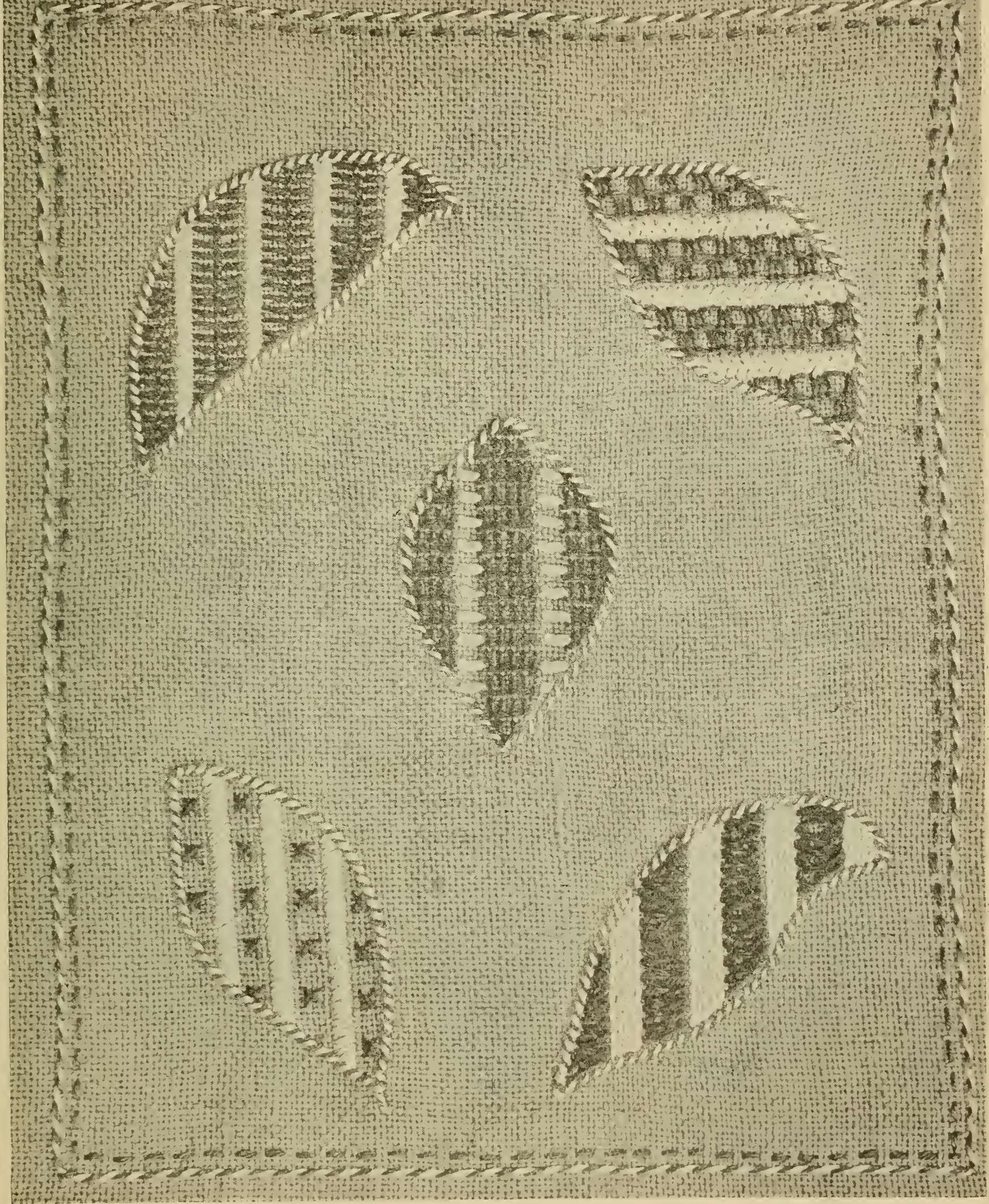




\section{DECORATIVE LEAVES AND STEMS.}

\section{Group 1. Plate XXXVIII.}

THE leaf and stem patterns illustrated in Plates XXXVIII-XLI indicate a few of the varied shapes and treatments that a study of natural forms will reveal to the student interested in embroidery.

In making notes for embroidery purposes, it is very necessary to ignore all accidental effects of light and shade or development, and to endeavour to translate into embroidery stitches the principal characteristics of the leaf or flower that is going to be used. An embroidery pattern has to grow on a piece of woven material, and when it is finished it should form an integral part of the ground it has been worked on, and not give the effect of a superimposed design. To obtain the right result all naturalistic treatments must be avoided; such as flowers and leaves in perspective giving the effect of distance, raised roses, elaborate shading of a turned-over leaf, and so on. The pattern must be clear and definite, with no overlapping or confusion of line, and the natural forms should be flat and decorative in appearance.

Many of the leaf and stem treatments in Plate XXXVIII need little explanation, as the stitches in most cases suggest themselves.

No. 1 is worked in any strong outline stitch and fly stitches;

No. 2 in Roumanian stitch and satin stitches;

No. 3 in stem or chain stitch, with a filling of feather-stitching.

No. 4 represents a stem worked in thorn stitch (see Miss Pesel's Portfolio of Stitches, No. 1).

No. 5 is carried out in fish-bone stitch, two colours being used.

No. 6 shows a stem worked in running and stem stitch.

No. 7 has the centre of the leaf filled with thick couched lines, and the edge worked in buttonhole stitch.

No. 8 has a background of threads laid horizontally across; on this is superimposed a network of veins worked in back stitch; the leaf is then outlined and the edge broken by small fly stitches.

No. 9 is another variation of No. 7. Coral stitch would be very suitable for the veins and buttonhole stitch for the edging. 


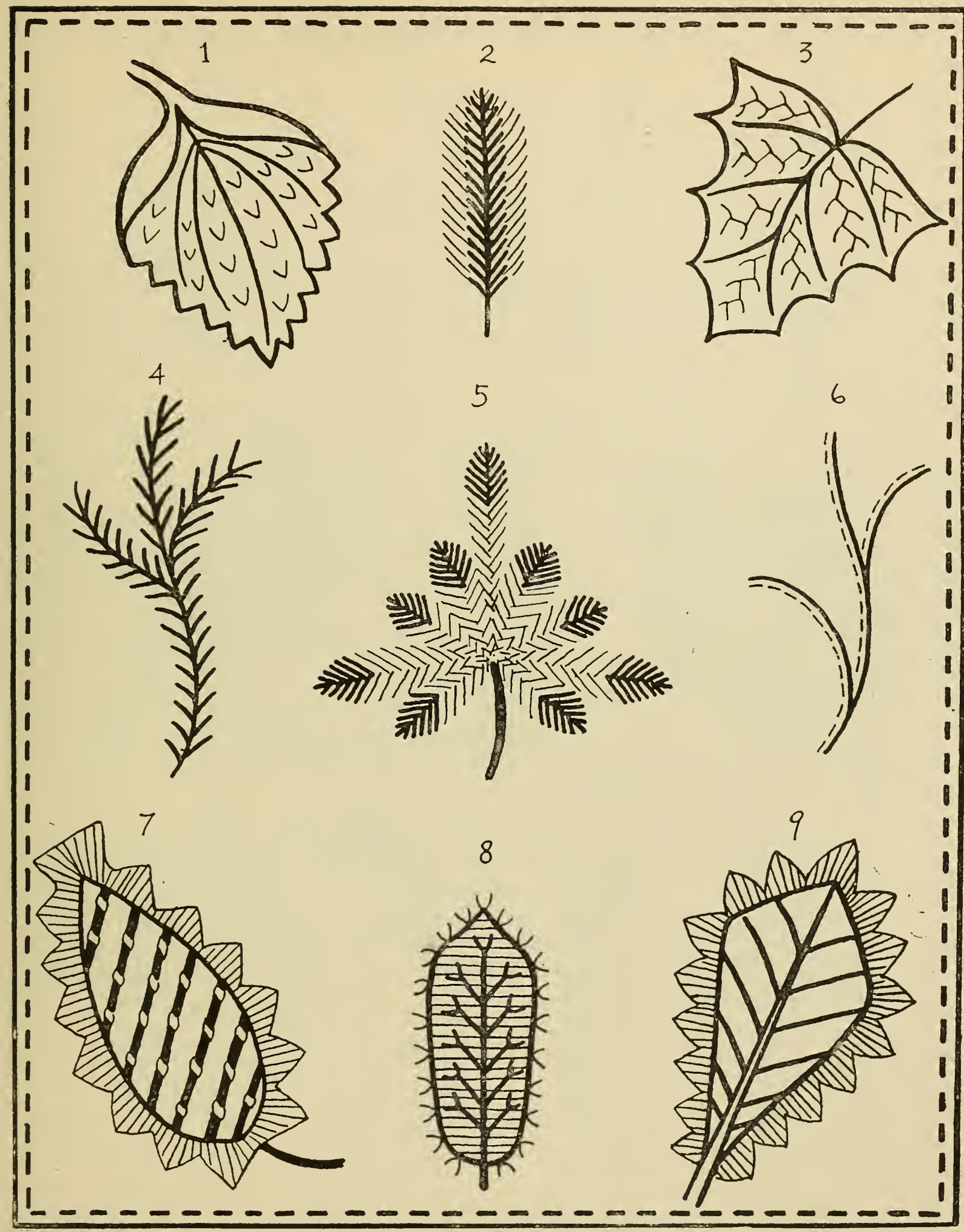

$6-(8 \% 0 A)$

Plate XXXVIII. 


\section{Group 2. Plate XXXIX.}

The leaves marked Nos. 1 and 4 in Plate XXXIX are both intended for a pattern worked principally in outline. When engaged on a piece of work of this kind, the embroideress must be very careful not to spoil the drawing of the outline while working upon it with a needle and thread, for the success of the embroidery will greatly depend on keeping the shapes of the leaves or flowers clear and accurate.

Nos. 1 and 4 can be outlined with stem, chain, or coral stitch; daisy stitches are added to the leaf marked No. 1, and lines of running stitches to No. 4.

The stem, No. 2, is another example of the use of running and stem stitch (see No. 6, Plate XXXVIII).

No. 3 can be worked in chain with a filling of single satin stitches; these should be done first and then the outline. No. 5, which is obviously a holly leaf, has a background of open buttonhole stitch with veins worked on top of it in stem or back stitch; the outline could be of whipped stem or chain stitch.

No. 6 shows a thick stem worked in buttonhole stitch, with a thread of contrasting colour run between the buttonhole stitches.

No. 7 has a filling of laid interlaced threads, around which is worked a heavy outline composed of two rows of chain stitch, separated by a line of stem stitch in a contrasting colour; or the three outlines could be of the same stitch, only varying the colour.

No. 8. The stiff veins could be worked in coral stitch, the inner outline in buttonhole stitch and the outer in chain or stem stitch.

No. 9 is worked with any strong outline stitch and a filling of herring-bone.

No. 10 is simply a stem composed of outline and running stitches with the addition of two satin stitches placed at regular intervals across the stem.

No. 11 has a strong vein of ladder stitch in the middle. The outline could be of whipped or simple chain, and the filling is, of course, of running stitches following the outline of the leaf. 


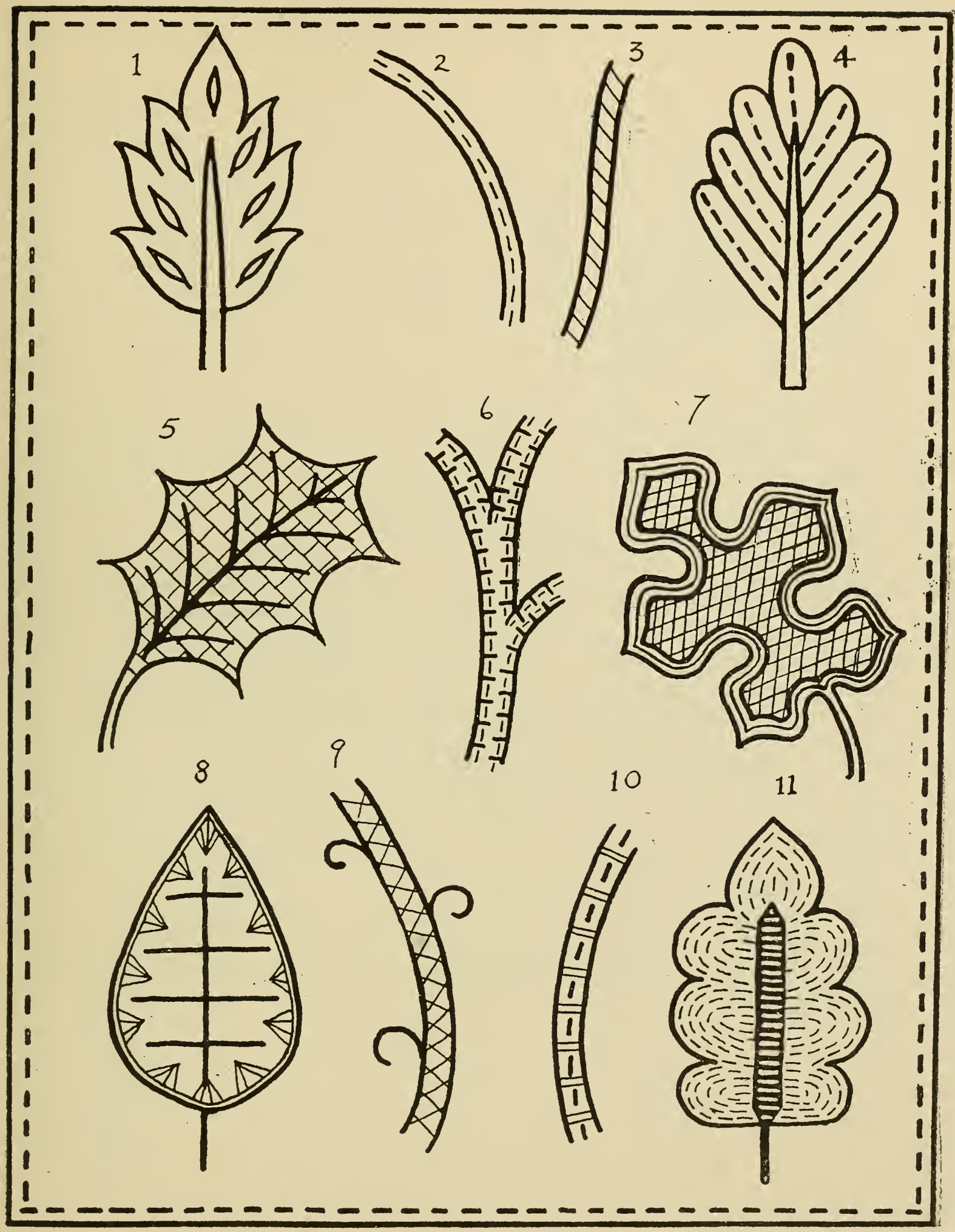

Plate XXXIX. 
Group 3. Plate XL.

No. 1 in Plate XL represents a primrose leaf worked in running and buttonhole stitch, with stem or back stitch for the veins.

Next to it, and marked No. 2, is a small curved stem embroidered in chequered chain stitch.

No. 3, a much more primitive-looking stem, is made of several thick threads couched with a contrasting colour.

No. 4 is another example of a leaf with a laid background (see No. 8, Plate XXXVIII), two outlines are worked around it, the outer one being enriched with several additional stitches. The vein is worked right over the background stitches, and could be embroidered in stem, chain or back stitch according to the thickness of the working thread.

No. 5 shows a seven-pointed leaf, filled with double chain stitch and outlined in two contrasting colours.

No. 6 should be worked with a thick outline of whipped stem or chain stitch, the filling of buttonhole stitches being worked in groups of three. Only two rows can be done in this way; for the third the stitches will have to be added separately.

No. 7. In this leaf the filling is the most interesting part; the veins are decorated with small buttonhole wheels which face outwards, and two outlines should be worked round the leaf, one thicker in appearance than the other.

No. 8, which would look well carried out in wools, is made up of long threads laid the whole length of the leaf; over these are worked bands of stitches in a contrasting colour, which could be in coral or chain stitch, etc.; large French knots placed fairly close together form a centre vein for the leaf.

No. 9 is worked in open buttonhole;

No. 10 in cable stitch, with the addition of a single satin stitch in a contrasting colour worked at right angles to the line.

No. 11 should be worked in fish-bone stitch, the edge of which is decorated with daisy stitches. 


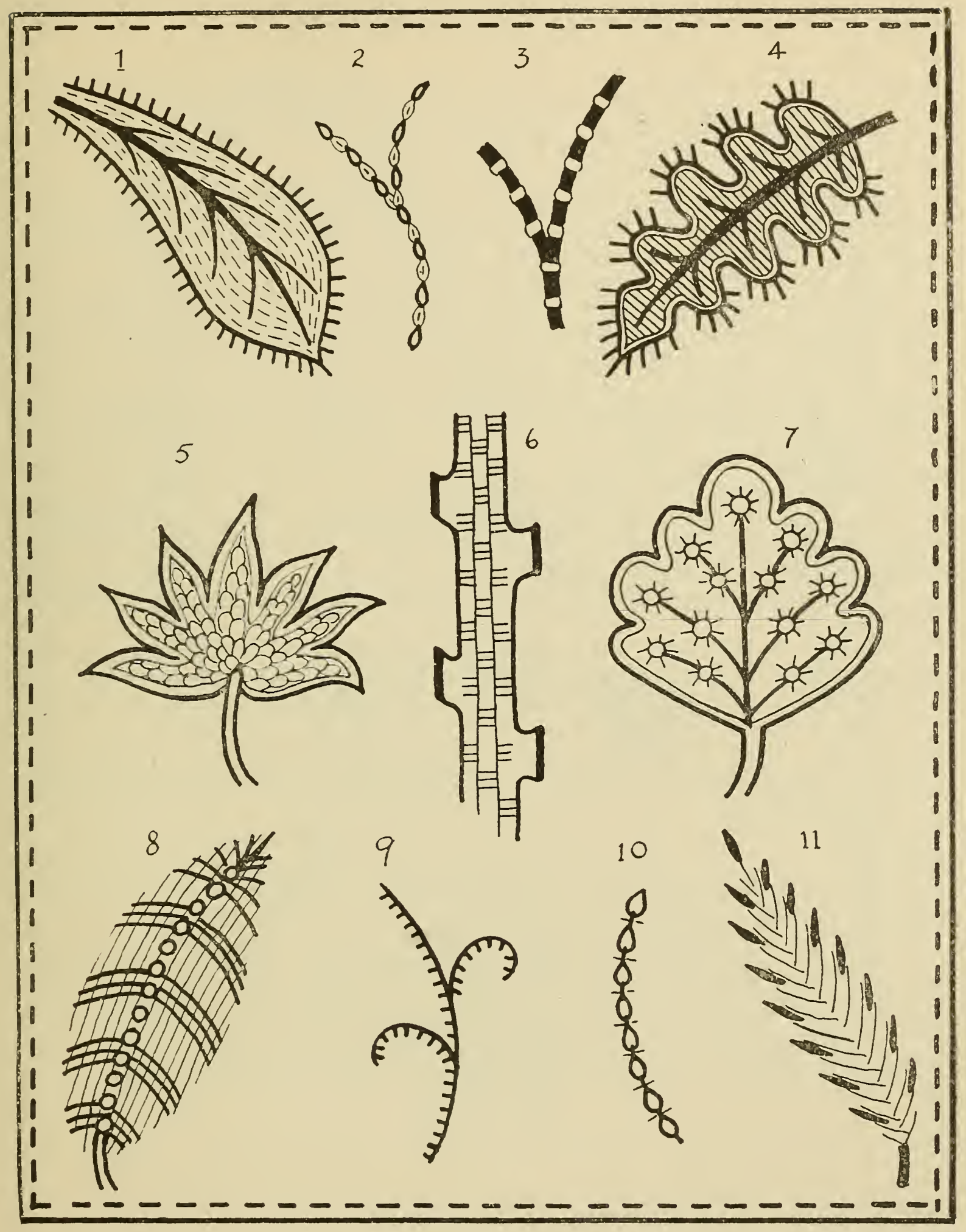

Plate XL. 


\section{Group 4. Plate XLI.}

In Plate XLI the leaves and stems are on a smaller, lighter scale than those already discussed on the three preceding pages. Though some of the stems are curved and some straight, the embroideress should be able to twist and arrange them into any shape that will best suit the design in hand.

No. 1, worked entirely in outline, is particularly suitable for making a strong foliated pattern. It could be worked in stem, chain, or coral stitch, and the short veins could be in either the same or a contrasting colour.

No. 2 is composed of three crossed fly stitches all meeting at one point. An example of this stitch actually worked in a border is shown in Plates XIII and XVII.

No. 3. The small leaves and stems are made with daisy stitches attached to a large stalk of chain or stem stitch, etc.

No. 4 is composed of groups of four over-lapping fly stitches, two on either side of the centre stem; for the top group a single stitch will have to be added; the leaves are simply daisy stitches.

No. 5 is a small sprig made up of four French knots and three Roumanian stitches.

No. 6. In this spray the leaves can either be made of daisy stitches or, if this method appears too clumsy, they could be worked in back stitch.

No. 7 is a small buttonhole wheel from the top of which sprout two daisy stitches.

No. 8. The black leaves could be in satin or double back stitch, the small ones are daisy stitches attached to the main stem by a long stitch in the working of them.

No. 9 is a small sprig worked in coral stitch, French knots, and single stitches.

No. 10 represents another variety, composed of groups of daisy stitches and a cross worked in back stitch.

No. 11 is embroidered entirely in stem or back stitch and French knots.

No. 12. The leaves are worked in buttonhole, and a dash of vivid colour could be introduced by a daisy stitch or two satin stitches placed in the centre of each leaf; the stems could be in chain or coral stitch or run and thread.

In the thirteenth and last spray, the leaves could be worked either in sutline or solidly in fish-bone, Roumanian, or double back stitch. 


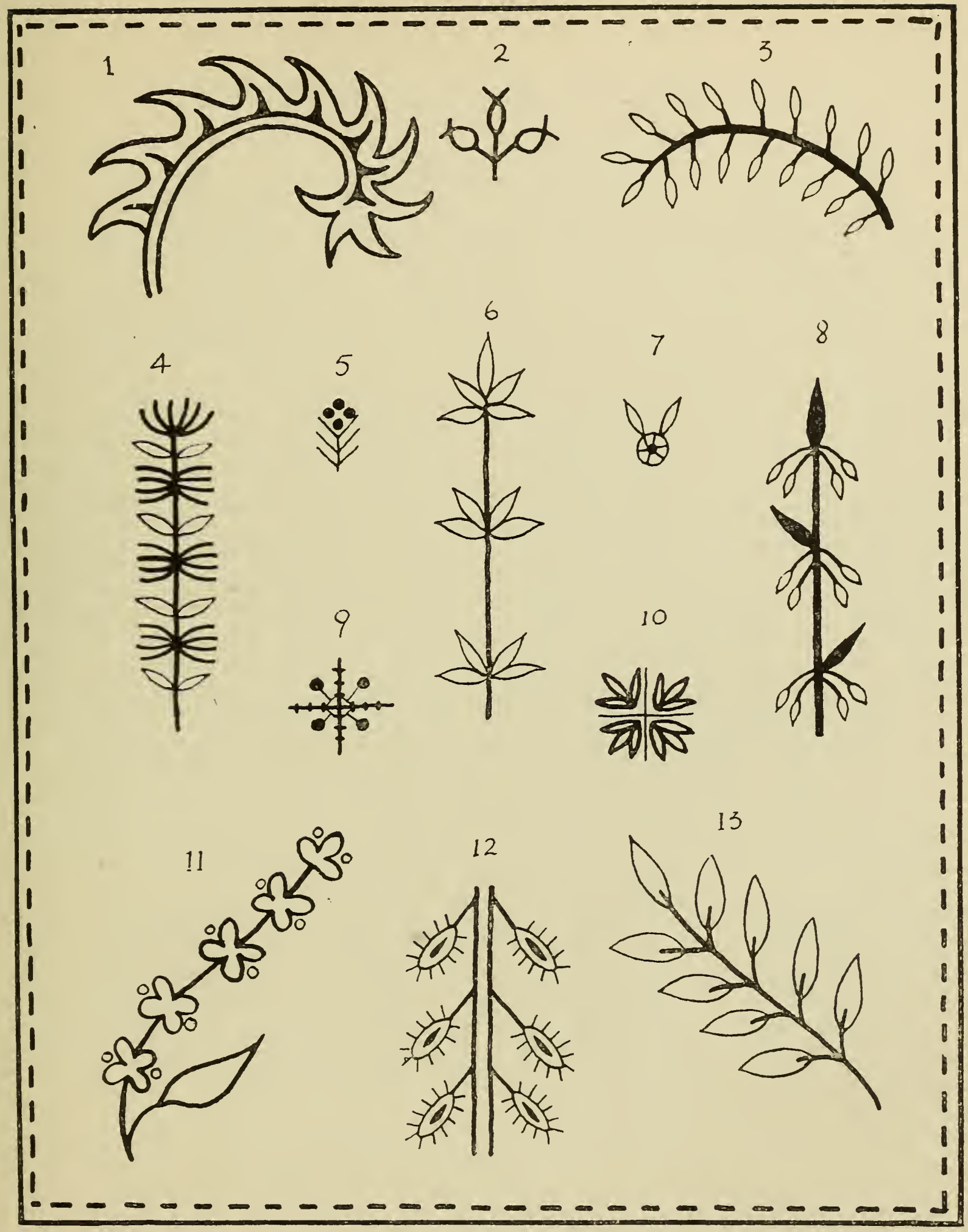

Plate XLI. 


\section{FLOWERS DEVELOPED FROM BUTTONHOLE WHEELS.}

\section{Plate XLII.}

ThE flowers illustrated in Plate XLII require nothing in the way of drawing but a circle traced on the material, and, for some of the flowers, this can be done mechanically by painting the circle round a threepenny bit.

First Row. No. 1 shows the buttonhole wheel from which the flowers are to be constructed; No. 2, the flower half-completed by the addition of fly stitches to each two buttonhole stitches; and No. 3, the finished flower, to which have been added daisy stitches. No. 4 is worked in the same way, but no spaces are left between the buttonhole stitches, the centre is filled with French knots, and a single stitch is placed in each petal.

Second Row. From left to right, No. 1 is worked with buttonhole wheel, zigzag chain connecting the points. Single stitches in the lighter colour are added to each petal. No. 2 is worked with two buttonhole wheels, one with the stitches facing inwards to form the centre, the other facing outwards with a fly stitch added to each point. No. 3 is worked with the buttonhole wheels facing outwards; the central one has a dark thread interlaced between the spokes and a French knot to fill the middle hole. The outer wheel is thickened by single stitches. In No. 4 the spokes are radiating, and daisy stitches in varied colours are added for the outer circle.

Third Row. No. 1 is worked with the spokes facing inwards, the heading is whipped with a different colour, daisy stitches are placed round the circles at regular intervals. In No. 2 the smaller wheel has every alternate spoke covered by an interlacing thread. Zigzag chain is worked round the outer one. No. 3 is composed of a small buttonhole wheel, and two rows of zigzag chain, the outer one enriched with daisy stitches. In No. 4 the centre is filled with French knots, groups of daisy stitches being arranged symmetrically round.

Fourth Row. No. 1 is made up of a small buttonhole wheel for the centre, and a large outer one in which the spokes are arranged in groups of three; single stitches are added to connect these groups. No. 2 is composed of two buttonhole wheels which partly overlap, the outer one is tied between each two stitches with a small cross. In No. 3 the centre is filled with a small buttonhole wheel; round this is a larger wheel, the spokes of which are caught together in pairs with a back stitch. No. 4 has the outer buttonhole wheel worked with three stitches into one hole, and single stitches and French knots are added to fill the spaces. 


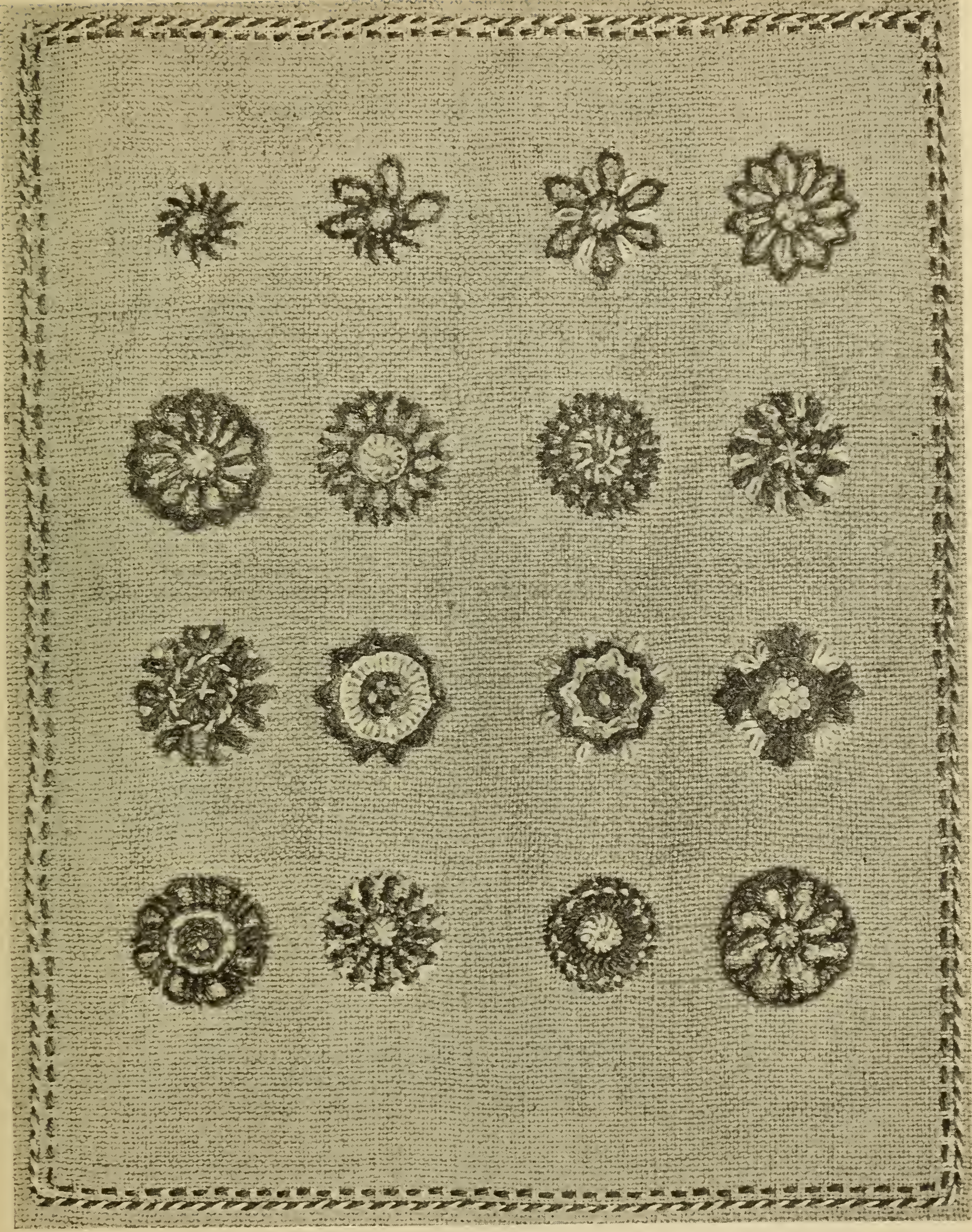




\section{DECORATIVE FLOWERS AND SPRIGS.}

\section{Group 1. Plate XLIII.}

THE first flower in Plate XLIII is worked in fish-bone stitch, the calyx is represented by two daisy stitches, the stem could be a solid thick line or worked as suggested in the drawing, and the same can be said of the leaf, but in any case the vein should be in a contrasting colour.

Outline stitches, which are so frequently referred to in these Plates, and which include for ordinary purposes stem, chain, coral, run and thread, back stitch, whipped stem and chain, and chequered or sideways chain, are so well known to the average embroideress that it should not be necessary in describing an outline to indicate which stitch should be used.

The second flower could be worked either solidly or in outline; if the former, ordinary or tailor's buttonhole could be used, when the little running stitches round the laid centre would have to be replaced by a stem or chain stitch.

Flower No. 3. The small black buds or berries would look nice in satin or buttonhole stitch; to obtain a rougher effect French or bullion knots, or small buttonhole loops placed close together, would be very suitable. The leaf is in outline, and the broken vein is composed of daisy stitches.

No. 4 is a very simple flower worked in outline stitches; it would look infinitely nicer if two colours of the same tone, such as scarlet and vermilion, or delphinium and cornflower blue, were used for the flower itself.

No. 5 should certainly be worked in outline as far as the flowers are concerned; the stamens could be suggested by a French knot; the leaves would look well in fish-bone, double back or Roumanian stitch.

No. 6 would make a very decorative representation of a clover flower if worked in buttonhole loops or bullion knots in two or more shades of pink.

No. 7. A foxglove flower, so often found in Elizabethan embroidery, is represented here in outline. The chevron lines can be worked either solid or open; if the latter, two rows of running stitches would look nice. The interior of the flower is outlined with open buttonhole stitches.

No. 8, a thistle, is carried out in three rows of satin stitch which overlap slightly and are not worked very close together. Three colours should be used for this part of the flower; the calyx is made of laid threads which should be held with a single stitch where they cross each other; an outline is then added to complete the flower.

No. 9 is worked in open buttonhole, a French knot is placed in the centre. and the stamens are in stem stitch.

No. 10 shows the combination of outline with solid treatment.

No. 11. The convolvulus flower is here shown in outline and buttonhole stitch. It could be worked solidly, but in any case the opening of the flower should not be filled in. 


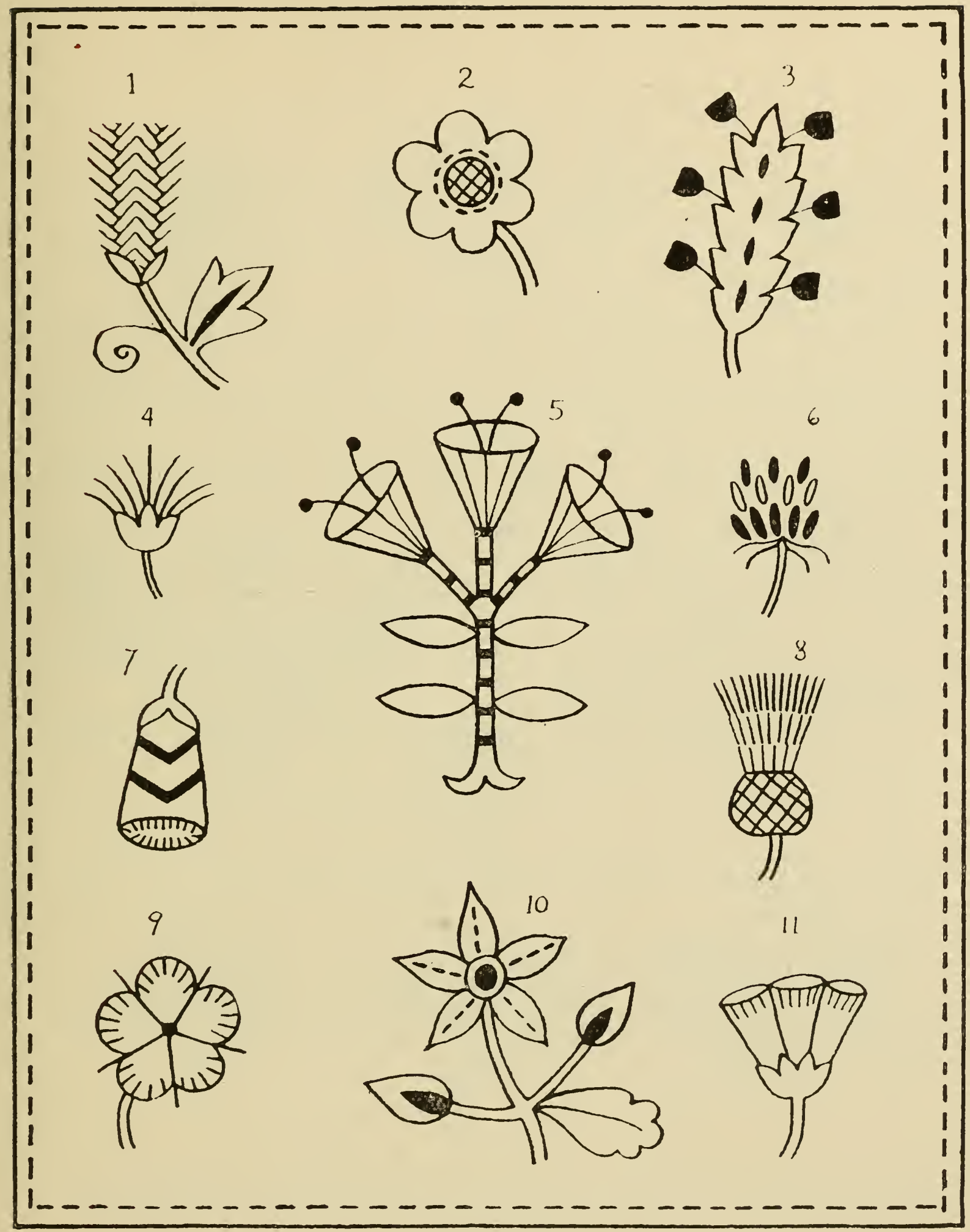

Plate XliII. 


\section{Group 2. Plate Xliv.}

The flower marked No. 1 in Plate XLIV should have rather a delicate fluffy appearance when embroidered. Unlike most of the other flowers, it has no surrounding outline, but is composed of a solid centre filled in with chain or stem stitch, or worked in buttonhole stitch, and detached satin stitches which overlap each other.

The stiff little sprig marked No. 2 is worked in an outline stitch for the stems and leaves, and buttonhole wheels, surrounded by running stitches, for the berries. No. 3, the acorn, has many possibilities in embroidery. In the drawing the cup is filled with French knots, while the acorn itself is simply outlined; if any solid stitching is used instead it should always be of a flat shining type, such as buttonhole worked close together or satin stitch in overlapping rows, etc. The cup should have a rough and broken texture in contrast.

No. 4, a teazle, is worked in outline for the leaves and stems, the sharp points being made by two single stitches worked into the same hole; the teazle itself is embroidered with radiating satin stitches, not placed quite close together, and the calyx is filled with a geometrical pattern of back stitches.

No. 5, the small round flower, has a spotted centre of back stitches and an outline of large chain stitches, on which are placed isolated satin stitches at regular intervals.

The sprig of flowers, No. 6, could either be worked in outline or solidly; if the former the serrated edges of the flowers could be either embroidered in chequered chain or couched in a zigzag line.

The small flower, No. 7, is worked in outline and the solid part in satin stitch.

No. 8 is composed of a group of buttonhole wheels, separated by slender leaves which could be worked in outline or filled in with two or three lines of stem stitch.

No. 9 is a decorative rendering of a dandelion gone to seed, the seeds being suggested by open buttonhole wheels.

The last flower, No. 10, shows a sharp contrast in the treatment of the petals: two of them are powdered with double crosses and French knots, the other two with stripes embroidered in chain stitch. The outline should be worked last of all. 


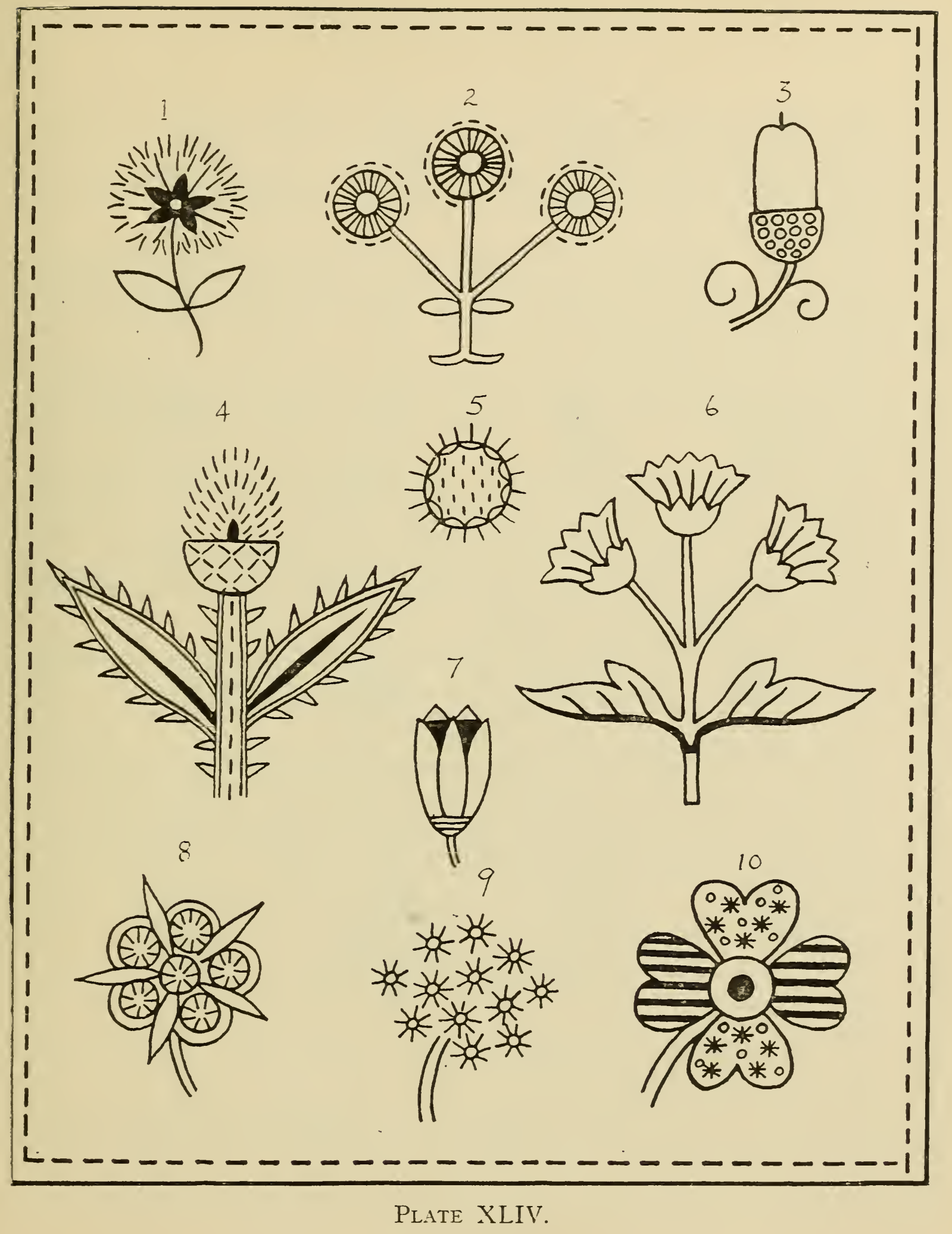




\section{Group 3. Plate XLV.}

No. 1 in Plate XLV represents a cluster of ivy berries worked in buttonhole wheels and stem stitch.

Nos. 2 and 8 are worked in the same stitches, i.e., running, stem, and satin stitches, but the placing of them is reversed and the proportion of the buds slightly altered.

No. 3 is a cowslip flower, which there are several ways of working. The calyx might be in outline and the flower worked solidly in buttonhole, stitch, or the calyx could also be filled in with double back stitch worked in three bands; and then, again, the whole flower might be worked in outline with a French knot in the centre.

No. 4, a carnation bud, if filled in with fish-bone or two bands of buttonhole stitch, should have a touch of deeper colour arranged at the top of the bud. If worked in outline, satin stitches could be added as suggested in the drawing.

No. 5. In this bud the calyx is powdered with French knots and the tight petals worked solidly in satin or fish-bone stitch.

In No. 6 the top of the bud is represented by a buttonhole wheel from which grow threc extra stitches; the calyx is filled with running stitches.

No. 7 represents a seed-pod. Two outlines should be worked for this and the seeds themselves could be worked in buttonhole loops.

No. 8 has already been described.

Nos. 9, 10, 11, and 12 are a series of nondescript little sprigs which nevertheless will be found of great value to the embroideress.

No. 9 is composed of a $\mathrm{Y}$-shaped stem worked in large back stitches, and into this four Roumanian stitches are fitted.

No. 10 is an arrangement of buttonholed half circles growing on a stem.

No. 11. This sprig is worked in stem or back stitch and daisy stitches; a few satin stitches are added between the stems to give a stronger note.

No. 12. The solid square could be worked in fish-bone or satin stitch, and the small upright lines might be made with a heading of buttonhole stitch or added singly.

Nos. 13, 14, 15 and 16 show four different embroidery treatments for the same shape, a trefoil.

No. 13 is outlined and has a filling of fern stitch.

No. 14 is filled solidly with fish-bone stitch, and the edge softened by an outline of running stitches.

No. 15 is outlined with buttonhole stitch, and the small interlacing knot should be worked in back stitch.

No. 16, the last trefoil, is composed of three circles worked in stem or back stitch. In the centre of each is a tiny buttonhole wheel; the circles should be held where they touch by one or two stitches in a contrasting colour. 


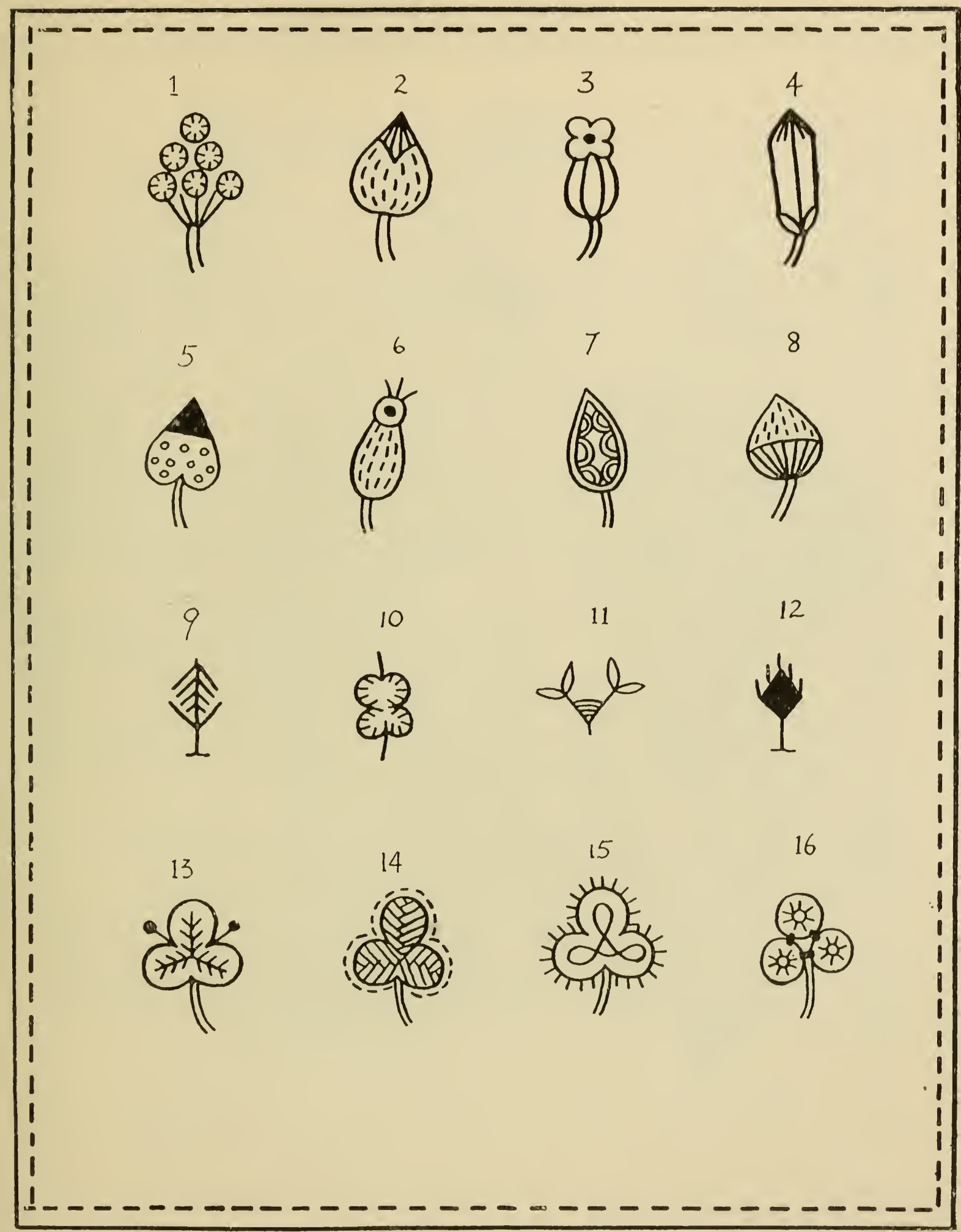

Plate XlV. 


\section{DECORATIVE PLANTS.}

\section{Group 1. Plate, XI.VI}

A STUDENT of embroidery with enough lnowledge of drawing to arrange patterns which are not entirely dependent on geometrical construction should have in her note-book a constantly growing collection of flowers and plants, which, by the simpleness and beauty of their structure, lend themselves particularly to reproduction in embroidery. The ideal way, of course, would be to go into the garden and make drawings from the flowers growing there, but people living in towns have to depend largely on books and photographs.

In the library of the Victoria and Albert Museum there are a large number of herbals, compiled for the most part in the sixteenth and serenteenth centuries. One of the best known of these is Gerarde's Herbal, the plant drawings of which are in black outline, and are so simply and decoratively rendered that very little alteration is necessary to make them suitable for an embroidery design.

An even more wonderful book than Gerarde's Herbal is an edition of Dioscorides's Materia Medica. Dioscorides was a Greek doctor who lived about the second century A.D. The plant drawings which illustrate this work are drawn with a brush so clearly and vigorously as to provide a tonic for any feeble-hearted designer that happened to look upon them. The thistle plant shown in Plate XLVI was adapted from this book and the quaking grass from Gerarde's Herbal, and several other small plants and flowers were also suggested by one or other of these works.

For the quaking grass the seeds should be worked in satin stitch, more than one colour being used, and the leaves either in some outline stitch or filled with double back, fish-bone, ladder, or Roumanian stitch.

The top left-hand sprig would look well worked in coral stitch, and the leaves should be outlined or filled with a different variety of stitch. The small campion spray could be either worked solidly or in outline; if the former, the petals of the flower should be embroidered in some stitch which has a shining appearance. The right-hand sprig would look well with the flowers worked in buttonhole stitch. 


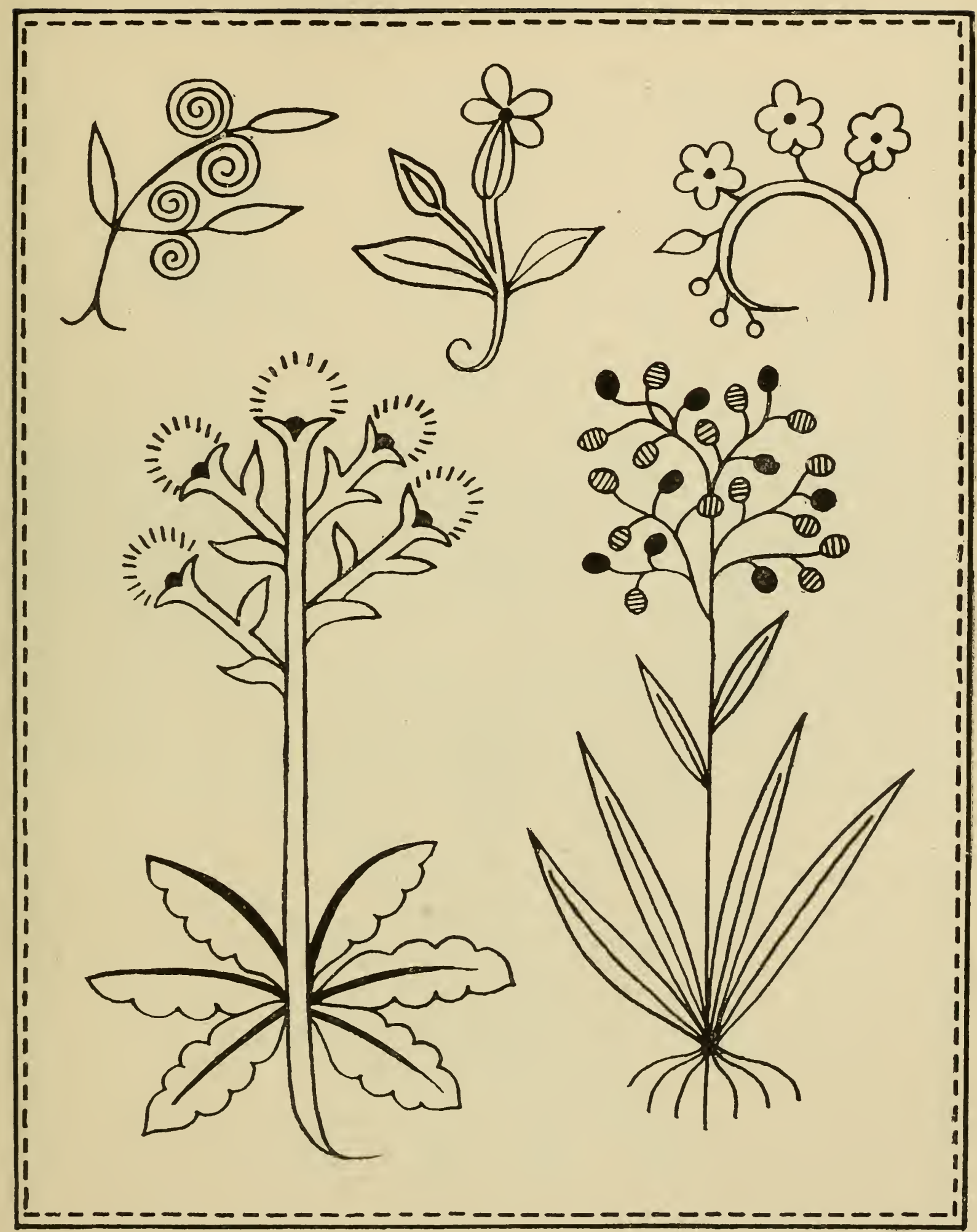




\section{Group 2. Plate XLVII.}

As all the plant sheets in this book are intended for more advanced students, it should not be necessary in all cases to describe in detail the stitches and treatment that should be used for each plant. The embroideress ought to think this out for herself, or the structure of a flower or leaf will often itself suggest the method that should be employed. In any case, there are so many varieties and combinations of embroidery stitches that it would be unwise to dictate any particular treatment to a worker who already possesses some knowledge of her craft.

There are only a few suggestions to be made with regard to Plate XLVIr. The leaves of the blue grape flower or grape hyacinth might very well be worked in ladder stitch, the flowers in satin stitch or outline. The flowers on the small centre sprig should be made with French knots, two colours being used. Those on the flowering bush, at the bottom of the page, if worked in outline, should be made with fly stitches or a couched zigzag line. 


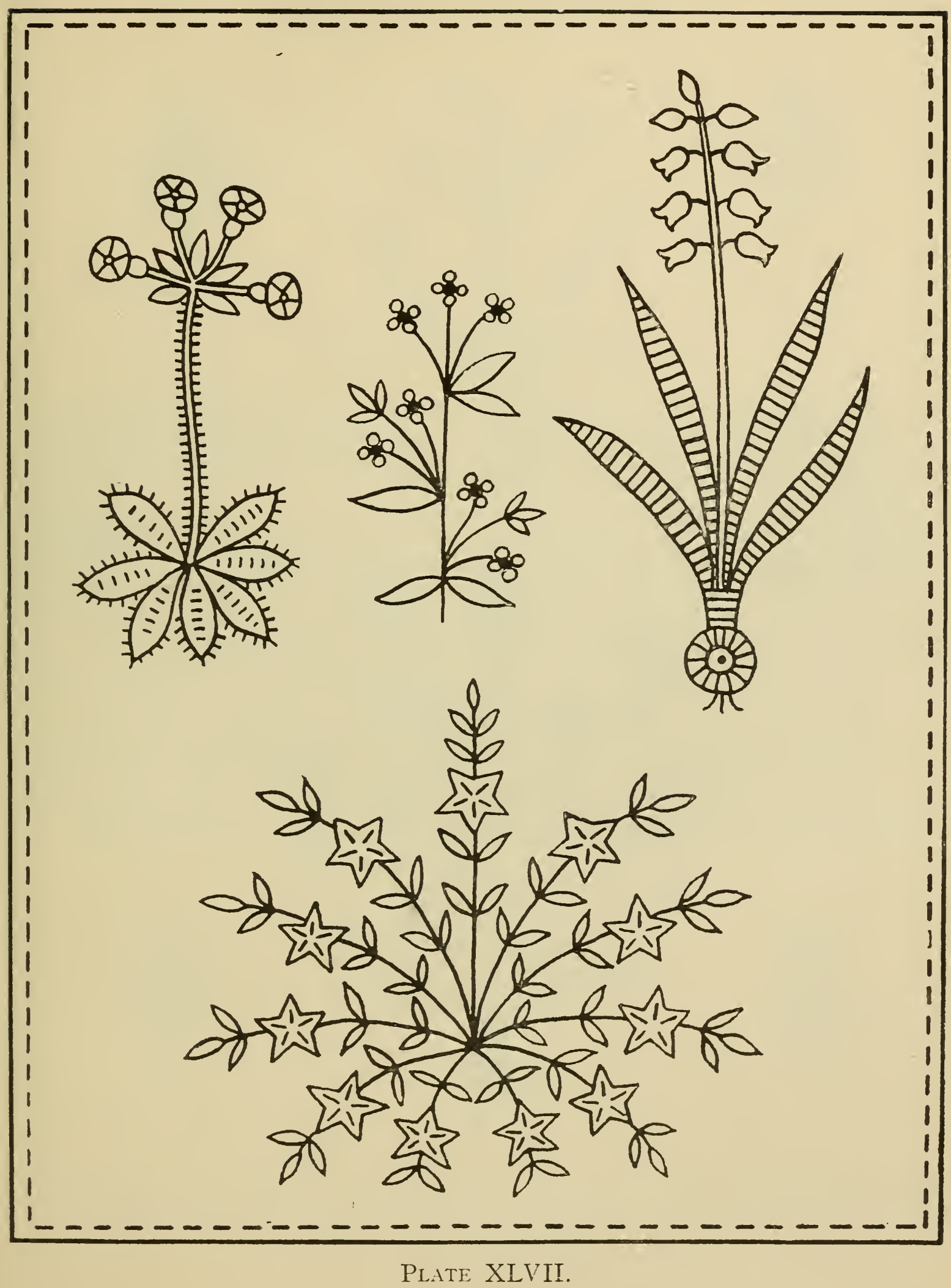




\section{Group 3. Plate XLVIII.}

The hairy stems of the small plant at the top of Plate XLVIII are worked in two rows of buttonhole stitch, set back to back and the stitches arranged in groups of three. French knots are placed at intervals along the stem, and the flowers are worked in the same stitches.

The flowering shrub at the bottom of the page is very quickly worked if drawn on the same scale as the one shown there. The flowers are buttonhole wheels, and the small leaves are made with daisy stitches.

The bud in the top left-hand corner could be filled with rows of chain or stem stitches for the solid black portions, the calyx suggests satin stitch, and for the edging, of course, French knots and single stitches are used.

The top right-hand bud has an outline of buttonhole stitch, and the same stitch worked close together would be quite suitable for the solid portions.

The bottom left-hand bud would look nice in Roumanian or satin stitch, two colours being used, and the lines should be embroidered in stem stitch.

For the bottom right-hand bud the chequered effect round the edge could be obtained with buttonhole stitch, or the solid black squares could be embroidered in satin stitch and the two outlines worked round afterwards. 


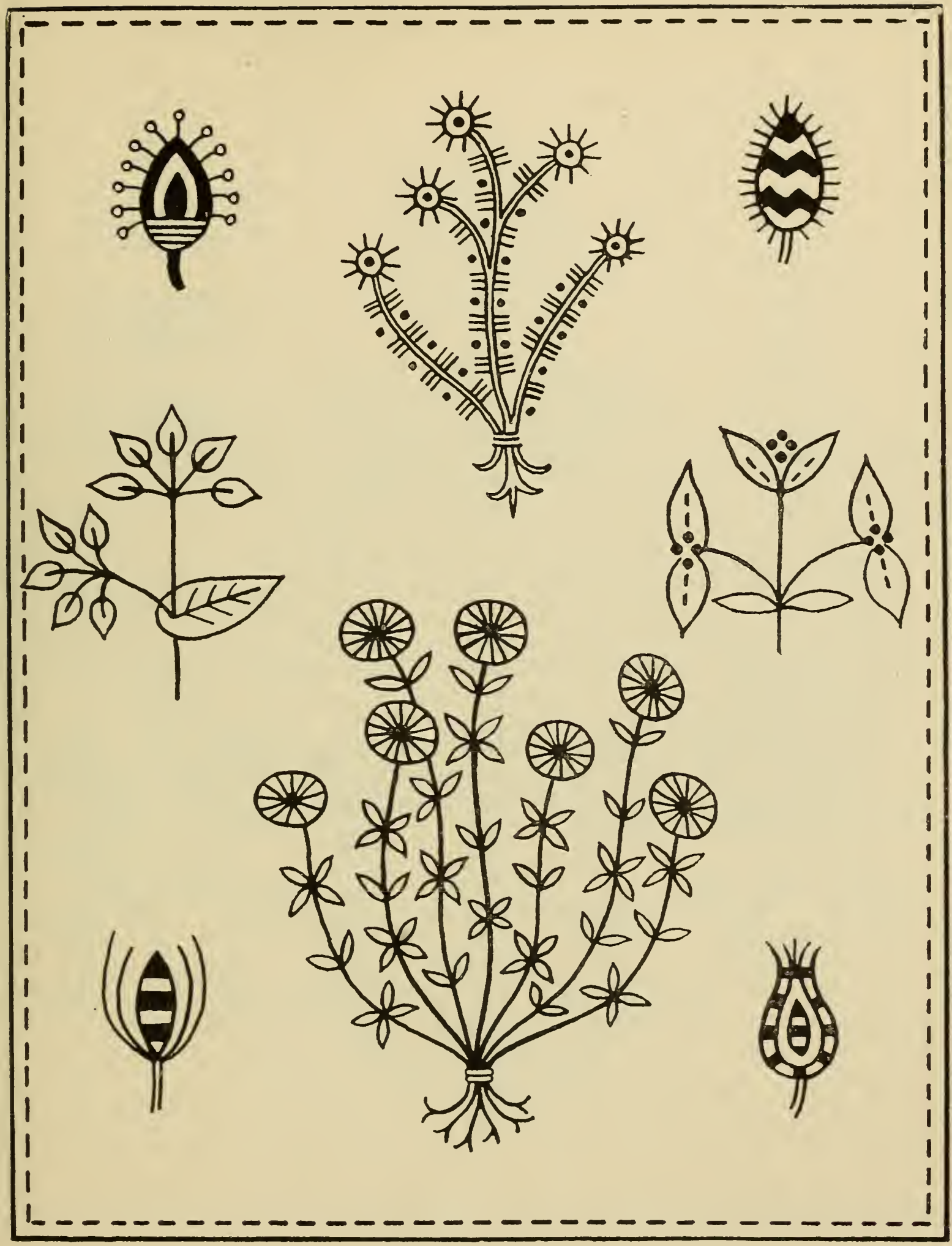

Plate XlVIII. 


\section{Group 4. Plate XLIX.}

The centre flower in the top row of Plate XLIX is embroidered with daisy stitches arranged in groups of four and French knots; the veins of the leaves could be in fern stitch if an outline treatment were decided on.

The top left-hand sprig is a combination of small solid leaves and lines, and for the latter stem stitch would be very suitable.

The top right-hand one has a stem of buttonhole stitch, and the leaves should be worked with one or more outlines of chain, stem, or back stitch.

The centre spray at the bottom of the page has leaves which are obviously intended for double back stitch, but many other stitches would do as well; the flowers suggest Roumanian, fish-bone, or some other stitch with a smooth appearance.

The bottom left-hand sprig could be worked only in buttonhole wheels for the flowers, though the leaves might be in Roumanian stitch of two colours.

The bottom right-hand sprig could have the leaves worked in much the same way as those just described; the flowers should be either outlined or filled in with coral stitch. 


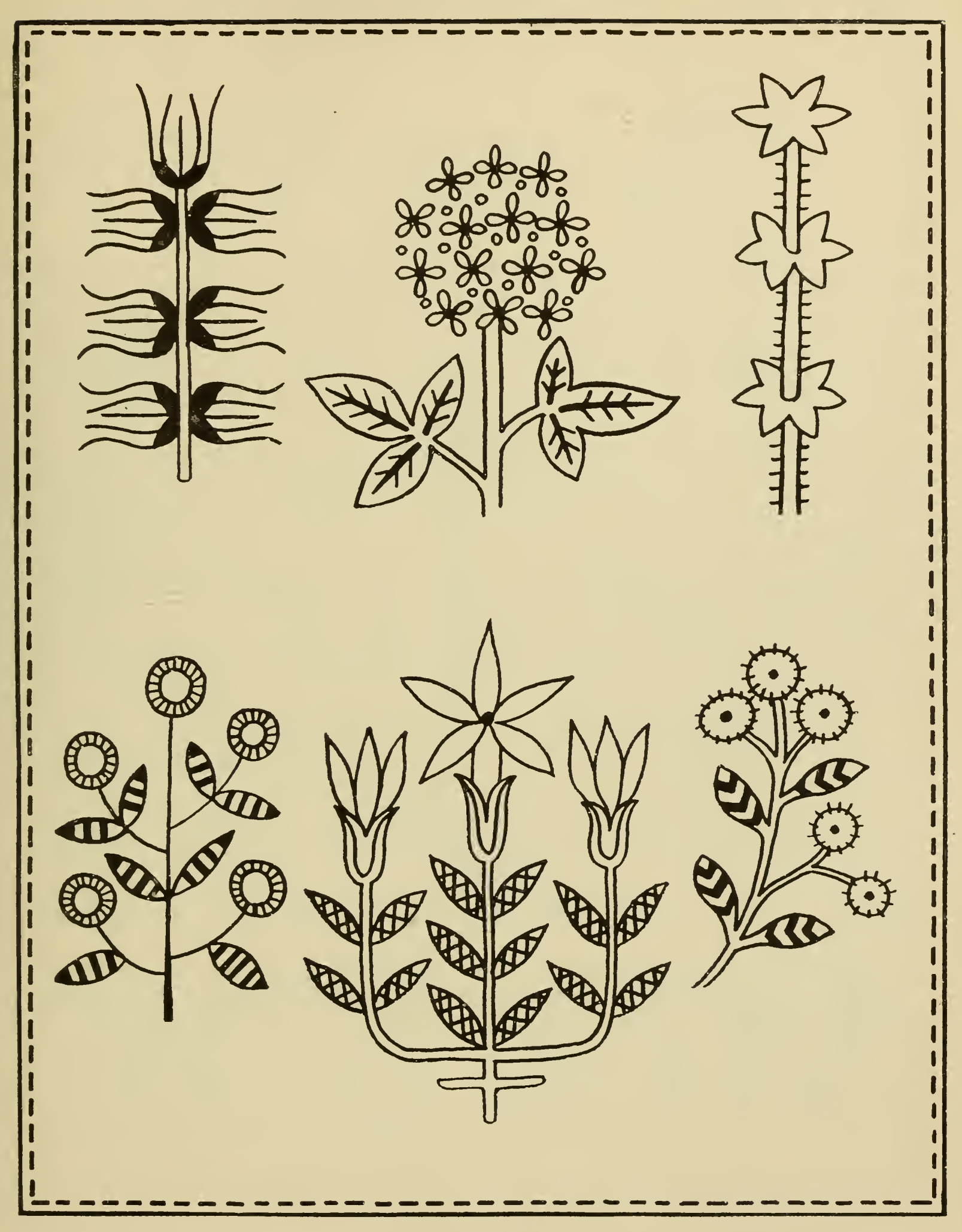




\title{
INSECTS, ETC.
}

\author{
Plate L.
}

Plate L gives a collection of small insects, butterflies, shells, etc., which might be useful for filling empty spaces in an embroidery design, and at the same time add a good deal of interest to the pattern. In the sixteenth and seventeenth centuries, the embroideress frequently introduced into her work examples of this kind with the most delightful results. A naturalistic treatment must be strictly avoided, or an unpleasant effect might be produced, particularly by too realistic a caterpillar or snail.

The caterpillar at the top of the page is outlined with buttonhole stitch, which should develop into stem stitch for the head and under part of the body; the body itself is decorated with French knots and single satin stitches. The other caterpillar is worked in ladder stitch, and the legs are suggested by fly stitches.

The top left-hand butterfly has the edges of its wings decorated with little blocks of satin stitch worked close together, while the zigzag lines could be couched into position or made with large back stitches.

The top right-hand butterfly should be embroidered with five rows of satin stitch, for which varying colours could be used, and the body would look nice worked in black and yellow.

For the bottom left-hand butterfly the solid black parts should be worked in satin stitch, while the light lines could be embroidered in stem or back stitches.

The spotted butterfly in the opposite corner could be worked with a thick outline of buttonhole stitch, and the spots embroidered in satin stitch or made with French knots.

The body of the dragon-fly in the centre of the plate could be worked in ladder or buttonhole stitch, or it could be outlined and the stripes suggested by satin stitches.

The other insects and the shells and small crab need little explanation, as the drawings themselves suggest which parts should be worked solidly and which in outline. 


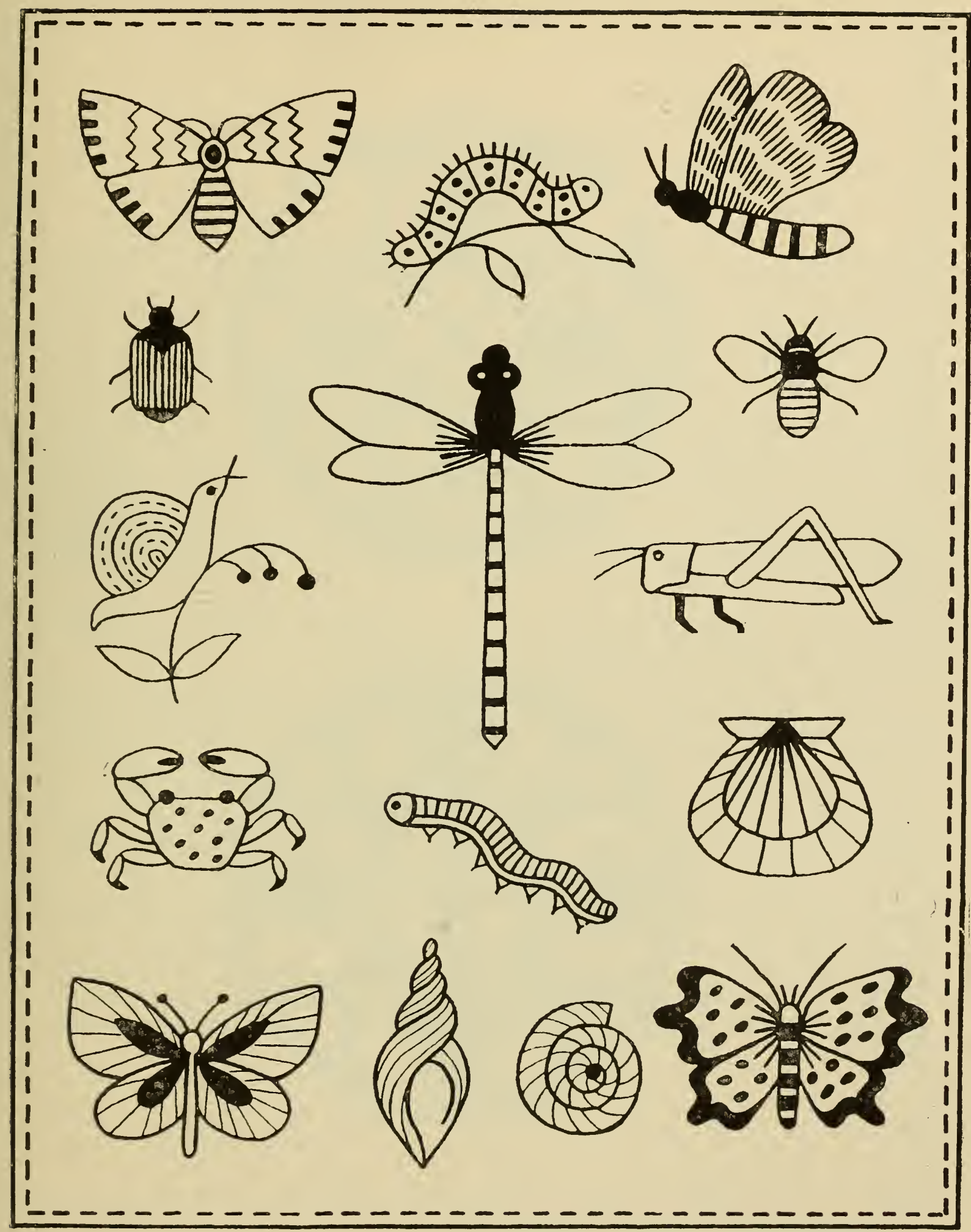

Plate L. 


\section{APPLIQUE PATTERNS.}

\section{Series 1. Plate LI.}

WE now come to a set of six plates of designs which are intended for appliqué. This is a branch of embroidery which deserves more attention than is generally devoted to it. There is something very enthralling in cutting out pieces of coloured material, fastening them on to the ground first with pins and then with tacking stitches, and finally sewing them firmly round the edge with a decorative line of embroidery or a small braid or cord; such large surfaces can be covered in this way, and such amusing patterns can be arranged for appliqué which in other forms of embroidery would probably involve too much labour and expense. There are several different methods of treating appliqué patterns; which, by the way, were used in England quite as far back as the thirteenth century-and very probably even further back still, though of this we have no actual proof, the earliest existing example being a fragment of a surcoat of William de Fortibus, who died in the year 1260 .

In other countries appliqué was used as a method of applying decoration long before we have any knowledge of it in England.

In Plate LI are shown two circular medallions, which in the originals are of leather stitched with a coarse thread. These patterns were taken from Coptic shoes of the fifth to seventh centuries now preserved in the Victoria and Albert Museum. They are naturally somewhat dilapidated in appearance, but the beauty and fitness of the decoration remains definite enough to give still further proof of the very high standard of workmanship achieved by the Copts, which is already so well recognised in their woven materials. These patterns, interesting as they are, would not have been included in this book if they had not suggested a practical application to modern embroidery. To work them again on shoes would, of course, be quite possible, particularly if the shoes were of felt, but to push a needle through two thicknesses of leather might become rather an irritating process; applied to a strong face-cloth, patterns such as these cut out in leather would make most suitable decoration for bags, cushions, boxes, or any article which had to stand hard and constant wear. 


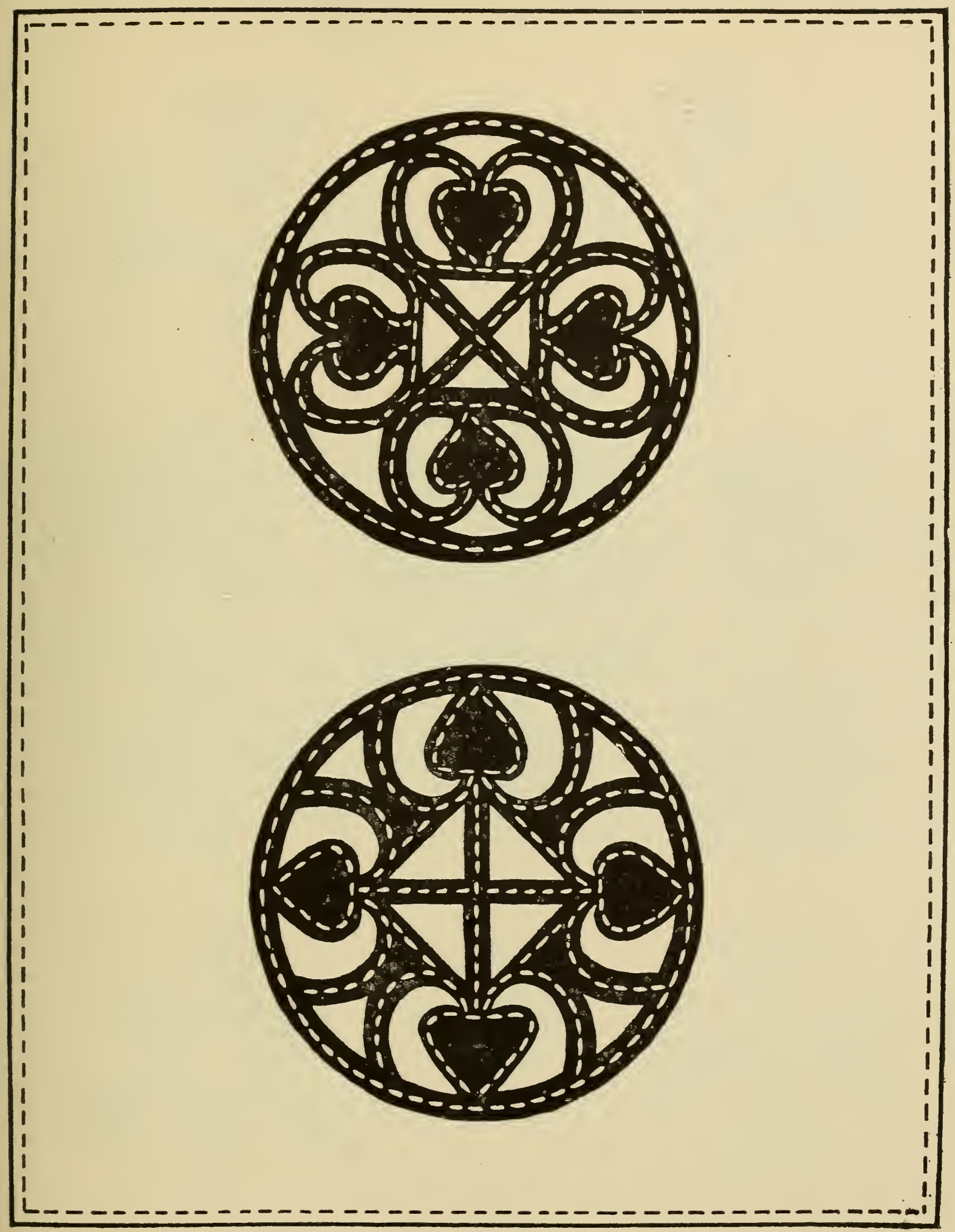

Plate LI. 
Series 2. Plate LII.

Plate LII gives some suggestions of flowers and geometrical shapes that could be easily cut out, either in leather or very closely-woven face-cloth or felt, and applied to the ground material without having the actual edges held down by couching or buttonhole stitches. This is, of course, only practicable when the applied decoration is of one of the above-mentioned materials; in any other woven substance the edges would fray out and the pattern would soon present a very disreputable appearance.

The Norwegians make very pretty little bags of white leather, on which are applied in this manner brightly-coloured flowers and leaves of felt or cloth. The method is a quick one, but it has, of course, some limitations: that of material, which we have already discussed, and certain restrictions as to shape, small serrated edges, or, indeed, any indefiniteness of outline, being quite out of the question. A primitive, almost crude, design will prove to be the most satisfactory for carrying out in this very simple method.

At the end of the book will be found a design for the cover of a circular box constructed from the patterns given on the opposite page, and adapted to the same method. (See Plate LXXIX.) 


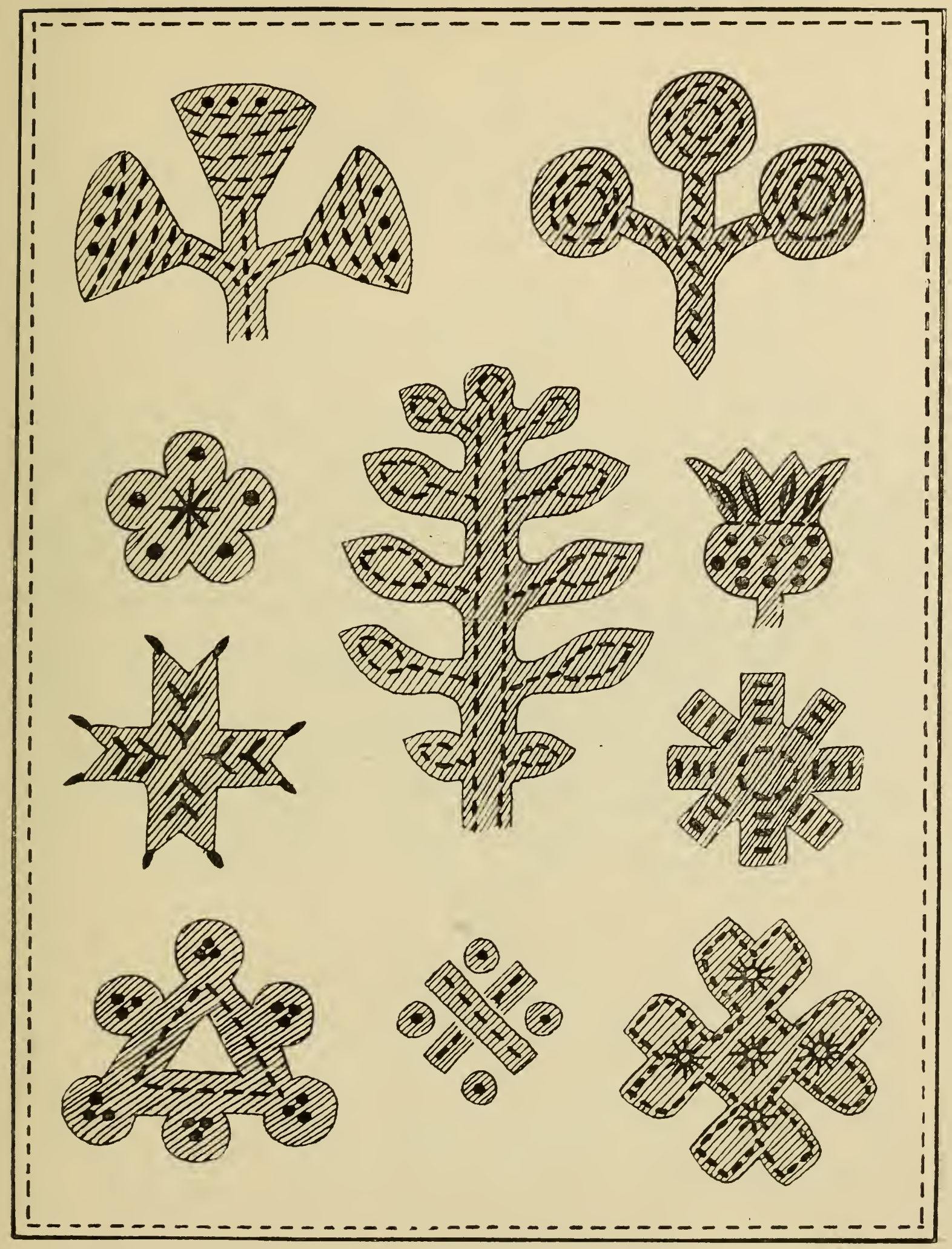

Plate LiI. 


\section{Series 3. Plate LIII.}

We now come to a more serious and accepted form of appliqué, namely, that in which the edge of the applied material is the subject of very rigid and close attention on the part of the embroideress. To prevent the edges fraying and to keep the two surfaces quite flat and unpuckered are the only vital considerations to the worker in embroidering an appliqué pattern. A frame is often used for this method of work, but if the pattern is carefully tacked on it is quite possible to work it in the hand; in fact, if the stitch used for covering the edges is buttonhole, it is obvious that it must be done in the hand, as this stitch cannot be worked in a frame.

One of the most usual methods is by couching several threads all along the edges of the pattern, and this is the case in Plate LIII. Designs such as these could be adapted to cushion-covers, bags, or bed-spreads; the borders (enlarged) could be worked on a small table-cover or cushion.

Linen is one of the most suitable materials for appliqué, and for washing purposes is practically the only one that can be used with safety; casement cloth has a very poor appearance, and, in fact, all cotton materials are much too flimsy to be suitable for patterns of the type given in Plate LIII. 


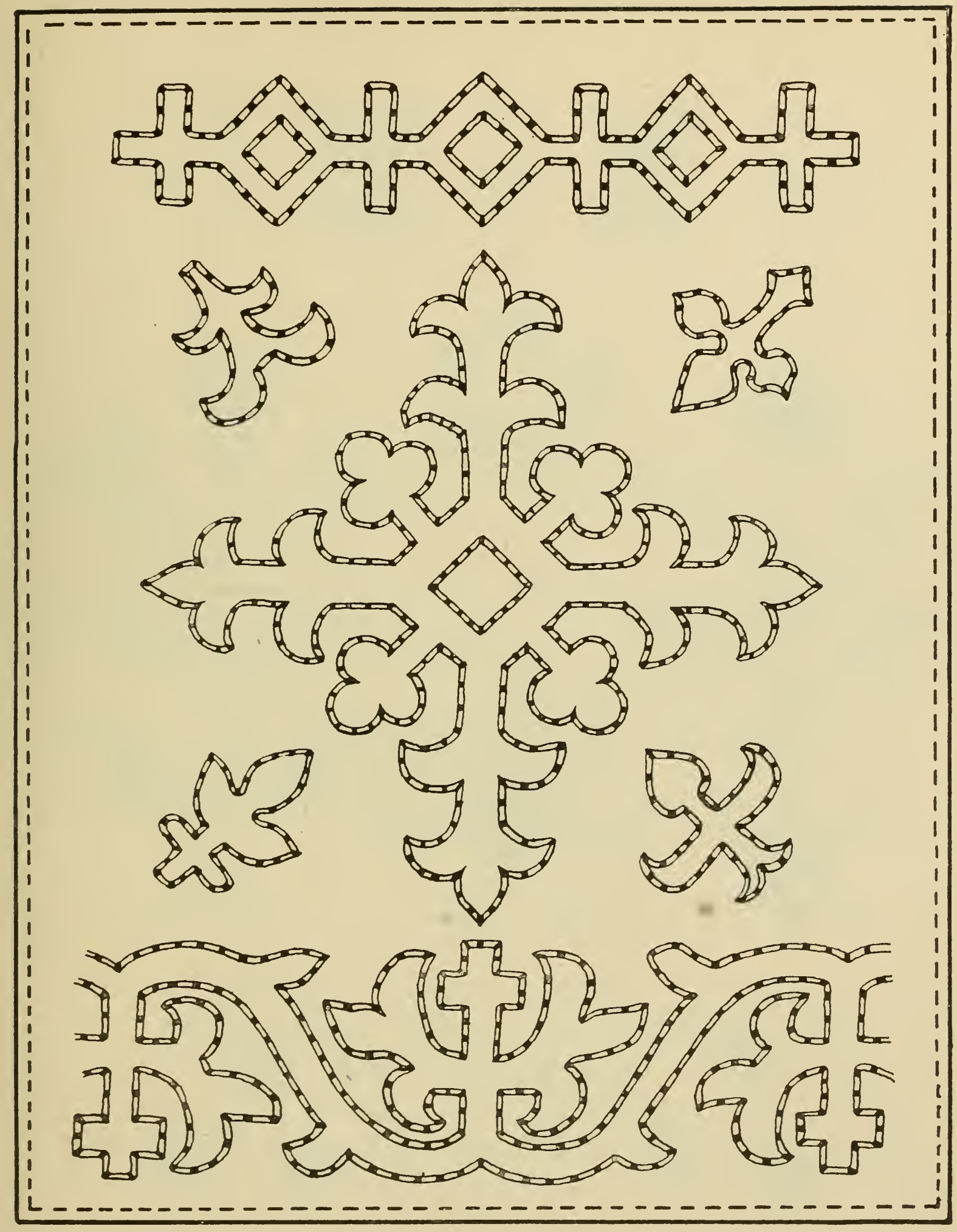

Plate LIII. 
Series 4. Plate LiV.

The set of patterns in Plate LIV will no doubt more readily suggest the use of velvet or silk for appliqué purposes. For certain richer forms of decoration these materials give a very beautiful effect, but they belong more especially to the realm of frame work, and objects devoted to the uses of the Church. Still a large field is open to their use in the more elaborate forms of secular embroidery.

The sprigs and borders in Plate LIV are composed of small pieces of applied material held in position by a fine couched cord (an eyeglass cord will do beautifully for this, but it can only be obtained in black). In these patterns the outline forms a very important part of the design, being entirely responsible for the stems, and for combining into an organised whole the isolated pieces of applied material.

It is quite possible to arrange patterns such as these with washing materials; a small cotton braid or cord will hold the appliqué in place as well as any other method, if it is carefully couched; on the other hand, if the embroideress wishes to make use of velvet or silk for appliqué purposes a fine silk cord will make a particularly suitable outline. 


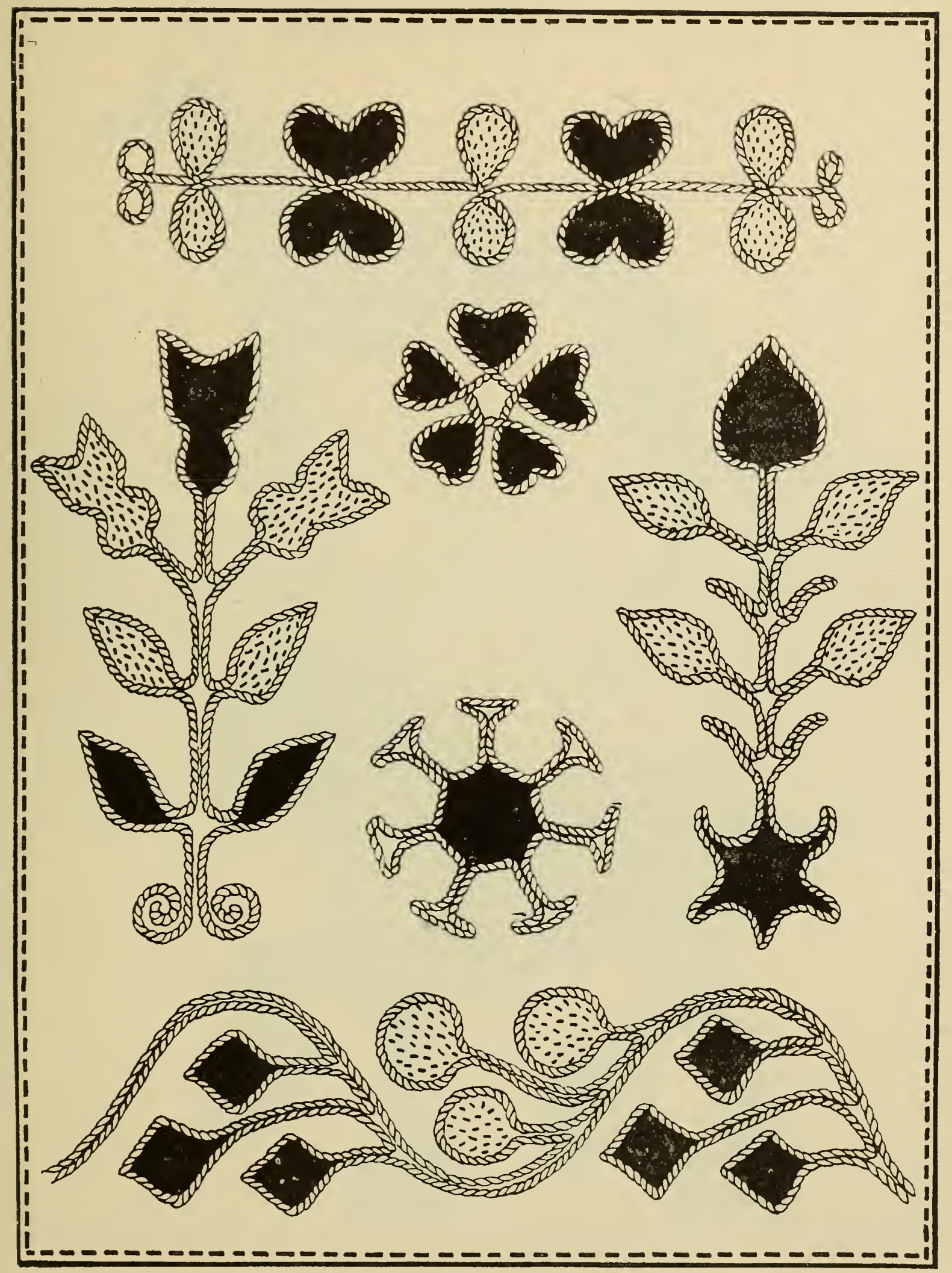

Plate LiV. 
Series 5. Plate LV.

The greyhound and cart-horse illustrated on Plate LV are, of course, intended to decorate some article which is going to be either seen or used by children. Appliqué animals are a most appropriate form of decoration for a "pram-cover" or cot-quilt, and they often prove a useful distraction in moments of anxiety in or out of the nursery. A row of animals arranged along the edge of a tablecloth or curtain, or placed as a frieze along the top of a folding screen, will not only prove of great interest to the young occupiers of the room, but might even end in becoming of some educational value. If they are well drawn, they will help the child to notice the most important characteristics of the different animals, and he will unconsciously compare his own belongings. with the live original when he meets it out of doors.

As everything to do with the furnishing of a nursery should be of a washable nature, linen is the most suitable material; for a dark " pram-cover," which would be less frequently washed, coloured cloth or flannel might be used. Any of the animals illustrated further on in this book, and most of the birds, with a little simplification, could be arranged easily enough for appliqué designs. Such details as the claws of the birds and the mouse's tail, etc., would, of course, be worked afterwards in some simple embroidery stitch. 


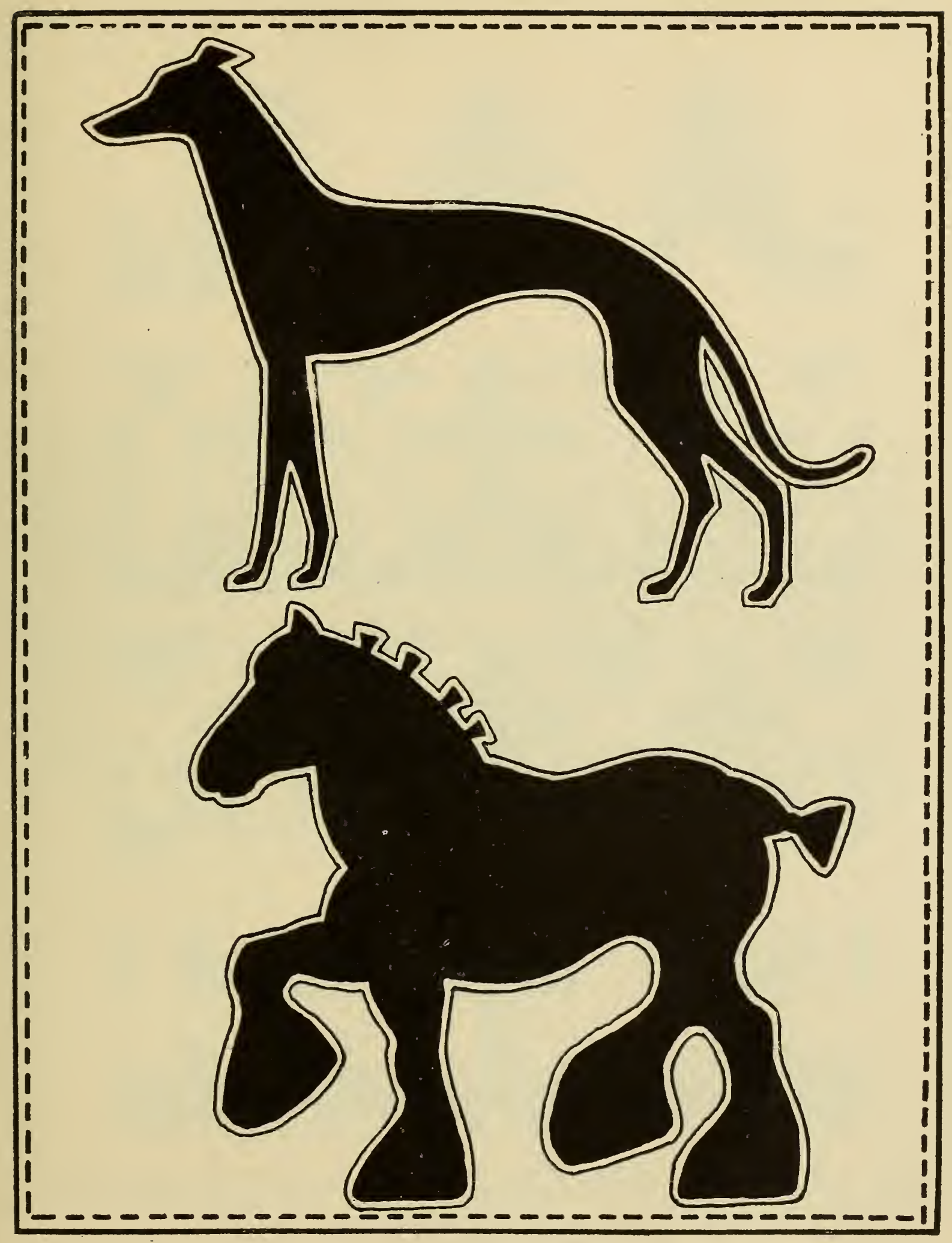

Plate LV. 


\section{Series 6. Plate LVI.}

Amongst the patterns suitable for appliqué have been included four borders constructed on the principle known as counterchange. In a true counterchange design both the ground and the pattern are identical in shape and size. The straight, steady lines which form such an essential part of these designs, and the ease with which they can be arranged into continuous borders or repeating patterns, make this construction particularly suitable for forming the basis of an appliqué design.

The borders shown in Plate LVI could be applied as a decoration to curtains or tablecloths, and, combined with floral motives, they could be arranged round a bed-spread, or if repeated so as to form an all-over pattern, they would make beautiful designs for cushions or the seat of a chair, etc. For this purpose, the ground material might be embroidered with darning or running stitches, or some other light form of decoration. By this means a very subtle effect of tone will be obtained which will add considerably to the richness of the completed design. 


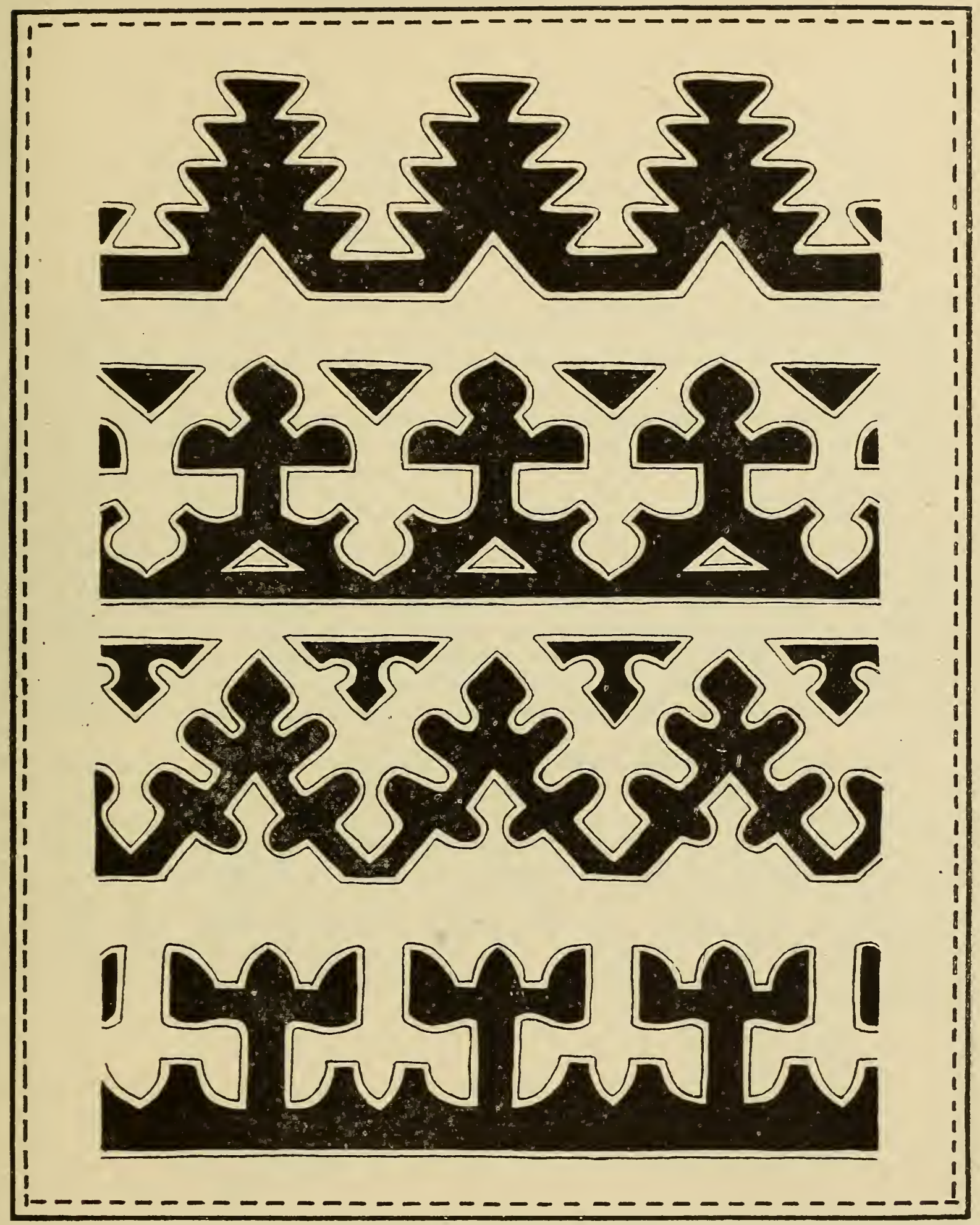

Plate LVI. 


\section{ANIMALS.}

\section{Series 1. Plate LVII.}

Plates LVII-LIX illustrate some examples of animals which, by their decorative characteristics, lend themselves easily to reproduction in embroidery. As with flowers, so it is with animals and birds- the simpler well-known varieties are always the most satisfactory to use, partly because there is nothing exaggerated or grotesque in their outline, and partly because it is more interesting to embroider objects with which we are quite familiar; for by actually observing them we can often gain fresh suggestions for treatment in embroidery.

The animals in the three following plates have all been drawn more or less in outline, for the method of work will so much depend on the character of the whole design, of which they form only a part, that it is impossible to say definitely which is the best way of embroidering any particular animal. But, whether they be worked solidly or in outline, the embroidery stitches should exaggerate rather than diminish the essential characteristics of the animalfor instance, a hedgehog must of necessity look very prickly and a small pig smooth, while a lamb is invariably associated with a woolly fleece and thick legs.

The hedgehog in Plate LVII, with the exception of the face and feet, is suggested in detached satin stitches, while the mouse could be outlined in stem stitch and filled in with small running stitches; satin stitch would give a nice smooth effect for the tail. The squirrel could be worked in overlapping rows of satin stitch of varying colours, or it might be treated with lines of stem stitch worked fairly close together; but in any case the bushy tail must be strongly accentuated. The two rabbits, if worked solidly, must have white tails, and the one in profile a white front also, but they lend themselves particularly well to an outline and powdered treatment as suggested in the drawings. 


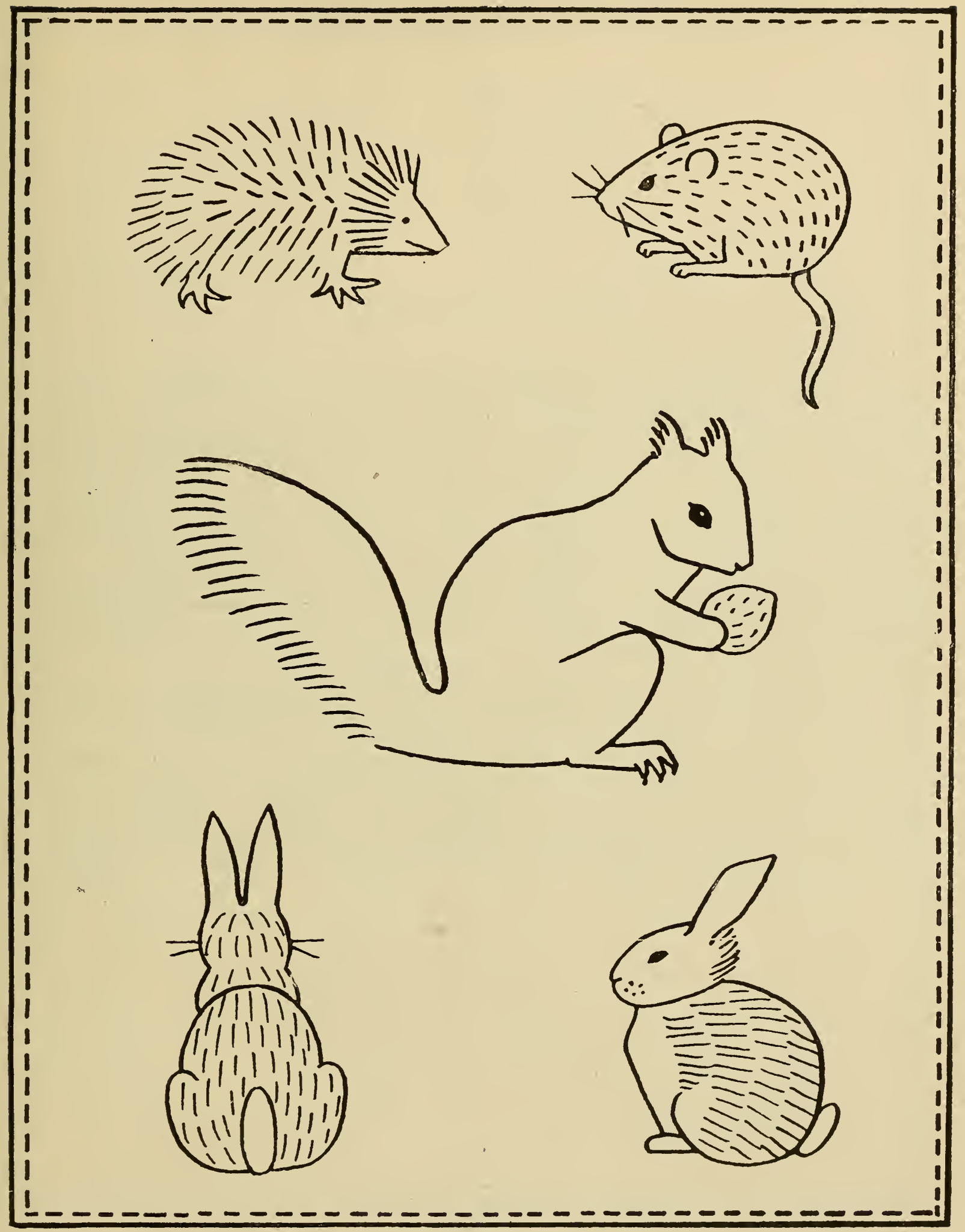

Plate LVII. 


\section{Series 2. Plate LViII.}

The small pig illustrated in Plate LVIII would look very well cut out in black linen for an appliqué design, but, if it were worked in outline, the body could be decorated with patches like those of the young calf; or for a solid treatment rows of buttonhole stitches worked rather close together would do very well. The deer suggests a more graceful treatment. The embroidery stitches if worked closely should follow the direction of the outline, and any markings should be arranged, as in the plate, on the upper part of the body, while the under part must be unmarked and worked in a lighter colour.

The cat could be suggested with a broken outline to indicate the fur, or with a simple one as shown in the drawing; for a tabby cat stripes of dark and light colour could be arranged across the legs, and the toes, ears and nose embroidered with a black thread.

The calf could have a few French knots arranged on its forehead to suggest its very characteristic fringe; apart from that it would probably look best in outline, with the addition of some patches of colour to the body. The lamb must have a broken outline to its coat, and this would be most easily suggested with French knots (see Plate LXXX), which can either be placed close together all over the body, or merely dotted over it. The drawing of the nose and mouth would be best suggested in back stitch, using a black thread. Black could also be introduced in working the eyes and feet. 


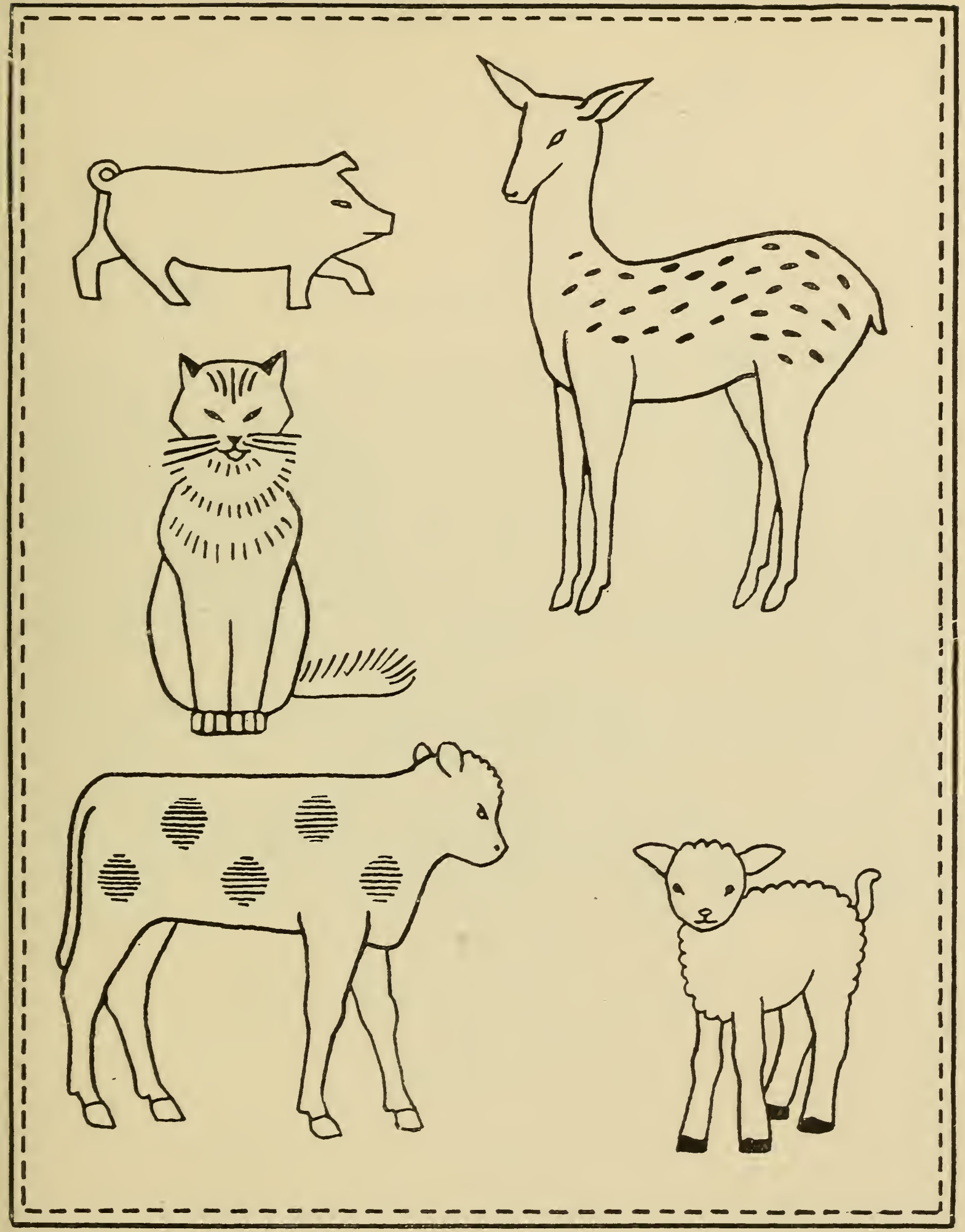

Plate LVIII. 


\section{Series 3. Plate LiX.}

The frog in Plate LIX could be worked in bright green or gold-coloured silk, and its eye must be black and staring. Its markings are very characteristic, and can be made much of in embroidery. As is the case with practically all animals, the under part of the body is much lighter than the upper part, so that if the frog is worked with stitches set closely together, there should be an opportunity of introducing a change of colour from green or gold to a creamy tint. The lizard is much the same as to colouring; the principal markings come down the centre of the back, and the toes could be worked in detached satin stitches or close back-stitching.

The grass snake should not be worked solidly unless it forms part of a very elaborate scheme of embroidery, but if worked in outline with the small markings suggested in a bright colour or black, the effect would be very decorative.

The fish is only one of many types that are suitable for embroidery designs, but in all cases the scales must not look so heavy in effect as the outline. A good deal can be made of the eye, which is always an important feature in a fish.

In Coptic woven patterns, splendid fishes and animals of various kinds can be found, which should be very useful in demonstrating to a student how to retain all the most important characteristics of an animal while eliminating unnecessary details. 


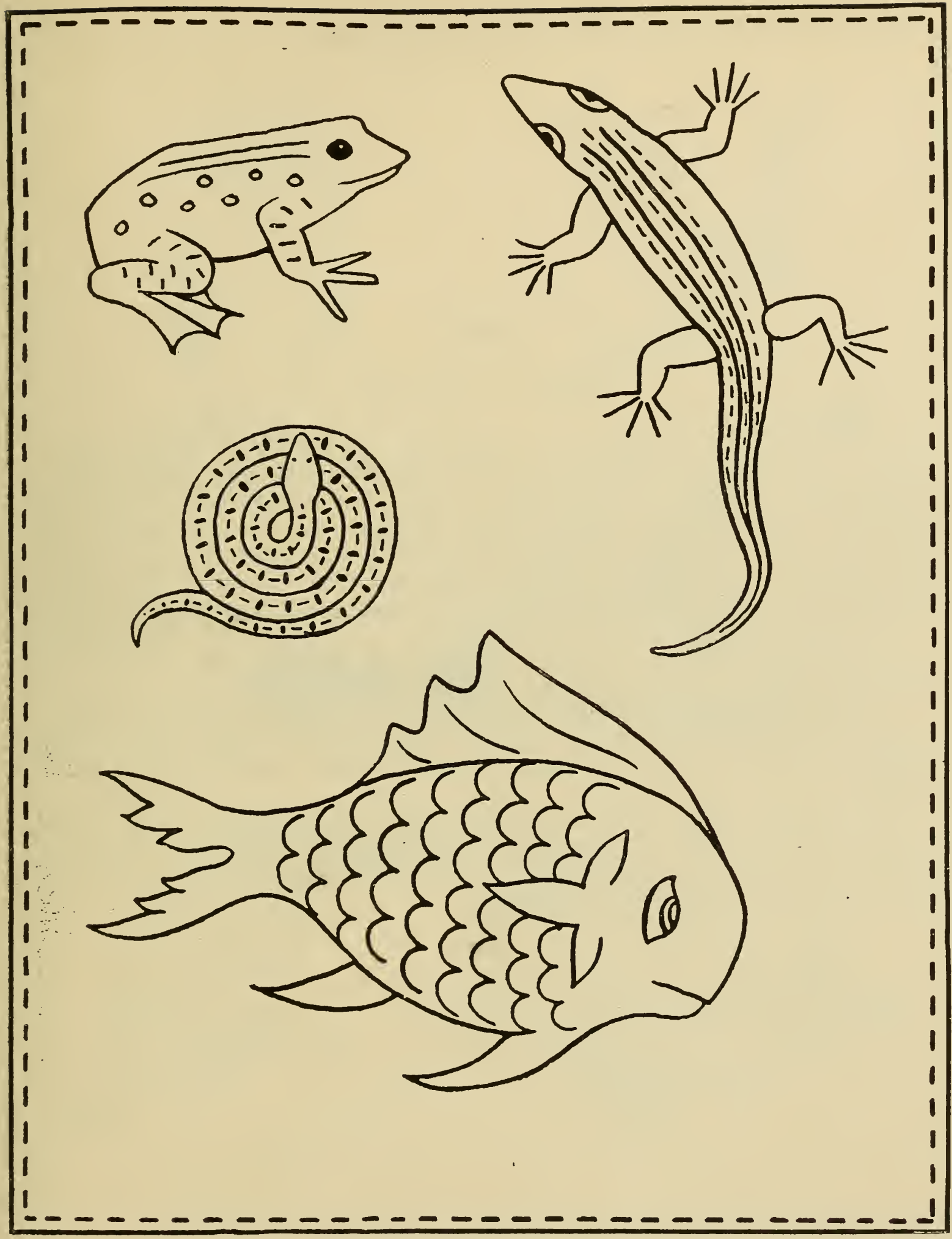

Plate LIX. 


\section{BIRDS.}

\section{Series 1. Plate LX.}

THE owl, illustrated in Plate LX, should have a buttonhole wheel embroidered round each eye, and the eye itself worked in solid satin stitch, with or without the addition of the high light. The breast could be decorated with small fly stitches, or two single stitches worked into the same hole. The little wren in the top right-hand corner should have two rows of open buttonhole stitch worked to suggest the wing feathers, with a touch of solid colour at the tips; and the breast is covered with running stitches worked in lines.

The flying wild duck in the centre would be a very suitable bird to carry out in appliqué, and a whole flight of them could be very well arranged as a decoration for a nursery window-curtain.

The kingfisher has been suggested in more or less parallel lines of embroidery, which are crossed on the head by small stitches placed at right angles to the outline; the beak could be worked in satin stitch with a dark brown or black thread.

In the case of the duck in the right-hand corner, the markings on the breast could be carried out like those already referred to on the owl, the beak and feet might very well be embroidered in an orange-coloured thread, and the eye in some dark colour or black. 


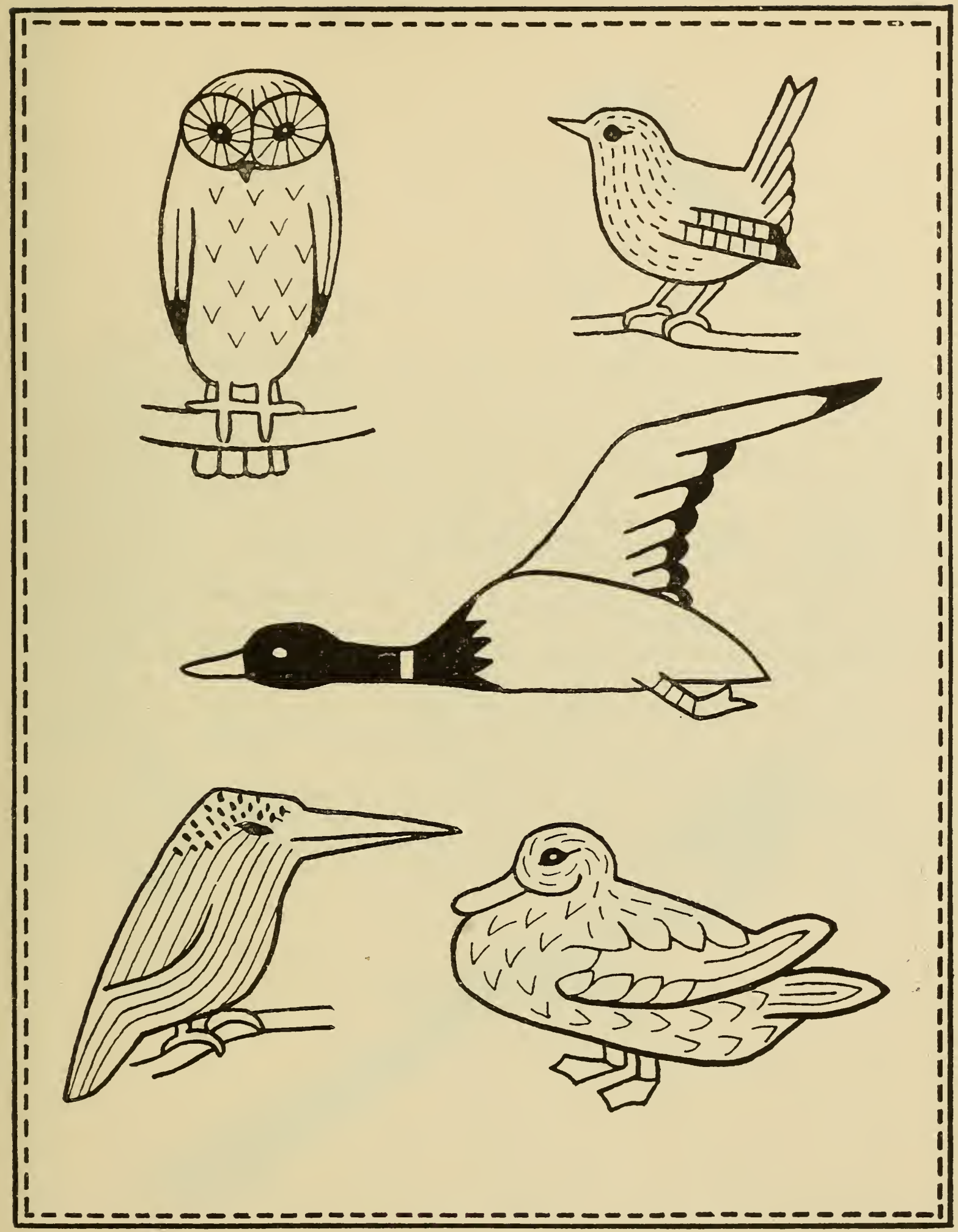

Plate LX. 


\section{Series 2. Plate LXI.}

The sparrowhawk, illustrated in Plate LXI, being naturally a large bird, should not be used for an embroidery design unless it is on a fairly large scale. For anything in the nature of a hanging, this hawk, in conjunction with other birds, such as the magpie illustrated at the bottom of this Plate and the jay in Plate LXII, would look very decorative perched about the branches of a variegated tree. The lines in the drawing indicate the typical markings of a sparrowhawk. The eyes and claws should be of a bright yellow colour, which forms a fine contrast to the drabs and whites of the feathers.

The stonechat in the top right-hand corner is a very useful little bird for embroidery designs. If it is worked solidly, the breast must be embroidered in light-coloured threads, for this is one of its principal characteristics; the legs and claws are very thin and should be worked with a single line of stitching, and the tail must end in a sharp point.

Although the goldfinch, which is busy with a worm, is a bird with which most people are familiar, a student who intends to embroider one should first of all study the arrangement of the colour.

The magpie, though it has a beautiful sheen on its feathers, can be safely treated in black and white, and, because it is so definitely black and white, a good deal of solid embroidery is needed to give the right effect. If it is worked on a white ground, the black feathers only need be embroidered, and the white ones could be suggested by the material. 


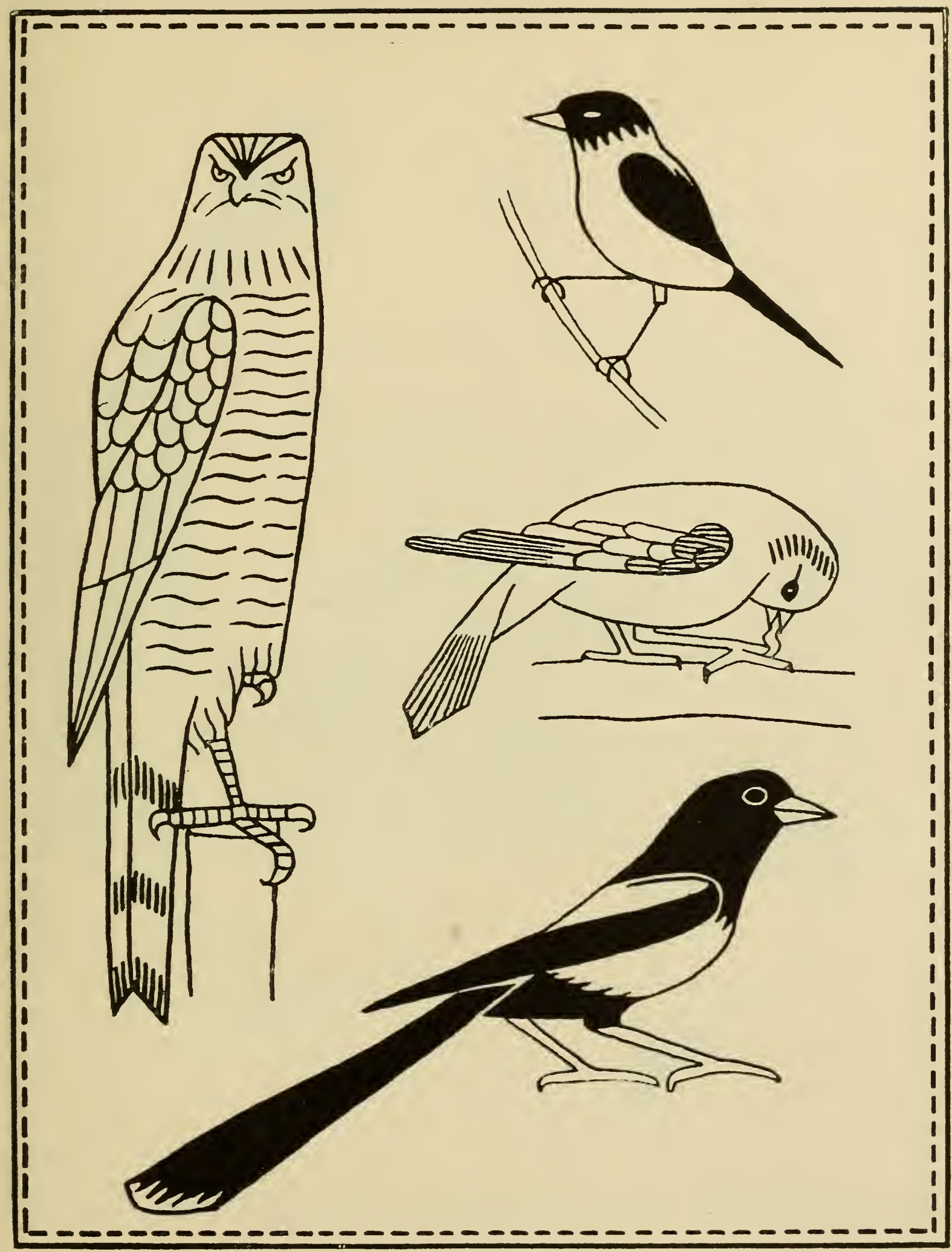

Piate LXI. 


\section{Series 3. Plate Lxil.}

The swallow shown in Plate LXII should be embroidered in dark blue and cream-coloured thread, with a patch of terra-cotta on the throat.

The white lines on the wing are put there merely to indicate the direction of the feathers. The tail could be embroidered in fish-bone or Roumanian stitch, and the rest of the bird principally in overlapping or long and short satin stitch.

The jay, next to the swallow, must have a light blue eye with a black spot in the centre, and blue and white stitches on the wing.

The flying tomtit in the centre of the Plate should have the wing and tail feathers worked in buttonhole stitch.

The robin is so well known a bird as to need no discussion as to colouring; the eye should look fairly important, and the claws and beak must be thin and sharp.

The blue-tit, hanging from a branch in a very characteristic position, has naturally beautiful colouring which should be carefully studied.

A student wishing to obtain information about good colour, or suggestions for new schemes, could not do better than study butterflies and birds, amongst which she will find the most daring and the most subtle arrangements of colour imaginable. 


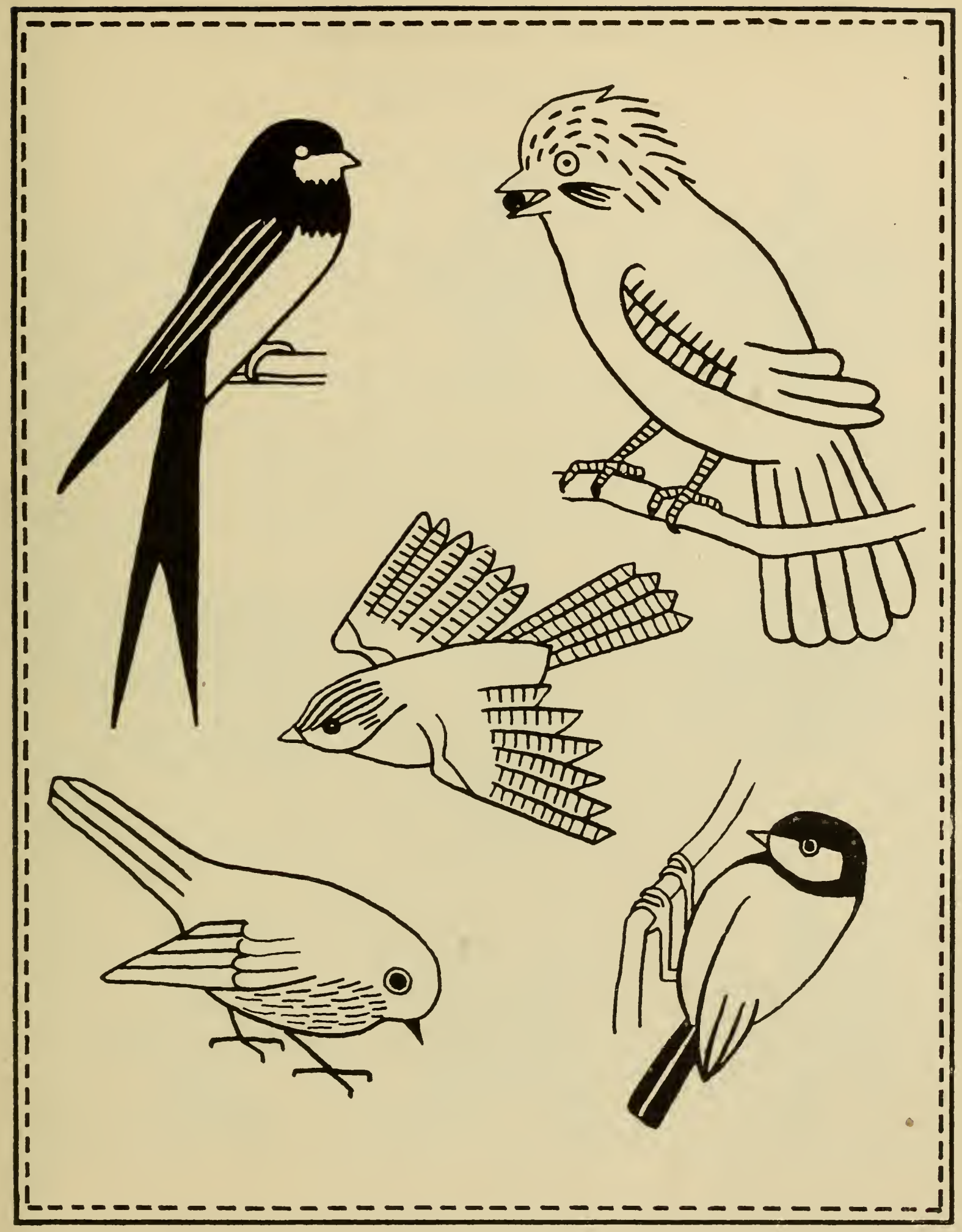

$9-(880 \mathrm{~A})$

Plate LXII. 


\section{INTERLACING KNOTS.}

\section{Group 1. Plate LXiII.}

INTERLACING knots and borders were used in English embroidery designs as far back as the reign of Henry VIII. It is only necessary to study the reproductions of his portraits, showing him clad in splendid tunics and breeches, braided and embroidered with gold and silk, to find that much of the decoration was supplied by the use of a fine cord twisted and couched into beautiful interlacing patterns.

For weaving and other branches of handicraft, interlacing patterns were used long before this in various parts of the world. The Celtic strap-work, for instance, is well known to most people, but the amazing intricacy and distinctly national character of these designs make them quite unsuitable material from which to build up modern embroidery patterns.

The Copts living in Egypt from the first to the seventh centuries A.D. perhaps knew better than any other people how to make use of interlacing lines in pattern designing.

There have been many books written on this subject, and in the Victoria and Albert Museum are some actual pieces of weaving and embroidery. The Coptic designs are so simple and masterly in conception, and so free from affectation, that they might well become a very fruitful source of inspiration to an embroidery designer, particularly if the pattern was intended to decorate such articles as a table cover, hanging or cushion.

Interlacing lines and knots, and also their relationship to embroidery designs, have been discussed in this book from four different points of view. First, the small interlacing knot, which can be used either as a spot pattern. or combined in a border with some floral pattern to which it will form a sharp contrast. Second, the larger interlacing knot, which might form the centre of a radiating design, and from which other geometrical or floral shapes may spring. Third, the interlacing border; and fourth, and last, the repeating interlacing pattern. On Plate LXIII are shown nine small interlacing knots. Some of the lighter ones alternating with sprigs of flowers would make very nice powdered patterns for a little girl's dress. Others would just fit the corner of a collar. An interesting design for a belt could be made with some of the heavier-looking knots by arranging them at intervals of $2 \frac{1}{2}$ " to $3^{\prime \prime}$ along the belt, and filling the intervening spaces with one of the curved bordersillustrated on Plates XXXI-XXXIV. The stitches in which these knots can be worked are numerous, but they, of course, depend on the character of the design, and the quality of the ground material upon which they are going. to be embroidered. 


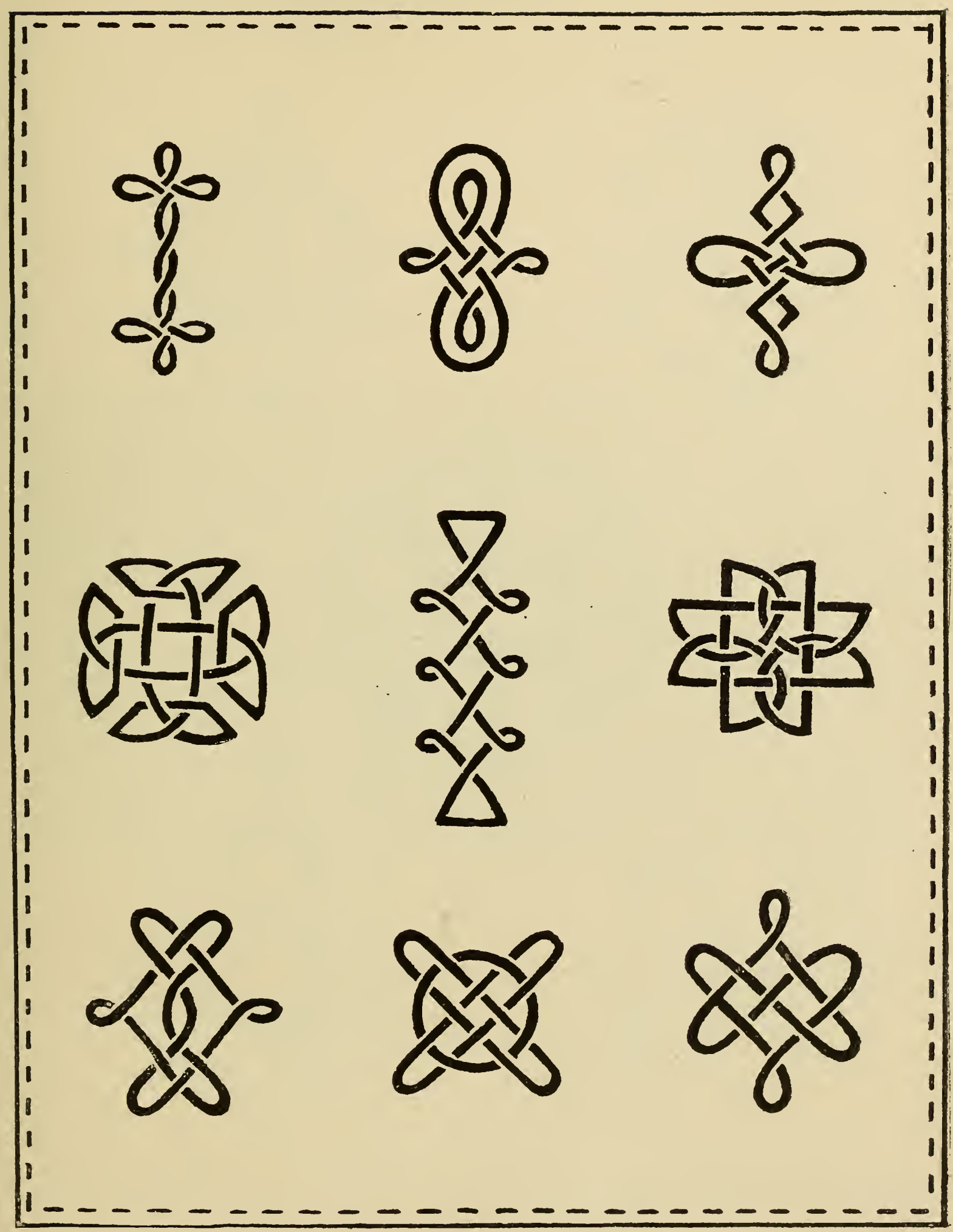

Plate LXIII. 


\section{Group 2. Plate LXIV.}

Interlacing knots of the type shown in Plate LXIV might very well be enlarged to twice the size of the originals. In this form they make a most excellent basis for simple embroidery designs suitable for decorating bags, blotters, pockets, nightdress cases, and so on. It is the easiest thing in the world to enrich them with a few floral sprays or geometrical stitchery, and in a surprisingly short time the embroideress will find that she has created quite an interesting pattern in the simplest possible way. (See Plate LXXXI.) The lines which make up an interlacing design can be embroidered solidly or in outline.

The use of several threads couched with a contrasting colour is particularly suitable; or German knot stitch, backwards chain, close fish-bone-any stitch, in fact, which makes a good clear line-may be employed. If a broken effect is needed, open buttonhole or fern stitch would both do very well; for a lighter treatment, back stitch, coral, chequered chain, and so on. The possibilities of stitch and arrangement of colour are endless, and afford plenty of scope for the taste and imagination of the embroideress. With the exception of the centre knot on the opposite page, all of them might be carried out in two distinct colours, and thus any confusion in the interlacing would be prevented. 


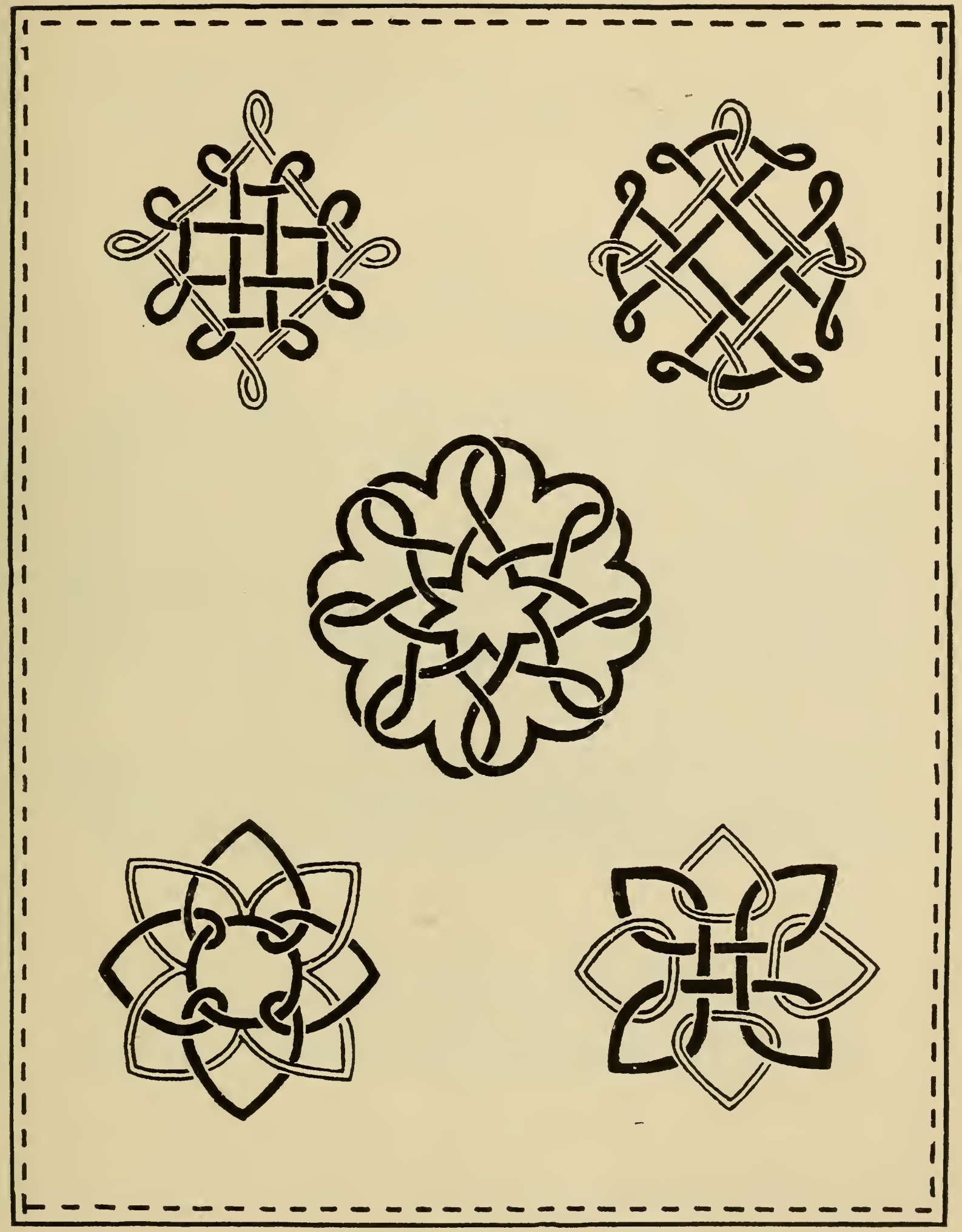

Plate LXIV. 


\section{INTERLACING BORDERS.}

\section{Plate LXV.}

ONLY a few very simple varieties of these borders have been given in this book, for more complicated ones are tedious both to arrange and to carry out. Those on Plate LXV might be traced or copied exactly the same size as the originals, or considerably enlarged to suit a design on a fairly big scale.

During the seventeenth century, in England, very beautiful patterns were made with a fine white cord couched on white linen. An interlacing border, if it were continuous, would lend itself particularly to this treatment, and would make a most effective trimming for the collar and cuffs of a white blouse, or for decorating an afternoon tea-cloth or tea-cosy. For borders carried out on a larger scale, a fine French tape, couched with threads of a different colour, would be extremely nice; for household linen a blue and white effect always looks well, and, if linen threads were used for the couching, would be sure to wash well also. The borders in Plate LXV are combined with small stitchery patterns, but these could be omitted if necessary or developed into a more important form of decoration. In any case they will certainly be found useful for introducing some variety of colour into the designs. 


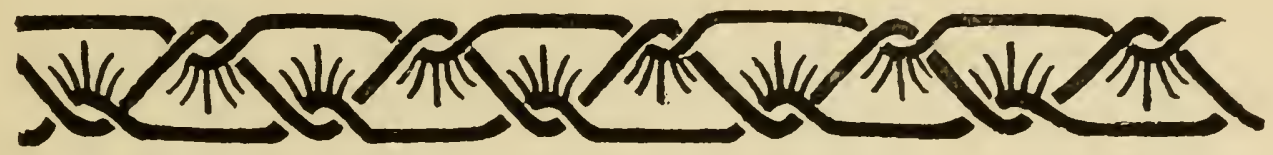

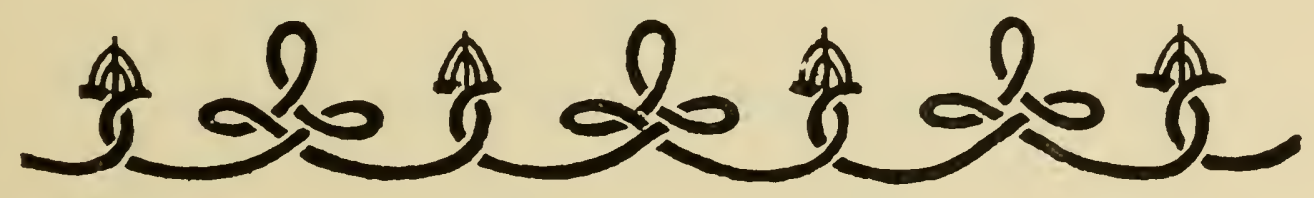

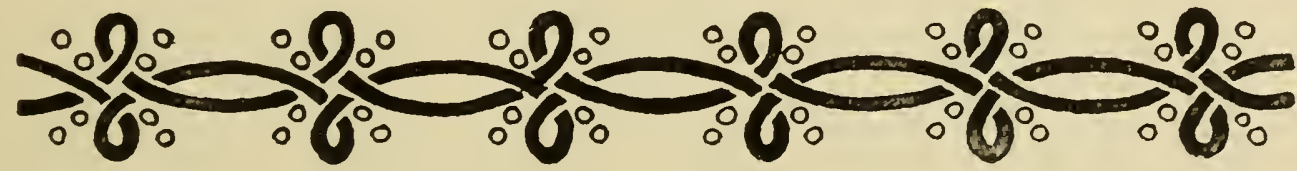
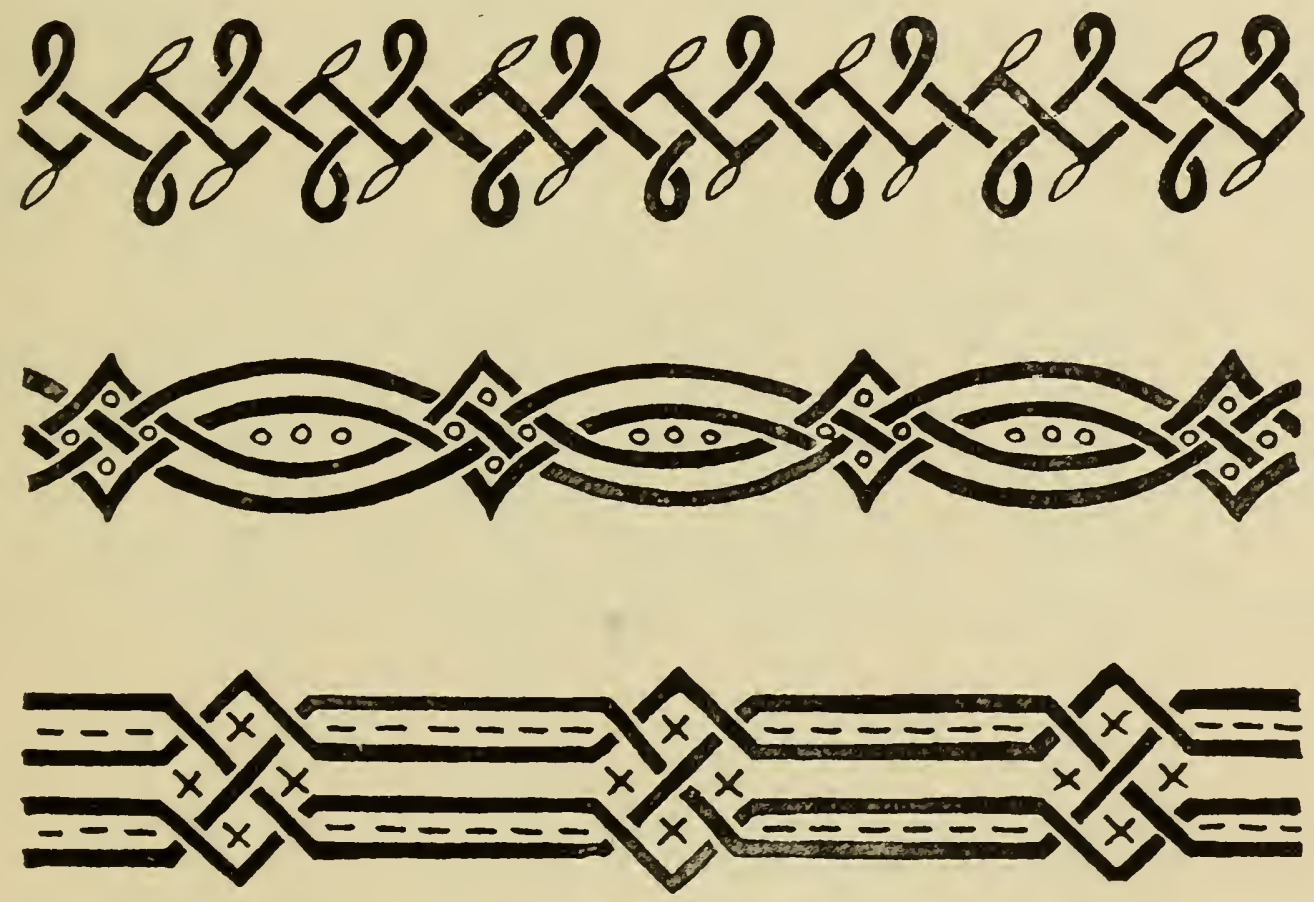

Plate LXV. 


\section{REPEATING INTERLACING PATTERNS.}

\section{Series 1. Plate LXVI.}

THERE are four repeating interlacing patterns given in this book, two of them constructed with the aid of a ruler and the other two with a compass. In both cases it is necessary to be very accurate in planning a design of this kind, for its main beauty lies in the straightness and symmetry of the geometrical setting.

An all-over interlacing pattern can be applied to many different articles, such as bags, waistcoats, " pram-covers," cushions, curtains, stools, etc. Used alone, these patterns might be just a little monotonous, but in conjunction with some other type of decoration, to which they form an austere setting, their possibilities are endless.

The upper design in Plate LXVI is composed of a network of lines and a decorative square design. This might be replaced by some other variety of square or flower, which could be selected from some of the earlier plates in this book. (See Plates XX, XXI, XLIII, XLIV.)

The same thing applies to the other design; the light subsidiary pattern can be altered and rearranged so as to suit the particular taste of the embroideress who is going to use the interlacing setting. There is only one pitfall to guard against in changing these patterns-either the interlacing must be lighter than the inset decoration, as is the case in the upper design on the opposite Plate, or it must be heavier, as in the lower one; for if the patterns are of equal weight and importance, the result will be most confusing. 


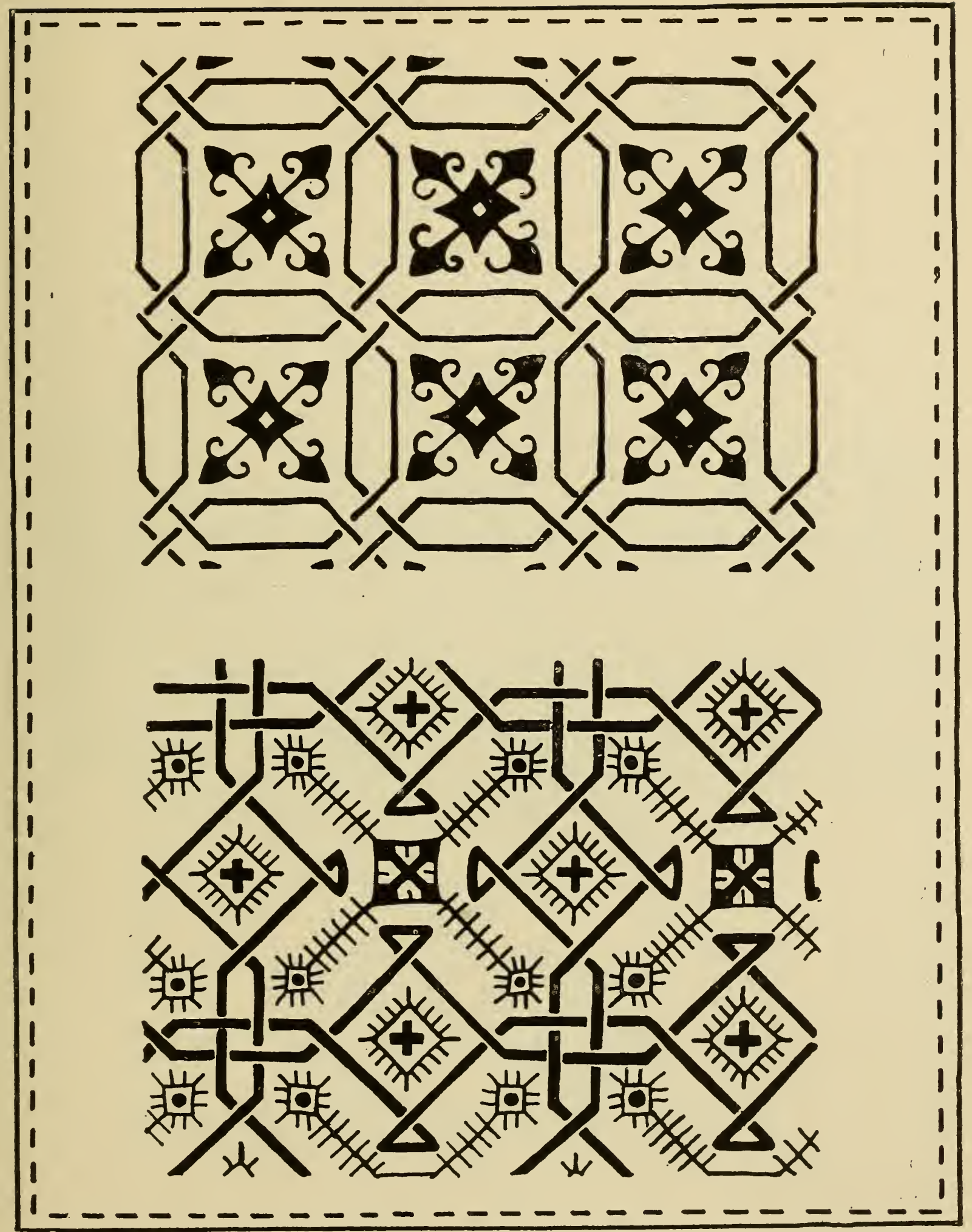

Plate LXVI. 


\section{Series 2. Plate LXVII.}

The two interlacing patterns illustrated in Plate LXVII can be reproduced almost entirely by the use of a compass.

The upper one is really constructed with overlapping circles, which are broken at four points to form an interlacing knot.

The lower one is composed of three circles of varying size. The solid black ones are complete, but the other two, one small and the other very large, are broken and made to appear as if they were part of one continuous line.

The only addition to this particular design is a powdered pattern of running stitches, which not only produce a very subtle effect of tone, but accentuate certain portions of the ground, and so prevent any confusion of the interlacing pattern.

In the other design, the flower is shown in outline and the interlacing lines solid, but this arrangement could easily be reversed, or a different flower substituted for the one already suggested. 


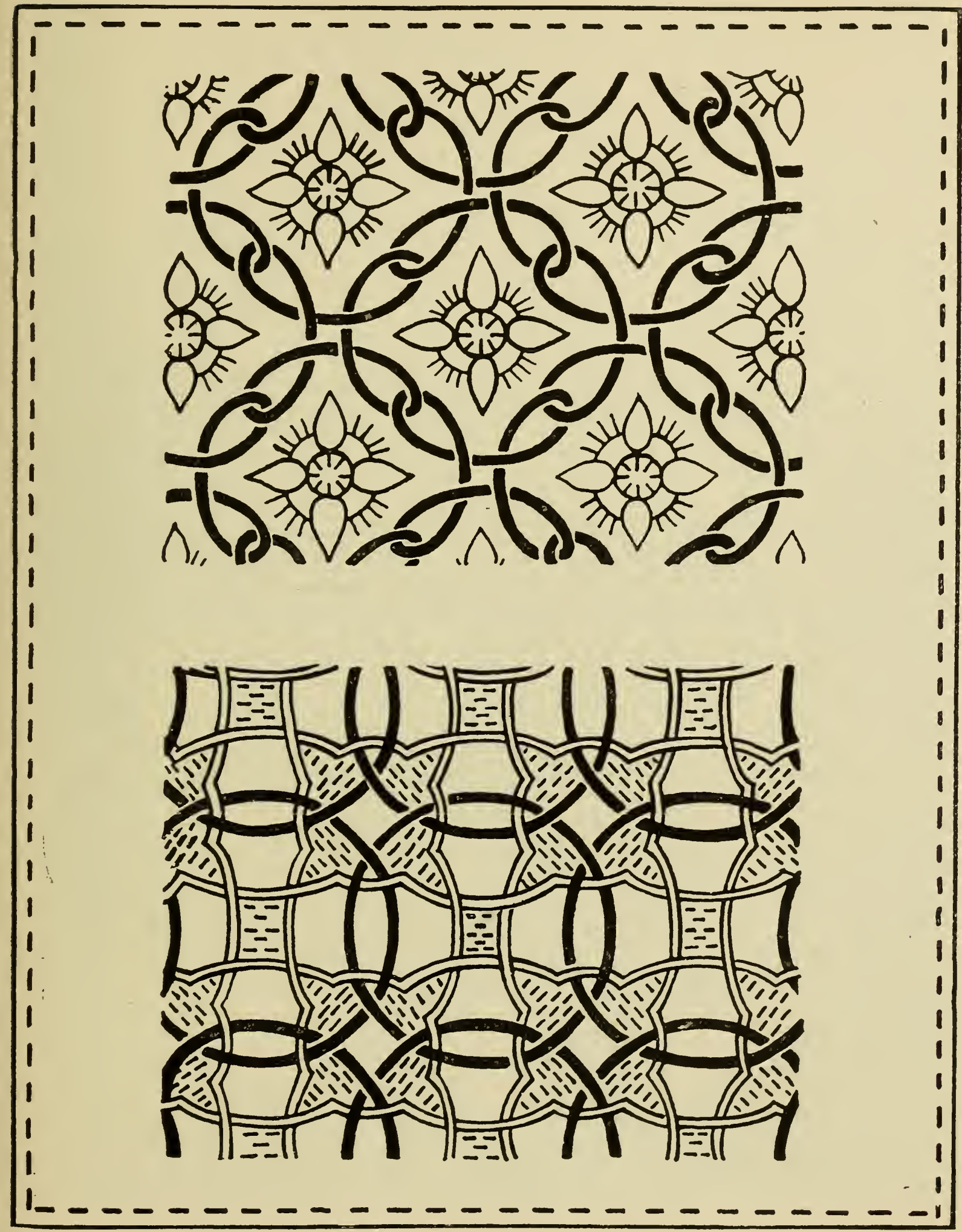

Plate lXVII. 


\section{A ROMAN ALPHABET.}

\section{Plate LXVIII.}

THE embroidered initials and monograms which are described on pages 144 and 150 are all drawn from either Roman or tenth century capitals.

For marking purposes these two alphabets are quite the most satisfactory ones to use, as they are so clear to read and so unexaggerated in proportion. Unfortunately, many people seem to think that a monogram is never really ornamental until it is so tortured out of shape as to be hardly recognisable. Some of the later Gothic characters now usually associated with Church work are really very confusing, especially if they are combined with some floral decoration.

The letters of the Roman alphabet illustrated on Plate LXVIII, if reduced in size, are particularly suited to marking handkerchiefs o $i$ any small dainty article of linen; on the other hand, they can be used equally well on a larger scale as seen in the cross-stitch $\mathrm{E}$ and $\mathrm{S}$, and the AWB in knotted stitches on Plate LXX. For large monograms the tenth century alphabet is undoubtedly more satisfactory. If only a single initial is needed, the student will be able to trace one directly from the book, but a monogram needs some experimenting, and two or three different arrangements should be tried before commencing the embroidery. To prevent confusion, the initial of the Christian name is often made smaller than that of the surname, and if the letters interlace, as is the case with the $\mathrm{CL}$ and $\mathrm{NH}$ at the bottom of Plate LXVIII, they should be so arranged that the initial of the Christian name is brought more into prominence than that of the surname. 


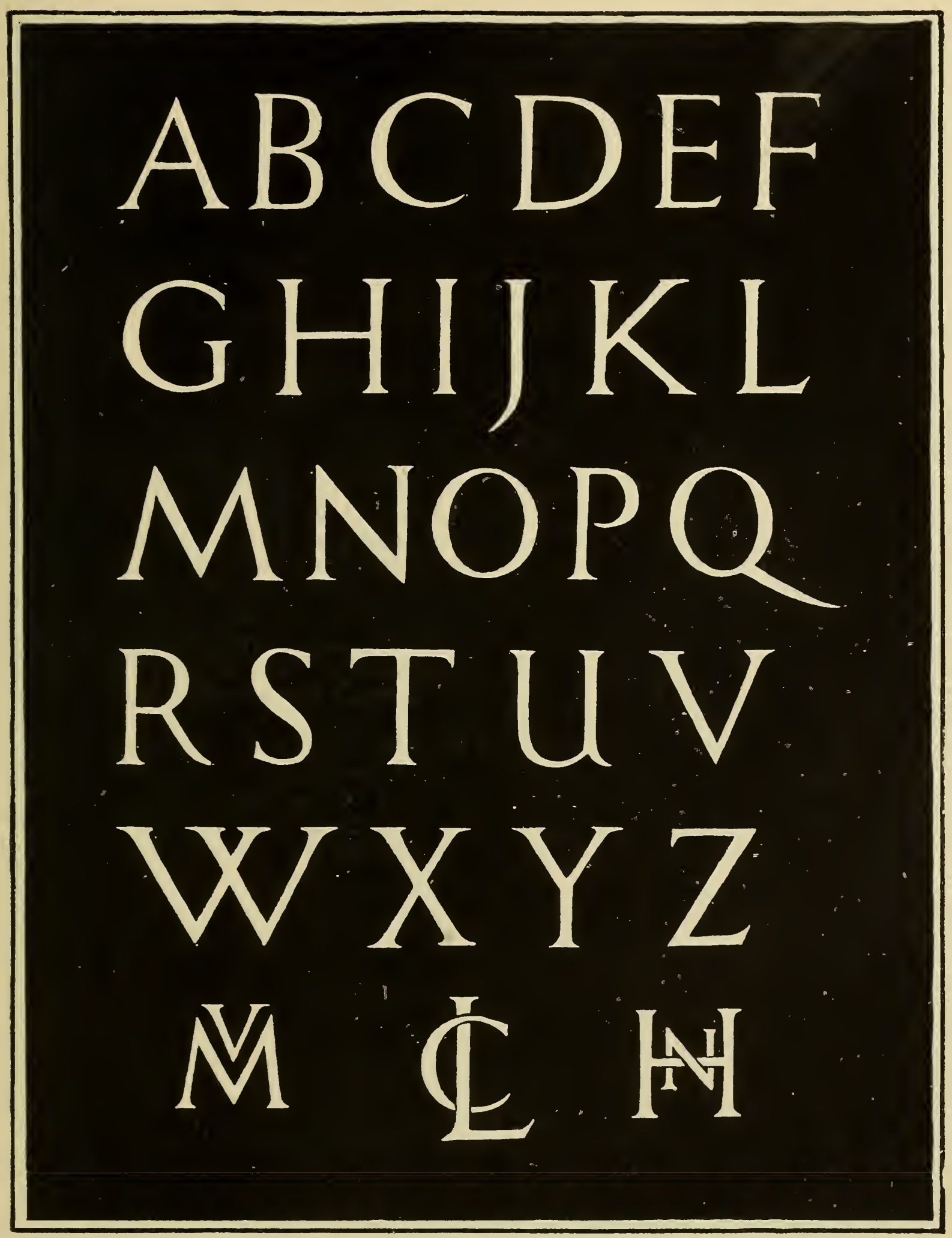

Plate LXVIII. 


\section{A TENTH CENTURY VERSAL ALPHABET.}

\section{Plate LXIX.}

THIs alphabet, shown in Plate LXIX, which has been compiled from various manuscripts of the tenth century, is just as beautiful as the Roman one, without being quite so severe in line. As regards the proportion of the letters, the two alphabets are very similar, but several of the letters, particularly the F, M, and W, show an entirely different construction from that of the same examples in the Roman alphabet. The embroideress will perhaps feel more in sympathy with the curved lines which characterise these letters than with the more austere Roman capitals; certainly for constructing monograms they. are less uncompromising to deal with than the earlier type, and for a single initial, too, the versals are always satisfactory. The large embroidered monogram on Plate LXX is carried out in tenth century characters, as are also the single initials $\mathrm{L}$ and $\mathrm{P}$.

In no case should both types of letters be used for the same monogram, as they belong to two entirely different periods of thought and must always be kept distinct. Good drawing is essential to the successful marking of letters in embroidery, which must be traced on the material with an unhesitating clear line, on which the needle can work accurately and with ease. 

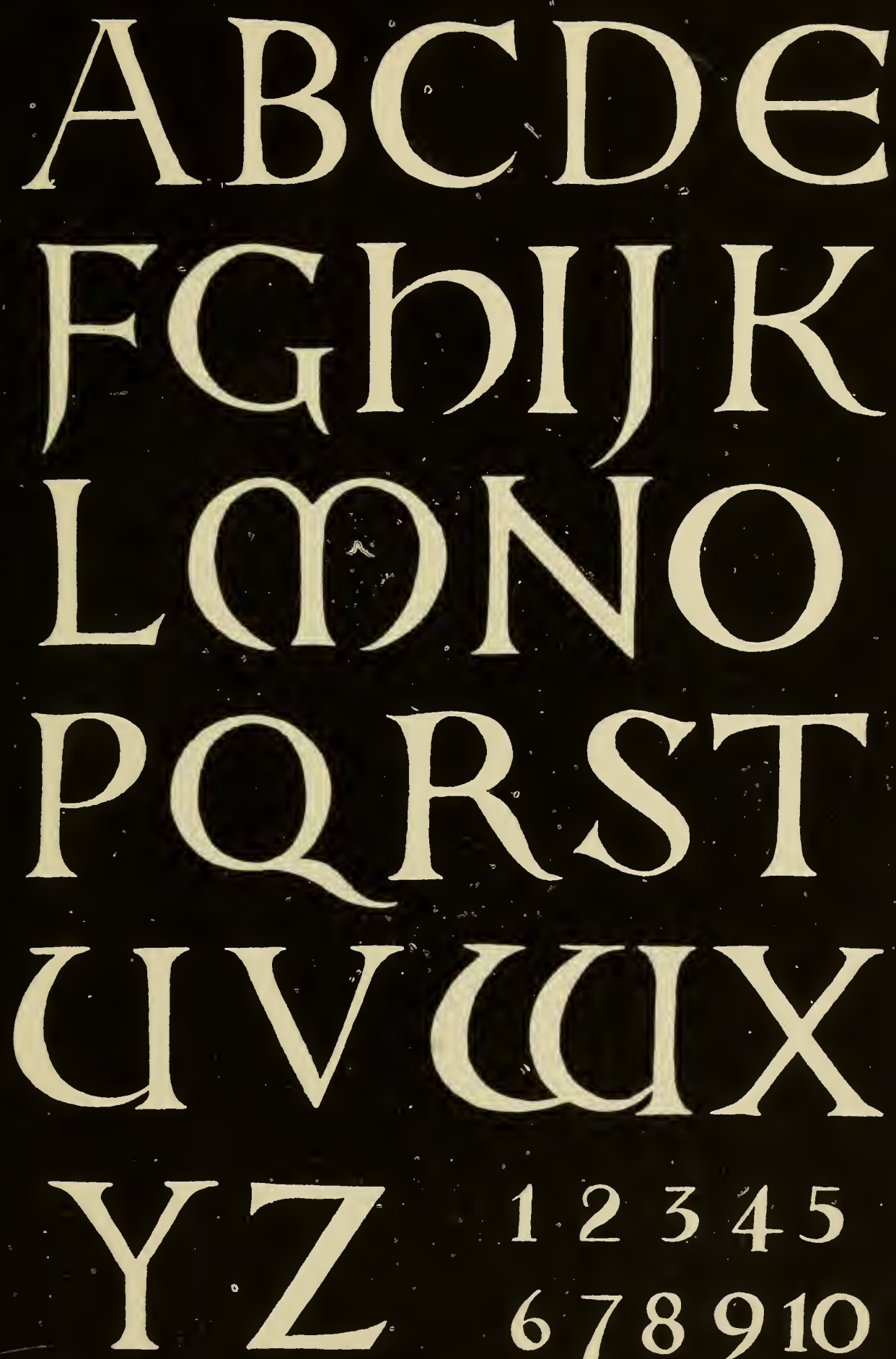

12345
678910

Plate LXIX. 


\section{EMBROIDERED INITIALS AND MONOGRAMS.}

\section{Plate LXX.}

WITH the introduction of an indelible ink for marking purposes, the practice of embroidering the initials of the owner on household linen and under garments has fallen very much into disuse. However, letters written in ink on a woven substance, though they may quickly dispose of the marking problem, can certainly not be called beautiful, and any article that we value especially deserves more careful and appropriate treatment.

In Plate LXX are shown letters that can be applied to a coarse or fine material. Those embroidered on the coarse ground, with the exception of the $\mathrm{M}$ on the top row, are quite easy to work, but it is no use hoping that a good result can be so quickly obtained with a finer treatment on white linen.

Beginning with the top of the sampler, the $\mathrm{E}$ and $\mathrm{S}$ are both worked in cross stitch, which is always a very suitable stitch to use for marking letters on both a large and a small scale; but as in the working of it the threads of the ground have to be counted, it is better applied to a coarse material. The $\mathrm{M}$ is carried out in eyelet stitch, which is easy to understand but rather slow to work; a hole is punched in the material with a stiletto, and this is oversewn with stitches set close together and arranged to form a small square. Many examples of this treatment and cross stitch can be seen on the samplers of the seventeenth century in the Victoria and Albert Museum.

The $\mathrm{L}$ worked on white linen is embroidered in double back stitch, and outlined with a row of single back stitch; it should be slightly padded first by two lines of running stitches. Both the $\mathrm{L}$ and the $\mathrm{P}$ are quick to work in comparison with the monograms in which satin stitch is used. The $\mathrm{P}$ is outlined with run and thread (see page 38), and French knots are added to the thicker parts of the letter.

The monogram JDR is worked in satin stitch, padded first, and separated at even intervals by French knots. The CN shows the value of contrast in embroidering a monogram; the $\mathrm{N}$ is in padded satin stitch, the $\mathrm{C}$ outlined with stem stitch and filled with small back stitches.

The large monogram in the centre is fairly quick to work; the $\mathrm{V}$ carried out entirely in even rows of stem stitch is the most tedious letter to embroider, but the $\mathrm{T}$ and $\mathrm{M}$ are more quickly disposed of; they are outlined with chain stitch whipped by a thread of the same size and colour; the little eyelet holes are simply oversewn by stitches not placed very close together.

The letters $\mathrm{AWB}$ on the bottom row are all quick to work; the $\mathrm{A}$ is in coral stitch, the $\mathrm{W}$ in chain stitch, whipped, and the B in German knot stitch (this stitch has been described by Mrs. Christie in the periodical entitled Needle and Thread, Part I). 


\section{thes}

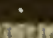

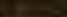

4.17

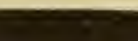

tos

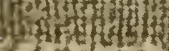

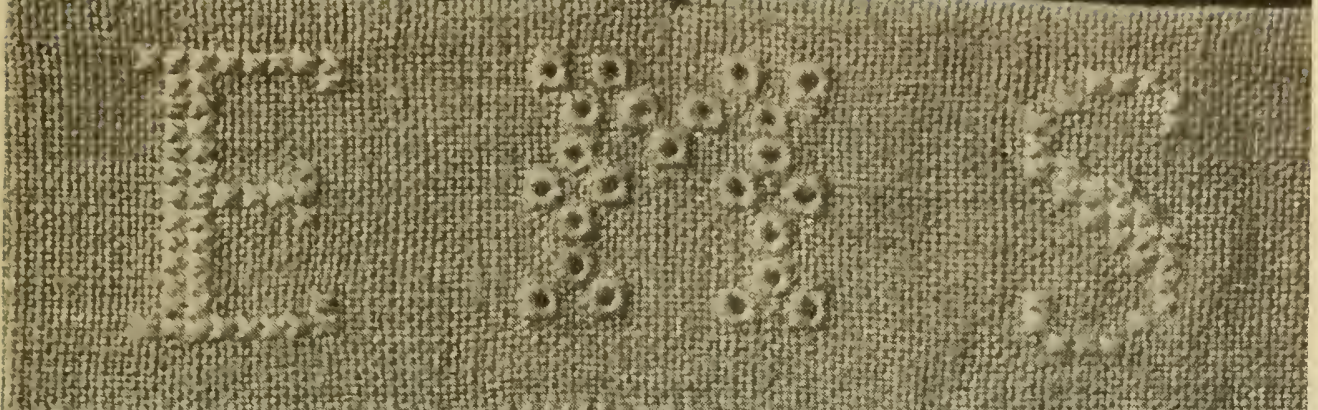

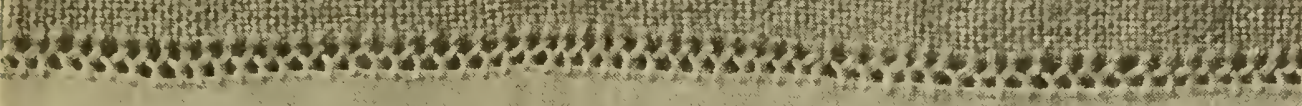

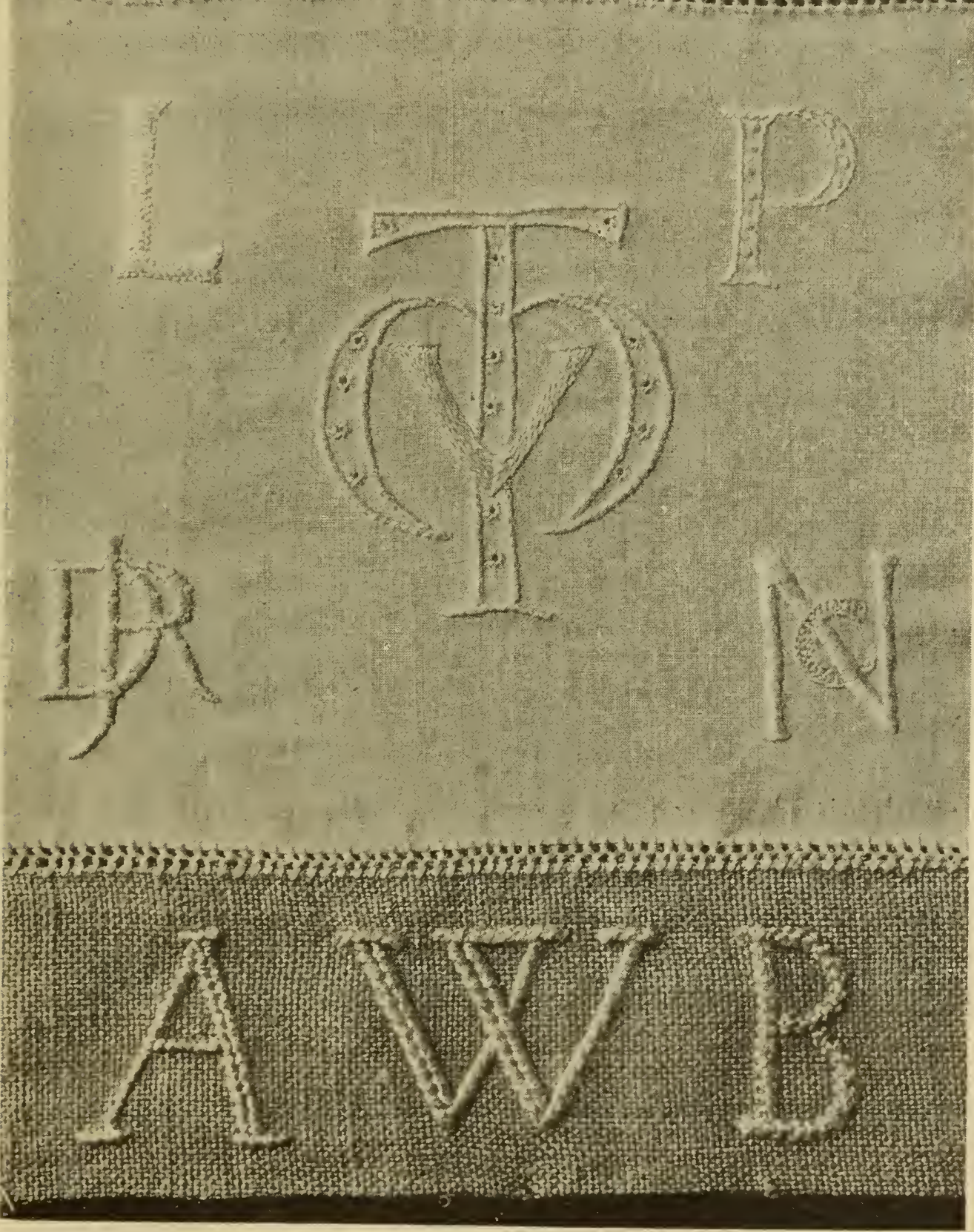

Plate LXX. 


\section{BRODERIE ANGLAISE AND WHITE EMBROIDERY.}

\section{Series 1. Plate LXXI.}

"BRODERIE anglaise" is the name given to a form of white embroidery which is very fashionable at the present time both in England and on the Continent. It really dates from as far back as the sixteenth century, and was probably introduced into England from France or Italy.

Patterns worked in "hroderie anglaise" are found on both household linen and articles of dress. In the loan collection of the late Sir Robert Filmer, at the Victoria and Albert Museum, are some beautiful examples applied to collars and cuffs of fine linen embroidered during the first half of the seventeenth century.

Although a great deal of "broderie anglaise" is produced to-day, and the utmost care and patience devoted to the technique of the embroidery, the designs upon which so much labour and skill are expended are rarely of a sufficiently high standard to justify the time spent on them. As a rule the holes cut or pierced in the material are not sufficiently grouped, but are spotted indiscriminately over the whole design, and the white leaves and flowers which are usually embroidered as a setting to the cut-work grow on weak, indefinite stems; the result is a graceful but formless pattern, which can only give pleasure to people quite ignorant of the wonderful possibilities of " broderie anglaise," with or without the addition of simple white embroidery.

In Plate LXXI are shown four decorative squares and a few simple sprigs. and borders. The bottom right-hand square is adapted from a repeating pattern which decorates a baby's bonnet of the early nineteenth century, now in the Victoria and Albert Museum. To work the cross, two or three threads have to be drawn from the material and the remaining ones hemstitched on either side. The rest of the design needs no explanation, nor, indeed, should any of the other patterns shown on this page, as the technique is obvious to an embroideress with any knowledge of "broderie anglaise"; but perhaps it would be as well to mention that the feathery lines which occur in two of the small sprays should be worked in small running stitches and then carefully overcast with a thread of the same size. (See Mary Symonds's Elementary Embroidery.) 


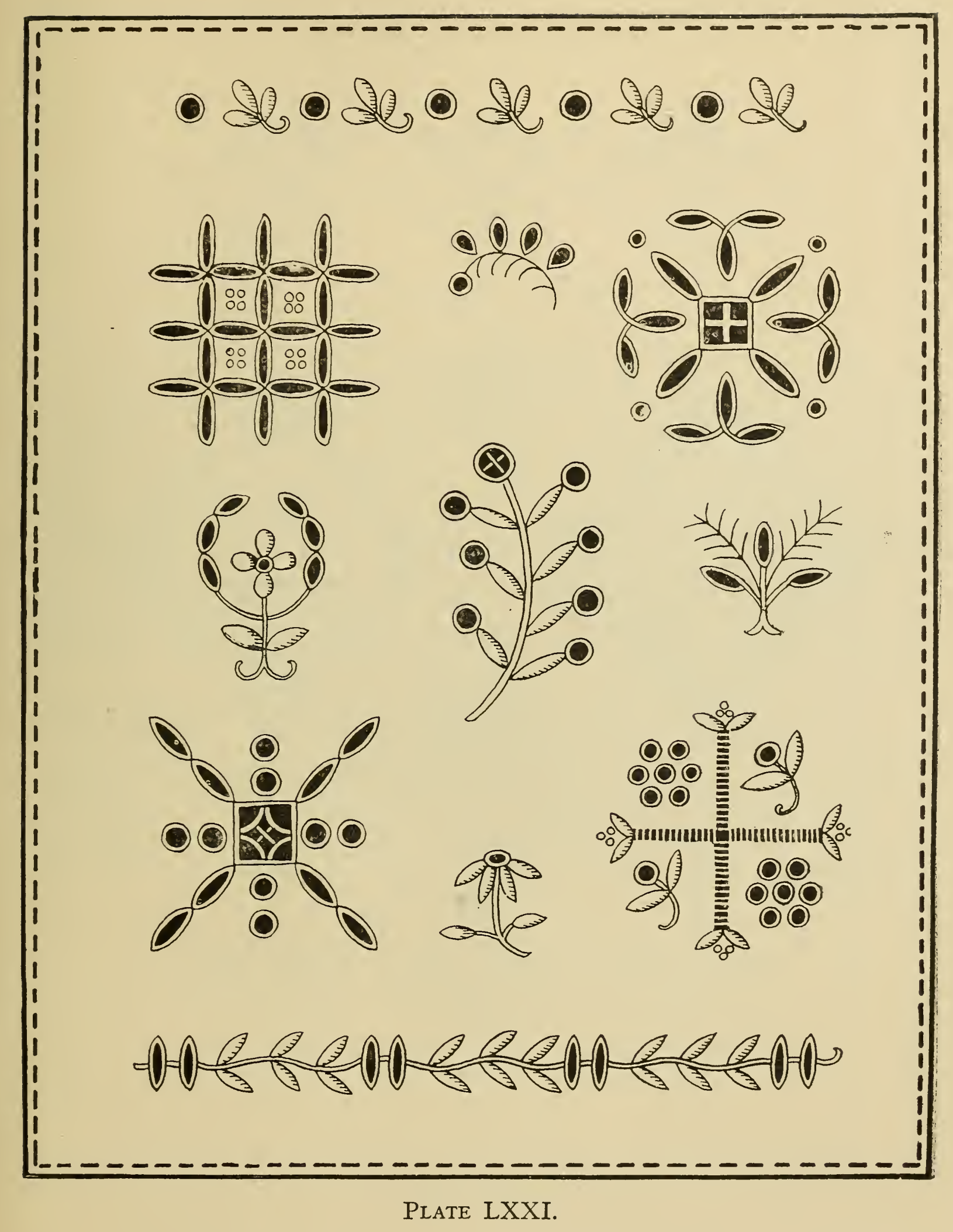




\section{Series 2. Plate LXXiI.}

The two borders shown respectively at the top and bottom of Plate LXXII would make very suitable edgings for underlinen or some other article of dress. They are rather slow to work, for all "broderie anglaise " patterns which are well executed need a good deal of skill and patience, and a student not possessing either of these qualifications should leave this branch of embroidery severely alone. If it had not been so popular and so little understood, patterns for "broderie anglaise" and white embroidery would not have been included in this book, which is otherwise devoted to mucl simpler forms of embroidered decoration.

However, if a student wishes to decorate her underlinen in this way, and is prepared to work the patterns carefully and accurately, she will be well repaid for the time spent by the beauty and distinction which the intelligent use of "broderie anglaise" on white linen always gives to an article of personal or household use.

In both the monograms shown on Plate LXXII, small bars are worked across some of the cut squares, which would otherwise have rather a hard appearance. The spotted background behind the letter $\mathrm{M}$ is worked in seed stitches, which are perhaps better understood as separate back stitches.

An excellent book is published by the French firm, Cartier-Bresson, entitled Les Points de Broderie, which fully explains the technique of "broderie anglaise," and also gives a few good designs for this method of work. 


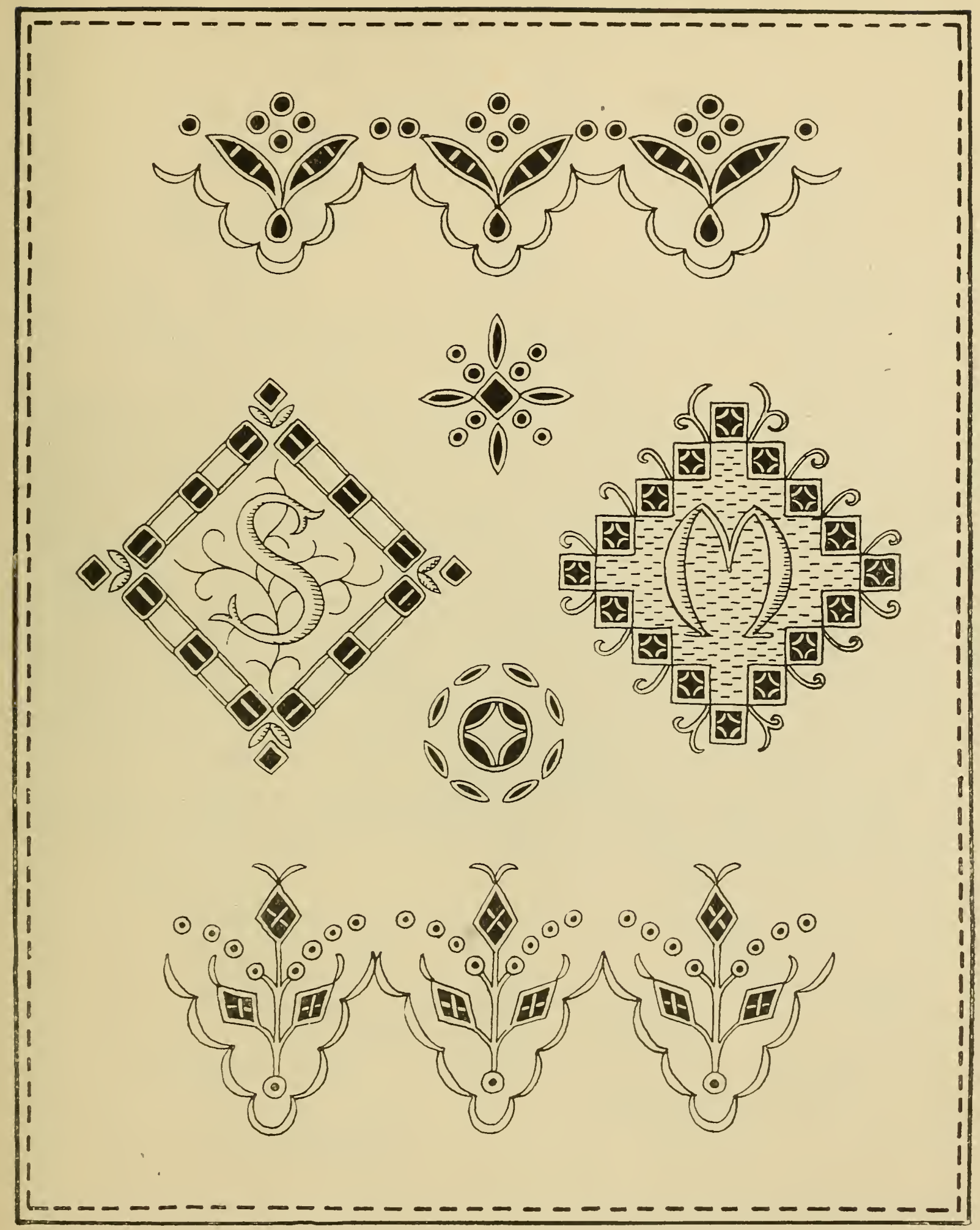

PLATE LXXII. 


\section{Series 3. Plate LXXIII.}

In Plate LXXIII, the last of the three plates devoted to this subject, "broderie anglaise" plays quite a subsidiary part, being confined entirely to small pierced holes which are merely added to give a sharp note of contrast to the embroidered sprays and flowers. These are to be carried out in the usual stitches associated with the simple white embroidery, such as satin stitch, French knots, seed and back stitches, overcast running, and stem stitch. All the solid parts of the embroidery must, of course, be padded first; as a rule two or three rows of running are quite sufficient for this purpose.

A slight degree of light and shade and a contrast of texture are all that an embroideress has to rely on to make a piece of white work subtle and interesting in effect. That is why small holes pierced with a stiletto and overcast are of such immense value in executing a design for white embroidery.

The two borders in the middle of Plate LXXIII are worked with buttonhole loops on one thread, and small overcast holes. In the lower border the buttonhole loops should slightly overlap.

There is a baby's bonnet in the Victoria and Albert Museum which was embroidered in the eighteenth century with a little border very similar to the one just described. 


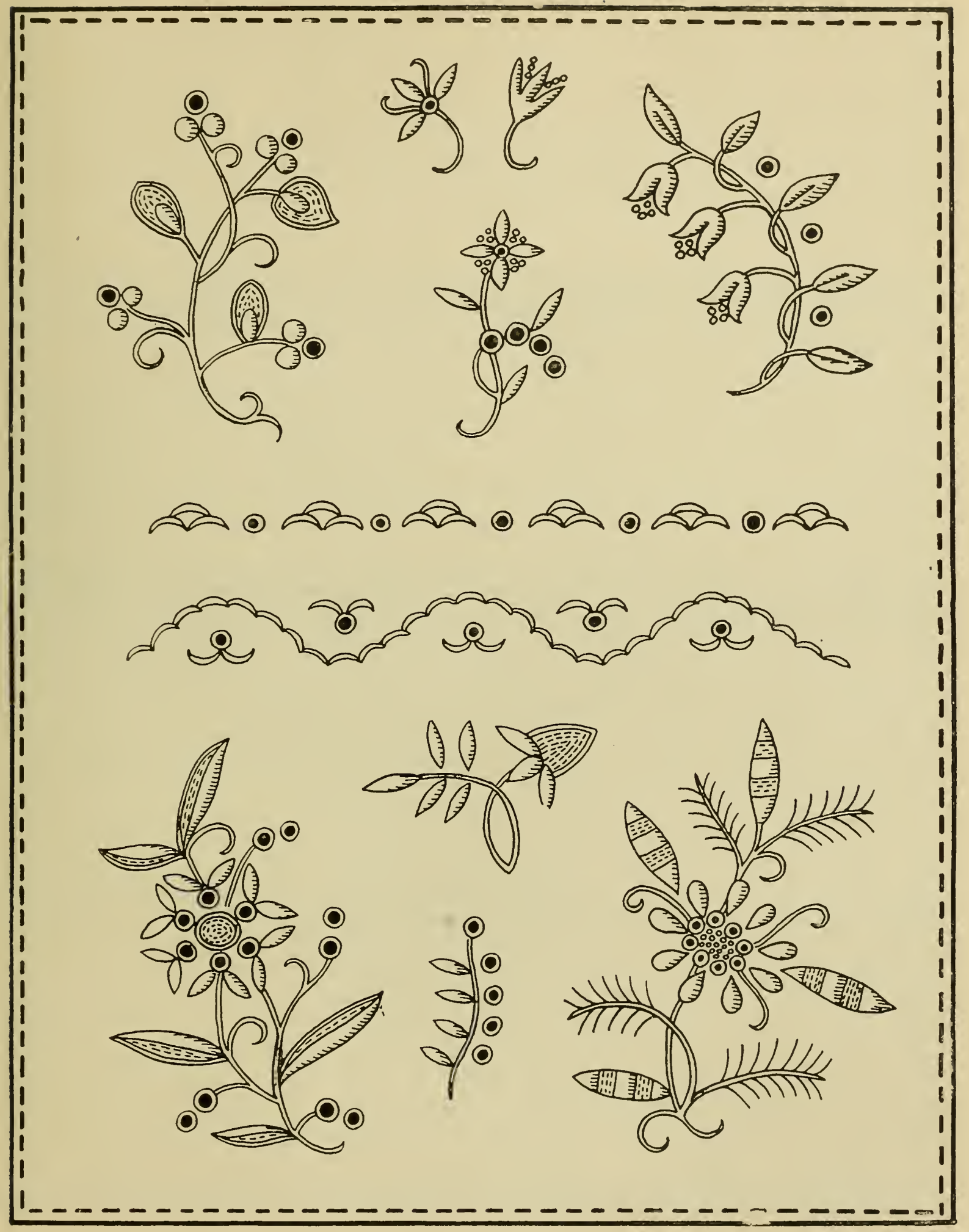

Plate LXXiII. 


\section{EMBROIDERED EDGINGS.}

Plate LXXIV.

THE little edging shown at the top of Plate LXXIV was copied from a baby's robe which was made about a century ago. The edging is very simple to work, and can easily be adapted to the decoration of a modern blouse or, as in the original, be applied to a baby's dress.

The first stitch is a buttonhole loop with the needle going through on the right side of the material in the usual way; for the second stitch, which is close to and on a level with the first stitch, the needle is put through the material from the back, brought out in front and slipped under the working thread; then another buttonhole loop is made, and so on. For the worked example, Pearsall's Mallard floss was used, but Pearsall's twisted embroidery silk would be quite as suitable.

The second edging can be worked with or without the beads. If it is applied to a garment which will be frequently washed and most probably mangled, the beads would be quite out of place, but, on a crêpe de Chine or silk blouse, the edging, as it is illustrated, would make a very charming finish to the collar and cuffs. This edging was suggested by one of the lace fillings illustrated in the D.M.C. Encyclopaedia of Needlework. It is constructed, as so many of the lace stitches are, with a large buttonhole loop, on which are arranged several smaller buttonhole stitches (four or five should be sufficient). The bead must, of course, be slipped over the needle before commencing each large buttonhole loop.

The next two edgings are adaptations of Danish Hedebo embroidery. They are really quick to embroider, for the pattern is completed as the needle works along from left to right. They make very suitable edgings for underlinen, blouses, or children's garments. Cartier-Bresson floche thread, size No. 10, was used for embroidering these edgings, and all information as to the technique of Hedebo embroidery can be obtained from a number which is published on that subject by " Needlecraft, Ltd." 


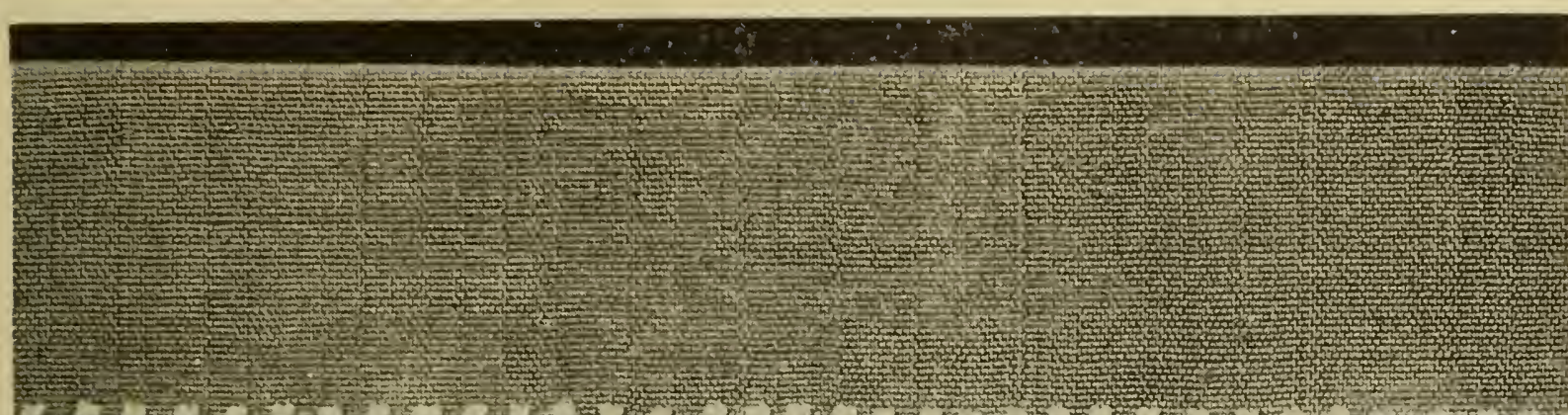

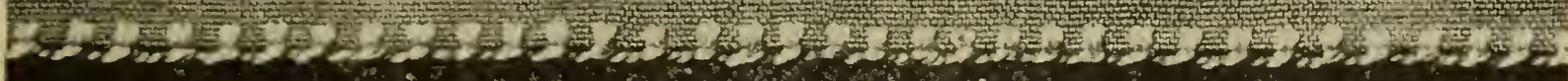

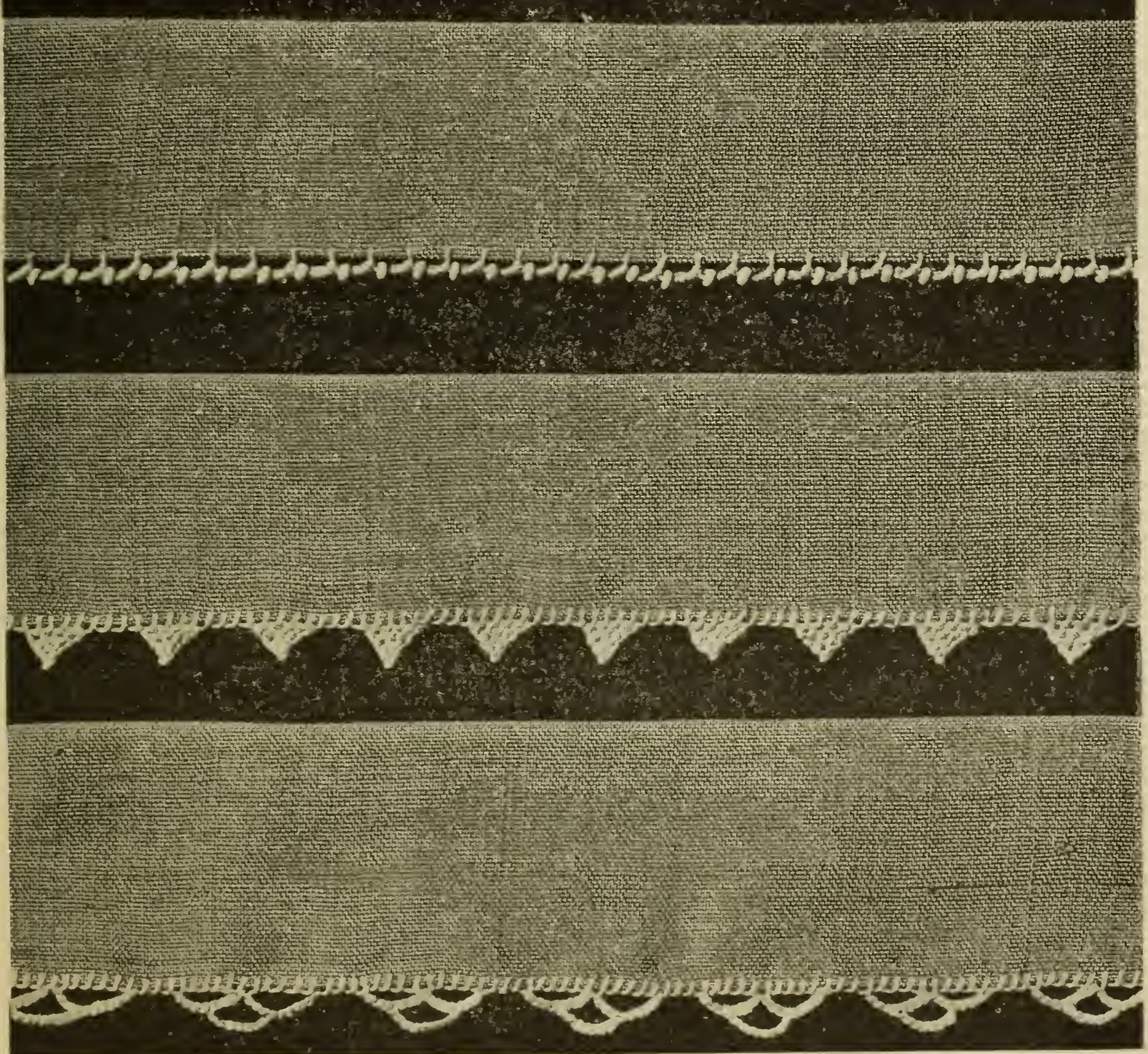

Plate LXXIV. 


\section{EMBROIDERED COLLARS.}

\section{Plate LXXV.}

THE methods of embroidering the corners of a collar often have to be considered in an embroidery class. There are numerous ways of dealing with this subject, and the corners represented in Plate LXXV merely show four very distinct types of decoration.

The top left-hand collar is of white Harris linen, embroidered with Cartier-Bresson floche thread, size No. 10. The lines round the edge are made with three rows of back stitching, and the small circles are done in the usual way by piercing a hole in the material with a stiletto and buttonholing round it.

The top right-hand collar is of coarse tussore silk embroidered with two shades of Pearsall's Mallard floss. The design for this corner is more floral in character than the others, and could be equally well applied to a crêpe de Chine or other silky material. Only three stitches are used for this design; viz., fern stitch for the little sprays, back stitch for the stems, leaves and outlines of the upper part of the buds, and satin stitch for the lower part.

The bottom left-hand collar is also embroidered with Pearsall's Mallard floss, and the ground is of Russian hand-made linen. Only two stitches are used and two colours; the lighter thread is couched to a zigzag line, and the spaces on the upper side of it are filled with two Roumanian stitches in the darker thread.

The fourth collar is made of canvas, and embroidered in cross stitch with two shades of Pearsall's filoselle. It is important to wash the canvas before commencing the embroidery, so as to guard against shrinkage and to make the material soft and pliable. 

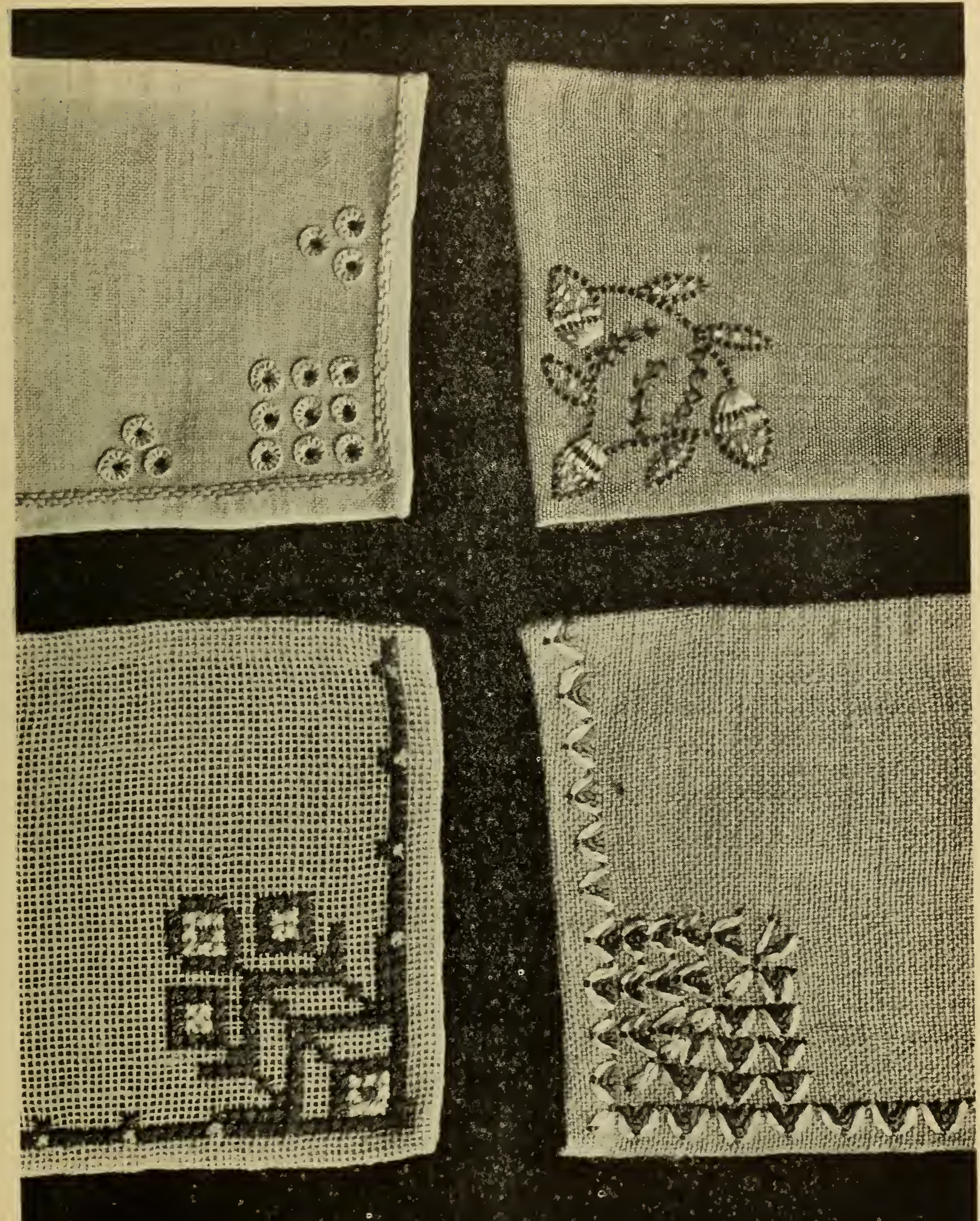


\section{FAGGOT-STITCHING.}

\section{Plate LXXVI.}

Every student of embroidery should know how to work and apply at least three or four varieties of faggot-stitching (Plate LXXVI). It is useful for so many purposes, and, if well executed, will greatly improve the appearance of the article it is applied to. For instance, if it is necessary to join two pieces of material together, faggot-stitching, by accentuating the join, will make it part of the decorative scheme of the embroidery. For repairing hemstitching, one of the stitches given in Plate LXXVI is very satisfactory; while for dressmaking purposes, especially at the present time, faggot-stitching is invaluable for making pretty seams in crêpe de Chine blouses, and so on.

The method of working the first two examples given on the opposite page can be found in the D.M.C. Encyclopaedia of Needlework, " Needle-made Lace."

The third example is a very simple form of faggot-stitching given in Mrs. Christie's text-book of Embroidery, with the addition of a row of featherstitching worked in a contrasting colour on the top of the completed faggotstitching.

The fourth example is a more complicated variety, which is found on modern Italian peasant work; it is made entirely with buttonhole stitches.

The fifth and last example is also illustrated in the book on Embroidery just mentioned.

For all these examples Pearsall's twisted embroidery silk is used, which is much more satisfactory than a loosely-woven thread. 


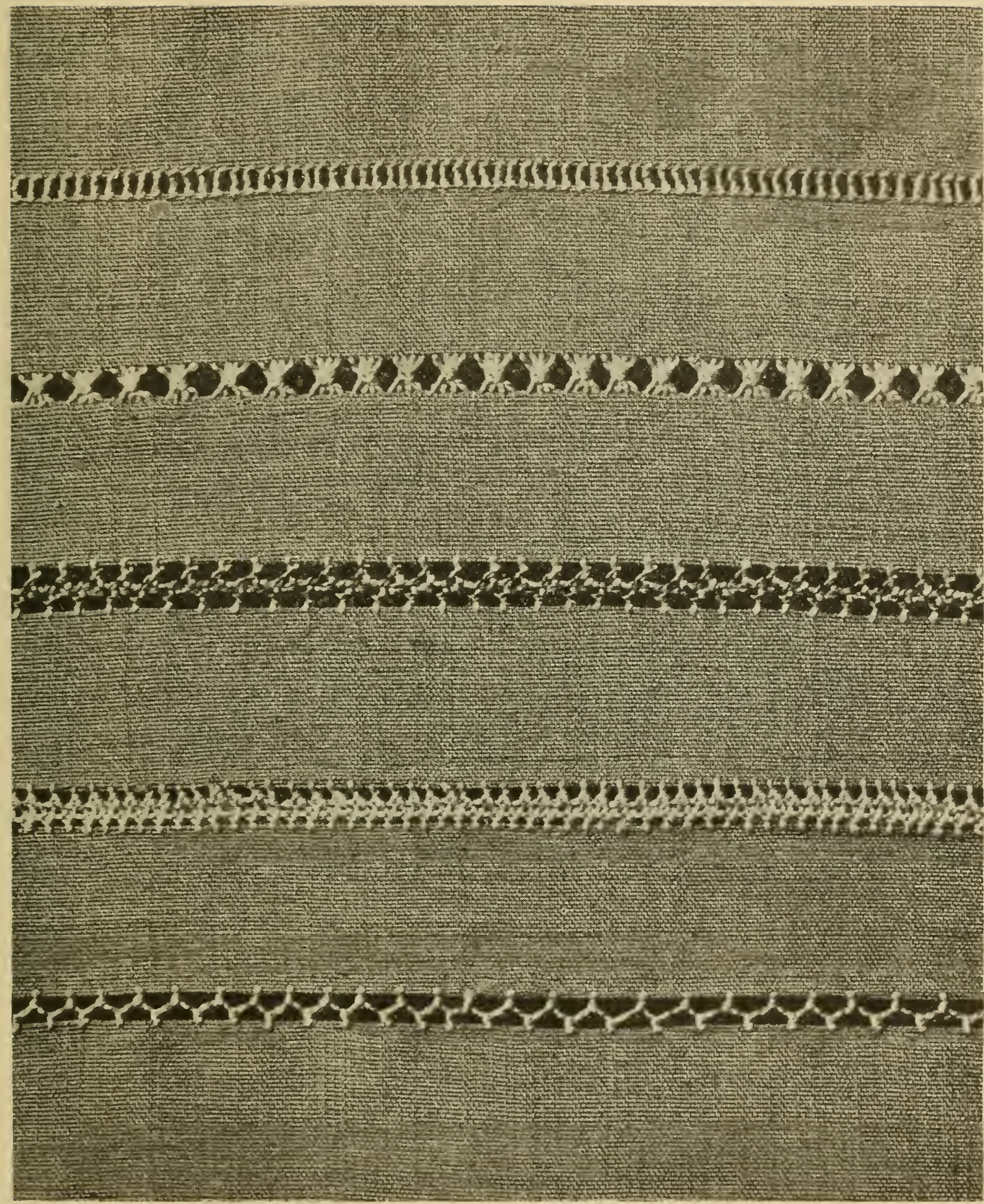

Plate LXXVI 


\section{TWO CUSHION COVERS.}

\section{Design 1. Plate LXXViI.}

A portion of a design for a cushion cover, to be carried out entirely in darning stitches, is seen in Plate LXXVII, and at the bottom of the plate a diagram is given showing the arrangement of the completed pattern. This is composed of sixteen oblongs separated by narrow borders, but for a smaller cushion twelve oblongs would be sufficient.

To prevent any confusion in the design, the alternating patterns show a very distinct contrast of line, one set being constructed on horizontal and the other on upright lines; the contrast between the two could be further accentuated by the arrangement of the colour scheme. The outlines of the border should be of quite a distinct colour from that of the rest of the pattern; this is necessary if the border is to retain its definite outline.

Linen is the only appropriate material for a cushion cover decorated with darning patterns, and the embroidery thread can be either of silk, flax, or cotton.

Pearsall's Mallard floss would be the most suitable silk thread; for the flax, Harris's flax thread; and for the cotton, D.M.C. ingrain thread.

The actual size of each oblong is $2 \frac{14^{\prime \prime}}{4}$ by $1_{\frac{4}{4}}^{3 \prime \prime}$, and the border is $\frac{3 . \prime}{8}$ wide. 


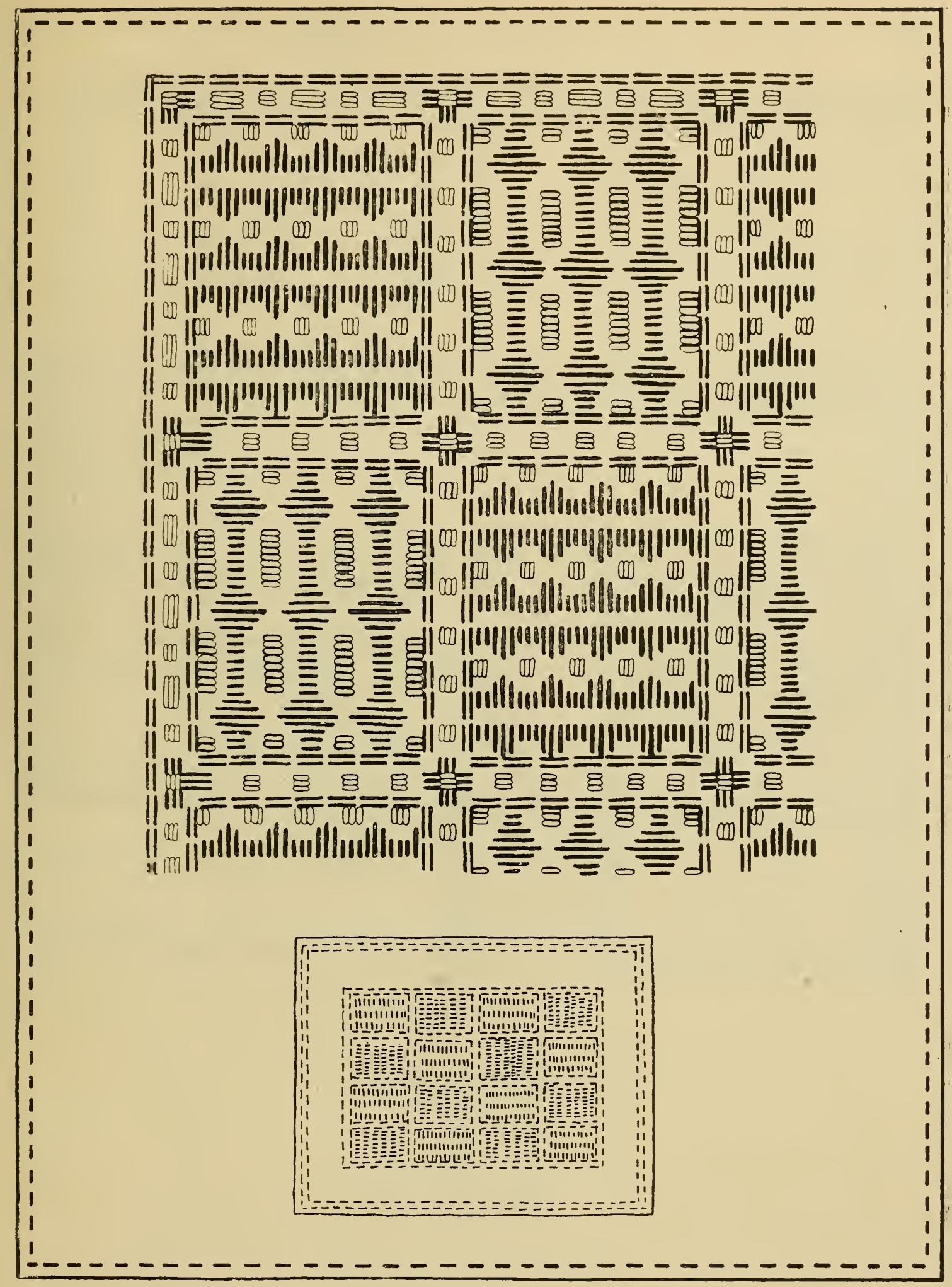

Plate LXXV:I. 


\section{Design 2. Plate LXXVili.}

The design for a cushion cover illustrated in Plate LXXVIII, has been constructed from the decorative squares shown in Plate XX. In principle, the arrangement of the design is similar to the one illustrated in Plate LXXVII, only in this case the cushion is a square one and the alternating decorative squares are placed much further apart than the oblongs in the preceding plate.

The top right-hand square should be embroidered in stem or chain stitch for the outline of the cross, back stitch for the curved lines, and Roumanian stitch for the filling; and blocks of satin stitch should be added to the centre square and the four smaller squares.

The top left-hand square should be embroidered in back stitch for the straight and curved lines; satin, Roumanian, or flat stitch for the solid portions; and French knots for the black spots in the centre and at each corner of the design.

The wide interlacing border should be outlined with stem or chain stitch, after which a row of buttonholing should be worked, the stitches being arranged in groups of three, and finally a running stitch in a contrasting colour should be placed between each group of buttonhole stitches.

The small outside border is worked in the same way, with the omission of the running stitches and the introduction of two interlacing threads, which should pass under the buttonhole stitches without entering the material. In the original this border is : ${ }^{\prime \prime}$ wide; the decorative squares are $2 "$ square and the spaces between them $1 \frac{1}{\alpha} "$ wide. 


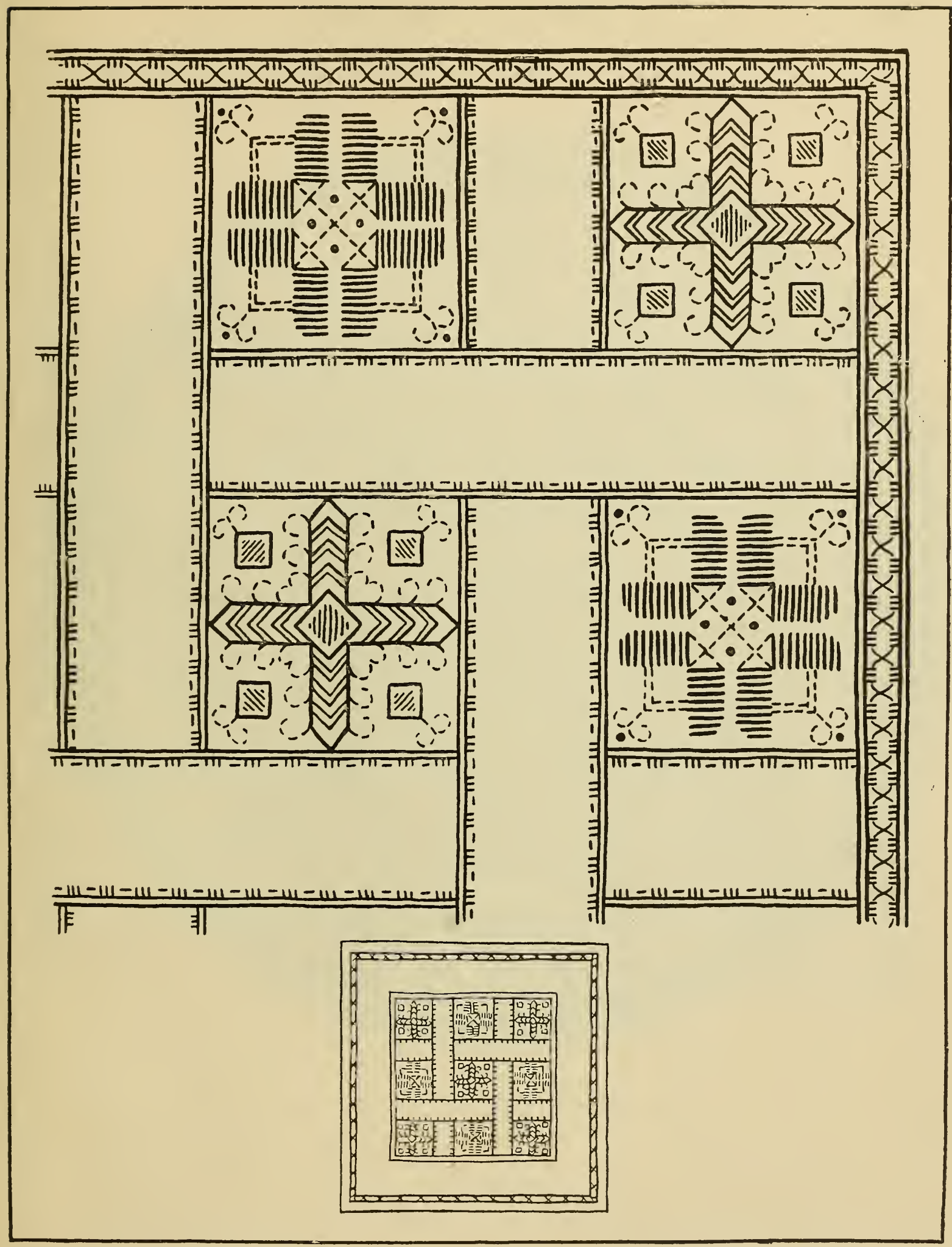




\section{A CIRCULAR BOX.}

\section{Plate LXXIX.}

THIS design for the cover of a circular box is exactly half the size of the original. The pattern has been constructed from flowers and leaves illustrated in Plate LII, and should be carried out in the method described on page 108; viz., by cutting out the design in cloth or leather, and sewing it on to the ground with back stitches. A contrast of texture is really very important to this design, so that, if the ground is of leather, the flowers and leaves should be of cloth, and vice versâ.

Three bright colours should be used for this pattern: one for the leaves, border, and centre flower; one for the stems; and another for the outer circle of flowers. The stitches which keep them all in place could be worked in black or coloured threads, but this can only be settled when the colour scheme has been arranged. The ordinary chamois leather which is sold for household purposes would make a most suitable background for this design, and the pattern carried out in red, green, and black felt or cloth would produce a most decorative effect. On the other hand, if the ground were of cloth and the pattern of leather, quite an interesting scheme could be arranged with flower and leaves cut from pieces of old suède gloves.

The design could be carried out in black, white, and yellow leather, and applied to a grey or bright green material. A very useful little leather bag could be made from the upper parts of a pair of three-quarter length gloves. The pieces could be decorated in the same manner as the circular box, either with coloured cloth or entirely in black and white. A bag of this kind should only take a very little while to make, and yet it would look extraordinarily effective. In carrying out the design for the circular box other stitches have been suggested in addition to the lines of back-stitching. The flowers are neld in place by French knots and single stitches, while the leaves aredecorated with double crosses. 


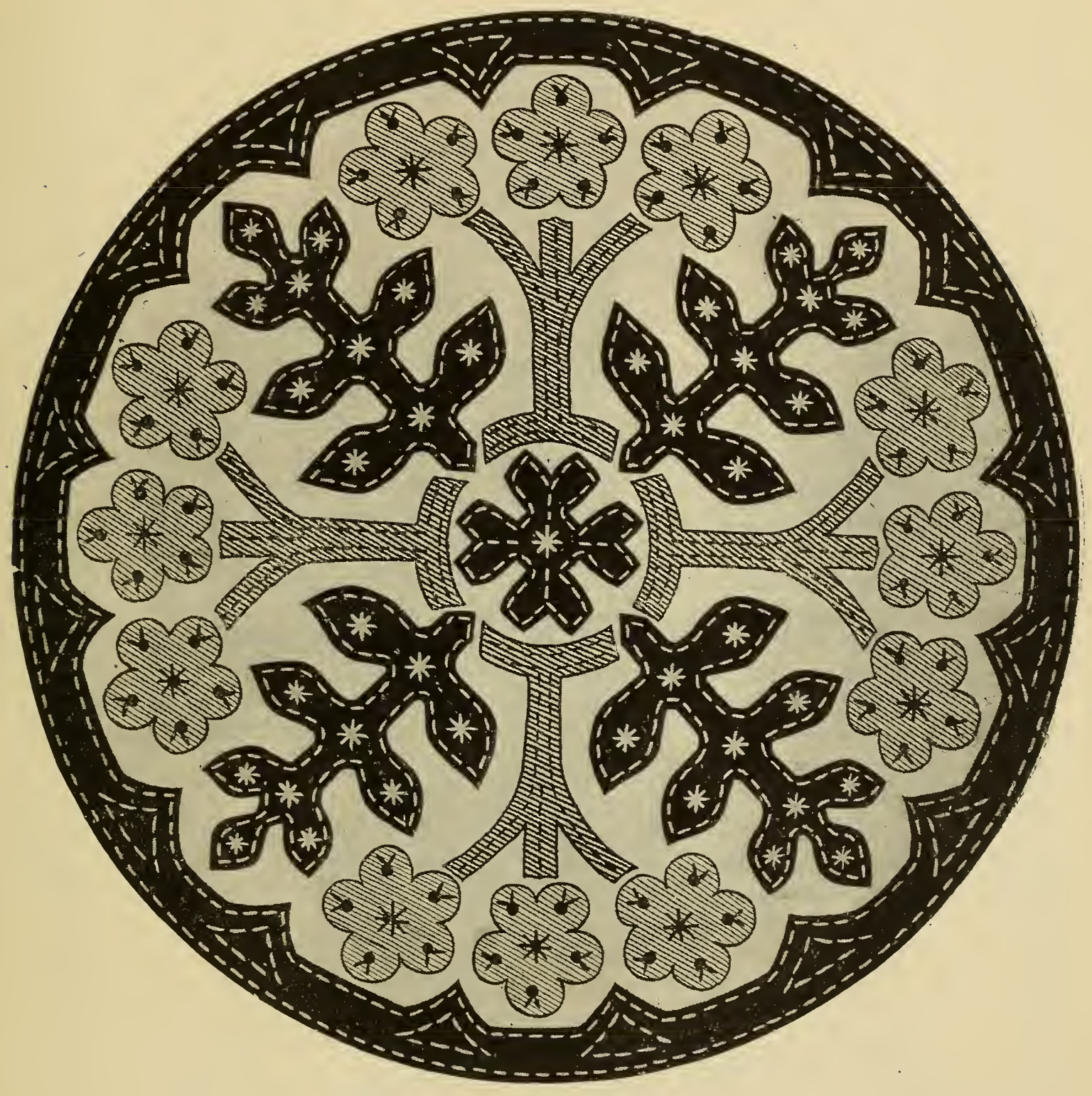

Plate LXXIX. 


\section{A BIB.}

\section{Plate LXXX.}

THE bib illustrated in Plate LXXX has been designed from various elements already illustrated in the pattern book. The lamb is identical with the one shown in Plate LVIII, the rabbit can be found in Plate LVII, the small sprigs in Plate XLV, and the tree is constructed in the same way as the upper one in Plate XXX, but has been made a little shorter to suit the limitations of a bib design, one of the most important of these being that the decoration should be confined to the lower part and yet not be so near the bottom edge as to disappear behind the table when it is being worn.

A bib is not an article upon the decoration of which much time should be spent, but it is possible to embroider it with quite interesting and amusing patterns, which will give great pleasure to the owner, without costing the embroideress much trouble or expense. The methods of working the animals and tree used in this design have already been suggested in the plates referred to above, but it must be understood that these methods are only suggestions, for many other ways of treating the same subject might occur to an embroideress intending to make use of this pattern.

D.M.C. ingrain threads, or Harris's flax threads, would perhaps be the most suitable ones to use; for constant washing would not be good for a silk thread, which would also be out of place on such a very unpretentious article. 


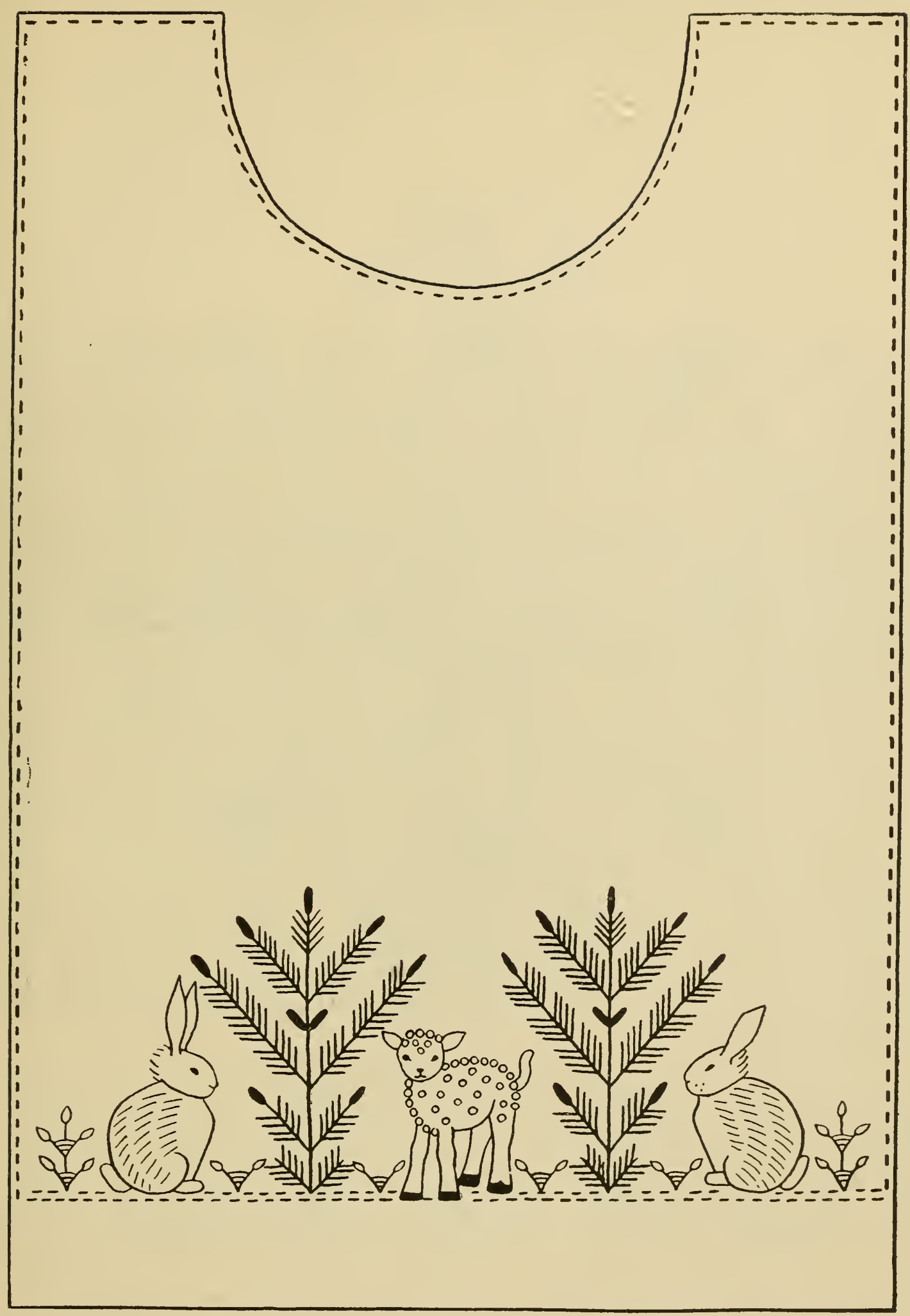

Plate LXXX. 


\section{A BAG.}

\section{PLATE LXXXI.}

THE basis of the bag design here shown is formed by interlacing knots and curved lines. The knot used in the diagonal square is an enlargement of one shown in Plate LXIV, and. the flowers are taken from Plates XLIII and XLVIII. The combination of the two produces a design which is decorative in appearance while being very simple to execute, and should illustrate conclusively how easy it is to construct an embroidery pattern, the basis of which is an interlacing knot. The actual size of the diagonal square is $6^{\prime \prime}$ across, and the border is $7 \frac{1}{2}$ " long by $1 \frac{1}{4}^{\prime \prime}$ wide. On this scale the design could be used for decorating not only an ordinary bag, or brush and comb bag, but also for a nightdress case or toilet cover, though for the latter a square and border would have to be worked at either end. If the square were enlarged and elaborated, it could be applied to the centre of a cushion cover with the border embroidered round the four edges of the material.

In Plate LXXXI some of the ground spaces in the interlacing knots are decorated with darning stitches, as these not only give a very pleasant tone to the background, but also help to give a little more solidity to the design itself. The treatment of the flowers has already been discussed on pages 90 and 100; the knot should be embroidered by two very distinct methods, one for the solid black lines and the other for the part drawn in outline. Some suitable stitches to use would be German knot stitch, backwards chain, chequered chain, or couching. The materials and colour scheme will depend entirely upon what article is to be decorated. The cushion cover would look well worked in silk, while the nightdress case, brush and comb bag, or toilet cover would look best worked in linen threads; and nothing is more effective for this purpose in the way of colour than three shades of delft blue, or blue and white. 


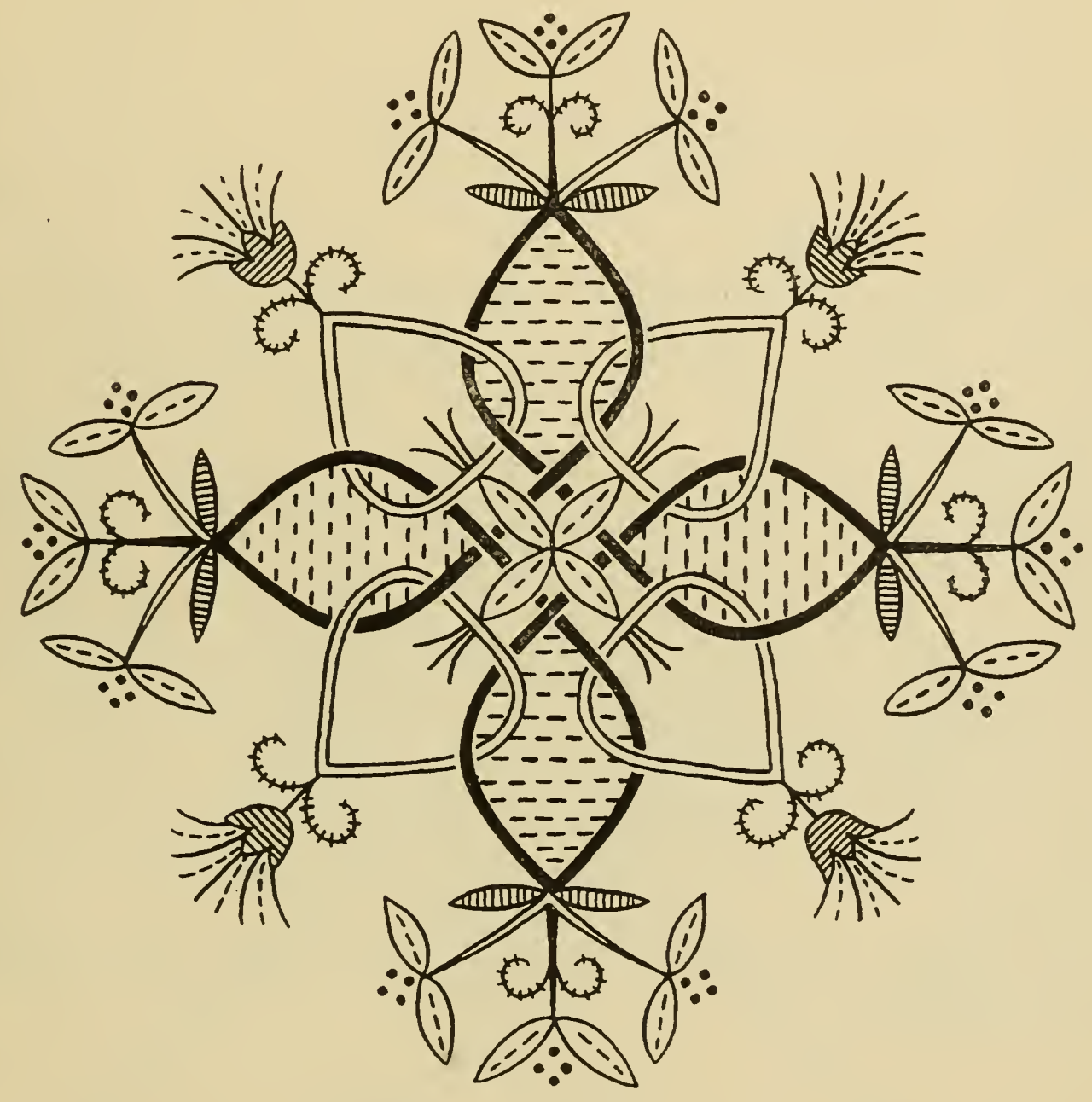

鈢 m 


\section{A HANDKERCHIEF CASE.}

\section{Plate LXXXII.}

A DESIGN for a small handkerchief case is given in Plate LXXXII, the actual size being $6 \frac{3{ }^{\prime \prime}}{4}$ square. It has been decorated with flowering plants taken from Plates XLIII and XLVII, and bees and butterflies illustrated in Plate L. The four flaps of the case are scalloped and edged with buttonhole stitch.

No solid embroidery has been suggested in this design, with the exception of the small markings on the butterfly and the bee's head, for the whole effect of the embroidery is intended to be light and fresh-looking. The convolvulus flower could be worked in stem stitch and the leaves and stems outlined with the same stitch or run and thread; an open filling of Roumanian stitch should be added to the leaves. The polyanthus flowers could be outlined with back stitch, and the lines on the flower made with single stitches, the centre being filled with a French knot.

The leaves of this plant should be outlined with open buttonhole stitch, and the markings could be suggested with two satin stitches or a daisy stitch. The head and body of the bee and the markings on the butterfly should be worked in satin stitch, and the wings of both insects embroidered with some outline stitch.

Linen cambric, or fine lawn or linen, would be the most suitable material to use for this handkerchief case, and the embroidery itself should be executed in Pearsall's filo-floss. 


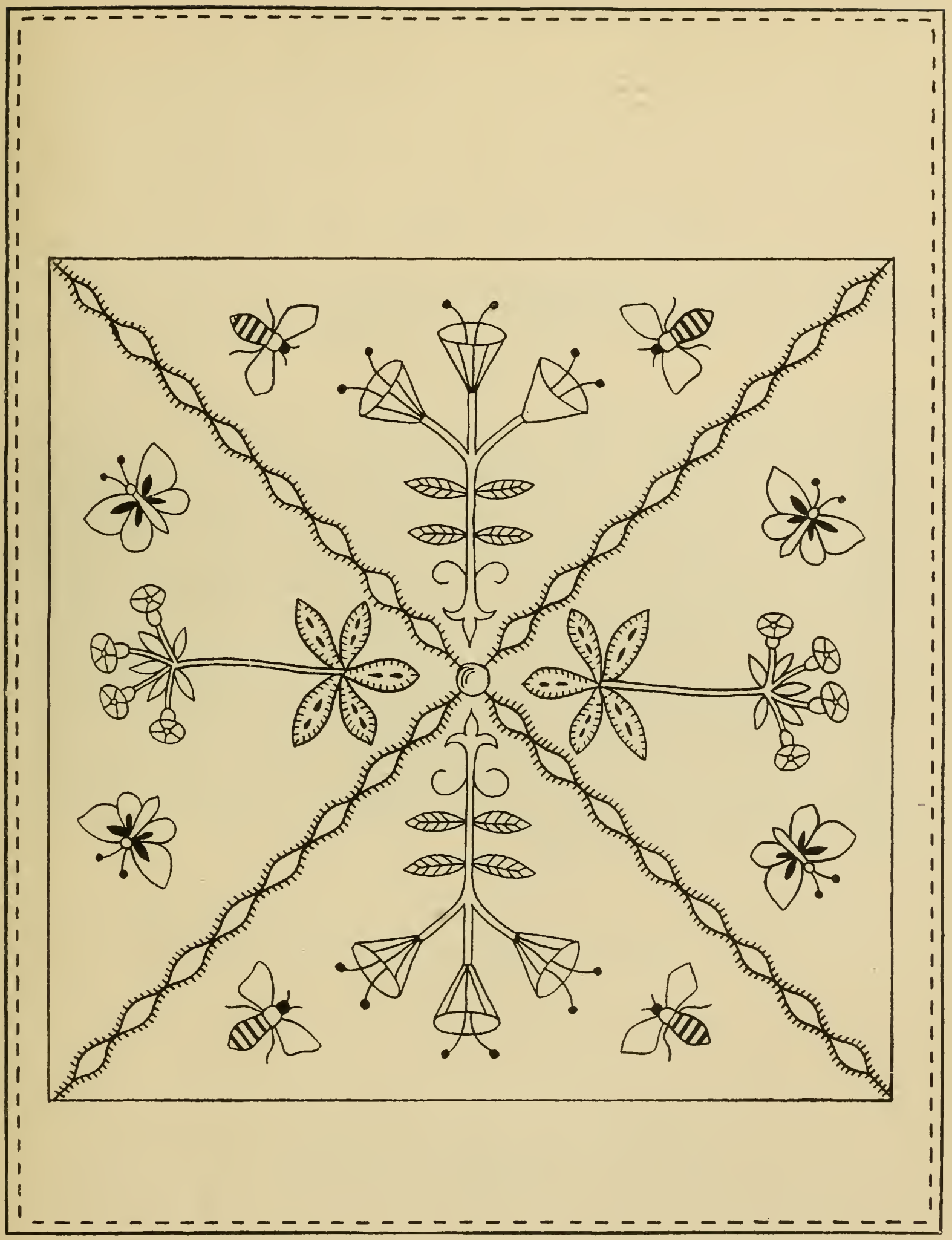

Plate LXXXII. 


\section{AN EMBROIDERED BAG.}

\section{Frontispiece.}

THE small bag illustrated there has been designed principally from patterns taken from Plate XXII. The circles which form the essential part of this design were traced first on the bag shape, the triangles were then added to fill the spaces between the circles, and, finally, the little sprigs were dotted evenly over the upper part of the bag to prevent the surface looking too empty. That completes the bag so far as the designing is concerned. The stitchery is equally simple, only two kinds of stitches being used, namely, back stitch and Roumanian stitch. The straight lines are all worked in back stitch, and the solid parts of the embroidery in Roumanian stitch. The light stitches are really detached back stitches, being worked in exactly the same way, but they generally go by the name of seed stitches to distinguish them from running or darning. Two shades of Pearsall's Mallard floss were used for embroidering this bag, three skeins of the darker and one of the lighter colour; this includes the working of the pattern on the other side of the bag and the covering of the two small bobs at the ends of the cord. The ground material, which in this case is a smooth cloth, should represent the middle tone in the colour scheme. 


\section{LIST OF BOOKS FOR REFERENCE.}

THOSE students who are interested in the history of Embroidery, or seek suggestions for original patterns, or require information about the working of any of the stitches mentioned in this book, are recommended to consult the following books.

Baildon, W. Paley . A Archaeologia, Vol. LXII, Part 2. "A Wardrobe Account of Richard II."

Barliet . . . . Les Tapisseries d'Antinoé au Musée d'Orléans.

Brock, Clutton. . . Life of William Morris.

Cartier-Bresson . . Points de Broderie.

Christie, Mrs. A. H. Embroidery and Tapestry Weaving.

Dillmont, THÉRÈSE DE . Encyclopaedia of Needlework.

Dioscorides . . . Materia Medica (Ed. 1906).

Frauberger, Heinich . Coptic Shoes.

GERARDE, JOHN . . Herbal.

Huish, Marcus B. . . Samplers and Tapestry Embroideries.

JOURDAIN, M. A. . . . History of English Secular. Embroidery.

KENDRICK, A. F. . . English Embroidery.

Palliser, Mrs. BURY. . History of Lace.

Pesel, Louisa F. . . Portfolio of Stitches in Old English Embroidery. No. 1.

. . . Portfolio of Stitches in Eastern Embroidery. No. 2.

SHORLEYKer, R. . . . Schoolhouse of the Needle, 1632.

STOTHARD, C. . . . Monumental Effigies.

SYMONDS, MARY. . Elementary Embroidery.

Todd, Dr. T. H. . Vetusta Monumenta, Vol. V'I. Ref. to Heraldic Appliqué.

Periodicals, etc.

Embroidery . . . . . . . James Pearsall \& Co.

Needle and Thread and Broderie Anglaise: . "Needlecraft, Ltd."

The National Portrait Collection of 1866-(Photographs). 



\title{
Simple Art Applied to Handwork
}

\author{
By H. A. RANKIN
}

Art Master, Silver and Bronze Medallist : Author of "Simple Lessons in Colour" (Vols. I and II), "Pencil Work," "Pastel Work or Colour with Crayons" (Vols. I and II), "Lantern Making," etc., etc. ;

and F. H. BROWN, A.R.C.A.

Art Master, Silver and Bronze Medallist ; Author of "Clay Modelling for Infants," "Clay Modelling for Juniors," etc.; and joint Author with H. A. Rankin of "Simple Pictorial Illustration."

In Two Volumes, each demy 8vo, eloth gilt; Vol. I, 248 pp., 17 coloured plates and nearly 200 black-and-white illustrations ; Vol. II, 206 pp., with coloured frontispiece and 129 black-and-white illustrations and diagrams. Each volume 4s. net.

"THIS is a work quite full of good things. . . With the book before us, a genuine attempt has been made to teach Art as applied to objects which children are likely to see or handle or make for themselves. This is the correct line to take, and the Authors have done it well indeed. So far as.we are aware, no other writers have tackled so systematically the art side of handwork as the Authors of this book have done. One is glad to note that the Authors have used geometry as their starting-point. They go on to treat it as the basis of decoration-needlework, stencilling, lettering, cardboard, etc. Teachers generally will do well to place this book on their bookshelves."-Educational Handwork.

\section{Needlework Without "Specimens"}

\section{THE MODERN BOOK OF SCHOOL NEEDLEWORK}

\section{BY ELLEN P. CLAYDON}

Head Mistress of Chuckery Council School, Walsall; Authoress of "Handwork and Needlework," and joint Authoress of "Knitting without 'Specimens", ;

\section{and C. A. CLAYDON}

Sewing Mistress, Tantarra Street Mixed School, Walsall; joint Authoress of " Knitting without 'Specimens.'"

Foolscap 4to, 238 pp., with 246 black-and-white illustrations and diagrams, 3s. 6d. net.

Is the scheme of instruction suggested in this book, an attempt has been made to arrange for the teaching of all varieties of stitches, by embodying them, from the beginning, in actual useful articles and garments cut out by the children themselves. Such a plan satisfies the girls' instinct to do and construct, instead of thwarting it ; and in working out her instinct, she not only becomes acquainted with materials, but has to think out how she can overcome obstacles and difficulties.

London: Sir Isaac Pitman \& Sons, Ltd, 1 Amen Corner, E.C. 


\section{Cutting Out for Student Teachers}

By AMY K. SMITH

Diplomée of the London Institute for the Advancement of Plain Needlework: Specialist under the London County Council and at the Day Training College, Moorfields; Examiner in Dressmaking and Needlework to the City and Guilds of London. Institute; late of St. Gabriel's College, Kennington, S.E.

The book contains upwards of 260 pages, Quarto size, and is illustrated with over 360 Diagrams. Price 5s. net.

THE Schoolmistress says: "The book is profusely illustrated, and affords every conceivable help to those for whom it is written. We can most heartily recommend it."

\section{Needlework for Student Teachers}

(FOR ALL TEACHERS AND STUDENTS OF THE SUBJECT)

By the Same Author.

The book contains 260 pages, demy $8 v 0$, and is illustrated with upwards of 200 illustrations. It has recently been revised, rearranged, and repaged. Price 4s. net.

THE Schoolmaster says: "A most exhaustive manual, the style being in advance of any work on the subject we have hitherto seen."

\section{Blackboard Diagram Drawing for Teachers of Needlecraft}

\section{By ETHEL R. HAMBRIDGE}

Trained Certificated Teacher: Art Teacher's Certificate; Diplómée (Gold Seal) of the London Institute for the Advancement of Plain Needlework.

Foolscap 4to, cloth, with 7 full-page coloured plates and nearly 300 black-and-white illustrations and diagrams, 3s. 6d. net.

THIS work is not only a useful collection of diagrams, but contains as many practical. hints as to their effective enlargement on the blackboard for class teaching; and should prove most valuable, not only to the Evening School Teacher in training, but also to those who are actually engaged in teaching the various subjects incluced. under the heading of Needlecraft. The diagrams are carefully graded.

\section{Handwork and Needlework}

\section{By E. P. CLAYDON}

Head Mistress Chuckery Council School, Walsall.

In demy 8 vo, cloth, 96 pages, with very many diagrams and patterns, 2 s. net. THIs book embodies in a practical form the suggestions for the teaching of Needlework recently issued by the Board of Education in Circular 730. The educational value of Needlework as a form of Handicraft for girls is specially dealt with. The drafting of patterns is not confined to a few garments for girls in the higher standards, but forty-eight patterns to scale are given, graded in difficulty for children from 7 to 14 years of age.

London: Sir IsaAc Pitman \& Sons, Ltd., 1 Amen Corner, E.C. 


\title{
Practical Plain Needlework
}

\author{
By ANNIE R. CHAMBERLAIN, B.A., (Lond.) \\ Diplômée of the London Institute for the Advancement of Plain Needlervork; \\ Needlework Instructress in the City of Nottingham Pupil Teachers' Centre.
}

Foolscap 4to, cloth, 212 pp., fully illustrated with diagrams in two colours, 3s. 6d. net. THIs Manual is intended for the use of teachers of Needlework in Elementary, Secondary, and Evening Continuation Schools, and of students preparing for the Needlework Examinations of the Board of Education. It is based on all the latest circulars issued by the Board. Directions for the cutting out, making, and mending of actual garments are a prominent feature of the book ; there is a wide range of simple and up-to-date patterns cut out by proportion, with full instructions for adapting them to give figure measurements as required in practical work and in the recent examinations of the Board of Education.

\section{Notes of Lessons on Pattern Drafting \\ By JOSEPHINE RILEY \\ Needlework Lecturer to the Teachers' Classes under the London County Council.}

Foolscap 4to, cloth, with 35 full-page diagrams, 128 pp.

Price 2s. 6d. net.

In this volume the author aims at presenting a recognised system, correlated with Art and graduated for standards on educational lines. It includes class lessons. in Pattern Drafting, in Cutting Out in the Material, in the Making-up of the Garments according to the ability of each class: e.g., Cutting Out and Making a Doll's Cloak, a Simple Dress, a Child's Pinafore, Petticoat Bodice, Chemise, Princess Petticoat, Drill Knickers, the "Magyar Overall," Girl's Nightdress, Cooking. Apron, Overall, Gored Skirt, Swimming Costume, etc.

\section{Embroidery and Design}

\section{A HANDBOOK OF THE PRINCIPLES OF DECORATIVE ART AS APPLIED TO EMBROIDERY}

BY JOAN H. DREW

WITH A FOREWORD BY

MISS M. M. ALLAN, L.L.A.

Principal of Homerton Training College, Cambridge.

In demy 4to, cloth, 116 pp., with 81 black-and-white illustrations and designs. Price 2s. 6d. net.

"A SPLENDID book-clear, instructive, and precisely written-it should recommend itself to all teachers in evening schools, and be very helpful to all tempted to embroider. The designs are clearly given, and require little instruction to be able to follow them from this embroidery book." -Educational News.

London: Sir IsaAC Pitman \& Sons, Ltd., 1 Amen Corner, E.C. 


\section{The Story of Girlie Bunting on the Island of "Never-Mind-Where"}

\section{By ETHEL R. HAMBRIDGE}

Trained Certificated Teacher; Lecturer to Teachers; Diplômée (Gold Seal) of the London Institute for the Advancement of Plain Needlework, and of the National Training School of Cookery and other Branches of Domestic Economy, in Millinery and Elementary and Advanced Dressmaking. Authoress of "Blackboard Diagram Drawing for Teachers of Needlecraft," etc.

Inscribed by kind permission to Mr. RUdyaRd KIPLING.

In crown 8vo, cloth, with many quaint illustrations, 120 pp. 1s. 3d.

THE Author has struck a most original note in the production of Givlie Bunting, for it introduces the child-student of Needlework to her subject on the lines of a delightful story. Step by step, as the tale unfolds, the child is taken through the various stages of the work, and even the smallest point has not been omitted. The young student will also grasp in a most attractive manner the nature and use of all her workbox implements. A knowledge gained in this interesting way is likely to remain permanently in the mind. The little heroine, Girlie Bunting, is certain to prove very fascinating, and the reader, while enjoying her adventures, will, in addition, absorb almost unconsciously a very thorough preliminary instruction in Needlework and Dressmaking. The book will be greatly valued in both Elementary and Secondary Schools.

\section{Knitting Without "Specimens"}

\section{THE MODERN BOOK OF SCHOOL KNITTING AND CROCHET}

\section{By ELLEN P. CLAYDON}

Head Mistress of Chuckery Council School, Walsall; Authoress of "Handwork and Needlework," and joint Authoress of "Needlework without 'Specimens' " ;

and C. A. CLAYDON

Sewing Mistress, Tantarra Street Mixed School, Walsall; joint Authoress of "Needlework without 'Specimens.'

In foolscap 4to, cloth, 204 pp., with frontispiece and 155 other illustrations and diagrams, 3s. 6d. net.

THE book aims at meeting in a practical manner the suggestions with regard to Knitting made in the recently issued Report on the teaching of Needlework. The plan here suggested for learning new stitches while making useful articles produces a keen and lasting interest in the subject, and ensures also, by introducing measurement of sizes and calculations of quantities and costs, that the subject shall be one of distinct educational value. The book is copiously illustrated, and deals exhaustively with School Knitting and Crochet.

London: Sir Isaac Pitman \& Sons, Ltd, 1 Amen Corner, E.C. 





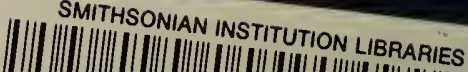

Inthent

3908

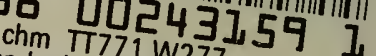

An embroide

pattern book 